19930000924

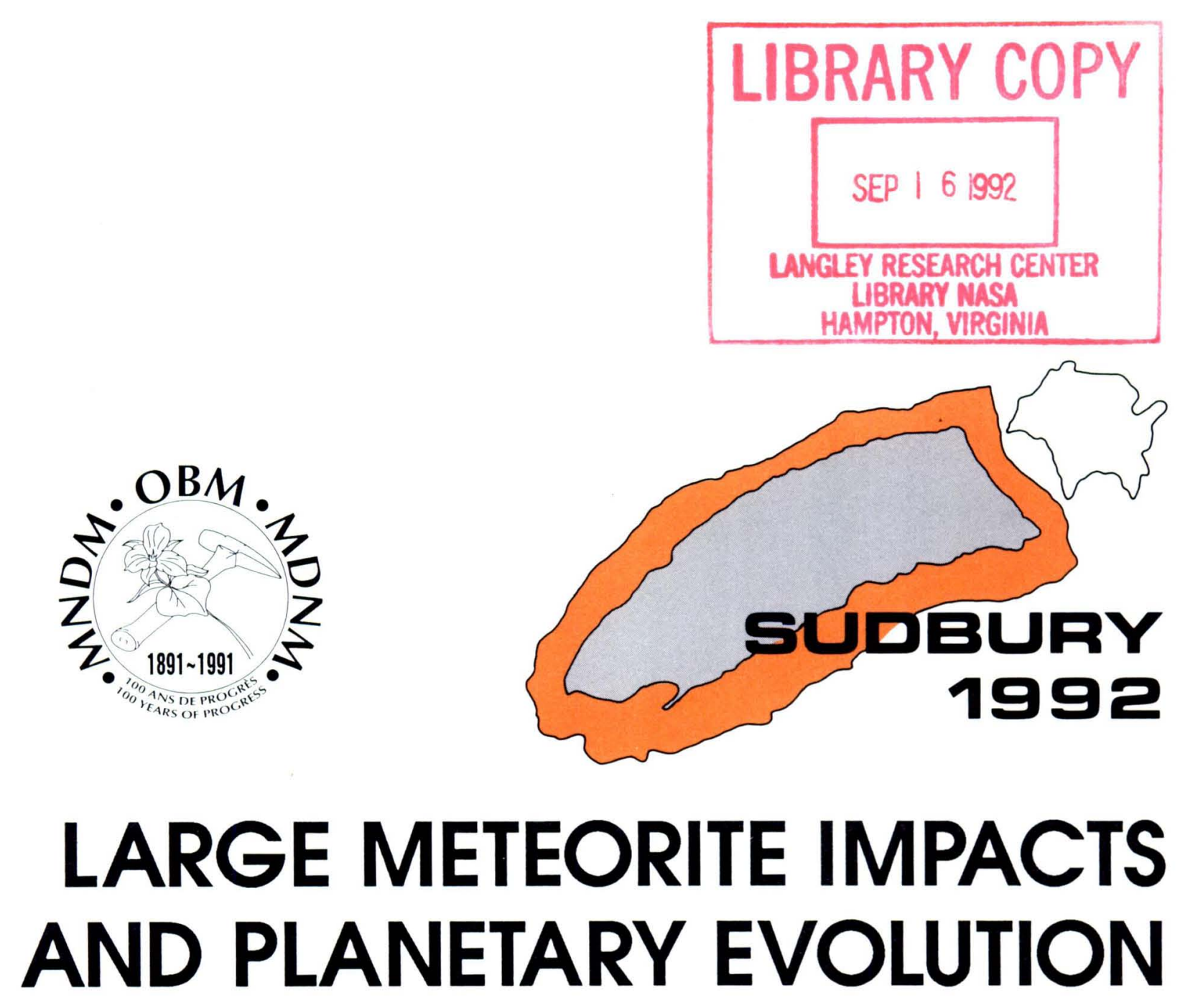

Sudbury, Ontario, Canada August 31-September 2, 1992 

$\mathbf{L} \perp \mathbf{L K}:$

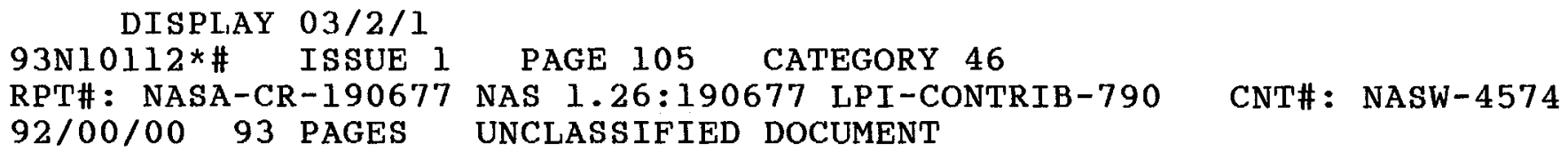

UTTL: International Conference on Large Meteorite Impacts and Planetary Evolution

CORP: Lunar and Planetary Inst., Houston, TX. CSS: (Publications Services Dept.)

SAP: Avail: CASI HC A05/MF A01

CIO: UNITED STATES Conference held in sudbury, Ontario, 31 Aug. - 2 Sep. 1992; sponsored by Barringer Crater Co., Falconbridge Ltd., Geological survey of Canada, Inco Ltd., International Union of Geological sciences, Laurentian Univ., LPI, and Ontario Ministry of Northern Development and Mines

MAJS: /*CANADA/*CONFERENCES/*HYPERVELOCITY IMPACT/*METEORITE COLLISIONS/* METEORITE CRATERS/*PLANETARY EVOLUTION

MINS: / BRECCIA/ CANADIAN SHIELD/ GEOMORPHOLOGY/ ROCK INTRUSIONS/ STRUCTURAL PROPERTIES (GEOLOGY)

ANN: The papers that were accepted for the International Conference on Large Meteorite Impacts and Planetary Evolution, 31 Aug. - 2 Sep. 1992, are presented. One of the major paper topics was the sudbury project. For individual titles, see N93-10113 through N93-10196. 

PAPERS PRESENTED TO THE

\title{
INTERNATIONAL CONFERENCE ON LARGE METEORITE IMPACTS AND PLANETARY EVOLUTION
}

\author{
August 31-September 2, 1992 \\ Sudbury, Ontario, Canada
}

\author{
Sponsored by \\ Barringer Crater Company \\ Falconbridge Limited \\ Geological Survey of Canada \\ Inco Limited \\ International Union of Geological Sciences \\ Laurentian University, Sudbury \\ Lunar and Planetary Institute, Houston \\ Ontario Ministry of Northern Development and Mines
}




\section{Compiled in 1992 by}

\section{Lunar and Planetary Institute 3600 Bay Area Boulevard Houston TX 77058-1113}

Material in this volume may be copied without restraint for library, abstract service, education, or personal research purposes; however, republication of any paper or portion thereof requires the written permission of the authors as well as the appropriate acknowledgment of this publication.

The Lunar and Planetary Institute is operated by the Universities Space Research Association under Contract No. NASW-4574 with the National Aeronautics and Space Administration. 


\section{PREFACE}

This volume contains papers that have been accepted for the International Conference on Large Meteorite Impacts and Planetary Evolution, August 31-September 2, 1992, in Sudbury, Ontario, Canada. The Scientific Organizing Committee consisted of B. Dressler and V. L. Sharpton, co-chairmen, and B. M. French, R. A. F. Grieve, and E. M. Shoemaker. Members of the Local Organizing Committee were H. Gibson (Chairman), S. Ball, C. J. A. Coats, B. Dressler, G. W. Johns (Treasurer), W. Meyer, W. V. Peredery, and D. H. Rousell.

Administrative support was provided by the Program Services Department staff at the Lunar and Planetary Institute. This abstract volume was prepared by the Publications Services Department staff at the Lunar and Planetary Institute. 



\section{TABLE OF CONTENTS}

Carbon and Oxygen Isotope Study of Carbonates from Highly Shocked Clasts

of the Polymict Breccia of the Haughton Crater (Canada)

P. Agrinier, I. Martinez, M. Javoy, and U. Schärer.

Research Core Drilling in the Manson Impact Structure, Iowa

R. R. Anderson, J. B. Hartung, D. J. Roddy,

and E. M. Shoemaker

A Quasi-Hertzian Stress Field from an Internal Source: A Possible Working Model

for the Vredefort Structure

L. A. G. Antoine, W. U. Reimold, and W. P. Colliston

Sudbury Project (University of Münster-Ontario Geological Survey):

(6) Origin of the Polymict, Allochthonous Breccias of the Onaping Formation

M. E. Avermann

Sudbury Project (University of Münster-Ontario Geological Survey):

(1) Summary of Results-An Updated Impact Model

M. Avermann, L. Bischoff, P. Brockmeyer, D. Buhl, A. Deutsch,

B. O. Dressler, R. Lakomy, V. Müller-Mohr, and D. Stöffler

Structural Aspects of the Araguainha Impact Structure (Brazil)

L. Bischoff, P. Brockmeyer, U. Jenchen, and R.-M. Swietlik

Sudbury Project (University of Münster-Ontario Geological Survey):

(2) Field Studies 1984-1989-Summary of Results

L. Bischoff, B. O. Dressler, M. E. Avermann,

P. Brockmeyer, R. Lakomy, and V. Müller-Mohr

Large Meteorite Impacts: The K/T Model

B. F. Bohor

Shocked Zircons in the Onaping Formation: Further Proof of Impact Origin

B. F. Bohor and W. J. Betterton

Suevite Superposition on the Bunte Breccia in Nördlinger Ries/Germany:

New Findings on the Transport Mechanism of Impactites

D. Bringemeier 10

Sudbury Project (University of Münster-Ontario Geological Survey):

(7) Sr-Nd in Heterolithic Breccias and Gabbroic Dikes

D. Buhl, A. Deutsch, R. Lakomy, P. Brockmeyer, and B. Dressler

Hong Kong is an Impact Crater: Proof from the Geomorphological and Geological Evidence

C.-I. Chan, S. Wu, and X. Luo 12 
Melt Production in Large-Scale Impact Events: Calculations of Impact-Melt

Volumes and Crater Scaling

M. J. Cintala and R. A. F. Grieve

Melt Production in Large-Scale Impact Events: Planetary Observations

and Implications

M. J. Cintala and R. A. F. Grieve

Structural Review of the Vredefort Dome

W. P. Colliston and W. U. Reimold

Intrusive Origin of the Sudbury Igneous Complex: Structural

and Sedimentological Evidence

E. J. Cowan and W. M. Schwerdtner

Enhanced Magnetic Field Production During Oblique Hypervelocity Impacts

D. A. Crawford and P. H. Schultz

Impactite and Pseudotachylite from Roter Kamm Crater, Namibia

J. J. Degenhardt Jr., P. C. Buchanan, and A. M. Reid.

Sudbury Project (University of Münster-Ontario Geological Survey):

(4) Isotope Systematics Support the Impact Origin

A. Deutsch, D. Buhl, P. Brockmeyer, R. Lakomy, and M. Flucks

Noril'sk/Siberian Plateau Basalts and Bahama Hot Spot: Impact Triggered?

R. S. Dietz and J. F. McHone

Mobilization of the Platinum Group Elements by Low-Temperature Fluids:

Implications for Mineralization and the Iridium Controversy

K. Dowling, R. R. Keays, M. W. Wallace, and V. A. Gostin

Does the Bushveld-Vredefort System (South Africa) Record the Largest

Known Terrestrial Impact Catastrophe?

W. E. Elston

Ruthenium/Iridium Ratios in the Cretaceous-Tertiary Boundary Clay:

Implications for Global Dispersal and Fractionation Within the Ejecta Cloud

N. J. Evans, W. D. Goodfellow, D. C. Gregoire, and J. Veizer.

Diaplectic Transformation of Minerals: Vorotilov Drill Core, Puchezh-Katunki

Impact Crater, Russia

V. I. Feldman

Breccia Dikes from the Beaverhead Impact Structure, Southwest Montana

P. S. Fiske, S. B. Hougen, and R. B. Hargraves 
New Perspectives on the Popigai Impact Structure

J. B. Garvin and A. L. Deino

The Zhamanshin Impact Feature: A New Class of Complex Crater?

J. B. Garvin and C. C. Schnetzler

Asteroids and Archaean Crustal Evolution: Tests of Possible Genetic Links

Between Major Mantle/Crust Melting Events and Clustered Extraterrestrial

Bombardments

A. Y. Glikson

The Acraman Impact and Its Widespread Ejecta, South Australia

V. A. Gostin, R. R. Keays, and M. W. Wallace

Optical and TEM Study of Shock Metamorphism from the Sedan Test Site

A. J. Gratz

Simulated Meteorite Impacts and Volcanic Explosions: Ejecta Analyses and Planetary Implications

A. J. Gratz and W. J. Nellis

Melt Production in Large-Scale Impact Events: Implications and Observations at Terrestrial Craters

R. A. F. Grieve and M. J. Cintala

Venusian Impact Basins and Cratered Terrains

W. B. Hamilton

Where's the Beaverhead Beef?

R. B. Hargraves

Report on the International Cambodian Crater Expedition-1992

J. Hartung, C. Koeberl, P. Lee, K. Pagnacith, and T. Sambath

The Distribution and Modes of Occurrence of Impact Melt at Lunar Craters

B. R. Hawke and J. W. Head

Large Impacts in the Baltic Shield with Special Attention to the Uppland Structure

H. Henkel and R. Lilljequist

The Panther Mountain Circular Structure, A Possible Buried Meteorite Crater

Y. W. Isachsen, S. F. Wright, F. A. Revetta, and R. J. Dineen

Geomechanical Models of Impact Cratering: Puchezh-Katunki Structure

B. A. Ivanov 
Thermobarometric Studies on the Levack Gneisses-Footwall Rocks to the Sudbury Igneous Complex

R. S. James, W. Peredery, and J. M. Sweeny

The Cretaceous-Tertiary (K/T) Impact: One or More Source Craters?

C. Koeberl

Tektite Origin by Hypervelocity Asteroidal or Cometary Impact:

The Quest for the Source Craters

C. Koeberl

Early Archean Spherule Beds of Possible Impact Origin from Barberton,

South Africa: A Detailed Mineralogical and Geochemical Study

C. Koeberl, W. U. Reimold, and R. H. Boer

$\mathrm{U}$-Pb Isotopic Results for Single Shocked and Polycrystalline Zircons Record

550-65.5-Ma Ages for a K-T Target Site and 2700-1850-Ma Ages

for the Sudbury Impact Event

T. E. Krogh, S. L. Kamo, and B. F. Bohor

Influence of the Preshock Temperature on Shock Effects in Quartz

F. Langenhorst and A. Deutsch

Search for a Meteoritic Component at the Beaverhead Impact Structure, Montana

P. Lee and R. W. Kay

Ordovician Impacts at Sea in Baltoscandia

M. Lindstrớm, V. Puura, T. Flodén, and A.. Bruun

Does the Sedimentology of the Chelmsford Formation Provide Evidence

for a Meteorite Impact Origin of the Sudbury Structure?

D. G. F. Long

Impact Origin of the Sudbury Structure: Evolution of a Theory

P. D. Lowman Jr.

Imaging Radar Investigations of the Sudbury Structure

P. D. Lowman, V. H. Singhroy, and V. R. Slaney.

Phase Transformations in 40-60-GPa Shocked Gneisses from

the Haughton Crater (Canada): An Analytical Transmission Electron

Microscope (ATEM) Study

I. Martinez, F. Guyot, and U. Schärer

Impactites from Popigai Crater

V. L. Masaitis 
Sudbury Breccia and Suevite as Glacial Indicators Transported $800 \mathrm{~km}$

to Kentland Astrobleme, Indiana

J. F. McHone, R. S. Dietz, and W. V. Peredery

What Can We Learn About Impact Mechanics from Large Craters on Venus?

W. B. McKinnon and J. S. Alexopoulos

Sudbury Project (University of Münster-Ontario Geological Survey):

(5) New Investigations on Sudbury Breccia

V. Müller-Mohr

A History of the Lonar Crater, India-An Overview

V. K. Nayak

Sudbury Igneous Complex: Impact Melt or Igneous Rock? Implications for Lunar Magmatism

M. D. Norman

Melting and Its Relationship to Impact Crater Morphology

J. D. O'Keefe and T. J. Ahrens

Impact Cratering Record of Fennoscandia

L. J. Pesonen and H. Henkel

Bohemian Circular Structure, Czechoslovakia: Search for the Impact Evidence

P. Rajlich

The Vredefort Dome-Review of Geology and Deformation Phenomena

and Status Report on Current Knowledge and Remaining Problematics

(Five Years After the Cryptoexplosion Workshop)

W. U. Reimold

The Pseudotachylites from the Vredefort Structure and the Witwatersrand Basin

W. U. Reimold and W. P. Colliston

Coincidence in Time of the Imbrium Basin Impact and Apollo 15 KREEP

Volcanic Series: Impact-Induced Melting?

G. Ryder

Apollo 15 Impact Melts, The Age of Imbrium, and the Earth-Moon Impact Cataclysm

G. Ryder and G. B. Dalrymple

Search for the 700,000-Year-Old Source Crater of the Australasian Tektite Strewn Field

C. C. Schnetzler and J. B. Garvin 
Recognizing Impactor Signatures in the Planetary Record

P. H. Schultz and D. E. Gault

Paradigm Lost: Venus Crater Depths and the Role of Gravity

in Crater Modification

V. L. Sharpton

K/T Boundary Stratigraphy: Evidence for Multiple Impacts and a Possible Comet Stream

E. M. Shoemaker and G. A. Izett

Geological Evidence for a 2.6-Ga Strewn Field of Impact Spherules

in the Hamersley Basin of Western Australia

B. M. Simonson

SAR in Support of Geological Investigations of the Sudbury Structure

V. Singhroy, R. Mussakowski, B. O. Dressler,

N. F. Trowell, and R. Grieve

Viscosity Determinations of Some Fractionally Generated Silicate Melts:

Implications for Slip Zone Rheology During Impact-Induced Faulting

J. G. Spray

The Large Impact Process Inferred from the Geology of Lunar Multiring Basins

P. D. Spudis

Sudbury Project (University of Münster-Ontario Geological Survey):

(3) Petrology, Chemistry, and Origin of Breccia Formations

D. Stöffler, A. Deutsch, M. Avermann, P. Brockmeyer,

R. Lakomy, and V. Müller-Mohr

"Bronzite" Granophyre: New Insight on Vredefort

A. M. Therriault and A. M. Reid

A Comparison of the Chemistry of Pseudotachylyte Breccias in the Archean

Levack Gneisses of the Sudbury Structure, Ontario

L. M. Thompson and J. G. Spray

${ }^{40} \mathrm{Ar}-{ }^{39} \mathrm{Ar}$ Ages of the Large Impact Structures Kara and Manicouagan

and Their Relevance to the Cretaceous-Tertiary and the Triassic-Jurassic Boundary

M. Trieloff and E. K. Jessberger

${ }^{40} \mathrm{Ar}-{ }^{39} \mathrm{Ar}$ Dating of Pseudotachylites from the Witwatersrand Basin, South Africa, with Implications for the Formation of the Vredefort Dome

M. Trieloff, J. Kunz, E. K. Jessberger, W. U. Reimold,

R. H. Boer, and M. C. Jackson 
Al Umchaimin Depression, Western Iraq: An Impact Structure?

J. R. Underwood Jr.

A Late Devonian Impact Event and Its Association with a Possible

Extinction Event on Eastern Gondwana

K. Wang and H. H. J. Geldsetzer.

Electron Petrography of Silica Polymorphs Associated with Pseudotachylite,

Vredefort Structure, South Africa

J. C. White

Floor-fractured Crater Models of the Sudbury Structure, Canada

R. W. Wichman and P. H. Schultz

Variation in Multiring Basin Structures as a Function of Impact Angle

R. W. Wichman and P. H. Schultz

Self-Organized Rock Textures and Multiring Structure in the Duolun Crater

$\mathrm{S}$. Wu and J. Zhang

Geochemical Aspect of Impact Cratering: Studies in Vernadsky Institute

O. I. Yakovlev and A. T. Basilevsky 82 



\section{Papers Presented to the International Conference on Large Meteorite Impacts and Planetary Evolution}

\begin{abstract}
CARBON AND OXYGEN ISOTOPE STUDY OF CARBONATES FROM HIGHLY SHOCKED CLASTS OF THE POLYMICT BRECCIA OF THE HAUGHTON CRATER (CANADA). P. Agrinier, I. Martinez, M. Javoy, and U. Schärer, Université Paris 7 et IPG Paris, 2 place Jussieu, 75251 Paris cedex 05, France.
\end{abstract}

It is known that the release of volatiles on impact is an important controlling factor in cratering processes in carbonate terranes and in the mobility of chemical elements $[1,2,3]$.

In order to assess the nature and the role of carbon- and oxygenbearing volatiles during impact-induced metamorphism of sedimentary rocks, the ${ }^{13} \mathrm{C} / 12 \mathrm{C}$ and ${ }^{12} \mathrm{O} / 16 \mathrm{O}$ ratios and carbonate contents were determined for $\mathbf{3 0}$ shocked clasts from the Haughton Crater polymict breccia as well as for some unshocked carbonates from the sedimentary cover adjacent to the crater. Shock-induced $\mathrm{CO}_{2}$ loss during decarbonation of calcite is known to be a function of peak pressure and ambient partial pressure of the volatile species [2,3]. In our clast samples, shocked from 20 to $60 \mathrm{GPa}$, we expect about $20 \%$ to $100 \% \mathrm{CO}_{2}$ loss and preferential depletion in ${ }^{13} \mathrm{C}$ and ${ }^{18} \mathrm{O}$ in the residual carbonate [4]. Rayleigh model (progressive loss of $\mathrm{CO}_{2}$ ) and batch model (single-step loss of $\mathrm{CO}_{2}$ ) curves for this depletion are shown in Figs. 1 and 2. The magnitudes of the ${ }^{13} \mathrm{C}$ and ${ }^{18} \mathrm{O}$ depletions increase with the increase of the $\mathrm{CO}_{2}$ loss. In addition, these isotopic depletions should be correlated with an enrichment in $\mathrm{CaO}$ and $\mathrm{MgO}$ in the residual solid.

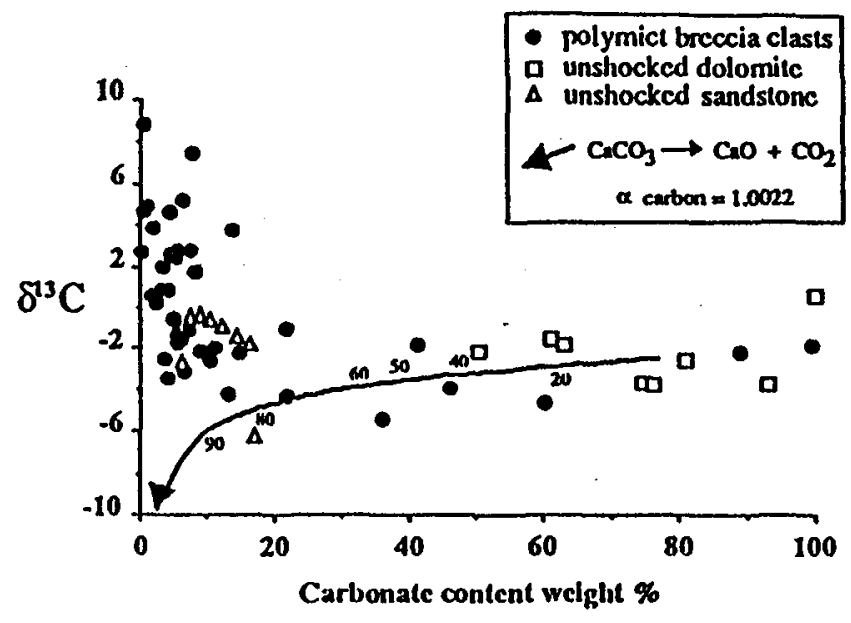

Fig. 1. $8^{13} \mathrm{C}$ vs. carbonate content diagram. The numbers along the curve correspond to the degree of Raleigh degassing.

In the shocked clasts, carbonates represent between 0.5 to $10 \mathrm{wt} \%$ of the rock and display isotopic composition of carbon between -4 to $+9 \%$. When compared to the unshocked samples, they are mostly enriched in ${ }^{13} \mathrm{C}\left(\delta^{13} \mathrm{C}\right.$ up to $9 \%$ ) or unchanged

TABLE 1. Carbon and oxygen isotopic compositions of carbonates from clasts of the Haughton Crater polymict breccia and from the adjacent sedimentary cover. Rocks were attacked in phosphoric acid [5] in order to analyze carbonates only.

\begin{tabular}{|c|c|c|c|c|c|c|c|}
\hline $\begin{array}{l}\text { Clasts } \\
\text { Sample }\end{array}$ & $\begin{array}{c}\text { Carbonate } \\
\text { Content }\end{array}$ & $\begin{array}{c}\delta^{13} \mathrm{C} \\
9_{00 \mathrm{PDB}}\end{array}$ & $\begin{array}{c}\delta^{140} \\
\%_{0} \text { SMOW }\end{array}$ & $\begin{array}{c}\text { Reference } \\
\text { Sample }\end{array}$ & $\begin{array}{c}\text { Carbonate } \\
\text { Content }\end{array}$ & $\begin{array}{c}\delta^{13} \mathrm{C} \\
\mathscr{x}_{0} \mathrm{PDB}\end{array}$ & $\begin{array}{c}8^{11} \mathrm{O} \\
\text { qaSMOW }\end{array}$ \\
\hline HAH 11 & 0.5 & 8.8 & 15.88 & DI52a & 36.1 & -5.4 & 14.17 \\
\hline HAH 8 & 4 & -3.5 & 15.15 & DI52b & 60.2 & -4.7 & 14.09 \\
\hline HАH 25 & 21.8 & -1.1 & 21.71 & 7275 & 21.7 & -4.3 & 12.67 \\
\hline HAH 68 & 5.5 & 2.7 & 17.61 & DI9 & 88.9 & -2.2 & 20.55 \\
\hline НАH 69 & 6.4 & 5.2 & 17.78 & 71314 & 13.1 & -4.3 & 9.70 \\
\hline HAH 5 & 0.5 & 4.6 & 19.45 & DI21 & 99.6 & -1.9 & 21.37 \\
\hline HAH 15 & 4.3 & 4.7 & 16.82 & 1984 & 41.2 & -1.8 & 20.8 \\
\hline HAH 17 & 1.8 & 3.8 & 18.70 & DIG2 & 92.9 & -3.7 & 28.48 \\
\hline НАН 19 & 3.1 & 0.8 & 19.44 & DIGI & 76.2 & -3.8 & 27.32 \\
\hline HAH 26 & 1 & 4.9 & 18.45 & DIG3 & 74.6 & -3.7 & 28.99 \\
\hline HAH 28 & 8.9 & -2.1 & 19.01 & DIG4 & 50.4 & -2.1 & 24.10 \\
\hline HAH 74 & 4 & 0.9 & 19.75 & DIGS & 61.2 & -1.5 & 24.74 \\
\hline HAH 73 & 3.3 & 1.9 & 18.53 & DI95 & 10.7 & -0.7 & 22.6 \\
\hline HAH 66 & 5.3 & 2.5 & 18.50 & DI92 & 100 & 0.6 & 21.06 \\
\hline HAH 19 & 3.1 & 0.8 & 19.44 & DI3 & 63.1 & -1.8 & 24.29 \\
\hline НАН 39 & 5.1 & -0.6 & 16.20 & D195 & 12.3 & -1 & 24.83 \\
\hline HАH 34 & 14.8 & -2.2 & 15.26 & D193 & 14.5 & -1.4 & 23.06 \\
\hline HAH 21 & 8.1 & 1.7 & 16.23 & DI96 & 7.6 & -0.5 & 23.43 \\
\hline HAH 71 & 7.4 & 2.8 & 17.40 & D197 & 9.1 & -0.4 & 22.7 \\
\hline HAH 29 & 7.8 & 7.5 & 17.24 & D119 & 17.1 & -6.2 & 25.44 \\
\hline НАH 30 & 4.6 & 2.6 & 15.02 & DI45 & 6.2 & -2.7 & 24.24 \\
\hline HAH 67-1 & 13.8 & 3.8 & 15.50 & DIG12 & 16.5 & -1.8 & 24.61 \\
\hline НАH 67-2 & 1.7 & 0.6 & 19.66 & 814 & 80.9 & -2.6 & 21.20 \\
\hline HAH um24 & 0.2 & 2.7 & 15.86 & 72614 & 46.1 & -3.9 & 18.14 \\
\hline
\end{tabular}




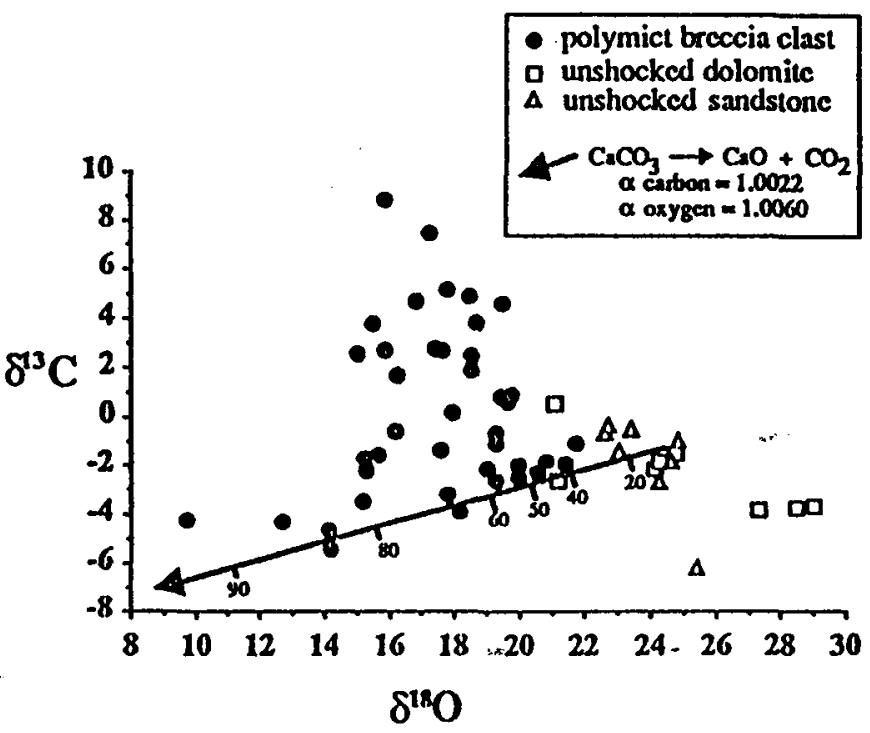

Fig. 2. $\delta^{13} \mathrm{C}$ vs. $\delta^{18} \mathrm{O}$ diagram. The numbers along the curve correspond to the degree of Raleigh degassing.

instead of being depleted as they should be if they were residues resulting from the ${ }^{13} \mathrm{C}$-enriched $\mathrm{CO}_{2}$ losses (Fig. 1). On the other hand, these carbonates are systematically depleted in 180 . The magnitude of the 180 depletion is variable (Fig. 2). Thus no systematic correlation between 180 and ${ }^{13} \mathrm{C}$ was observed as expected from the Rayleigh model or the batch model for $\mathrm{CO}_{2}$ loss (Fig. 2), nor was any clear relationship observed between the carbon and oxygen isotopic shifts and $\mathrm{CaO}+\mathrm{MgO}$ contents of the shock clasts. The spread of the carbon and oxygen isotopic composition is probably due to a variety of processes that may affect $\mathrm{C}$ and $\mathrm{O}$ during the shock. Several explanations can be suggested for the volatile release from sedimentary rocks: (1) degassing of $\mathrm{CO}_{2}$ with a peculiar carbon isotope fractionation coefficient $\left(\alpha<1, \mathrm{CO}_{2}\right.$ preferentially concentrates ${ }^{12} \mathrm{C}$ ), (2) other reactions with production of $\mathrm{CO}$ or $\mathrm{C}$, or (3) oxygen isotope exchange with coexisting silicates. Moreover, the absence of $\mathrm{CaO}+\mathrm{MgO}$ enrichments in the shocked clasts, which is a general feature, may indicate that substantial amounts of $\mathrm{CaO}+\mathrm{MgO}$ are mobilized during the shock processes since original sedimentary samples contain up to $66 \mathrm{wt} \%$. The modalities of this inferred mobilization of $\mathrm{CaO}+\mathrm{MgO}$ are still unknown.

However, for some samples, late secondary processes may have partly altered the primary characteristics (nature) of the residues resulting from the volatile release because carbonate crystals are observed along cavity walls (bubbles, cracks). It suggests that some C-rich fluids $\left(\mathrm{CO}_{2}\right.$ ?) were pervasive during the formation and the cooling of the polymict breccia. In these samples, the observed ${ }^{13} \mathrm{C}$ enrichments can therefore be partly explained by the trapping of some heavy $\mathrm{CO}_{2}$ released during the shock process itself.

References: [1] Kieffer S. W. and Simonds C. H.(1980) Rev. Geophys. Space Phys., 18, 143-181. [2] Lange M. A. and Ahrens T. J. (1986) EPSL, 77, 409-418. [3] Tyburczy J. A. and Ahrens T. J. (1986) JGR, 91,4730-4744. [4] Bottinga (1968) J.Phys. Chem., 72, 800-808. [5] McCrea J. M. (1950) J. Chem. Phys., 18, 849-857.
RESEARCH CORE DRILLING IN THE MANSON IMPACT STRUCTURE, IOWA. R. R. Anderson', J. B. Hartung ${ }^{1}$, D. J. Roddy', and E. M. Shoemaker?, 'Jowa Department of Natural Resources Geological Survey Bureau, 109 Trowbridge Hall, Iowa City IA 52242-1319, USA, '2U.S. Geological Survey, Branch of Astrogeologic Studies, 2255 North Gemini Dr., Flagstaff AZ86001, USA.

The Manson impect structure (MIS), located in north-central Iowa, has a diameter of $35 \mathrm{~km}$ and is the largest confirmed impact structure in the United States. The MIS has yielded a ${ }^{40} \mathrm{Ar} /{ }^{\circ 9} \mathrm{Ar}$ age of $65.7 \mathrm{Ma}$ [1] on microcline from its central peak, an age that is "indistinguishable" from the age of the Cretaceous-Tertiary boundary.

In the summer of 1991 the Iowa Geological Survey Bureau and U.S. Geological Survey initiated a research core drilling project on the MIS. The first core (M-1) was located on the edge of the Central Peak (Fig. 1). Beneath $55 \mathrm{~m}$ of glacial drift, the core penetrated a 6$\mathrm{m}$ layered sequence of shale and siltstone and $42 \mathrm{~m}$ of Cretaceous shale-dominated sedimentary clast breccia (Fig. 2). Below this breccia, the core encountered two crystalline rock clast breccia units. The upper unit is $\mathbf{5 3} \mathrm{m}$ thick, with a glassy matrix displaying various degrees of devitrification. The upper half of this unit is dominated by the glassy matrix, with shock-deformed mineral grains (especially quartz) the most common clast. Clast content increases toward the base of the unit. The glassy-matrix unit grades downward into the basal unit in the core, a crystalline rock breccia with a sandy matrix, the matrix dominated by igneous and metamorphic rock fragments or disaggregated grains from those rocks. The unit is about $45 \mathrm{~m}$ thick, and grains display abundant shock deformation features. Preliminary interpretations suggest that the crystalline rock breccias are the transient crater floor, lifted up with the central peak. The sedimentary clast breccia probably represents a postimpact debris flow from the crater rim, and the uppermost layered unit probably represents a large block associated with the flow.

The second core (M-2) was drilled near the center of the crater moat in an area where an early crater model suggested the presence of postimpact lake sediments. The core encountered $39 \mathrm{~m}$ of sedimentary clast breccia, very similar to that in the $M-1$ core. Beneath the breccia, $120 \mathrm{~m}$ of poorly consolidated, mildly deformed and sheared siltstone, shale, and sandstone was encountered. The

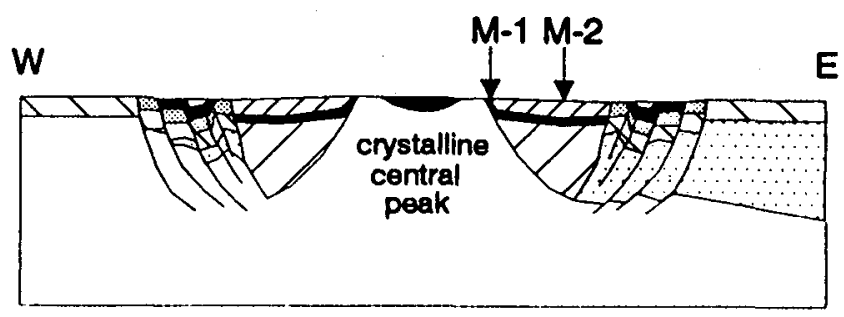

Fig. 1. East-west cross section of the Manson Impact Structure showing the location of the Manson $M-1$ and $M-2$ cores. 


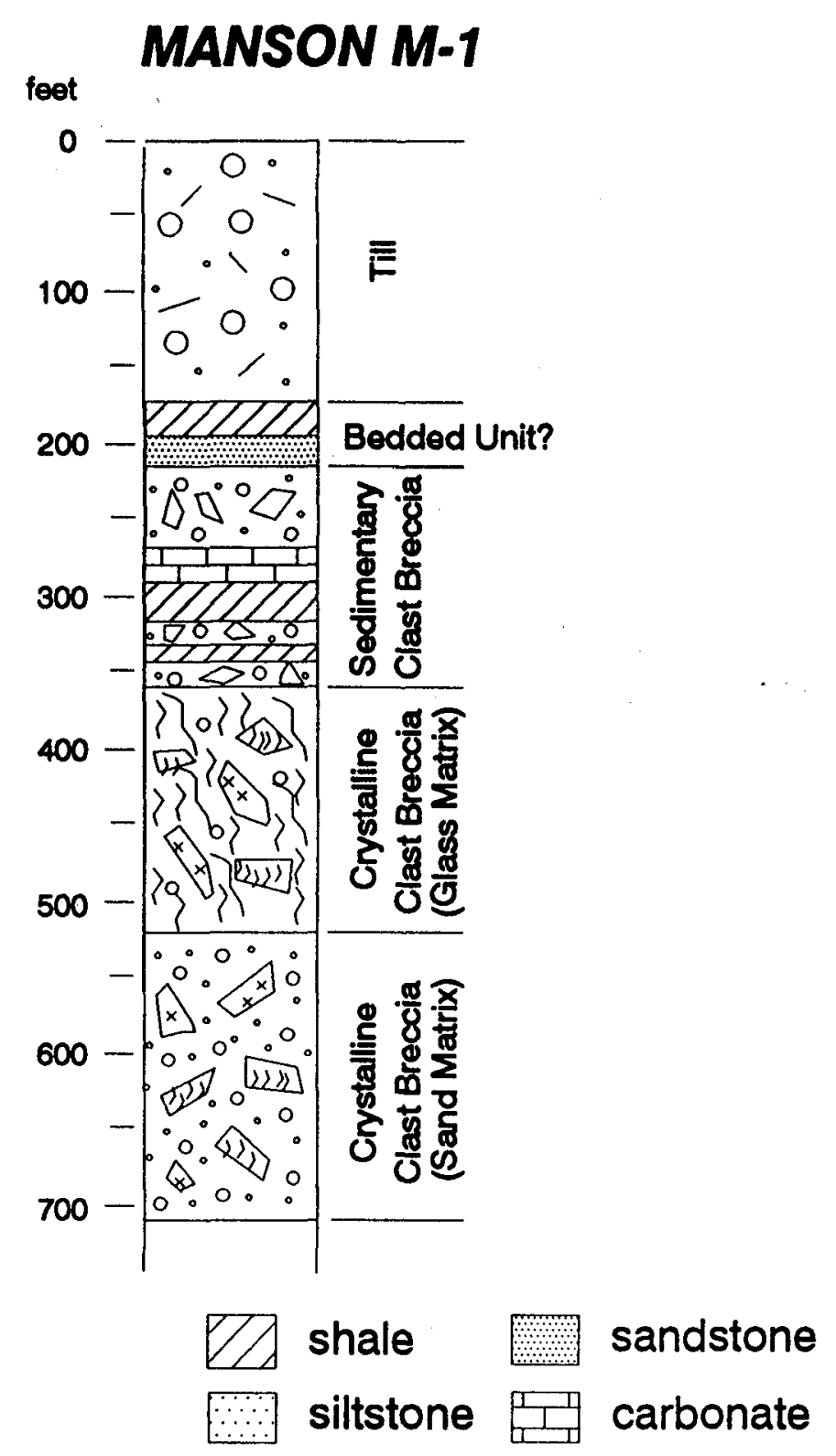

\section{MANSON M-2}

feet

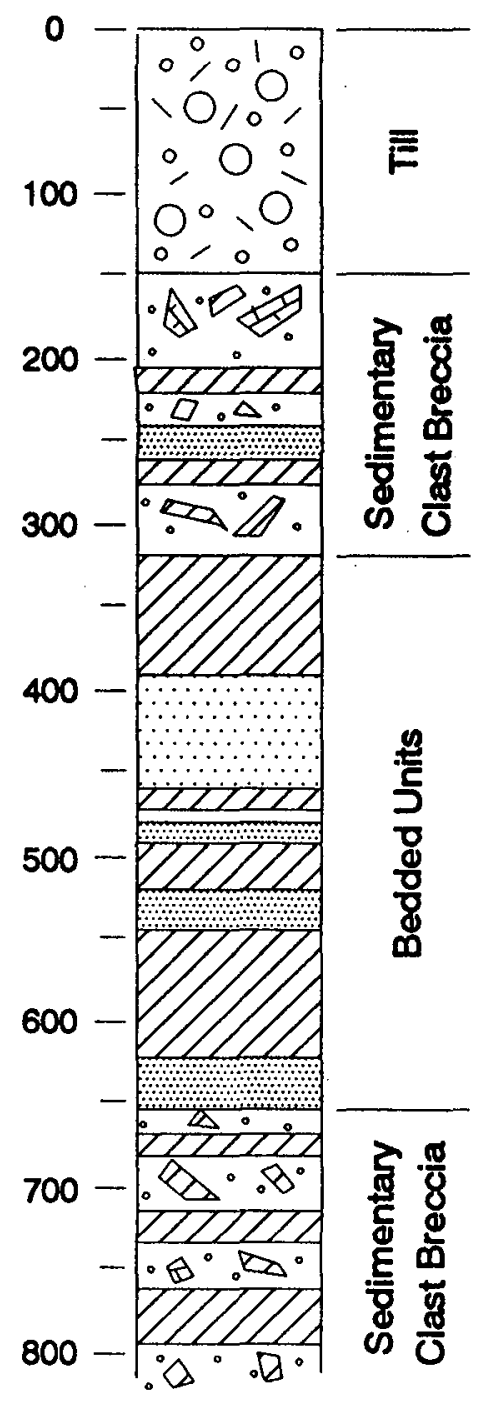

Fig. 2. Generalized lithologic logs of the Manson M-1 and M-2 cores.

basal unit in the core was another sequence of sedimentary clast breccia, $51 \mathrm{~m}$ thick, and similar to the upper interval in the core. The two sedimentary clast units, like the lithologically similar unit in the M-1 core, probably formed as debris flows from the crater rim. The middle, nonbrecciated interval is probably a large, intact block of Upper Cretaceous strata transported from the crater rim with the debris flow. Alternatively, the sequence may represent the elusive postimpact lake sequence.

Additional drilling is planned for the late spring and summer of 1992. Targets include structurally preserved Upper Cretaceous strata on the Terrace Terrane, a zone of complete melting, and postimpact lake sediments in the Crater Moat.

Reference: [1] Kunk M. J. et al. (1989) Science, 244. 1565-1568.
A QUASI-HERTZIAN STRESS FIELD FROM AN INTERNAL SOURCE: A POSSIBLE WORKTNG MODEL FOR THE VREDEFORT STRUCTURE. L. A. G. Antoine', W. U. Reimold', and W. P. Colliston', 'Department of Geophysics, University of the Witwatersrand, Private Bag 3, Wits 2050, Johannesburg, South Africa, ${ }^{2}$ Economic Research Unit at the Department of Geology, University of the Witwatersrand, Private Bag 3, Wits 2050, Johannesburg, South Africa, ${ }^{3}$ Department of Geology, University of the Orange Free State, P.O. Box 339, Bloemfontein 9300, South Africa.

The Vredefort structure is a large domal feature approximately $110 \mathrm{~km}$ southeast of Johannesburg, South Africa, situated within and almost central to the large intracratonic Witwatersrand Basin. 

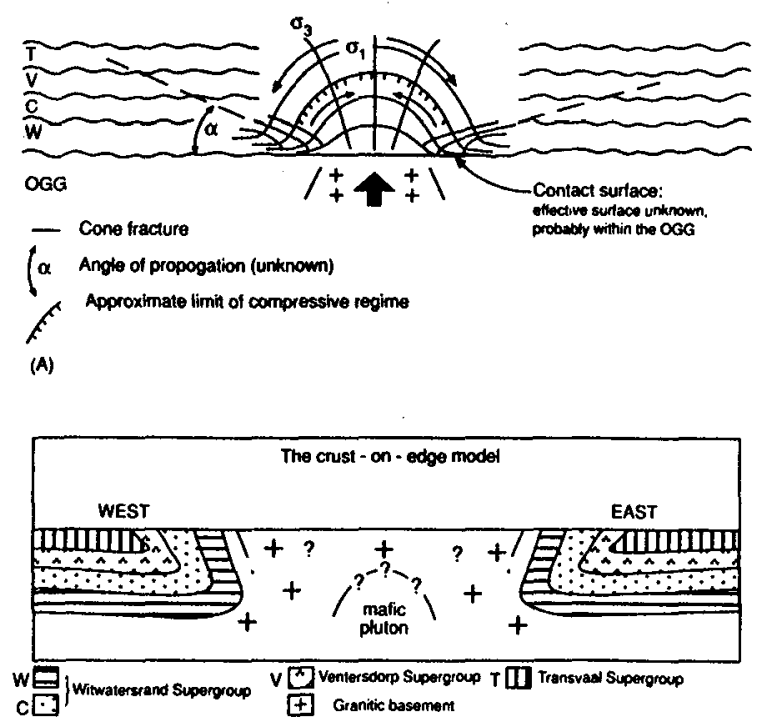

(B)

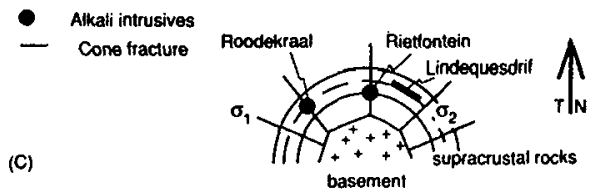

Fig. 1. Schematic illustrating a diapiric quasi-Hertzian stress field as a possible working model for the Vredefort structure: (a) predeformation cross section showing the quasi-Hertzian stress field, (b) postdeformation cross section (the crust-on-edge model), and (c) postdeformation plan view with superimposed stress field.

This structure consists of an Archean core of ca. $45 \mathrm{~km}$ in diameter, consisting largely of granitic gneiss, surrounded by a collar of metasedimentary and metavolcanic supracrustal rocks of the Dominian Group, Witwatersrand and Ventersdorp Supergroups, and Transvaal Sequence (for geological descriptions see, e.g., [1]).

The interpretation of images of the gravity and magnetic fields over Vredefort has permitted the delineation of several important features of the structure and of its immediate environment [2]. The polygonal, concentric outline of the collar strata is a prominent feature of both the gravity and the magnetic fields. The Vredefort structure shares this distinctive geometry with other structures (e.g. . Manicouagan, Decaturville, Sierra Madera) of debated impact origin. In all these, successively older strata with steep outw ard dips are encountered while traversing inward to the center of the structure. A further attribute of these structures is the shortening of the outcrop of a particular stratigraphic unit compared to the original perimeter of that unit.

To account for the geometric attributes of the Vredefort structure a mechanical scheme is required where there is radial movement of horizontal strata toward, with uplift in, the center of the Vredefort structure. Two models can be proposed: (1) one in which there is a rapid rise and violent disruption of cover rocks in response to expansion of a fluid accumulation [3] and (2) one in which there is, in contrast, a nonexplosive, quasi-Hertzian stress field resulting from a diapiric process. Both models can accommodate the geometry and structural components of Vredefort. The proponents of the former model, for the Vredefort case, argue that it could provide a mechanism for deformation phenomena widely regarded as evidence of shock metamorphism (pseudotachylite, quartz with planar microdeformations, and shatter cones). Conversely, these same deformation phenomena are currently being debated $[4,5]$ and it has been hypothesized that they could be formed by high-strain tectonic processes.

In Fig. 1, a Hertzian stress field is sketched (after [6]), both in plan- and cross-section. The stress component $\sigma_{3}$ is compressive, while $\sigma_{1}$, the principal component, is tensile and subparallel to the overiying strata. The trajectories of these stress fields can well account for overturning of collar stratigraphy and the subvertical attitude of the gneissic fabric in the core. In the collar rocks pseudotachylite veins generally occur along bedding plane faults, while in the core they are parallel to the principal shear directions [78]. In plan, $\sigma_{1}$ is tensile radially, whereas the intermediate $\sigma_{2}$ component is a "hoop stress." It is noteworthy that the lineaments of geophysical images comply with the $\sigma_{1}$ orientation and the triad of alkali granitic complexes (Roodekraal, Rietfontein, and Lindequesdrif), intruded into the collar, describe an arc similar to the $\sigma_{2}$ hoop stress. The location of these intrusives could be at the intersection of the $\sigma_{1}, \sigma_{2}$ tensile stress components.

This postulated quasi-Hertzian deformation model is dynamic, so the contact stress and resultant strain would be expected to be complex and to modify in time (see, e.g., [9]). Within the compressive regime (which may have a radius as much as the contact diameter of the indentor, in this case the diapir) $[8,9]$ the $\sigma_{1}$ stress component is compressive and may account for the radial inward riding of sedimentary strata. The observed polygonal geometry results from the outward rupture and relative brittle strain of overlying strata outside the compressive regime (Fig. 1a).

In conclusion, the geometric and structural attributes of the Vredefort structure are consonant with a quasi-Hertzian stress field. In particular, it corroborates the many observations of ubiquitous subhorizontal structures that have led investigators to deduce that the Vredefort structure was produced by subhorizontal forces (see. e.g., $[8,10])$.

References: [1] Hart R. J. et al. (1991) Tectonophysics, 182. 313-331. [2] Antoine L. A. G. et al. (1990) Tectonophysics, 171 , 63-74. [3] Nicolaysen L. O. and Furgeson J.(1990) Tectomophysics, 171, 303-335. [4] Antoine L. A. G. and Reimold W. U. (1988) Global Catastrophes in Earth History, 2-3, LPI Contrib. No. 673. [5] Reimold W. U. and Wallmach T. (1991) S. A. J. Sci., 87, 412-417. [6] Lawn B. R. and Willshaw E. (1975) J. Mater. Sci., 10, 1049-1081. [7] Reimold W. U. and Colliston W. P., this volume. [8] Colliston W. P. and Reimold W. U., this volume. [9] Bahat D. (1980) J. Geol., 88, 271-284. [10] Colliston W. P. (1990) Tectonophysics, 171, 115-118.

SUDBURY PROJECT (UNIVERSITY OF MÛNSTERONTARIOGEOLOGICALSURVEY): (6)ORIGIN OF THE POLYMICT, ALLOCHTHONOUS BRECCIAS OF THE ONAPING FORMATION. M. E. Avermann, Institute of Planetology, University of Münster, Wilhelm-Klemm-Str. 10, W-4400 Münster, Germany.

The Sudbury structure has been interpreted as a deeply eroded remnant of a peak-ring basin [1]. The polymict, allochthonous breccias of the Onaping Formation (OF) occur in the central part of the Sudbury structure, which is surrounded by the 1.85-Ga-old [2] 
"Sudbury Igneous Complex" (SIC). From bottom to top the OF can be divided into Basal, Gray, Green, and lower and upper Black Members [3,4]. The breccias were mapped in detail in the east range of the structure. The SIC and the lower part of the OF (Basal Member) are interpreted as the impact melt system [1,3,5; compare also 6].

The Basal Member occurs as a fragment-laden polymict meltbreccia on top of the granophyre of the SIC and as isolated bodies (formerly called melt bodies [7]) in the Gray and Black Members. The Basal Member contains abundant rock fragments that consist of metasediments of the Huronian Supergroup and minor amounts of Archean crystalline basement. In the upper part of the granophyre a similar fragment population is observed. Therefore, these rocks must have been present in the target area at the time of the impact. Geochemical investigations of the main elements and rare earth elements underline the close genetic relationship of the SIC and the Basal Member and their formation of crustal rocks.

The overlying Gray Member is a breccia unit with a clastic matrix and has a sharp contact to the Basal Member. The polymict, allochthonous breccias of the Gray Member are characterized as a suevitic breccia by a high amount of melt particles and fragments with shock metamorphic features. Signs of multiple brecciation and intemal contacts found during the mapping provide evidence for turbulent movements during the emplacement of the Gray Member $[4,8]$. Based on its petrographic character, the lower part of the Gray Member is interpreted as a ground-surge deposit, which grades into fall-back breccias.

The Green Member is considered as a continuous uniform breccia layer on top of the Gray Member and comprises the former "chlorite shard horizon" [7]. This breccia layer is characterized by a microcrystalline matrix, chloritized "glassy" particles, and a high content of small mineral clasts. The Green Member is regarded as gradational and fine-grained fall-back material, which was affected by high temperatures during the deposition. The Green Member and the chloritized particles originated by early excavation to high atmospheric regimes, condensation out of a vapor phase, and deposition with the final fall-back material.

The uppermost unit of the OF (BlackMember) can be subdivided into a lower and an upper Black Member unit. The lower part (100-150 $\mathrm{m}$ thick) still shows petrographic features of suevitic breccias, small fragments of basement rocks, melt particles, chloritized particles, and breccia fragments in a dark, clastic matrix. These signs indicate that the lower unit has been transported from its original position outside the crater into the central depression of the crater. The upward increase of sedimentary features, signs of multiple brecciation in the upper part of the Black Member, and the gradational contact to the overlying Onwatin slates of the Whitewater Group indicate the subsequent change in the depositional environment. Investigations of the carbonaceous material in the matrix of the Black Members and the Onwatin slates suggest an origin by biogenetic material deposited at a slow rate lasting into a local, euxinic basin, which was created by the Sudbury event.

References: [1] Stöffler D. et al. (1989) Meteoritics, 24, 328. [2] Krogh T. E. et al. (1984) In Ont. Geol. Sur. Spec. Vol. 1 (E. G. Pye et al., eds.). [3] Brockmeyer P. (1990) Ph.D. thesis, Münster, 228 pp. [4] Avermann M. E. (1992) Ph.D. thesis, Münster, 175 pp. [5] Deutsch A. et al. (1990) LPSC XX, 282-283. [6] Faggart B. E. et al. (1985) Science, 230,436-439. [7] Muir T. L. and Peredery W. V. (1984) In Ont. Geol. Sur. Spec. Vol. 1 (E. G. Pye et al., eds.). [8] Avermann M. E. and Brockmeyer P. (1992) Tectonophysics, in press.
SUDBURY PROJECT (UNIVERSITY OF MÜNSTERONTARIO GEOLOGICAL SURVEY): (1) SUMMARY OF RESULTS-AN UPDATED IMPACT MODEL. M. Avermann 1,2, L. Bischoff', P. Brockmeyer, ${ }^{1,2}$, D. Buhl', A. Deutsch', B. O. Dressler, R. Lakomy 1,2, V. Maller-Mohr',2, and D. Stofffler', 'Institut für Planetologie and ${ }^{2}$ Geologisch-Palliontologisches Institut, Universitat Münster, Wilhelm-Klemm-Str. 10 and Corrensstr. 24, W-4400 Münster, Germany, Institut für Geologie, Universităt Bochum, W-4360 Bochum, Germany, ${ }^{4}$ Ontario Geological Survey, 77 Grenville Street, Toronto, Ontario M7A IW4, Canada.

In 1984 the Ontario Geological Survey initiated a research project on the Sudbury structure (SS) in cooperation with the University of Münster. The project included field mapping (1984-1989) and petrographic, chemical, and isotope analyses of the major stratigraphic units of the SS. Four diploma theses and four doctoral theses (Avermann, Brockomeyer, Lakomy, Müller-Mohr) were performed during the project (1984-1992). Specific results of the various investigations are reported in five accompanying abstracts [1-5]. As shown in Fig. 1 of [1], selected areas of the SS were mapped and sampled: Footwall rocks, Footwall Breccia and parts of the sublayer and lower section of the Sudbury Igneous Complex (SIC), Onaping Formation and the upper section of the SIC, and Sudbury breccia and adjacent Footwall rocks along extended profiles up to $55 \mathrm{~km}$ from the SIC. All these stratigraphic units of the SS had been studied in substantial detail by previous workers $[6,7]$. The most important characteristic of the previous research is that it was based either on a volcanic model or on a mixed volcanic-impact model for the origin of the SS. The present project has been clearly directed toward a test of the impact origin of the SS without invoking an endogenic component. In general, our results confirm the most widely accepted stratigraphic division [6] of the SS. However, our interpretation of some of the major stratigraphic units is different from most views expressed in [6]. The stratigraphy of the SS and its new interpretation is given in [3] as a basis for the following discussion.

The main conclusion to be drawn from our results is that (1) the SS is the erosional remnant of a peak- or multiring impact basin with an original diameter in the 200 - to $240-\mathrm{km}$ range and (2) the SIC is no endogenic intrusion but rather the main part of an impact melt sheet that occupies the central depression of the basin and has been produced by shock-induced total melting of crustal rocks [8-12]. Independently, R. A. F. Grieve of the Geological Survey of Canada has come to quite identical conclusions [9]. The individual stratigraphic units or impact-related rocks can be characterized and interpreted as follows.

Footwall Rocks and Related Breccias: The Archean and Proterozoic crystalline basement of the SIC displays impact-induced features up to a radial distance of at least $55 \mathrm{~km}$, possibly $80 \mathrm{~km}$ [6], from the SIC. At the contact to the SIC it forms a (mega)breccia that is thermally metamorphosed and partially molten by the SIC (Footwall Breccia). This breccia grades into a weakly shocked (and, further out, into unshocked) brecciated basement. All basement units contain at least three generations of breccia dikes (Sudbury breccias) formed by frictional melting and shearing during the compression, excavation, and modification stages of the crater formation-a feature typical of all complex terrestrial craters (c.g., [13]).

SIC and Basal Member of the Onaplng Formation: This unit represents a layered complex of rocks that crystallized from an impact melt. It comprises from bottom to top (1) the sublayer, including the offset dikes, a noritic to quartz-dioritic, clast-rich melt 
breccia that covers the floor of what is considered the transient cavity of the impact basin; (2) the norite, quartz gabbro, and granophyre units that are interpreted as clast-free, differentiated impact melt; and (3) the Basal Member of the Onaping Formation, a clast-rich melt breccia. The complete melt sequence has the chemical and isotope signatures of a mixture of upper and lower crustal rocks $[12,14,15]$.

Gray, Green, and Black Members of the Onaping Formation: The rocks of these units form a layered sequence of polymict, melt-bearing, clastic matrix breccias showing strong similarities to suevitic breccias. The lithic fragments of these breccias are derived mainly from the Huronian Supergroup and more rarely from the Archean basement. The melt particles appear to represent whole-rock melts of a mixture of such basement rocks $[14,15]$. The lower unit (Gray Member), which is interpreted as a ground-surgetype suevite, is affected by thermal metamorphism induced by the underlying melt complex. It is topped by a thin layer of melt-rich clastic fall-back material (Green Member, formerly called the chloritized shard horizon) that might have temporarily formed the impact basin floor before the suevitic breccia material of the Black Member was deposited by slumping during the gravity-induced modification stage of the basin formation [16]. We believe that the lower part of the Black Member formed in this way whereas the upper part was deposited aquatically under euxinic conditions. These conditions are responsible for the carbonaceous matter (derived from organic material according to the $C$ isotopes) in the matrix of these breccias.

The distribution and stratigraphic relation as well as the petrographic, chemical, isotope, and shock metamorphic characteristics of the rock units of the SS are clearly compatible with its interpretation as an impact basin whose transient cavity had a diameter $D_{\text {tc }}$ in the 100 - to $140-\mathrm{km}$ range. These figures are derived from the radial extension of shock effects in quartz, of shatter cones, and of the Sudbury breccias, and from the position of the down-faulted "megablocks" of Huronian rocks within the Archean basement north of the structure [9]. They translate into a diameter of the apparent basin $D_{a}$ of at least $150 \mathrm{~km}$ [9], more probably of 200 to $240 \mathrm{~km}[8,10]$, depending on what empirical relation between $D_{t c}$ and $D_{a}$ is used. A major uncertainty in determing these dimensions is caused by the postimpact deformation of the basin during the Penokean Orogeny. Recent geophysical and structural data $[17,18]$ have removed previous objections against a primary circularity of the SS. The present interpretation of the subbasin structure [17] indicates a minimum diameter of the outer margin of the SIC of $60 \mathrm{~km}$. Taking the deformation of the east range by the Wanapitei impact structure into account [6], we believe that this diameter was at least $65 \mathrm{~km}$ although the curvature of the north range would allow a diameter of up to $80 \mathrm{~km}$. In the latter case, $D_{a}$ could exceed even $250 \mathrm{~km}$.

From the present interpretation of the SS additional conclusions can be drawn: (1) The depth of the transient cavity was in the order of 30 to $40 \mathrm{~km}$ and the depth of excavation near 12 to $20 \mathrm{~km}[8,10]$. According to current models for melt zones in impact craters [16], the melt zone at Sudbury probably reached a depth of about $30 \mathrm{~km}$. which is the base of the transient cavity $[8,10]$. This may explain why the Sudbury basin never had a morphologically expressed central uplift [9] but instead a had a central depression bordered by a peak ring with a diameter of 80 to $90 \mathrm{~km}$. (2) The Sudbury impact occurred during an active orogeny (Penokean), 1.85 b.y. ago [19], during which the southeastem part of the basin and peak ring was deformed by thrust faulting to the northwest. This deformation took place while the central part of the melt complex had not yet been cooled and fully crystallized [20] and is therefore not foliated, whereas the rocks above and below were deformed [6]. It is highly probable that the section of the SIC exposed in the south range is from a deeper position of the impact basin than the section of the northrange. (3) As the SS is not only the largest impact structure and the only peak- or multiring basin on Earth but also the largest $\mathrm{Cu}$ Ni deposit, it has gained considerable importance as a model for the study of large impact basins on the terrestrial planets and as a pathway for exploring the geological processes and the genesis of crustal ore deposits in the early history of the Earth. The recognition of a nearly 3-km-thick differentiated impact melt sheet at Sudbury has far-reaching consequences for the interpretation of the >4-b.y.old "plutonic" pristine rocks of the lunar highland crust.

References: [1] Bischoff L. et al., this volume. [2] Deutsch A. et al., this volume. [3] Stöffler et al., this volume. [4] Avermann M., this volume. [5] Müller-Mohr V., this volume. [6] Pye E. G. et al., eds. (1984) The Geology and Ore Deposits of the Sudbury Structure, Ministry of Natural Resources, Toronto, 603 pp. [7] Dressler B. O. (1987) In Research in Terrestrial Impact Structures, Earth Evolution Series (J. Pohl, ed.), 39, F. Vieweg, Braunschweig. [8] Stðffler D. et al. (1989) Meteoritics, 24, 328. [9] Grieve R. A. F. et al. (1991) JGR, 96, 22753. [10] Lakomy R. (1990) Meteoritics, 25, 195. [11] Deutsch A. et al. (1989) EPSL, 93, 359. [12] Faggant B. E. (1985) Science, 230, 436. [13] Stöffler D. et al. (1988) In Deep Drilling in Crystalline Bedrock, Vol. 1 (A. Boden and K. G. Eriksson, eds.), 277, Springer-Verlag, New York. [14] Brockmeyer P. and Deutsch A. (1989) LPSC XX, 113. [15] Deutsch A. et al. (1990) LPSC XXI , 282. [16] Melosh H. J. (1989) Impact Cratering: A Geologic Process, Oxford, New York, 245 pp. [17] Milkereit B. et al. (1992) Geology, in press. [18] Shanks W. S. and Schwerdtner W. M. (1991) Can. J. Earth Sci., 28, 411, 1677. [19] Krogh T. E. et al. (1984) In The Geology and Ore Depasits of the Sudbury Structure (E. G. Pye et al., eds.), Ministry of Natural Resources, Toronto. [20] Grieve R. A. F. (1992) personal commumication.

STRUCTURAL ASPECTS OF THE ARAGUAINHA IMPACT STRUCTURE (BRAZIL). L. Bischoff, P. Brockmeyer, U. Jenchen, and R.-M. Swietlik, Institute of Geology, University of Münster, Germany.

A report is given on the results of two months' field studies carried out in 1988. During that time the northeast segment was mapped and the structural setting of the central area was studied in detail. In addition, the structure of outer zones of the Araguainha Crater was investigated along three radial sections.

The Araguainha impact occurred $243 \pm 19 \mathrm{Ma}$ ago [1] under shallow marine conditions on a mixed target consisting of Devonian, Carboniferous, and Permian mainly clastic sediments overlying a Precambrian phyllitic and granitic basement. The intrusion of the granite probably took place $449 \pm 9 \mathrm{Ma}$ ago [1]. A peripheral ring-fault system, $40 \mathrm{~km}$ in diameter, forms the outer boundary of the complex structure [2]. The central part of the structure, $6-6.5 \mathrm{~km}$ in diameter, consists of a ring of steep hills rising $150 \mathrm{~m}$ above the surrounding plain. The ring is made up of large uplifted blocks of Devonian sandstone, which surround a central 2.5-3-km-wide depression. The interior of the central depression consists of uplifted alkaligranitic basement. The outer limit of the granite is mostly covered by polymict suevitic breccias forming another ring of hills. 
The granite, which is shocked to stage $I$, often shows in its upper part in situ melting, which gradually increases toward the top. This partly molten granite is not part of the allochthonous coherent melt sheet [3] that covered the granite and induced its melting. Except for some relics this layer of molten target rock was eroded like most of the ground-surge and fall-back breccias.

The original bedding of the Paleozoic formations is deformed by impact-induced fracturing and folding. The concentric arrangement with increasing younger formations from the center to the margin of the structure give the structure the apparent domelike appearence. This is due to the combination of a central uplift and the peripheral graben structure. But, in fact, most contacts between the different formations are of tectonic origin and each ring consists of a multitude of fault blocks. Bedding in these blocks has a steep dipping in the central ring, but has moderate to gentle dipping in the outer parts of the structure. Folds are best developed in the sandstones of the Devonian Fumas Formation of the interior hills. The axis of the steeply outward plunging open folds scatter remarkably in different directions. They are sometimes arranged in a complex fanlike pattern. From the analysis of the fault pattern and the geometry of the folds, the principal stress components can roughly be estimated with $\sigma_{1}$ radial to the center.

Pebbles of some target rocks are heavily sheared. Shear plane analysis may be used to reconstruct stress distribution during the cratering process if the original position of the pebble-containing beds is known.

References: [1] Deutsch A. et al. (1992) Tectonophysics, in press. [2] Theilen-Willige B. (1982) Geol. Rdsch., 71, 318-327. [3] Engelhardt W. v. et al. (1992) Meteoritics, in press.

\section{SUDBURY PROJECT (UNIVERSITY OF MUNSTER- ONTARIO GEOLOGICAL SURVEY): (2) FIELD STUDIES 1984-1989-SUMMARY OF RESULTS. L. Bischoff', B. 0 . Dressler', M. E. Avermann ${ }^{1,3}$, P. Brockmeyer, ${ }^{1,3}$, R. Lakomy ${ }^{1,3}$, and V.Müller-Mohr ${ }^{1,3},{ }^{1}$ Geologisch-Palälontologisches Institut, Univer- sity of Münster, Corrensstr. 24,W-4400 Münster, Germany, ${ }^{2}$ Ontario Geological Survey, 77 Grenville Street, Toronto, Ontario, M7A IW4, Canada, Institut für Planetologie, University of Münster, WilhelmKlemm-Str. 10, W-4400 Münster, Germany.}

In cooperation between the Ontario Geological Survey (B. $O$. Dressler) and the Institute of Geology and Institute of Planetology, both of Westfalische Wilhelms-Universität, Münster, geological, petrological, and geochemical studies were carried out on impactrelated phenomena of the Sudbury structure during the last decade. The main results of the field studies are briefly reviewed (see also [1-5]). As shown in Fig. 1, Footwall rocks, sublayer, and lower sections of the Sudbury Igneous Complex (SIC) were mainly mapped and sampled in the northem (Levack Township) and western (Trillabelle and Sultana Properties) parts of the north range. Within these mapping areas Sudbury Breccias (SB) and Footwall Breccias (FB) have been studied; SB have also been investigated along extended profiles beyond the north and south ranges up to $55 \mathrm{~km}$ from the SIC [5]. The Onaping Formation (OF) and the upper section of the SIC were studied both in the north range (Morgan and Dowling Townships) and in the southern east range (Capreol and McLennan Townships) (see Fig. 1).

The Footwall rocks [6-12] exhibit shock metamorphic phenomena of shock stage $I$, which is characteristic of an impact crater floor. Shock metamorphism, including especially planar elements in quartz and shatter cones, can be observed up to a radial distance of $9 \mathrm{~km}$ from the lower SIC contact or up to $17 \mathrm{~km}$ (shatter cones). The Footwall rocks were subjected to a thermal overprint by the SIC up to a distance of $1 \mathrm{~km}[8,12]$.

The FB $[3,6,10,12,13]$ is the remnant of a clastic matrix crater floor breccia. It occurs as irregularly or lenticularly shaped bodies at the contact between the Footwall and the SIC. Further on FB dikes intrude into the brecciated crystalline basement rocks up to $250 \mathrm{~m}$ away from the $\mathrm{FB}$ layer $[10,12,13]$. The contacts between $\mathrm{FB}$ and the underlying Footwall rocks are always sharp, even on a microscale. The fragment content reflects a local origin. Fragments of FB occur enclosed in the sublayer and norite. The crystalline matrix was formed after localized melting of the originally clastic matrix due to the thermal overprint by the SIC. Locally megaclasts ( $>25 \mathrm{~m}$ ) adjacent to the country rock are embedded in huge intercalations of FB matrix.

The SB $[5,7,9,11,12,14]$ occur as various types of clastic or crystalline matrix breccia forming irregular dikes whose orientations appear not to be controlled by the geometry of the Sudbury structure. In the north range dikes have been observed up to a distance of at least $55 \mathrm{~km}$ from the lower contact of the SIC, but are abundant within a zone of $10 \mathrm{~km}$ adjacent to the SIC and a second zone located approximately between 20 and $33 \mathrm{~km}$ north of the SIC. The thickness of the dikes ranges from centimeters to several hundred meters. Most of the dikes exhibit sharp contacts to the wall rock. Several phases of brecciation can be distinguished by breccia fragments in SB, whereas crosscutting of different breccia types is extremely rare. Most of the fragments of the SB are directly derived from the country rock, but in large dikes relative movements of clasts over several hundred meters can be found. The SB were formed by shearing and friction of Footwall rocks.

The breccias of the OF [4,15-17] can be divided from bottom to top into Basal Member, Gray Member, Green Member, and lower and upper Black Member according to their lithological composition, matrix, clast population, contacts, and texture. The term "Basal Member" comprises a clast-rich melt breccia on top of the SIC and the "melt bodies" [18], as they were formerly called, whereas the term "Green Member" implies the former "chlorite shard horizon" [18]. The Black Member was subdivided due to obvious changes upward in fragment content, size, matrix texture, grade of foliation, and occurrence of both carbonaceous material and sedimentary features. The lower part of the polymict allochthonous breccias of the OF are interpreted as impact-melt breccias, the overlying breccias as ground-surge breccias, and the uppermost as original or resedimented fall-back breccias [see 1,2,4].

References: [1] Stöffler D. et al., this volume. [2] Avermann M. et al., this volume. [3] Deutsch A. et al., this volume. [4] Avermann M., this volume. [5] Müller-Mohr V., this volume. [6] Lakomy R. (1986) Unpublished diploma thesis, Münster, 135 pp. [7] Brockmeyer P. (1986) Unpublished diploma thesis, Müster, 101 pp. [8] Avermann M. E. (1988) Unpublished diploma thesis, Münster, 113 pp. [9] Müller-Mohr V. (1988) Unpublished diploma thesis, Münster, 106 pp. [10] Lakomy R. (1989) Ph.D. thesis, Münster, 165 pp. [11] Müller-Mohr V. (1992) Ph.D. thesis, Münster, 139 pp. [12] Dressler B.O. (1984) In Ont.Geol.Surv.Spec.Vol. I (E.G.Pye et al., eds.). [13] Lakomy R. (1990) Meteoritics, 25, 195-207. [14] Müller-Mohr (1992) Tectonophysics, in press. [15] Brockmeyer P. (1990) Ph.D. thesis, Münster, 228 pp. [16] Avermann M. E. (1992) Ph.D. thesis, Münster, 175 pp. [17] Avermann M. E. and Brockmeyer P. (1992) Tectonophysics, in press. [18] Muir T. L. and Peredery W. V. (1984) In Ont. Geol. Surv. Spec. Vol. I (E. G. Pye et al., eds.). 


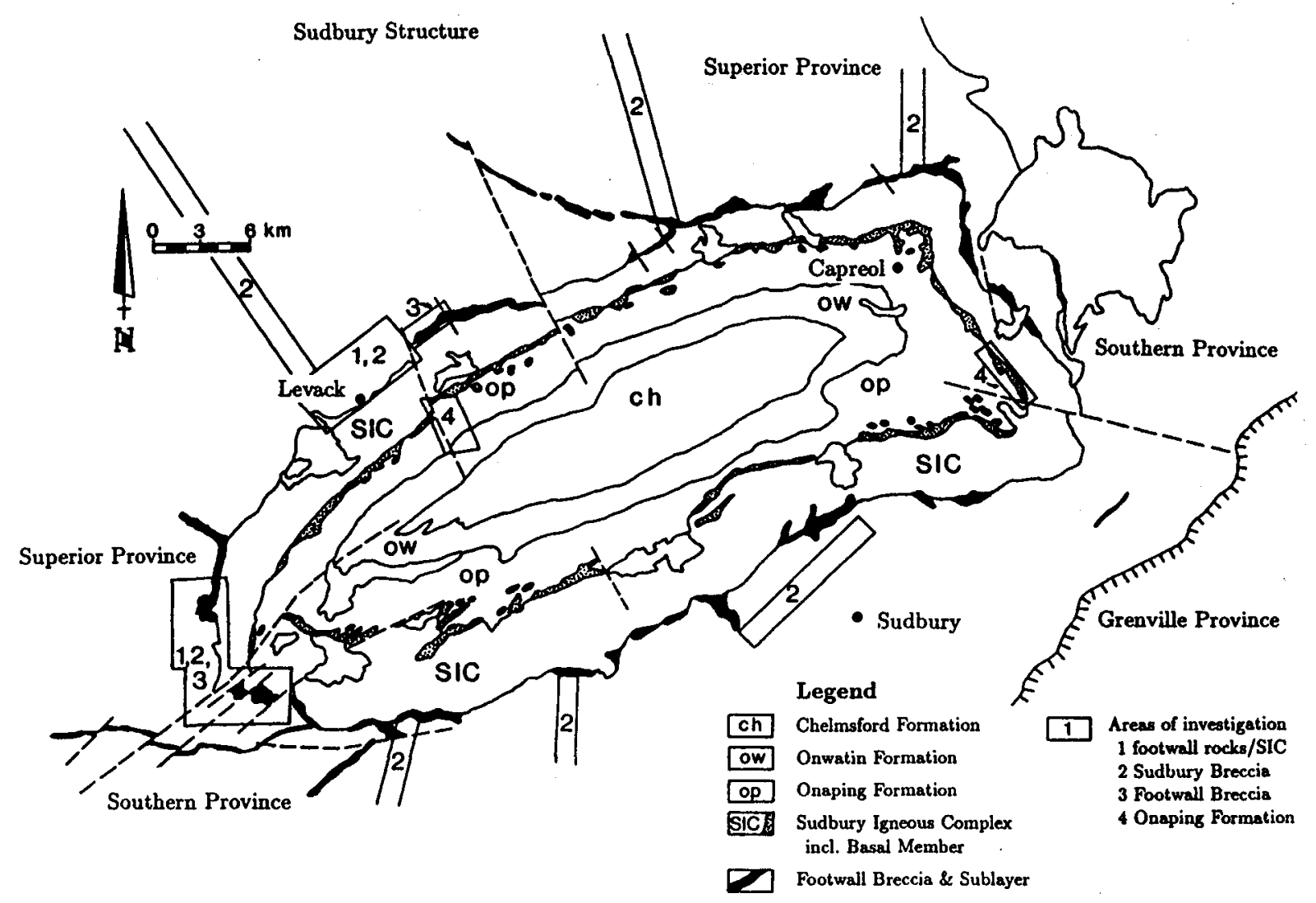

Fig. 1. Sketch map of the Sudbury structure showing the areas of investigation.

LARGE METEORITE IMPACTS: THE K/T MODEL. B. F. Bohor, U.S. Geological Survey, Box 25046, MS 972, Denver CO 80225, USA.

The Cretaceous/Tertiary (K/T) boundary event represents probably the largest meteorite impact known on Earth. It is the only impact event conclusively linked to a worldwide mass extinction, a reflection of its gigantic scale and global influence. Until recently, the impact crater had not been definitively located and only the distal ejecta of this impact was available for study. However, detailed investigations of this ejecta's mineralogy, geochemistry, microstratigraphy, and textures have allowed its modes of ejection and dispersal to be modeled without benefit of a source crater of known size and location [1,2].

Initially, only $\mathrm{K} / \mathrm{T}$ boundary sites in marine rocks with a single, thin ( $-3-5 \mathrm{~mm}$ ) layer of Ir-rich ejecta were known. Subsequently, nonmarine sites were discovered in the western interior of North America with thicker $(-3 \mathrm{~cm})$ boundary claystone units composed of two distinct layers [3]. The uppermost of these two layers, which I have called the "fireball" layer, contains a substantial Ir anomaly, skeletal Ni-rich magnesioferrite crystals, and a large population of shocked minerals in the nonclay fraction. The maximum grain size of these shocked minerals decreases regularly away from the site of the putative crater, both in the western interior [4] and on a global basis [5]. Geochemically, the fireball layer has a basaltic signature and is mainly composed of laminated smectitic clay. It immediately overlies the lower layer with a sharp textural contact. This lower layer, which I have named the "melt ejecta" layer, has a very subdued Ir anomaly, contains only a small amount of shocked minerals and no magnesioferrite, has a silicic geochemical signature, and displays a turbated texture of unsorted, altered, imbricate shards [6], vitric clasts [7], and microtektites [8] in a microspherulitic kaolinite matrix [6]. The melt ejecta layer thins radially aw ay from the putative crater location in the Caribbean region and cannot be identified beyond $-4000 \mathrm{~km}$ of the crater. Both the fireball and melt ejecta layers contain a similar suite of trace minerals [9], which argues for a mutual origin from a single impact.

The partitioning of these impact components and signatures between the two layers supports a dual-phase model of ejection and dispersal from a single impact [2]. Moreover, the distinctive clay minerals formed from the vitric components in each of these two layers in the western interior lends further support to the dual-phase model [10]. In this model, the fireball layer represents sedimentation from a radially expanding cloud of vaporized bolide and entrained target material dispersed above the atmosphere. The melt ejecta layer represents melted target rock ejected from the crater and 


\section{LARGE METEOROID IMPACT}

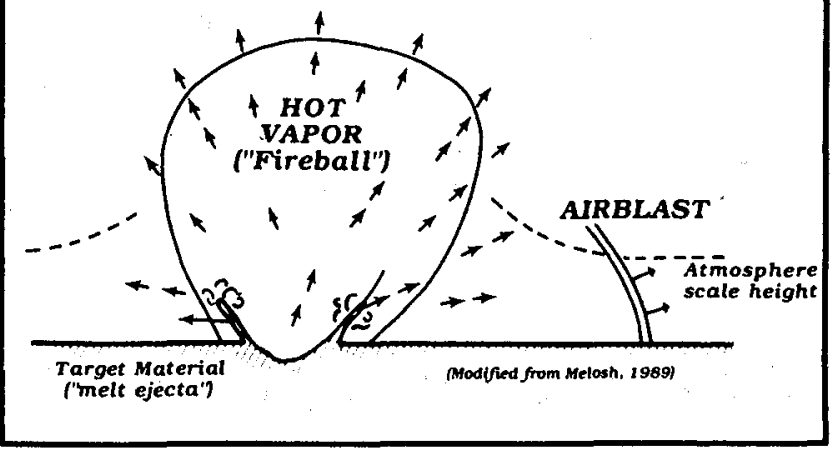

Fig. 1. Vapor plume cloud (fireball) exceeds the scale height of atmosphere and expands globally above it.

transported both ballistically and in a detached ejecta curtain within the atmosphere [11], forming an areally limited, continuous ejecta blanket. This dual-phase impact model applies only on planets with atmospheres when the size of the stabilized vapor plume exceeds the scale height of the atmosphere (Fig. 1) [12]. In this case, the cloud of vaporized bolide penetrates above the atmosphere and is dispersed globally, resulting in two-layer deposition within the limits of the continuous ejecta blanket. Only a single layer (fireball) is present elsewhere beyond the bounds of the basal melt ejecta blanket. This pattern of ejecta dispersal explains many of the early misconceptions about the nature of the $\mathrm{K} / \mathrm{T}$ target rocks and impact site that were based on geochemical analyses of far-field ejecta comprised solely of the fireball layer.

Distal ejecta from other large terrestrial impacts should resemble this dual-phase $\mathrm{K} / \mathrm{T}$ model. Thus, if distal ejecta from the Sudbury structure can be located, it would be expected to be composed of two layers within the extent of the continuous ejecta blanket and single-layered beyond this limit. However, analyses of ejecta deposits from Archean impacts in South Africa and Australia [13] indicate that most of these thick spherulitic beds are comprised of both fireball (Ni-spinels and high Ir) and melt ejecta (microtektites) components. This comingling of components suggests either lack of a significant atmosphere during the late bombardment period, or small-scale impacts where the fireball is contained within the atmosphere (Fig. 2) [12]. Other planets with atmospheres, such as Venus and Mars, may also show a dual-phase distribution of ejecta for large impacts.

Acknowledgments: This work was partially supported by NASA Grant T5715P. W. J. Betterton provided valuable technical support.

References: [1] Bohor B. F. (1990) In GSA Spec. Pap. 247, 335-342. [2] Bohor B. F and Betterton W. J. (1992) LPSC XXIII, 135-136. [3] Izett G. A. and Bohor B. F. (1986) GSA Abst. with Prog., 19, 644. [4] Bohor B. F. and Betterton W. J. (1991) Meteoritics, 26, 321. [5] Bohor B. F. and Izett G. A. (1986) LPSC XVIII, 6869. [6] Pollastro R. M. and Pillmore C. L. (1987) J. Sed. Petrol.,
SMALL METEOROID IMPACT

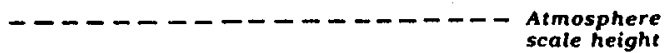
scale height

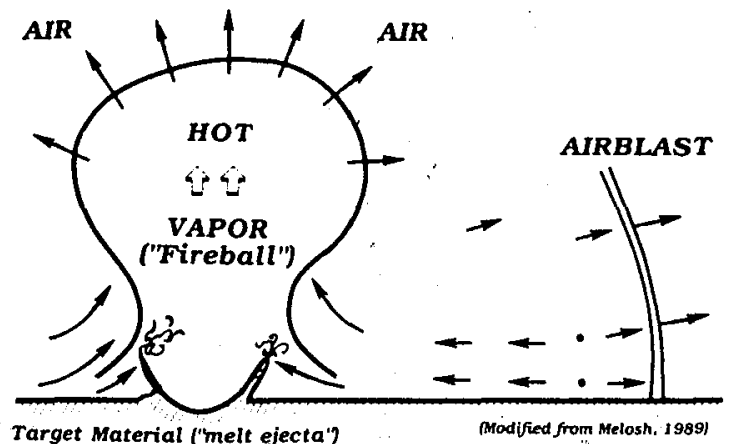

Fig. 2. Vapor plume cloud (fireball) contained and dispersed within scale height of the atmosphere.

54, 456-466. [7] Bohor B. F. (1988) Meteoritics, 23, 258-259. [8] Bohor B. F. and Betterton W. J. (1991) Meteoritics, 26, 320. [9] Bohor B. F. et al. (1989) Meteoritics, 24, 253. [10] Pollastro R. M. and Bohor B. F. (1991) Clay Min. Soc. Prog. and Abst., 129, LPI Contrib. No. 773 [11] Bamouin O. and Schultz P. H. (1992) LPSC XXIII, 65-66. [12] Melosh H. J. (1989) Impact Cratering, Oxford, New York. [13] Lowe D. R. et al. (1989) Science, 245, 959-962.

SHOCKED ZIRCONS IN THE ONAPING FORMATION: FURTHER PROOF OF IMPACT ORIGIN. B. F. Bohor and W. J. Betterton, U.S. Geological Survey, Box 25046, MS 972, Denver CO 80225, USA.

The Onaping Formation fills the structural basin at Sudbury, Ontario, Canada. This formation is composed of three members: a basal, coarse, mainly quartzitic breccia (Basal Member), a lightcolored, heavily included, polymict middle unit (Gray Member), and a similar but dark-colored upper unit (Black Member). Two different origins have been proposed for the Onaping: (1) volcanic ash-flow sheet and (2) impact fall-back ejecta. These origins are critically discussed in a review paper coauthored by proponents of each view [1].

French [2] identified multiple sets of shock lamellae in quartz and feldspar grains from the Onaping Formation at Sudbury. We have also identified sets of shock lamellae (called planar deformation features, or PDF) in a single quartz grain from a thin section of the Black Member. These PDF usually consist of "decorated" lamellae that are much less distinct than those in younger impacted rocks and ejecta, such as the $\mathrm{K} / \mathrm{T}$, because of annealing by subsequent metamorphic events.

Because it is more refractory than quartz and feldspar, zircon should resist annealing by thermal metamorphism. We have already shown that some zircons from $\mathrm{K} / \mathrm{T}$ distal ejecta display PDF when 


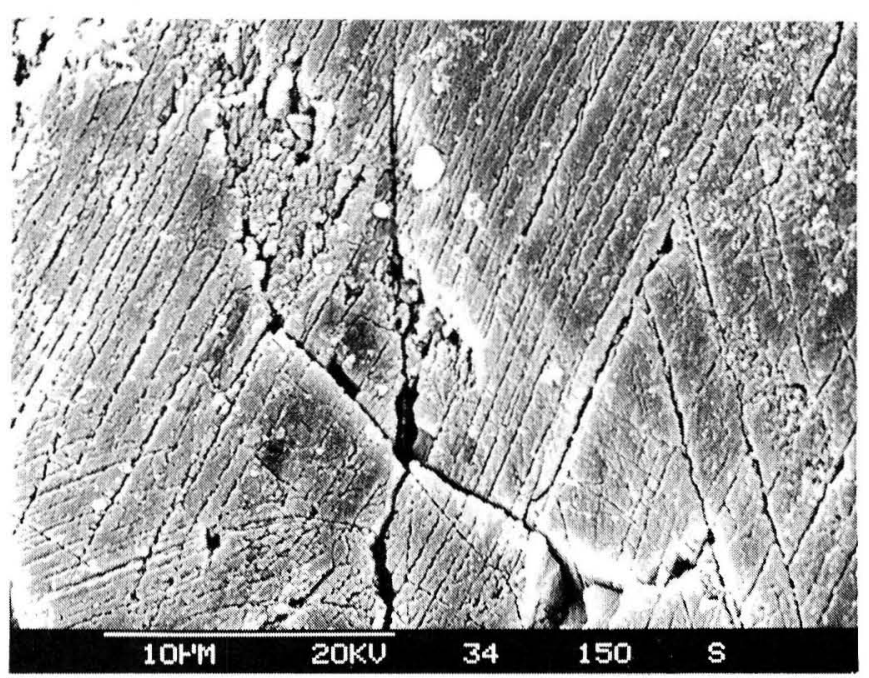

Fig. 1. PDF (4 sets).

subjected to an alkaline etch [3]. We dissolved samples of both the Gray and Black Members of the Onaping with acids to free the contained zircons, which were then etched in alkaline solutions to reveal any PDF. These samples were collected from outcrops of the Onaping along Highway 144 south of Levack and west of the High Falls on the Onaping River. In the process of separating the zircons, we also recovered other resistant trace minerals indicative of target rock lithologies. These include tourmaline, garnet, kyanite, rutile, staurolite, chromite, pyrite, and pyrrhotite.

Many of the etched zircons from both the Gray and Black Members display PDF when viewed in an SEM. Figure 1 shows an area of a shocked zircon from the Black Member that displays at least four sets of PDF. These shock lamellae in zircon are much narrower than those in quartz and do not etch as deeply, probably because they contain less glass within them. Precession X-ray photos of zircons from K/T ejecta with PDF show extreme broadening and streaking (asterism) of diffraction maxima, confirming that they have been highly shocked [3].

Krogh et al. [4] reported zircons from the Onaping Formation at Sudbury that show linear, crystallographically oriented fracturing. They ascribed these features to shock caused by impact, and this conclusion is supported by $\mathrm{U}-\mathrm{Pb}$ data. The discordance of these zircons is crudely proportional to the amount of fracturing they display, caused by the Sudbury event dated from a lower intercept age of $\sim 1836 \mathrm{Ma}$. We have also observed both linear and irregular fractures in our Onaping zircons, but the finer-scale PDF probably indicate a significantly higher level of shock than do these coarse, open features.

In addition to fractures and PDF, Onaping zircons also show another type of textural feature that indicates exposure to a high level of shock. We have called this texture, first noted in zircons from K/T ejecta [3], "granular" or polycrystalline (Fig. 2). Often, zircons displaying this texture are idiomorphic with some of the original crystal surfaces still visible. This indicates that the zircons have not melted, but instead have been recrystallized due to shock. Thus, these granular zircon grains can be considered to be diaplecticthat is, shock-converted by solid-state transformation into polycrystalline zircon below their fusion temperature. On the other hand, zircons also can be melted by impacts, as shown by fused grains partially or completely converted to baddeleyite in high-temperature impact glasses [5]. The granular zircons in $\mathrm{K} / \mathrm{T}$ ejecta and from

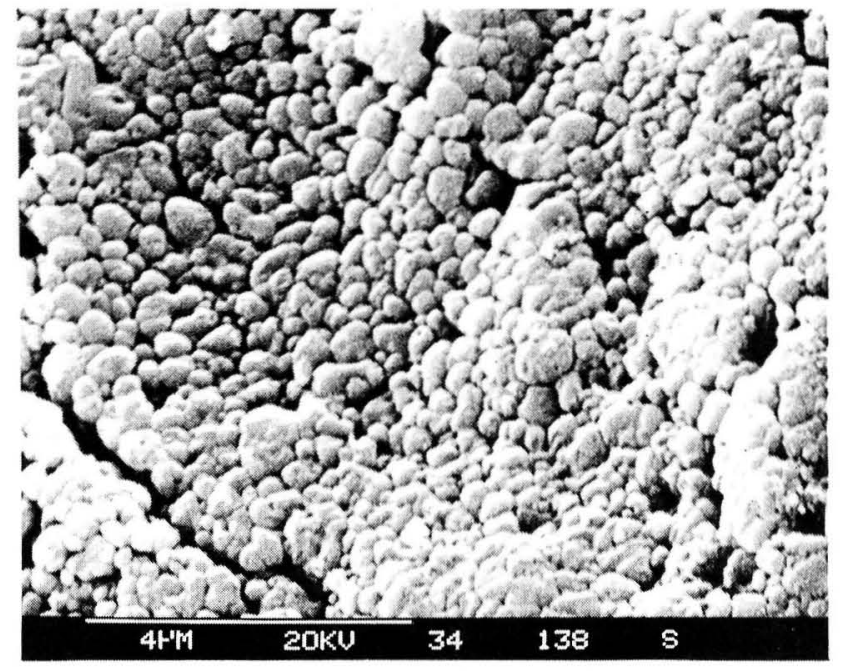

Fig. 2. Granular texture.

the Onaping show no phase or compositional changes by $\mathrm{X}$-ray analyses, in either diffraction or energy-dispersive modes. This is another indication that their texture is due to solid-state transformation induced by shock, and not thermal melting.

It is instructive that these granular-textured zircons have been found only in ejected material, and not in shocked, in situ target rocks around craters. However, zircons bearing impact-generated PDF have been identified from three types of sites and materials: $\mathrm{K} / \mathrm{T}$ distal ejecta, Sudbury fall-back ejecta (Onaping), and Manicouagan target rocks. More importantly, PDF and granular textures have never been seen in volcanic zircons. Therefore, zircons can provide corroborating evidence of impact-generated shock; this discovery could prove very useful in evaluating the metamorphic histories of quartz-poor lunar rocks and meteorites.

Acknowledgments: We thank B. Dressler for guiding one of us (BFB) to the "type" locality of the Onaping. T. Krogh provided the Manicouagan zircons, and E. Foord performed the X-ray analyses.

References: [1] Muir T. L. and Peredery W. V. (1984) In Ont. Geol. Sur. Spec. Vol. 1 (E. G. Pye et al., eds.), 139-210. [2] French B. M. (1967) Science, 156, 1094-1098. [3] Bohor B. F. et al. (1990) Meteoritics, 25, 350. [4] Krogh T. E. et al. (1984) In Ont. Geol. Sur. Spec. Vol. 1 (E. G. Pye et al., eds.), 431-446. [5] El Goresy A. (1968) In Shock Metamorphism of Natural Materials (B. M. French and N. M. Short, eds.), 531-553, Mono, Baltimore.

\section{SUEVITE SUPERPOSITION ON THE BUNTE BRECCIA IN NÖRDLINGER RIES/GERMANY: NEW FINDINGS ON THE TRANSPORT MECHANISM OF IMPACTITES. D.} Bringemeier, Marie-Hedwig-Str. 15, W-3392 Clausthal-Z., Germany.

Research undertaken in the last decades in Nördlinger Ries, Germany, has repeatedly emphasized the sharp contact between Bunte breccia and suevite. However, extensive investigations into this layer boundary have not yet been possible due to insufficient outcrop ratios.

New outcrops enabled an in-depth investigation into the superposition of suevite on the Bunte breccia, which is assigned a key role in interpreting the transport mechanisms of ejecta of large impact. 
In two quarries lying several kilometers east and south-southwest of the crater (Otting. Aufhausen/Seelbronn), the contact between the suevite and Bunte breccia was recorded in detailed sections on outcrops of over $50 \mathrm{~m}$ in length.

It was possible to confirm studies made in the 1960 s by Wagner [1] that suggested a division of the suevite into main suevite, rich in pancake bombs (also called "fladle"), and a relatively well-sorted, thin-base suevite consisting of fine gravel. A semiquantitative analysis of the just slightly consolidated base suevite revealed the main constituent to be "fresh," bubble-abundant, albeit sometimes bubble-deficient, angular glasses. Secondary crystalline and sedimentary rock clasts and very rarely "flädle" were detected. Significant to the transport mechanism of the base suevite is its content of Bunte breccia fragments and the discovery of shell fragments. Between the base suevite and the Bunte breccia is a crystalline breccia of ca. $0.1 \mathrm{~m}$ in thickness that is separated from the Bunte breccia by a sharp boundary. In some areas a transition bed is visible between the crystalline breccia and the base suevite. This transition bed indicates an erosive reworking of crystalline breccia by the base suevite. In one of the sections (Aufhausen/Seelbronn) the base suevite was not observed, as the main suevite lay either on the crystalline breccia or directly on the Bunte breccia. The crystalline breccia is highly altered and in the transition to main suevite contains disintegrated glasses.

In both sections structures were established that can be explained only by an erosive reworking of the subsoil caused by a shifting viscous suevite flow. Particulary on the flanks of the hummocks of Bunte breccia, lying several meters higher, the layers below the main suevite have been plained, compressed, and mixed by the suevite flow. In the Aufhausen/Seelbronn section hook-shaped, decimeter-sized, fingerlike compressions of Bunte breccia and crystalline breccia project into the main suevite. A clear erosive discordance between the main suevite and the base suevite is visible in the Otting section.

Reference: [1] Wagner G. H. (1965) Jh. Geol. Landesamt Baden-Wiurttemberg, Vol. 7, 199-222.

SUDBURY PROJECT (UNIVERSITY OF MŨNSTERONTARIO GEOLOGICAL SURVEY): (7) Sr-Nd IN HETEROLITHICBRECCIASANDGABBROICDIKES. D.Buhl', A. Deutsch'2, R. Lakomy2, P. Brockmeyer', and B. Dressler', 'Inst. f. Geologie, RU Bochum, Postfach 1021 48, D-4630 Bochum 1, Germany, 2Inst. f. Planetologie, Univ. Münster, Wilhelm-KlemmStr. 10, D-4400 Münster, Germany, ${ }^{3}$ Ontario Geological Survey, 77 Grenville Street, Toronto, Ontario M7A 1W4, Canada.

One major objective of our Sudbury project [1-6] was to define origin and age of the huge breccia units below and above the Sudbury Igneous Complex (SIC), i.e., the Footwall Breccia (FB) and the Onaping Formation, which caps the SIC. For the terminology used here we refer to the companion abstracts in this volume $[1,3]$; petrographic descriptions of the FB and of the Onaping breccias are found in [3,5,7-10].

The heterolithic FB, which is up to $150 \mathrm{~m}$ thick, represents a part of the uplifted crater floor [7,8]. It contains subrounded fragments up to several meters in size and lithic fragments with shock features ( $>10 \mathrm{GPa}$ ) embedded into a fine- to medium-grained matrix $[8,9]$. $\varepsilon_{\mathrm{Nd}}-\varepsilon_{3 \mathrm{r}}$ relationships point to almost exclusively parautochthonous precursor lithologies (sce Fig. 1 in [3]). The different textures of the matrix reflect the metamorphic history of the breccia layer: Thermal annealing by the overlying hot impact melt sheet (SIC) at temperatures $>1000^{\circ} \mathrm{C}$ resulted in melting of the fine crushed material, followed by an episode of metasomatic $\mathbf{K}$-feldspar growth and. finally, formation of low-grade minerals such as actinolite and chlorite. Figures 1 and 2 show that the Rb-Sr method on thin slabs and mineral fractions clearly can separate these events, whereas the Sm-Nd system apparently did not respond to either the thermal or the "late" metarnorphic episode [7,8]. This is due to the fact that the highly refractory accessory phases that are the main REE carriers survived the melting in part [10].

Isotope relationships in the Onaping breccias (Gray and Green Member) are much more complex ([10-14]; compare also Fig. 1 in [3]). All attempts to date the breccia formation failed: Zircons are entirely derived from country rocks and lack the pronounced $\mathrm{Pb}$ loss caused by the heat of the slowly cooling impact melt sheet (SIC), which is documented in the crater basement [15]. Rb-Sr techniques using either lithic fragments of different shock stages [12], carefully separated, now recrystallized melt particles and melt matrices or the thin slab method $[13,14]$ just set time limits for the apparently pervasive alkali mobility in these suevitic breccias. The data array

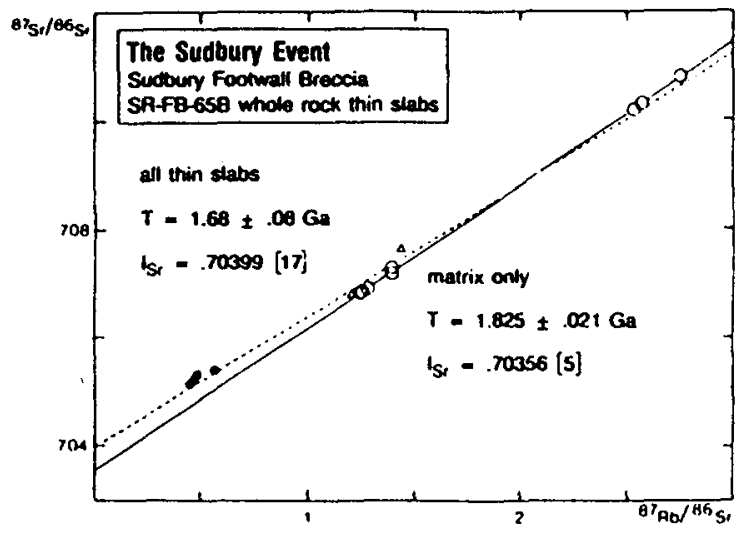

Fig. 1. Rb-Sr isochuon diagram for thin slabs of the Footwall Breccia (north of Stathcona mine, Levack Township, North Range). Thin slabs of the quartzdioritic (= melt) matrix yield the age of the impact.

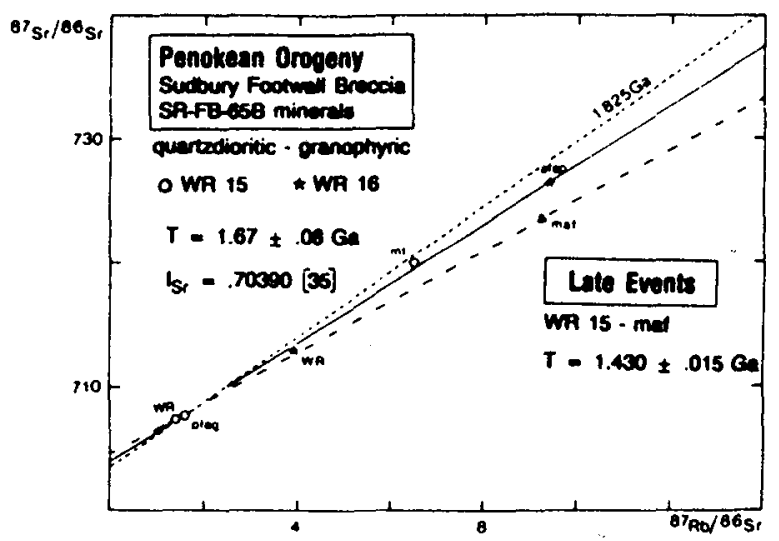

Fig. 2. Same samples as in Fig. 1. K-spar-rich granophyric matrix date a metasomatic episode; mineral fractions define a late, lowgrade event. 


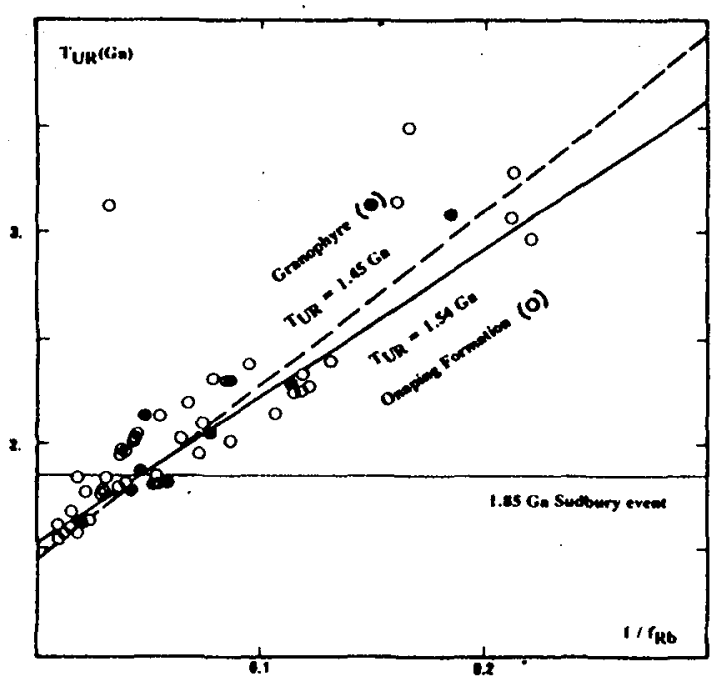

Fig. 3. $T_{U r}$ vs. $1 / f_{R b}$ diagram after [16] for Onaping breccias and whole-rock samples from the granophyre (SIC). Data sources $[10,12-14,17,18]$.

and the intercept in $T_{U r}$ vs. $1 / f_{R b}$ plots [16] point to a major $\mathbf{R b}-S r$ fractionation around $1.54 \mathrm{Ga}$ ago (Fig. 3). This model age is in the same range as $1.63 \pm 0.07 \mathrm{Ga}$ obtained for the metasomatic matrix of the FB (Fig. 2). It has to be pointed out that Rb-Sr whole-rock data for the granophyre of the SIC $[17,18]$ also show this event (Fig. 3), whereas the norite behaved as a closed system during this phase.

Preliminary Sm-Nd results for gabbroic dikes of tholeitic composition that intrude Chelmsford wackes [19] are listed in Table 1. They have an intemal isochron age of $1648 \pm 103 \mathrm{Ma}(2 \sigma)$ with $\varepsilon_{\mathrm{Nd}} \mathrm{T}=165 \mathrm{Ga}$ of -5.4 . The $\varepsilon$-value, their model age $\mathrm{T}_{\mathrm{DM}}$ relative to the depleted mantle [20] of $\sim 2.7 \mathrm{Ga}$, and the intrusion age point to a remobilization of old crust during the Penokean orogeny, but a mantle magma heavily contaminated with crustal material may be also consistent with the data. These dikes apparently have no connection with the SIC and postdate the impact event.

Rb-Sr dating of a shock event in impact-related breccias seems to be possible only if their matrix had suffered total melting by the hot melt sheet (FB) or if they contain a high fraction of impact melt (suevitic Onaping breccias), whereas the degree of shock metamorphism in rock or lithic fragments plays a minor role [11]. In the Sudbury case, however, the impact melt in the suevitic breccias is devitrified and recrystallized, which changed $\mathrm{Rb} / \mathrm{Sr}$ ratios quite

TABLE 1. Sm-Nd analytical results for gabbroic dykes, Sudbury structure.

\begin{tabular}{lcccc}
\hline & $\begin{array}{c}\mathrm{Sm} \\
{[\mathrm{ppm}]}\end{array}$ & $\begin{array}{c}\mathrm{Nd} \\
{[\mathrm{ppm}]}\end{array}$ & $\begin{array}{l}14 \mathrm{Sm} / 14 \mathrm{Nd} \\
\text { WR }\end{array}$ & $\begin{array}{c}100 \mathrm{Nd} / \mathrm{N}^{\mathrm{N}} \\
\pm 2 \sigma\end{array}$ \\
\hline coarse-gmined & 1.692 & 6.755 & 0.15139 & $0.511872 \pm 16$ \\
plag 180-250 mm & 1.009 & 5.302 & 0.11501 & $0.511464 \pm 10$ \\
mafics 180-250 mm & 2.386 & 9.490 & 0.15197 & $0.511860 \pm 7$ \\
WR & 2.619 & 11.86 & 0.13311 & $0.511687 \pm 23$ \\
\hline
\end{tabular}

*Nomalized to ${ }^{1 \omega \mathrm{Nd} / 4} \mathrm{Nd}=0.7219 ; 2 \sigma$ errors refer to the last significant digits. drastically. Therefore, the Onaping breccias give only age limits for alteration and low-grade metamorphism. The Sm-Nd system was not reset during the Sudbury event; clasts as well as the matrix in the FB and in the Onaping breccias show preimpact "Archean" Nd isotope signatures.

References: [1] Avermann M. et al., this volume. [2] Bischoff L. et al., this volume. [3] Stöffler D. et al., this volume. [4] Deutsch A. et al., this volume. [5] Avermann M., this volume. [6] MullerMohr V., this volume. [7] Deutsch A. et al. (1989) EPSL, 93, 359. [8] Laromy R. (1990) Meteoritics, 25, 195. [9] Dressler B. O. (1984) In The Geology and Ore Deposits of the Sudbury Structure (E. G. Pye et al., eds.), 97-136, Toronto. [10] Brockmeyer P. (1990) Ph.D. thesis, Univ. Münster, 228 pp. [11] Deutsch A. (1990) Habil-Schrift FB Geowiss Univ Mamiter. [12] Fullagar P. D.et al. (1971) Can.J. Earth Sci., 8, 435. [13] Brockmeyer P. and Deutsch A. (1989) LPSC $X X, 113$. [14] Deutsch A. et al. (1990) LPSC XXI, 282. [15] Krogh T. E. et al. (1984) In The Geology and Ore Deposits of the Sudbury Structure (E. G. Pye et al., eds.), 431-446, Toronto. [16] Shaw H. F. and Wasserburg G. J. (1982) EPSL, 60, 155. [17] Hurst R. W. and Fahart J. (1977) GCA, 41, 1803. [18] Gibbins W. A. and McNutt R. H. (1975) Can.J. Earth Sci., 12, 1970. [19] Dressler B. O. (1984) In The Geology and Ore Deposits of the Sudbury Structure (E. G. Pye et al., eds.), 57-82, Toronto. [20] DePaolo D. J. (1981) JGR,86, 10470.

HONG KONG IS AN IMPACT CRATER: PROOF FROM THE GEOMORPHOLOGICAL AND GEOLOGICAL EVIDENCE. Chu-lok Chan', Wu Siben', and Lwo Xiuquan', 'Hong Kong Amateur Astronomical Society, Hong Kong, 2 Institute of Mineral Deposits, Chinese Academy of Geological Sciences, China.

Hong Kong is a famous city in southern China, $22^{\circ} 19^{\prime} \mathrm{N}, 114^{\circ} 10^{\prime} \mathrm{E}$, within which the urban districts of Hong Kong, Kowloon, and Victoria Harbour are situated. Hong Kong is surrounded by mountains with a diameter of $11 \mathrm{~km}$. Three million people live inside the basin.

The round structure of the mountains in Hong Kong has been described as a granite dome that is deeply eroded (batholith). In this paper, the circularity of the mountains, the existence of a central hill, the inner slope of the mountains being greater than the outer slope, the presence of deep layer rock inside the basin, and the depth-todiameter ratio have been studied. All this evidence shows that the Hong Kong structure satisfies the geomorphological requirement of an impact crater.

Some shock metamorphic phenomena of the rocks in Hong Kong such as planar features, microspherilitic silica glass (lechaterlierite), fused margins of rock fragments, concussion fractures, impact glass in which some schlierens are consistent with pyroxene spiculites, etc., were first discovered in October 1990. In Hong Kong Island, an impact melt sheet has been observed from the Victoria Peak to the southern shore. Quenching fractures of quartz in Kowloon finegrained granite has also been discovered.

In our work, the K-Ar age (83.34 +1.26 m.y.) of the impact melt rock, which is younger in comparison to the K-Ar age $(117 \mathrm{~m} . \mathrm{y}$.) in Hong Kong and Kowloon granite, has been measured, and the phenomena indicate that after the granite body formed, there was another geologic event. Maybe it is the Hong Kong impact cratering event. 
MELT PRODUCTION IN LARGE-SCALE IMPACT EVENTS: CALCULATIONS OF IMPACT-MELT VOLUMES AND CRATER SCALING. Mark J. Cintala ${ }^{1}$ and Richard A. F. Grieve', 'Code SN4, NASA Johnson Space Center, Houston TX 77058, USA, ${ }^{2}$ Geophysics Division, Geological Survey of Canada, Ottawa, Ontario K1A OY3, Canada.

Along with an apparent convergence in estimates of impact-melt volumes [1-3] produced during planetary impact events, intensive efforts at deriving scaling relationships for crater dimensions have also been yielding results [4]. It is now possible to examine a variety of phenomena associated with impact-melt production during large cratering events and apply them to planetary problems. This contribution describes a method of combining calculations of impact-melt production with crater scaling to investigate the relationships between the two.

Calculations ofImpact-Melt Volumes: This study uses meltvolume calculations that treat vertical impacts into a flat target; the projectile and target are described by a modified, material-specific Murnaghan equation of state, the details of which have been described elsewhere [3,5]. It does not use the "constant-energy shell" assumption of Charters and Summers [6] and Gault and Heitowit [7], and yields a closer approximation to the results of more complex, finite-difference models [1,2]. In an attempt to approximate the off-axis stress decay evident in more detailed models of the impact process [1,2,8], the particle velocity in the target behind the shock front is assumed to vary as $\cos ^{\beta} \theta$, where $\beta$ is the ratio of target to projectile compression, and $\theta$ is the angle from the axis of penetration (equivalent to the direction of the velocity vector) to the point of interest, measured at the center of flow in the target. Energy is added to the target until the projectile decompresses, whereupon the detached shock front is treated as a thin region whose intensity decays due to entropy production and geometric effects. The results of this procedure in calculating melt volumes for the impact of chondrite (simulated by an artificially dense basalt) into Hardhat granite and Tahawus anorthosite are compared in Fig. 1 to those for anorthosite into anorthosite, using a finite-difference model [1].

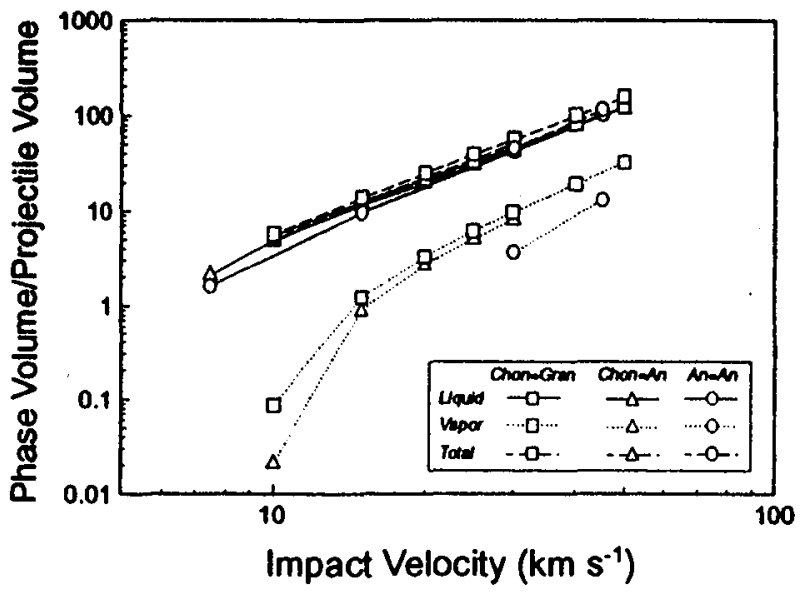

Fig. 1. Volumes of pure melt and pure vapor produced for impacts of chondrites into granite and anorthosite and for anorthosite into anorthosite [1]. The chondrite calculations were performed with the model described above.
TABLE 1. Impact-melt volumes at terrestrial craters.

\begin{tabular}{lcc}
\hline Crater & $\begin{array}{c}\mathrm{D}_{2} \\
(\mathrm{~km})\end{array}$ & $\begin{array}{c}\text { Melt Volume } \\
(\mathbf{k m})\end{array}$ \\
\hline Brent & 3.8 & $2 \times 10^{-2}$ \\
Zapadnaya & 4.5 & $1 \times 10^{-2}$ \\
II'nets & 8 & $7 \times 10^{-1}$ \\
Kaluga & 15 & 8 \\
Logoisk & 17 & $7 \times 10^{-2 *}$ \\
Lappajarvi & 17 & 8 \\
Ries & 24 & $2 \times 10^{-1 *}$ \\
Boltysh & 25 & 11 \\
Mistastin & 28 & 20 \\
W. Clearwater & 32 & 80 \\
Karn & 65 & 480 \\
Manicouagan & 100 & 1200 \\
Popigai & 100 & 1750 \\
Sudbury & 200 & 8000 \\
\hline
\end{tabular}

*Values are low probably due to mixed nature of target and presence of volatiles in sedimentary strata [9].

IAssumes Sudbury Igneous Complex and part of overlying Onaping Formation are a coherent melt sheet [10].

Melt Volumes and Cavity Scallng: Even though it is far from complete, the terrestrial dataset is the best one available for the determination of impact-melt volumes associated with large craters. Values for these volumes for impacts into crystalline rock have been estimated from information culled from the literature (Table 1), and are presented in Fig. 2 against transient-cavity diameters, which were derived from the observed crater diameters with Croft's [11] modification scaling relationship. In order to extrapolate from the terrestrial data to planetary events, provision must be made for the effects of variations in gravity, impact velocity, and target and projectile properties. Calculations were performed for the impact of chondritic projectiles into Hardhat granite, covering a velocity range of 10 to $50 \mathrm{~km} \mathrm{~s}^{-1}$; chondrites are considered to be representative of silicate impactors, and the velocity range falls within that allowable for the Earth. The scaling relationship as given by

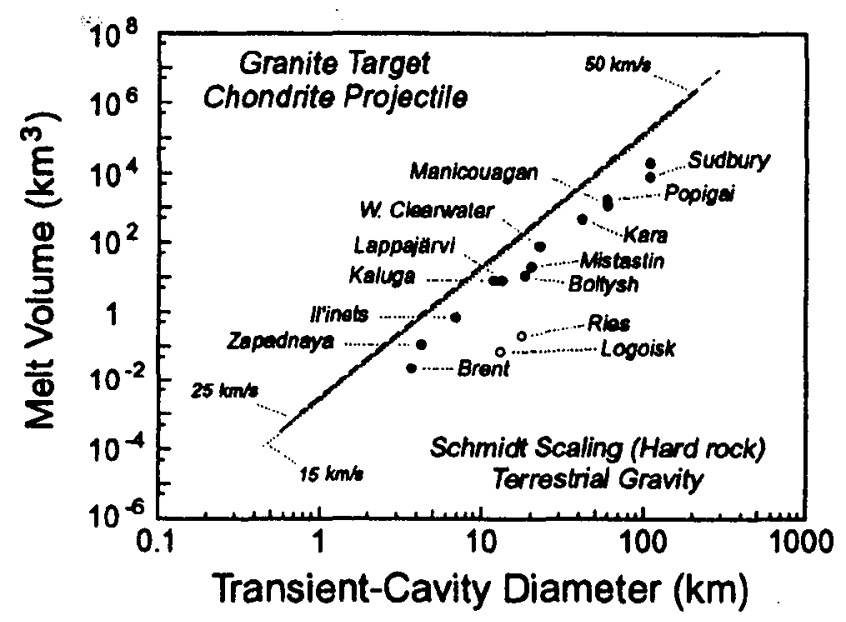

Fig. 2. Comparison between model calculations and actual terrestrial data for craters in crystalline rock. Note the displacement between the three curves and the observed values. Because they were formed in mixed targets, the Ries and Logoisk structures were not included in the analyses. 
Schmidt and Housen [4] was then used to estimate transient-cavity diameters for a range of projectile sizes. Since the melt volumes are originally expressed in terms of impactor volume, it is a simple matter to relate the volume of impact melt to the dimensions of the transient cavity as given by the scaling relationship [4]. Three such curves are also included in Fig. 2. It is immediately apparent that the theoretical curves overestimate the quantity of melt by, in some cases, more than an order of magnitude. We believe that this reflects an underestimate of the transient-cavity dimensions rather than an overestimate of melt production for the following reasons: (1) The scaling relationship used for cavity dimensions was formulated partly on the basis of the final dimensions of craters formed in sand, which almost certainly represent adjusted transient cavities. (2) The melt-volume estimates are accurate to within a factor of 2 , with underestimates being equally likely as overestimates, and thus cannot account for the differences. (3) Melt ejection could account for removal of up to $50 \%$ of the total produced at the smallest craters, but will have a vanishingly small effect in the cases of the largest craters in the figure. (4) The melt volumes calculated here, as evidenced by Fig. 1, are in good agreement with those determined from the more complex models. Lacking a detailed physical basis for changing the scaling relationship-which, it must be emphasized, combines with the melt calculations to yield a slope that is statistically indistinguishable from that of the terrestrial data-the model curve is brought into agreement with the terrestrial data simply by multiplying the model relationship for $25 \mathrm{~km} \mathrm{~s}^{-1}$ (the rms terrestrial impact velocity [12]) by a constant. The resulting relationship is

$$
D_{t c}=1.39\left(\frac{\rho_{p}}{\rho_{t}}\right)^{\frac{1}{3}} D_{p}^{0.78} V_{i}^{0.43} g^{-0.22}
$$

where $D_{t c}$ is the transient-cavity diameters, $p_{p}$ and $p_{t}$ are the projectile and target densities respectively, $V_{i}$ is the impact velocity, and $\mathrm{g}$ is the gravitational acceleration, all in cgs units.

Final Crater Dimensions: Equation (1) can be written for final crater dimensions by direct incorporation of Croft's [11] modification scaling relationship, which can be written as

$$
\mathrm{D}_{\mathrm{R}} \approx \mathrm{D}_{\mathrm{Q}}^{-0.18} \mathrm{D}_{\mathrm{tc}}^{1.18}
$$

in which $D_{R}$ is the final rim-crest diameter and $D_{Q}$ is the diameter of the simple-to-complex transition for the planet (and terrain) in question. Substitution for $D_{t c}$ into equation (1) and solving for $D_{R}$ yields an equation of the form

$$
D_{R}=k\left(\frac{\rho_{p}}{\rho_{t}}\right)^{0.39} D_{p}^{0.92} V_{i}^{0.51}
$$

where $k$ is a constant related to $g$ and the value of $D_{Q}$. Values for $D_{Q}$ and $k$ are given in Table 2. Relationships described by equations (1) and (3) are used elsewhere in this volume in relating model melt volumes to observed characteristics of the terrestrial and planetary impact record, and in deriving certain implications of those relationships for the cratering record.

References: [1] O'Keefe J. D. and Ahrens T. J. (1977) Proc. LSC 8th, 3357. [2] Orphal D. L. et al. (1980) Proc. LPSC 11th, 2309. [3] Cintala M. J. (1992) JGR, 97, 947. [4] Schmidt R. M. and Housen K. L. (1987) Int. J. Impact Eng., S, 543. [5] Grieve R. A. F. and Cintala M. J. (1992) Meteoritics, submitted. [6] Gault D. E. and Heitowit E. D. (1963) Proc. 6th Hypervel. Impact Symp., 419. [7] Charters A. C. and Summers J. L. (1959) NOLR 1238, U.S.
TABLE 2. Planet-specific constants for use in equation (3).

\begin{tabular}{lcc}
\hline Planet & $\mathrm{D}_{\mathrm{Q}}(\mathrm{cm})$ & $\mathbf{k}(\mathrm{cm} \times 10 \mathrm{~g} 0 \mathrm{si})$ \\
\hline Mercury & 10.0 & $2.61 \times 10^{-2}$ \\
Venus & 4.0 (assumed) & $2.54 \times 10^{-2}$ \\
Earth & 4.0 & $2.24 \times 10^{-2}$ \\
Moon & 10.9 & $3.38 \times 10^{-2}$ \\
Mars & 3.1 & $3.39 \times 10^{-2}$ \\
\hline
\end{tabular}

Naval Ordnance Laboratory, 200. [8] Thomsen J. M. et al. (1980) Proc. LPSC 10th, 2741. [9] Kieffer S. W. and Simonds C. H. (1980) Rev. Geophys. Space Phys., 18, 143. [10] Grieve R. A. F. et al. (1991) JGR, 96, 753. [11] Croft S. K. (1985) Proc. LPSC 15th, 828. [12] Shoemaker E. M. (1977) In Impact and Explosion Cratering (D. J. Roddy et al., eds.), 617, Pergamon, New York.

MELT PRODUCTION IN LARGE-SCALE IMPACT EVENTS: PLANETARY OBSERVATONS AND IMPLICATIONS. Mark J. Cintala' and Richard A. F. Grieve', 'Code SN4, NASA Johnson Space Center, Houston TX 77058, USA, 2 Geophysics Division, Geological Survey of Canada, Ottawa, Ontario K1A OY3, Canada.

Differences in scaling relationships for crater formation and the generation of impact melt should lead to a variety of observable features and phenomena. These relationships infer that the volume of the transient cavity (and final crater) relative to the volume of impact melt (and the depth to which melting occurs) decreases as the effects of gravity and impact velocity increase. Since planetary gravity and impact velocity (Table 1) are variables in the calculation of cavity and impact-melt volumes [1], the implications of the model calculation will vary between planetary bodies; this contribution will address some of those differences. Details of the model calculations of impact-melt generation as a function of impact and target physical conditions have been provided elsewhere [1], as have attempts to validate the model through ground-truth data on melt volumes, shock attenuation, and morphology from terrestrial impact craters $[2,3]$.

Melt Volumes: The volume of impact melt as a function of rim-crest diameter is shown in Fig. 1 for typical impact velocities at the five terrestrial planets [4] (Table 1). In the calculation of rimcrest diameter, a modified version of Schmidt and Housen [5] scaling was used to calculate transient-cavity diameters [3], which were converted to final rim-crest diameters using the "modification scaling" relation of Croft [6]. Chondritic projectiles were used in all calculations, and assumed target materials varied by planet (Table 1). Figure 1 indicates that relative melt volumes at craters of a given

TABLE 1. Variables used in the calculations of impact melting and crater dimensions. All targets were assumed to have a tempernture of $273 \mathrm{~K}$ except for Venus, for which $700 \mathrm{~K}$ was used.

\begin{tabular}{lccc}
\hline & & & $\begin{array}{c}\text { Gravitational } \\
\text { Acceleration } \\
\left(\mathrm{cm} \mathrm{s}^{-2}\right)\end{array}$ \\
Planet & Target & $\left(\mathrm{km} \mathrm{s}_{\mathrm{i}}\right)^{-1}$ & 370 \\
Mercury & Anorthosite & 23.6 & 891 \\
Venus & Diabase & 19.3 & 981 \\
Earth & Granite & 17.8 & 162 \\
Moon & Anorthosite & 14.1 & 371 \\
Mars & Anorthosite & 12.4 & \\
\hline
\end{tabular}


size increase in the order Moon, Mars, Mercury, Earth, and Venus; for the purpose of illustration, we concentrate here on the endmember cases, Venus and the Moon. For example, an impact event creating a $100-\mathrm{km}$ crater on the Moon also results in about $1200 \mathrm{~km}^{3}$ of impact melt, compared to about $3500 \mathrm{~km}^{3}$ in a comparably sized crater on Venus. Because the bulk of the impact melt inside large, complex craters in crystalline targets occurs as coherent melt sheets, this disparity means that features such as visible central structures and floor roughness, which reflect parautochthonous target material of the true crater floor and walls, will be less buried by melt and most prominent in lunar craters compared to craters on the other terrestrial planets.

It has become something of a tenet that the depth of craters and the diameters at which they undergo morphological transitions are inverse functions of planetary gravity $[7,8]$. Although there is a general progression toward increasing depth with decreasing gravity, the data show considerable variance and the inverse relationship is not strict [9]. The effects of gravity in determining crater depth are generally assumed to be in limiting and maintaining topography during and after cavity modification [8]. This work indicates another potential role for gravity through its effect on relative impact-melt volumes. If rectangular cross sections were assumed, for instance, our standard $100-\mathrm{km}$ lunar crater would have an interior melt sheet about $125 \mathrm{~m}$ thick, compared to one about $450 \mathrm{~m}$ thick for its venusian counterpart. This disparity is a minimum, as the lower lunar gravity will favor relatively more ejection of melt. Current estimates of the ratio of the apparent depth/diameter relationships $[7,10]$ for complex craters on the Moon and Venus are between 4 and 6 , compared to a $1 / \mathrm{g}$ ratio for the two planets of 5.5 . Taking the melt volumes into account and calculating true depths (i.e., depth to the true crater floor) gives a ratio of true depth/ diameter of $\sim 2.5-3$. This suggests that the called-for $1 / g$ relation for apparent depths may be fortuitous and that gravity and other planetspecific properties (such as impact velocity and physical properties of the target, including the presence of volatiles on planets such as Mars), might play a complex and sometimes competing role.

Crater and Basin Morphology: Previously, we have suggested that the increased depth of melting with increasing crater size will result in weakening of the base of the transient cavity $[2,3]$. On

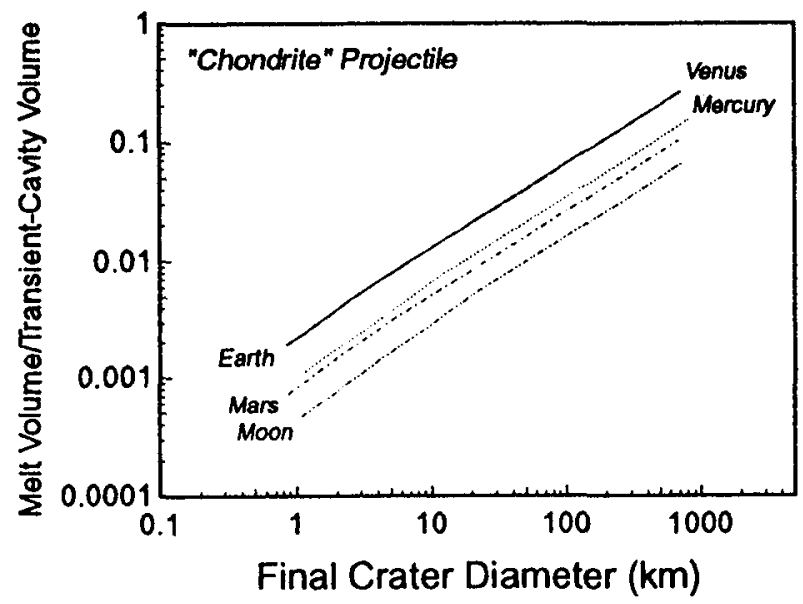

Fig. 1. Volume of impact melt relative to that of the transient cavity as a function of final crater diameter. Generated for the conditions listed in Table 1, a separated curve is presented for each planet.

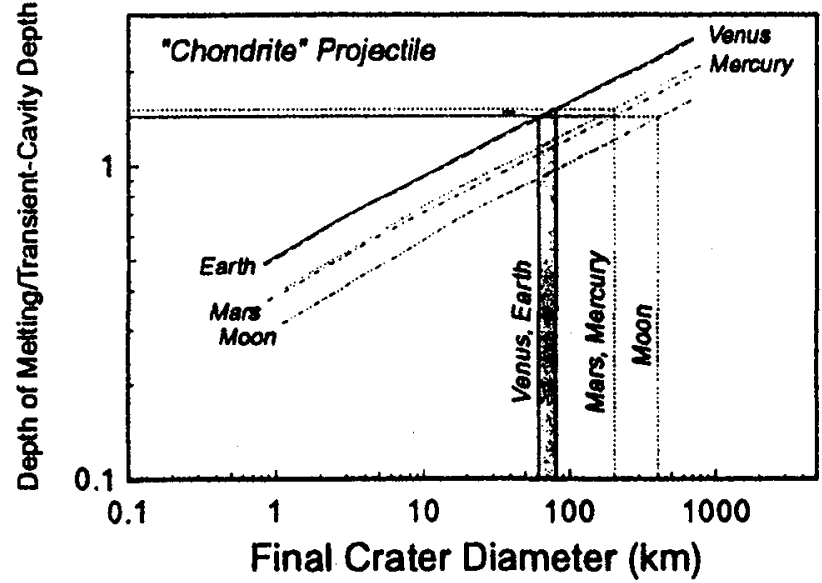

Fig. 2. Depth of melting relative to the transient cavity's depth as a function of final crater diameter. Similar values appear on the vertical axis for the diameters at which maxima occur in the frequency of peak-ring basins.

cavity modification and uplift, this material will be unable to form a coherent central peak. The zone of melting will approach and ultimately intersect the base of the transient cavity (Fig. 2), at which point the base of the cavity will have no strength. The only possible central topographic form in such a case is an interior ring. When the diameter at which maximum development of peak rings in craters on the terrestrial planets is considered, and the corresponding relative depths of melting are determined, they define a very restricted set of melting depths (Fig. 2). While we will not defend these actual values, we do suggest that the small range over which they occur (Fig. 2) could be considered as a validation of the general concept that impact melt could have a role in peak-ring formation. While one could argue that this could also be fortuitous, we note the additional prediction of this model that, as crater diameter increases and progressively more of the transient-cavity floor is melted, the diameter of the inner (peak) ring will increase. Although not emphasized in the literature, this has been noted for a relatively small set of 12 lunar basins, where the peak-ring diameter/rim-crest diameter ranges from 0.45 to 0.56 , and is generally inversely correlated with size [11]. This change in relative ring diameter with size, from 0.28 to 0.67 [12], is more obvious from a larger mercurian dataset of 45 craters. It has most recently been shown to occur on the basis of 16 venusian craters [13] changing from 0.29 to 0.67 , with even smaller ratios occurring at the transition from central peak to peak-ring craters.

We offer the impact-melting mechanism of peak-ring formation as an alternative, at least supplemental, explanation to the previous hypothesis that invoked the collapse of overheightened central peaks [14]. Even if it accounts for the formation of rings, this latter hypothesis does not specifically allow for the disappearance of central peaks with increasing crater size. The model here also maintains functionality with variations in planetary gravity through the scaling of crater dimensions. While at first glance it might seem to be at variance with other mechanisms suggested for ring formation [15], it is an al ternative method of reducing rock strength in and around the transient cavity, as required in some of those models. In addition, wholesale, deep-seated melting in truly large basin-forming events will result in in ward flow during modification, possibly leading to circumferential faulting and outer-ring formation. Thus, 
it might reduce the need for such weakening mechanisms as acoustic fluidization [16], and might provide a substitute for the "asthenospheric" flow required in these models of basin-forming events.

A few central uplifted structures in complex craters are acentrally located, which has been ascribed to preimpact structural control [17]. Oblique impact, however, can produce asymmetric melt zones, with increased melting in the direction of impact [18]. Thus, asymmetric impact melting followed by uplift may be an alternative mechanism of formation of acentral peaks.

Impact Lithologies: There will be second-order differences in the impact lithologies at comparable-sized craters on the terrestrial planets because of the effect of gravity on scaling relations. For example, the levels of recorded shock in uplifted central structures and the ratio between melted and clastic material will be lower in lunar craters than in those on other terrestrial planets, other parameters being equal. These potential differences must be considered when interpreting remote-sensing data [19]. Similarly, the various proportions of impact lithologies and their second-order characteristics will vary with the size of the event. At larger impact events, for instance, there will be less clastic debris available within the transient cavity for incorporation into the melt. Such implications of differential melting and cratering have been used to explain some of the observations at large terrestrial impact melt sheets such as at Sudbury [20]. Similar arguments apply to lunar samples. The lack of clasts is therefore an insufficient single condition to rule out an impact-melt origin for relatively coarse-grained, igneous-textured rocks in the samples from the lunar highlands.

References: [1] Cintala M. J. (1992) JGR, 97, 947. [2] Grieve R. A. F. and Cintala M. J., this volume. [3] Grieve R. A. F. and Cintala M. J. (1992) Meteoritics, submitted. [4] Strom R. G. and Neukum G. (1988) In Mercury (F. Vilas et al., eds.), 336, Univ. Ariz., Tucson. [5] Schmidt R. M. and Housen K. L. (1987) Int. J. Impact Eng., 5, 543. [6] Croft S. K. (1985) Proc. LPSC 15th, 828. [7] Pike R. J. (1980) Icarus, 43, 1. [8] Melosh H. J. (1989) Impact Cratering: A Geologic Process, Oxford, 245 pp. [9] Cintala M. J. et al. (1977) Proc.LPSC 8th, 3409. [10] Garvin J.B. and Schaber G. G. (1992) LPSC XXIII, 399. [11] Head J. W. (1977) In Impact and Explosion Cratering (D. J. Roddy et al., eds.), 563, Pergamon, New York. [12] McKinnon W. B. (1981) In Multi-Ring Basins, 259. Pergamon, New York. [13] Alexopoulos J. S. and McKinnon W. B. (1981) JGR, in press. [14] Grieve R. A. F. et al. (1981)InMulti-Ring Basins, 37, Pergamon, New York. [15] Melosh H. J. (1982) JGR, 87, 371. [16] Melosh H. J. (1979) JGR, 87, 7513. [17] Schultz P. H. (1972) Moon Morphology, Univ. Texas, Austin, 626 pp. [18] O'Keefe J. D. and Ahrens T. J. (1986)Science, 234, 346. [19] Pieters C.M. (1982)Science, 215,59. [20] Grieve R. A. F.etal.(1991)JGR, 96. 753.

STRUCTURAL REVIEW OF THE VREDEFORT DOME. W. P. Colliston' and W. U. Reimold', 'Department of Geology, University of the Orange Free State, P.O. Box 339, Bloomfontein 9300, South Africa, ${ }^{2}$ Economic Geology Reseanch Unit at the Department of Gcology, University of the Witwatersrand, P.O. Wits 2050, Johannesburg, South Africa.

The structure of the older-than-3.2-Ga Archean basement and Archean-to-Precambrian sedimentary/volcanic rocks (3.07 to ca. $2.2 \mathrm{Ga}$ ) in the center of the Witwatersrand Basin to the southwest of Johannesburg (South Africa) is dominated by the ca. 2.0-Ga megascopic Vredefort "Dome" structure.
The effect of the "Vredefort event" is demonstrably large and is evident within a northerly arc of about $100 \mathrm{~km}$ radius around the granitic core of the structure. Northerly asymmetric overtuming of the strata is observed within the first $17 \mathrm{~km}$ (strata is horizontal in the south), followed by a $\mathbf{4 0 - k m - w i d e ~ r i m ~ s y n c l i n c r i u m . ~ F o l d ~ a n d ~}$ fault structures (normal, reverse, and strike-slip) are locally as well as regionally concentrically arranged with respect to the northem and westem sides of the structure.

The unusual category of brittle deformation, the so-called "shock deformation," observed in the collar strata has attracted worldwide attention over the past two decades. These deformation phenomena include the presence of coesite and stishovite, mylonites and pseudotachylites, cataclasis at a microscopic scale, and the ubiquitous development of multiply striated joint surfaces (which include "shatter cones," orthogonal, curviplanar, and conjugate fractures).

The macroscopic to microscopic deformation features have led to the formulation of various hypotheses to account for the origin of the Vredefort structure: (1) tectonic hypotheses: deep crustal shear model [1], doming and $\mathrm{N}$-directed thrust fault model [2], fold interference model [3], and diapir model [4]; (2) the exogenous bolide impact hypothesis [e.g., 5,6]; and (3) the endogenous cryptoexplosion model [7].

Ongoing structural studies on the dome [8] have aided in narrowing the field of possible hypotheses. The subvertical faults and shears associated with diapirs or an endogenic cryptoexplosion could not be identified in either the basement or the collar rocks. The subvertical conjugate northwest- and northeast-trending shear zones that occur in the migmatitic basement predate the extrusion of the ca. 3.07-Ga-old Dominion Group volcanics. Toward the southern extremity of the structure, subhorizontal gneissic fabrics, which are deformed by the subvertical shears, become more prominent. The majority of the macrostructural deformation (faulting, folding) in the collar is related to the Vredefort event, and the remainder to reactivation of pre-Vredefort structures. Pseudotachylite occurrence is not exclusive to the Vredefort structure and is found throughout the northern and northwestern Witwatersrand Basin. Several pseudotachylite generations were produced over a wide interval from 2.2 to $1.1 \mathrm{Ga}$ (pre- to post-Vredefort event) [9]. This suggests the regional occurrence of episodic brittle deformation events with associated high-strain intensities.

It has been identified that the multiply striated joint surfaces postdate the overturning and related faulting in the structure, as well as a phase of postoverturning pseudotachylite development. These observations do not conform to the generalizations proposed by other workers who assume a horizontal stratigraphy prior to shatter cone development by an impact-generated shock wave [e.g., 10,11]. It also places doubt on the validity of using shatter cones as a diagnostic criterion for impact structures. Although the presence of coesite and stishovite cannot yet be fully explained, it is suggested that these high-pressure polymorphs and multiply striated joint surfaces may also be produced in a tectonic regime by MohrCoulomb fracture within varying local stress fields.

According to regional gravity and aeromagnetic data the domal structure is interpreted to be located at the intersection of a northwest-trending anticlinal arch (which uplifts lower crust) and a north/ northwest-axis of cnustal downwarp (corresponding to the long axis of the Witwatersrand Basin) [12]. Reflection seismic data along a line roughly parallel to the northwest-anticlinal arch confirms regional structural data and interpretations of the structure [13,1]: The deep structure in the basement reveals only subhorizontal reflectors, which undergo a change in dip (overturned with the collar 
rocks) in the northwest. Structural information suggests that the structure is open to the southeast. From this it may be inferred that contractional forces acted from south to north.

In conclusion, the structural studies coupled with the geophysical results suggest that the Vredefort structure was produced by subhorizontal forces. No macro- or megascopic structural deformation that could be related to a 2-Ga central catastrophic event could be identified.

References: [1] Colliston W. P. (1990) Tectonophysics, 171, 115-118. [2] Du Toit A. L. (1954) The Geology of South Africa, Oliver and Boyd, Edinburgh, 611 pp. [3] Brock B. B. and Pretorius D. A. (1964) Geol.Soc. S. Afr. Spec. Publ. 1,549-599. [4] Ramberg H. (1967) Gravity, Deformation and the Earth's Crust, Academic, London, 214 pp. [5] Dietz R. S. (1961) J. Geol., 69, 499-516. [6] Hargraves R. B. (1961) Trans. Geol. Soc. S. Afr., 64, 147-154. [7] Nicolaysen L. O. (1972) GSA Mem., 132, 605-620. [8] Colliston W. P. and Reimold W. U. (1990) Econ. Geol. Res. Unit Inf. Circ. 229, 31 pp. [9] Reimold W. U. et al. (1990) Tectonophysics, 171, 139-152. [10] Manton W. I. (1965) N.Y. Acad. Sci. Ann., 123, 1017-1049. [11] Albat H. M. (1988) S. Afr. J. Geol., 91, 106-113. [12] Comer B.et al.(1990) Tectonophysics, 171, 9961. [13] Colliston W. P. and Reimold W. U. (1989) Abstr. First Tech. Meet. S. Afr. Geophys. Assoc., 13-14, BPI Geophysics.

\section{INTRUSIVE ORIGIN OF THE SUDBURY IGNEOUS} COMPLEX: STRUCTURAL AND SEDIMENTOLOGICAL EVIDENCE. E. J. Cowan and W.M. Schwerdtner, Department of Geology, University of Toronto, Toronto, Ontario, Canada M5S 3 B1.

In recent years, many geoscientists have come to believe that the Sudbury event was exogenic rather than endogenic [1-3]. Critical to a recent exogenic hypothesis is the impact melt origin of the
Sudbury Igneous Complex (SIC) [3]. Such origin implies that the SIC was emplaced before deposition of the Whitewater Group, in contrast to origins in which the SIC postdates the lithification of the Onaping Formation. Structural and sedimentological evidence is summarized herein that supports an intrusion of the SIC after lithification of all Whitewater Group strata, and conflicts with the hypothesis advanced by Grieve et al. [3].

The SIC has the map pattern of an oval ring, and dips inward at the present erosion level. The bilobate eastern part of the SIC resembles fold interference patterns figured by Stauffer and Lisle et al. [4,5]. yet the granophyre, gabbro, and norite have undergone no solid-state deformation at most localities. This rules out the foliation pattern in Fig. 1a, which is consistent with the impact-melt hypothesis [3]. If the SIC acquired its foldlike shape during or immediately after emplacement, metamorphic-foliation trajectories in the Onaping Formation would continue as igneous-foliation trajectories into the granophyre, gabbro, and norite (Fig. 1b) $[6,7]$. This is true in the northeast lobe of the SIC, and rules out the possibility of post-fold sheet injection (Fig. 1c) [8].

The Chelmsford Formation, a turbidite deposit with nearly invariant bed thickness ( $1.2 \mathrm{~m}$ average), detrital composition, and high sand/mud ratio, was deposited by uniformly southwestdirected currents $[9,10]$, and was part of a very large nonchannelized foreland basin turbidite system [11]. The lack of facies change in the northwest-southeast direction implies that the preserved Chelmsford strata were far from the original foreland basin margin or from a site of syndepositional tectonic disturbance. This suggests that the South Range Shear Zone [12], which probably had a geomorphic expression at surface, postdates the Chelmsford Formation and its lithification.

The combined sedimentary and structural evidence constrains the time of emplacement of the SIC and its consolidation. Turbidite complexes have sedimentation rates of $100-1000 \mathrm{~m} / \mathrm{m} . \mathrm{y}$., with foreland basin-fill systems typically ranging $400-900 \mathrm{~m} / \mathrm{m} . \mathrm{y}$.

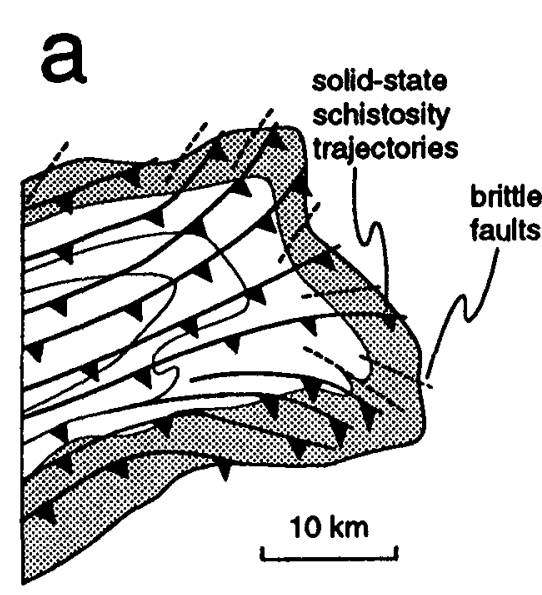

Pre-fold emplacement of the Sudbury Igneous Complex:

Solid-state strain whithin the SIC with schistosity trajectories concordant to that of the sedimentary core

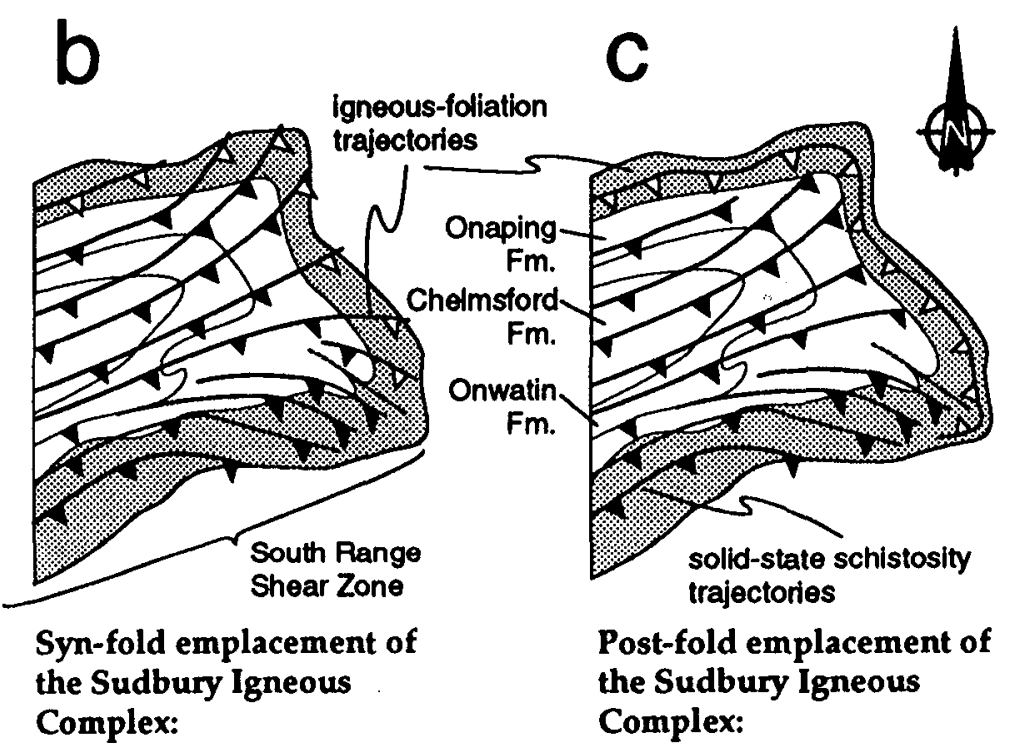

SIC with igneous-foliation trajectories concordant to schistosity trajectories of the sedimentary core
SIC with igneous-foliation trajectories concordant to intrusive contacts

Flg. 1. Eastern Sudbury structure: SIC (shaded), Whitewater Group (white). 
[13-15]. The minimum stratigraphic thickness of the Chelmsford Formation is $600 \mathrm{~m}$, so that the depositional time required is $>1 \mathrm{~m}$.y. The fastest deposition rate of hemipelagic deposits is $300 \mathrm{~m} / \mathrm{m}$.y., so that $600-\mathrm{m}$ thickness of the Onwatin Formation corresponds to $>2$ m.y. [15], and possibly as much as 6 m.y. (D. G. F. Long, personal communication, 1992). This amounts to a time interval of at least $3 \mathrm{~m}$.y. between the Sudbury event and the tectonic deformation of the Whitewater Group and the SIC.

If the SIC was formed as an impact melt, the sequence of events proposed herein requires the SIC deform in an unconsolidated state, 3-10 m.y. after its intrusion. Plutons emplaced at mid to upper crustal levels are thought to take 1-10 m.y. to cool to the ambient wall-rock temperatures; however, consolidation of a pluton takes a fraction of that time [7]. Impact melt sheets of the size of the Igneous Complex would crystallize well within $1 \mathrm{~m}$.y. of their formation [3]. This duration is shorter than the time interval required for the deposition of the Onwatin and Chelmsford Formations. Together with the evidence for magmatic folding of the SIC, this time constraint renders the impact melt hypothesis of the SIC untenable.

References: [1] Peredery W. V. and Morrison G. G. (1984) Ont. Geol. Surv. Spec. Publ. 1, 491-512. [2] Faggart B. E. et al. (1985) Nature, 230, 436-439. [3] Grieve R. A. F. et al. (1991) JGR, 96, 22753-22764. [4] Stauffer M. R. (1988) Tectonophysics, 149, 339-343. [5] Lisle R. J. et al. (1990) Tectonophysics, 172, 197-200. [6] Paterson S. R. et al. (1989) J. Struct. Geol., 11, 349-363. [7] Paterson S. R. et al. (1991) Min. Soc. Am. Rev. Min., 26, 673-722. [8] Schwerdtner W. M. et al. (1983) J. Struct. Geol., 5, 419-430. [9] Cantin R. and Walker R. G. (1972) Geol. Ass. Can. Spec. Pap. 10, 93-101. [10] Rousell D. H. (1984) Ont. Geol. Surv. Spec. Pub. 1, 211-218. [11] Long D. G. F., this volume. [12] Shanks W. S. and Schwerdiner W. M. (1991) Can. J. Earth Sci., 28, 411-430. [13] Ricci Lucci F. and Valmori E. (1980) Sedimentology, 27, 241-270. [14] Hiscott R. N. et al. (1986) Intl. Assoc. Sediment. Geol.Spec.Publ.8, 309-325. [15] Pickering K. T.etal. (1989) Deep Marine Environments, Unwin Hyman, 416 pp.

ENHANCED MAGNETIC FIELD PRODUCTION DURING OBLIQUE HYPERVELOCITY IMPACTS. D. A. Crawford and P. H. Schultz, Department of Geological Sciences, Brown University, Providence RI 02912, USA.

The natural remanent magnetization of the lunar surface as displayed in returned lunar samples and the data returned by the Apollo subsatellite magnetometer has an unexpectedly high magnitude and exhibits spatial variation at all scales. The origin of the lunar remanent fields may be due to crustal remanence of a core dynamo field occurring early in lunar history prior to extensive modification by impact [1] or remanence of transient fields, particularly associated with impacts, occurring on a local scale throughout lunar history [2-5]. The presence of an early core dynamo field would have strong consequences for the formation and early evolution of the Moon, yet to deconvolve the role that an internally generated core dynamo field may have had, it is necessary to understand how the magnetic state of the lunar surface has developed through time. Impact-induced magnetism may be an important component of the present magnetic state of the lunar surface.

New theoretical considerations suggest that transient magnetic fields within plasma produced by hypervelocity meteorite impacts may have greater significance at larger scales than previously thought [6]. Self-similar, one-dimensional solutions for the evolu- tion of the magnetic field and electron energy within impectgenerated plasma demonstrate that the peak magnetic field strength may only weakly depend on projectile size. Because the ratio of projectile size to crater size increases at larger scales for gravitylimited growth, the peak strength of transient impact-generated magnetic fields probably increases with increasing crater size at the same diameter-scaled distance. A conservative estimate (from extrapolated experimental data) for 10-100-km craters formed by vertically incident meteorite impacts at $25 \mathrm{~km} / \mathrm{s}$ predicts magnetic field streng ths of at least $0.03-0.1 \mathrm{G}$ for several minutes or more [6]. This is within the range of paleointensity values determined for certain relatively young ( $3 \mathrm{Ma}$ to $1.5 \mathrm{Ga}$ ) lunar samples [7-9] and more generally may help account for the lunar magnetic record during the last $\sim 3.5$ b.y. Recently acquired experimental evidence suggests that impact at oblique incidence may further enhance magnetic field production by as much as an order of magnitude.

Experimental investigations of magnetic field generation and evolution during hypervelocity impacts have been conducted at the NASA Ames Vertical Gun Range, MoffettField,Califormia [10-12]. The vertical gun is a two-stage hydrogen light gas gun capable of launching macroscopic projectiles at up to $7 \mathrm{~km} / \mathrm{s}$ with the angle of impact varying from nearly horizontal to vertical in increments of $15^{\circ}$. The large impact chamber, which can be evacuated to less than $\sim 1$ Torr, is large enough to accommodate, surnounding the impact point, a mu-metal shield that reduces the $35-\mu \mathrm{T}$ terrestrial magnetic field to $450 \pm 80 \mathrm{nT}-$ comparable to lunar surface field strength.

Impacts of aluminum projectiles into powdered dolomite $\left(\mathrm{Mg}_{0.5} \mathrm{Ca}_{0.5} \mathrm{CO}_{3}\right)$ targets readily produce a self-luminescent, slightly ionized vapor cloud that we infer to be the source of impactgenerated magnetic fields $[3,6]$. Oblique impacts demonstrate enhanced vapor yield producing a vapor cloud that retains a portion of the impactor momentum with a leading edge that travels downrange at a significant fraction of the impact velocity [13].

The configuration and duration of impact-generated magnetic fields observed during laboratory hypervelocity impacts are strongly dependent on impact angle (Figs. 1-3). Magnetic search coil data from many experiments under identical impact conditions were combined to produce the plots shown. The observed magnetic fields exhibit a regular transition from a cylindrically symmetric field configuration at vertical incidence to a strong bilaterally antisymmetric field configuration at high obliquity (Figs. 1 and 2). The stronger magnetic fields observed during oblique impacts (see Fig. 3) could result simply from the close proximity of impactgenerated plasma to the target surface, from a fundamental change in the field production mechanism within the plasma or from increased vaporization [13] yielding a greater volume of magnetized plasma; however, this could not be resolved with the data obtained. In addition to impact angle, experiments demonstrate that the configuration and duration of impact-generated magnetic fields are dependent on impact velocity and projectile/target composition [11].

A remnant of the impact-generated magnetic field could be induced within the target material during passage of the impactinduced shock wave $[14,15]$ or by cooling through the Curie point of small portions of impact melt or hot target material. During oblique impacts, spalled fragments of the projectile may impact further downrange at hypervelocities [16], thereby inducing a shock and/or thermal remanence significantly offset from the crater rim. Because of these dependencies, remnant impact-generated magnetic fields could be a useful geophysical tool for the study of impact craters on the Earth and planetary surfaces by helping to determine the impact angle, direction, and composition of impactors. The 

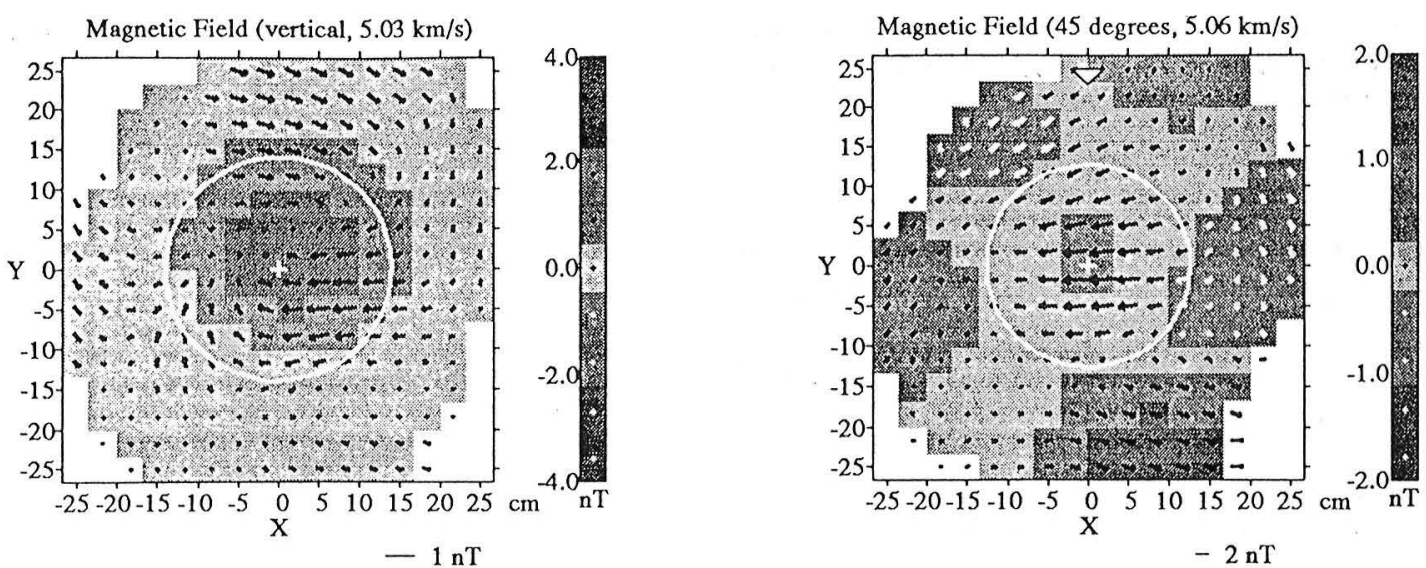

Fig. 1. Average magnetic field observed during the time interval $0.3-0.5 \mathrm{~ms}$ after hypervelocity $(\sim 5 \mathrm{~km} / \mathrm{s})$ impacts of $0.64-\mathrm{cm}$ aluminum projectiles into powdered dolomite targets. Each plot represents the magnetic field as seen in a horizontal plane $9 \mathrm{~cm}$ below a vertical impact (left) and an oblique impact, $45^{\circ}$ from horizontal (right). Shading represents the vertical component of the field whereas vectors represent the horizontal component with white vectors appearing where the field is directed into the page (down). The crater (shown as a white circle) defines the origin (shown as a white cross) of the coordinate system. A white triangle indicates the projectile trajectory prior to impact.
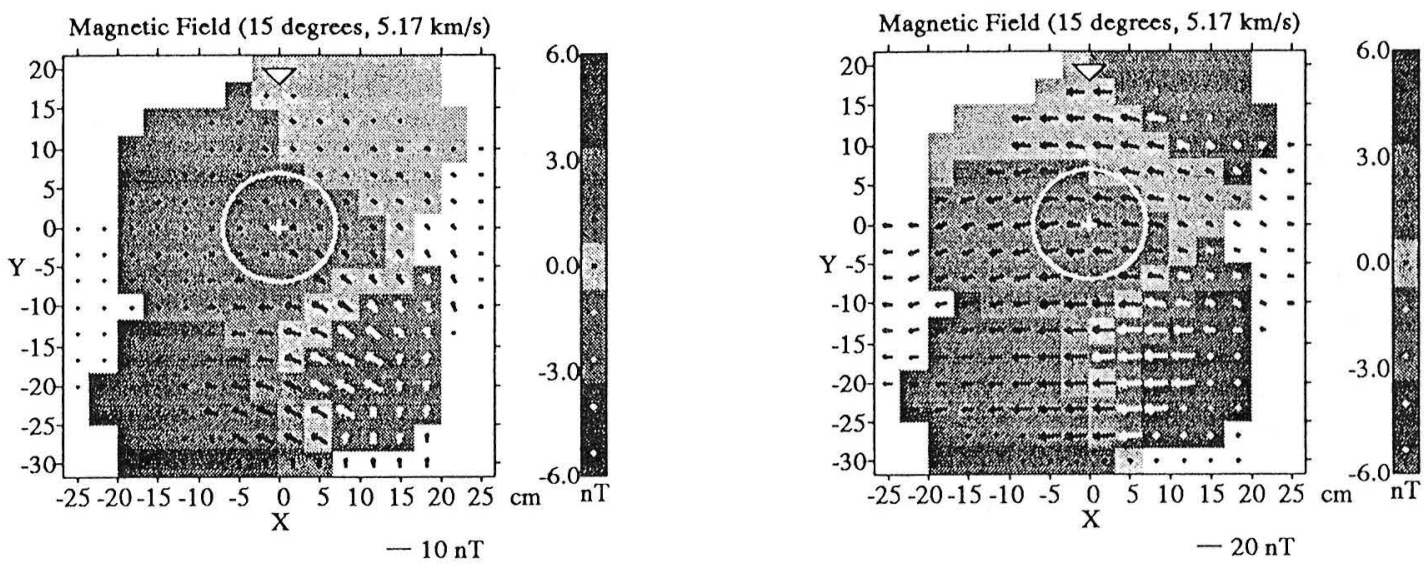

Fig. 2. Magnetic field during an oblique $15^{\circ}$ impact at the same time as in Fig. 1 (left) and $0.4 \mathrm{~ms}$ later (right).

many possible time-dependent impact-related magnetic field patterns and the various possible remanence acquisition mechanisms (some or all of which may come into play during a given impact event) yield a broad spectrum of possible crater-related remnant field patterns. An understanding of this complex contribution of impact-induced magnetism to the magnetic state of solid body surfaces, in general, and the lunar surface, in particular, is necessary to assess the role of internally derived fields such as from a core dynamo and may help to define future magnetic survey missions to solid surface planets, satellites, and asteroids.

References: [1] Runcorn S. K. (1983) Nature, 304, 589-596. [2] Gold T. and Soter S. (1976) Planet. Space Sci., 24, 45-54. [3] Srnka L. J. (1977) Proc. LSC 8th, 893-895. [4] Schultz P. H. and Srnka L. J. (1980) Nature, 284, 22-26. [5] Hood L. L. and Huang Z. (1991) JGR, 96, 9837-9846. [6] Crawford D. A. (1992) JGR, submitted. [7] Sugiura N. et al. (1979) Proc.LPSC 10th, 2189-2197. [8] Cisowski S. M. et al. (1983) Proc. LPSC 13th, in JGR, 88, A691-A704. [9] Collinson D. W. (1984) PEPI, 34, 102-116. [10] Crawford D. A. and Schultz P. H. (1988) Nature, 336, 5052. [11] Crawford D. A. and Schultz P.H.(1991)JGR,96,18807-18817. [12] Crawford D. A. and Schultz P. H. (1992) LPSC XXIII, 259-260. [13] Schultz P. H. (1988) LPSC IX, 1039-1040. [14] Cisowski S.M.

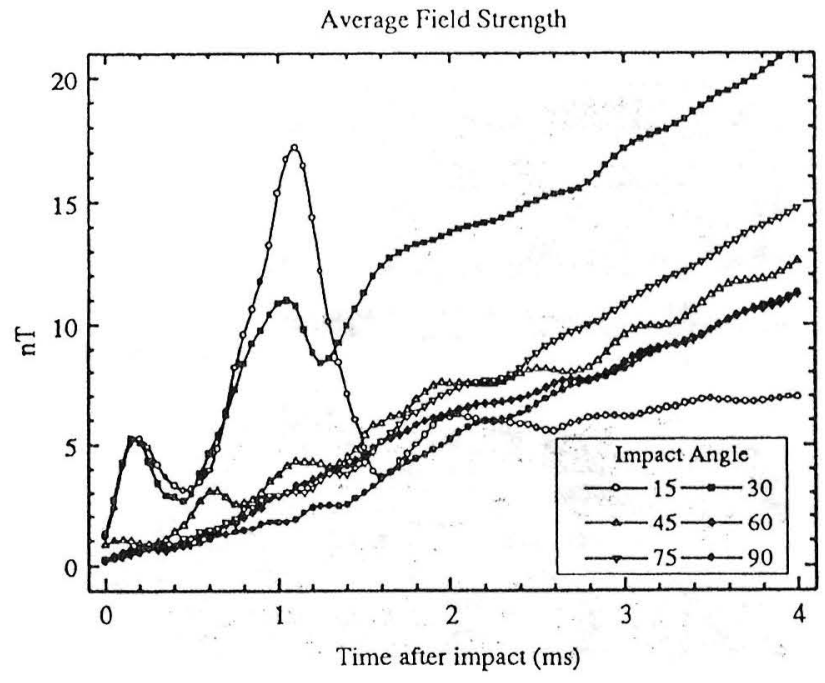

Fig. 3. Spatially averaged magnetic field strength as a function of time after impact. Results from six impact angles are shown. Enhanced field production during the first millisecond after impact is apparent for oblique impacts at $15^{\circ}$ and $30^{\circ}$ from horizontal. 
et al. (1975) Proc. LSC 6th, 3123-3141. [15] Cisowski S. M. et al. (1976) Proc. LSC 7th, 3299-3320. [16] Schultz P. H. and Gault D. E. (1990) GSA Spec. Pap. 247.

IMPACTITE AND PSEUDOTACHYLITE FROM ROTER KAMM CRATER, NAMIBIA. J. J. Degenhardt Jr. ${ }^{1,2}$, P. C. Buchanan', and A. M. Reid', ${ }^{1}$ Department of Geosciences, University of Houston, Houston TX 77204, USA, ${ }^{2}$ Texaco Inc., E\&P Technology Division, 3901 Briarpark, Houston TX 77042, USA.

Pseudotachylite is known to occur in a variety of geologic settings including thrust belts (e.g., the Alps and the Himalayas) and impact craters such as Roter Kamm, Namibia. Controversy exists, however, as to whether pseudotachylite can be produced by shock brecciation [1] as well as by tectonic frictional melting. Also open to debate is the question of whether pseudotachylites form by frictional fusion or by cataclasis [2]. It has been speculated that the pseudotachylite at Roter Kamm was formed by extensional settling and adjustment of basement blocks during "late modification stage" of impact [3]. The occurrence of pseudotachylite in association with rocks resembling quenched glass bombs and melt breccias in a relatively young crater of known impact origin offers a rare opportunity to compare features of these materials. Petrographic, X-ray diffraction, and electron microprobe analyses of the impactites and pseudotachylite are being employed to determine the modes of deformation and to assess the role of frictional melting and comminution of adjacent target rocks. The first findings are reported here.

The Roter Kamm Crater is located in the southern part of the Namib Desert about $80 \mathrm{~km}$ north of Oranjemund, Namibia. The crater rim has a crest diameter of ca. $2.5 \mathrm{~km}$ with the highest exposed point reaching $158 \mathrm{~m}$ above the lowest point of the crater floor. The impact, which excavated Precambrian granitic-granodioritic orthogeneisses of the 1200-900-m.y.-old Namaqualand Metamorphic Complex, has been dated at 3.5-4.0 Ma by Hartung et al. [4]. No volcanic rocks have been discovered in the area [5]. This has been substantiated by others [3]. A detailed account of the crater geology was published by Reimold and Miller [6].

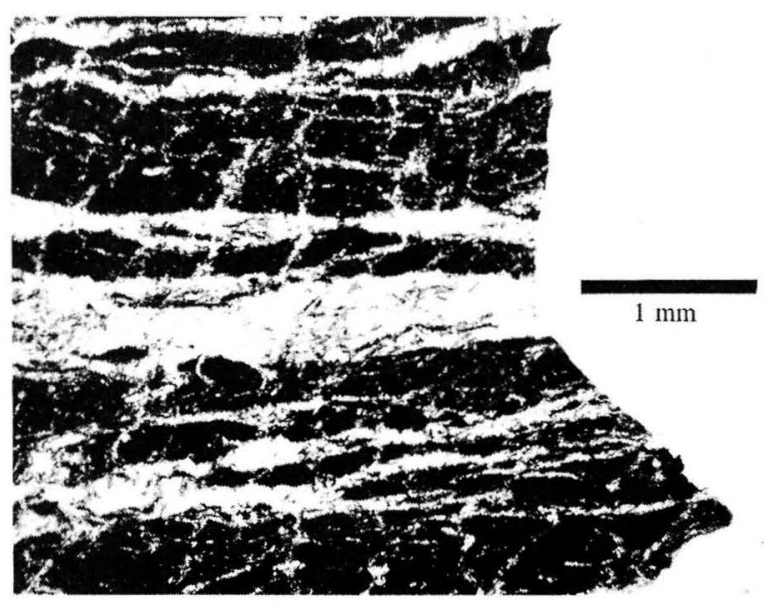

Fig. 1. Photomicrograph of flädle in transmitted light illustrating veinlets of subhedral mica and quartz set in opaque matrix. Veinlets terminate abruptly at edge of sample.

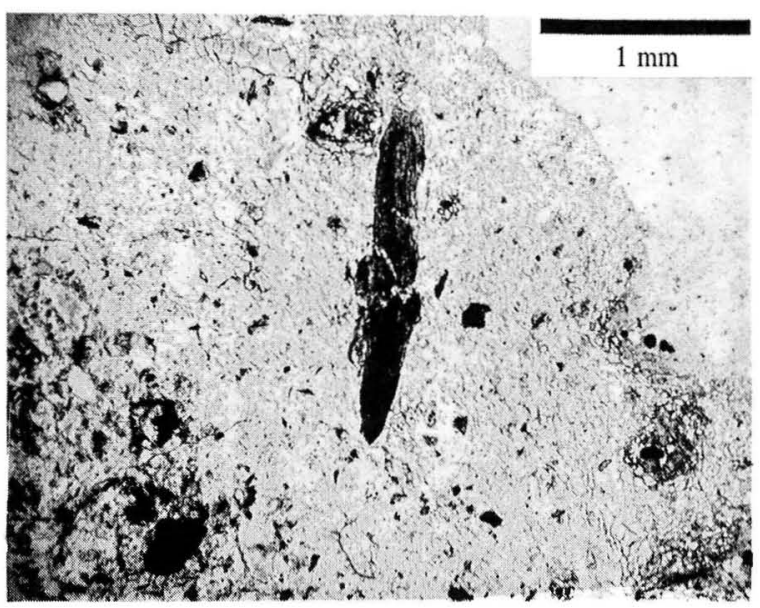

Fig. 2. Plane light photomicrograph of opaque clasts entrained in quartz breccia matrix. Large clast (center) is $1.6 \mathrm{~mm}$ in length.

A variety of impactites was collected from the crater rim. These have been described in the literature as "impact-melt breccias," "melt bombs," and "ejecta melts." In this study, three main rock types have been examined:

1. Meltlike rocks (also called flädle), common only along the northwest crater rim, are dark gray to black in color and exhibit apparent flow patterns characteristic of quenched glass "bombs." Because of their smooth, fluidlike shapes, the flädle have been interpreted as impact melt. In spite of their meltlike appearance, the specimens that were examined exhibited pervasive subparallel millimeter-wide veinlets containing subhedral mica and quartz. The fact that these veins are sharply (visibly) truncated by the surfaces of the flädle brings into question the interpretation that these rocks were melt-derived (see Fig. 1). XRD and electron microprobe analyses of the veins confirmed the mica-quartz composition and showed the mica to be a $\mathrm{K}, \mathrm{Mg}$-bearing variety. The finer-grained, optically opaque matrix is composed of mica and quartz similar to that of the veins. A Ti-rich mineral was also found to be present in the matrix, mainly in the form of clustered grains scattered throughout. Further analysis is being carried out to determine the cause of the opacity.

2. Quartz breccias containing large irregular shocked quartz fragments were also collected along the north crater rim. The fragments are cemented by an aphanitic matrix that resembles pseudotachylite in hand specimen. In contrast to the flädle, this matrix is not opaque in thin section, but appears finely crystalline. Of significance is the presence of opaque clasts (some containing micaceous veins) located throughout the matrix, which upon preliminary examination appear to be composed of the same material as the flädle (Fig. 2). Work is currently being done to determine if the chemical compositions of these entrained clasts match that of the flädle, and thus whether the flädle material predates the quartz breccia.

3. Pseudotachylite samples in the form of allochthonous fragments were collected at the south rim. Petrographic examination reveals the presence of angular entrained clasts that have not undergone recrystallization. However, finely crystalline quartz resembling the quartz breccia matrix appears in (plastically?) deformed grains and intermediate zones that often separate the pseudotachylite from its host rock. The composition of the vein material, including nonrecrystallized entrained clasts, was found to 
be essentially that of the host rock. It is apparent from grain deformation that transport distances were on the order of millimeters to centimeters along the veins.

The textures of fi:dle, quartz breccia, and pseudotachylite are fundamentally different when viewed petrographically. Although each of the rock types appears darkly opaque (dark gray or black) in hand specimen, the only sample with a matrix that is truly opaque in thin section is the flädle. No clasts representing compositions and textures of the other impactites have been observed in the pseudotachylite thus far. Present work is directed at determining what textural and compositional changes were involved during formation and whether the pseudotachylite represents material comparable to associated impactites.

References: [1] Schwarzman E. C. et al.(1983) GSA Bull.,94, 926-935. [2] Wenk H. R. (1978) Geology, 6, 509-511. [3] Koeberl C. et al. (1989) GCA, 53, 2113-2118. [4] Hartung J. et al. (1991) 54th Annu. Met. Soc. Mtg., Monterey, CA. [5] Fudali R. F. (1973) Meteoritics, 8, 245-257. [6] Reimold W. U. and Miller R. McG. (1989) Proc. LPSC, Vol. 21, 711-732.

SUDBURY PROJECT (UNIVERSITY OF MŨNSTERONTARIO GEOLOGICAL SURVEY): (4) ISOTOPE SYSTEMATICS SUPPORT THE IMPACT ORIGIN. A.Deutsch', D. Buhl'2, P. Brockmeyer', R. Lakomy', and M. Flucks', 'Institute for Planetology, University of Münster, Wilhelm-Klemm-Str. 10, D-4400, Münster, Germany, 2Institute for Geology, RU Bochum, Postfach 1021 48, D-4630 Bochum 1, Germany.

Introduction: Within the framework of the Sudbury project [1-3] a considerable number of $\mathrm{Sr}-\mathrm{Nd}$ isotope analyses were carried out on petrographically well-defined samples of different breccia units [4-7]. Together with isotope data from the literature these data are reviewed in this abstract under the aspect of a self-consistent impact model $[5,8-10]$. The crucial point of this model is that the Sudbury Igneous Complex (SIC) is interpreted as differentiated impact melt sheet $[5,8-11]$ without any need for an endogenic "magmatic" component such as "impact-triggered" magmatism or "partial" impact melting of the crust and mixing with a mantlederived magma [e.g., 12]. For the terminology used here we refer to the companion abstracts in this volume [1-3].

Strontium and Neodymium Isotopes: Impact melt rocks such as the sublayer [12], the SIC [11,12], and the clast-rich melt breccia on its top [5,6], as well as melt breccia bodies, matrix, and melt particles from the Onaping breccias $[5,6]$, are characterized by $\varepsilon_{N d}$ between -5 and -12 with Onaping lithologies tending toward lower $\varepsilon_{\mathrm{Nd}}$ values (Fig. 1). Their Nd-model ages TDM relative to a depleted mantle [13] cluster around $2.7 \mathrm{Ga}$, which agrees well with the time of the last major crust-forming event in the Archean Superior Province northwest of the Sudbury structure [e.g., 14,15]. It is important to note that ultramafic inclusions in the sublayer plot among other SIC rocks with negative $\varepsilon_{N d}$ and positive $\varepsilon_{S \cdot}$ [12]. Figure 1 shows that the SIC has highly radiogenic and variable $I_{S r}$. All those findings fit with the proposed total melting of the crust in the Sudbury region by the impact event that leads to $-1.5 \times 10^{4} \mathrm{~km}^{3}$ of impact melt [10], namely the SIC and the melt breccia, and the melt in the suevitic Onaping breccias [3]. In contrast, the data are incompatible with the input of fresh mantle magma as up to $75 \%$ contamination by upper crustal material would be required [12] to explain the Nd-Sr isotope systematics of these units, but an endogenic melt cannot assimilate such a high fraction of relatively cold material.

\section{SUDBURY MMPACT STRUCTURE}

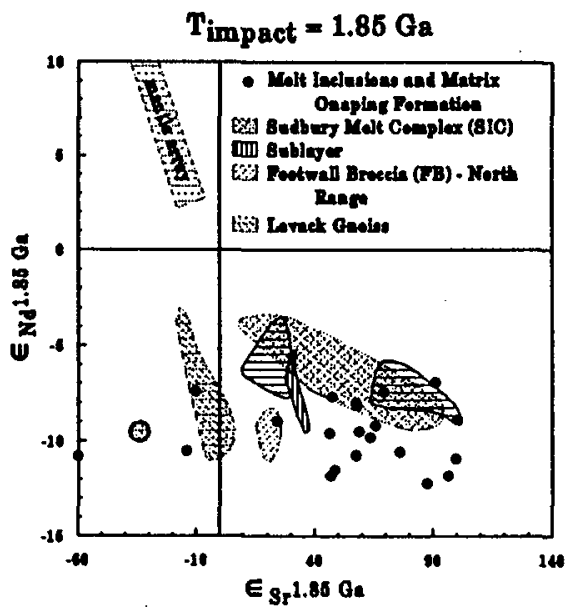

Fig. 1. $\varepsilon_{\mathrm{Nd}}-\varepsilon_{S_{x}}$ diagram for different lithologies of the structure with data recalculated to $1.85 \mathrm{Ga}$, the time of the impact event [14]; data sources $[4-6,11,12,15-17,19]$.

Neodymium isotope ratios of the impact melt concur with Nd characteristics of the target lithologies in the Sudbury region, for example, the Levack gneiss [12]. The observed spread in $\varepsilon_{s,}$ reflects the widely varying $\left({ }^{87} \mathrm{Sr} /{ }^{86} \mathrm{Sr}\right) \mathrm{T}=1.85 \mathrm{O}$ for the Archean basement $[4,15]$, Proterozoic Intrusives [16,17], and the Huronian Supergroup $[16,18]$ that were mixed into the melt. Distinct fields for the sublayer from different localities [12,19] in Fig. 1 show that the impact melt sheet (SIC) assimilated local bedrocks after its emplacement in the final modified crater. Strongly deviating $\mathrm{Sr}$ isotope ratios for some Onaping rocks in Fig. 1 with $\left(87 \mathrm{Sr} /{ }^{36} \mathrm{Sr}\right) \mathrm{T}=1.85 \mathrm{Ch}$ as low as $0.700[6,7]$ or 0.67 [20] are due to a reopening of the $\mathrm{Rb}-\mathrm{Sr}$ system during the Penokean orogeny [4, see also 7]. This is demonstrated with selected growth curves in Fig. 2: Some recrystallized melt particles and devitrified glass have enhanced $\mathrm{Rb} / \mathrm{Sr}$ ratios but the majority of the material has $I_{3 \mathrm{r}}$ identical to the granophyre. Together with their $\varepsilon_{\mathrm{Nd}}$ this fact supports our view that the melt-breccia on top of the granophyre and the melt material in the suevitic Onaping breccias and in the Green Member originated from the same source as the SIC, namely impact-melted crustal material.

Oxygen isotope data [21] support our findings. The norite, the granophyre, and the matrix of Onaping breccias all show a considerable spread in 8120 , but typical trends as known from differentiated layered intrusions are absent. The $\delta^{10} \mathrm{O}$ values of these lithologies are bracketed by oxygen isotopic compositions observed for local Archean and Proterozoic bedrocks with the Onaping breccias reflecting a higher input of Huronian greywackes. To explain the Os isotope ratios for the Sudbury ores [22] by mixing between a mantle magma and crust would need up to $90 \%$ crustal material. Therefore these data are also in line with a derivation of the ores exclusively from ancient crustal sources by impact melting followed by segregation of a sulfide liquid out of the melt sheet.

Summary and Outlook: While in the original contributions SIC isotope systematics were discussed preferentially in terms of a possible mixing between a hypothetical mantle component with up to $75 \%$ crustal material, the impact melt model does not have any problem explaining the crustal signatures of the SIC, the Onaping breccias, and the Sudbury ores-total melting of basement and supracrustal lithologies can only produce crustal signatures. Future studies on Sudbury should concentrate on combined analyses of 


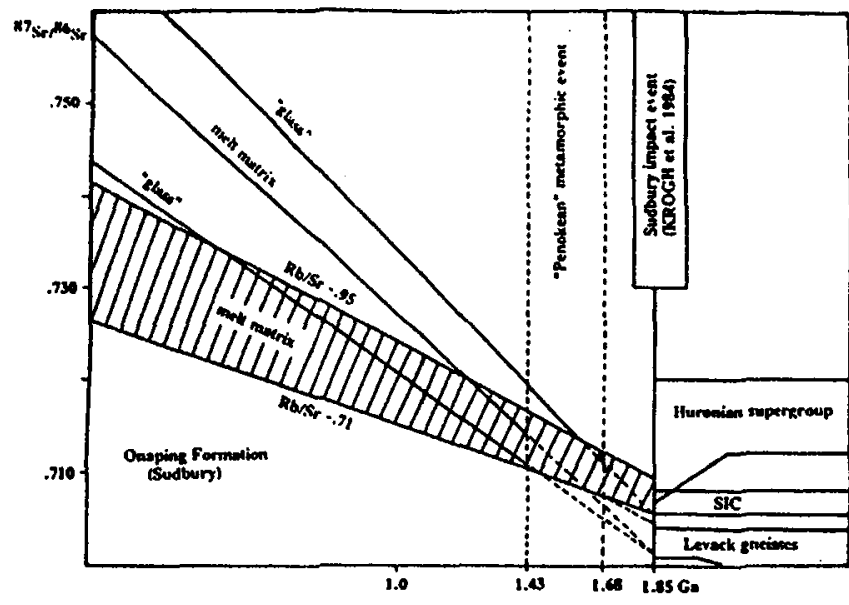

Fig. 2. Selected Sr growth curves for recrystallized Sudbury melt particles and devitrified glass from the Gray and Green Member of the Onaping Formation [3], and the matrix of the melt breccias topping the granophyre; data sources $[5,6]$.

stable and radiogenic isotopes on petrographically defined samples in order to understand the mixing process in impact melts in more detail. Isotope data could also help to decipher the complex process of assimilation by a large hot impact melt sheet for both lithic fragments and crater floor lithologies.

References: [1] AvermannM. et al., this volume. [2] Bischoff L. et al., this volume. [3] Stöffler et al., this volume. [4] Deutsch A. et al. (1989) EPSL, 93, 359. [5] Deutsch A. et al. (1990) LPSC XXI, 282. [6] Brockmeyer P. and Deutsch A. (1989) LPSC XX, 113. [7] Buhl D. et al., this volume. [8] Stöffler D. et al. (1989) Meteoritics, 24, 328. [9] Lakomy R. (1990) Meteoritics, 25, 195. [10] Grieve R.A.F.etal.(1991)JGR,96,22753-22764. [11] Faggart B. E. Jr. et al. (1985) Science, 230,436-439. [12] Naldrett A. J. et al. (1986) In Metallogeny of Basic and Ultrabasic Rocks, 75-91, Inst. of Mining Metallurgy, London. [13] DePaolo D. J. (1981)JGR, 86, 10470. [14] Krogh T. E. et al. (1984) In The Geology and Ore Deposits of the Sudbury Structure (E. G. Pye et al., eds.), 431-446, Toronto. [15] Hurst R. W. and Fahart J.(1977) GCA, 41, 1803-1815. [16] Fairbaim H. W. et al. (1969) Can. J. Earth Sci., 6, 489. [17] Gibbins W. A. and McNutt R. H. (1975) Can. J. Earth Sci., 12, 1970. [18] Fairbairn H. W. et al. (1967) ISth Annu. Rept M.I.T., 1381. [19] Rao B. V. et al. (1984) Misc. Pap. Ontario Geol. Surv. 121, 128. [20] Fullagar P. D. et al. (1971) Can. J. Earth Sci., 8,435. [21] Ding T. P. and Schwarcz H. P. (1984) Can. J. Earth Sci., 21 , 305. [22] Walker R. J. et al. (1991) EPSL, 105, 416.

NORIL'SK/SIBERIAN PLATEAU BASALTS AND BAHAMA HOT SPOT: IMPACT TRIGGERED? R. S. Deitz and J. F. McHone, Department of Geology, Arizona State University, Tempe AZ 85287, USA.

Twenty-eight years after one of us [1] argued that Sudbury was an astrobleme, this interpretation has only recently attained wide acceptance; not so for his view that the Sudbury $\mathrm{Cu} / \mathrm{Ni}$ sulfide ores are cosmogenic [2,3]. Papers such as by Alt et al. [4] have provided the triggering of plateau basalts by super-large impacts a modicum of respectability. Also, the recent apparent successful tying in of the $\mathrm{K} / \mathrm{T}$ extinctions to the Chicxulub astrobleme in Yucatan encournges the search for an impact event that may have caused the other two major post-Paleozoic extinctions ( $\mathrm{P} / \mathrm{Tr}, \mathrm{Tr} / \mathrm{J})$. This gives us heart to offer two further outrageous hypotheses.

Norl'sk Ores/Siberian Basalts: The cosmogenic concept for the Sudbury ore deposit remains viable because it is giant, nonultramafic, and unique (except for Noril'sk). It also has telling geologic relationships; for example, the ore-hosting sublayer appears to be a splash-emplaced target/bolide melt lining the Sudbury Basin cavity like spackle on a bowl that was also injected centrifugally into tensional cracks (offsets) (sec [3] for further evidence). At Sudbury, endogenic scenarios usually have been assumed, especially the concept of the ring-dike sublayer fed from a deep magma reservoir [5]. This view has recently been seriously challenged by Grieve and Stoffler [6], who explain the Sudbury Intrusive Complex as an impact melt sheet. Although the geologic relationships between the ore and the country rock at Noril'sk remain enigmatic, it seems a remarkable Sudbury look-alike. Their ore mineralogy is similar, including platimum group metals, and they are both large scale (one Noril'sk sulfide body covers $2 \mathrm{sq} \mathrm{km}$ and is $20 \mathrm{~m}$ thick.) Naldrett et al. [7] believe that the Noril'sk ores and adjacent Siberian plateau basalts are intimately related and consanguineous. A similar view was offered by several other authors at the 1991 American Geophysical Union Fall Meeting symposium (Noril'sk Siberia: Basalts, Intrusions, and Ores). Using argon/argon laser fusions, Dalrymple et al. [8] assigned a date for the ores and flood basalt of $249 \pm 1 \mathrm{Ma}$, indistinguishable from the Permian/Triassic boundary. We therefore suggest that the Noril'sk ores may be of cosmogenic parenthood and that this impact also triggered the Siberian plateau basalts. An associated event then might be the great extinction of life forms at the P/Tr boundary, all tied together as an event horizon.

Bahama Nexxus: Olsen [9] has attributed the Triassic/Jurassic boundary catastrophic extinctions to the Manicouagan asteroidal impact, but recent radiometric dating [10] indicates these events are diachronous (Manicouagan astrobleme $212 \pm 2 \mathrm{Ma}$ and $\mathrm{Tr} / \mathrm{J}$ boundary $200 \mathrm{Ma}$ ). This boundary is also marked by extensive tholeitic basalts (flows, sills, and dikes) of the rapidly extruded Newark Supergroup. Radially emplaced dikes on Pangaea (now broken up into Africa, North America, and South America) focus toward the Bahamas [11]. Dietz [12] has previously termed this presumed hidden hot spot (now buried beneath $6 \mathrm{~km}$ of shallow water coral reef limestone) as the Bahama Nexxus (a great triple junction connection) that marked the birth of the Atlantic rift ocean. The Bahama Platform might then be a mega coral reef laid down ensimatically on a subsiding plateau basalt. The floor spreading process calls for symmetrical repaving of the ocean floor by dike splitting. This clearly applies to the North Atlantic continental drift (North America/Africa) from Nova Scotia southward until the Bahama platform is reached. Then the conjugate point between North America and Africa jumps to the eastem tip of the Bahama cresentic platform rather than being at the tip of Florida. Clearly the seafloor spreading (dikesplitting) was overprinted by the hot spot, causing newly fragmented Gondwana (Africa/South America) to remain fixed (relative to the Earth's spin axis) while North America drifted away. (We can observe a modern example by the eastward offsetting of the Mid-Atlantic ridge as it transects Iceland hot spot.) Eventual death of the hot spot allowed the Mid-Atlantic Ridge to pave the ocean floor symmetrically. Thus almost the entire Bahama platform was stranded on the North American plate, leaving but a very small conjugate volcanic excrescence attached to Africa-the Bijagos Plateau off Portuguese Guinea. This great magmatic event 
may have been a mantle plume, but, altematively, it may have been triggered by an asteroidal impact. An impact fall-out layer with shocked debris has been reported at the $\mathrm{Tr} / \mathrm{J}$ boundary in Italy [13]. The synchronicity of extrusion and extinction appear established as an event horizon independent of radiometric or fossil stratigraphy.

Of course, enthusiasm for impacts does not score points in the scientific forum, but the current evidence of their importance in shaping other terrestrial planets (Venus has $\mathbf{9 0 0}$ impact craters as well as 1500 volcanos) suggests that impacts need not be assigned a role of last resort.

References: [1] Dietz (1964)J.Geol., 72,412-434. [2] Dietz (1972) Geol. Assoc. Canada, Spec.Pub.10,29-40. [3] Dietz (1991) Earth, 1, 36-41. [4] Alt et al. (1988) J. Geol., 96, 647-662. [5] Muir (1984) Geology and Structure of Sudbury Ore Deposits, 449-490, Ont. Geol. Surv. Spec. Vol. 1. [6] Grieve and Stöffler (1991) Geol. Assoc. Canada, 16, A48. [7] Naldrett et al. (1991) Geol. Assoc. Canada, A88. [8] Dahlrymple (1991) Eos, 570. [9] Olsen (1986) Lamont, Annu. Rept. 12. [10] Hodych and Dunning (1992) Geology, 20,5154. [11] Dietz et al. (1971) GSA, 82, 1131-1132. [12] Dietz (1986) 49th Annu. Met. Soc. Mtg., I-10. [13] Bice and McDauley (1990) GSA Abstr., A322.

MOBILZATION OF THE PLATINUM GROUPELEMENTS BYLOW-TEMPERATUREFLUIDS: IMPLICATIONSFOR MINERALIZATION AND THE IRIDIUM CONTROVERSY. Kim Dowling ${ }^{1}$, Reid R. Keays', Malcolm W. Wallace', and Victor A. Gostin', 'Department of Geology, University of Melbourne, Australia, ${ }^{2}$ Department of Geology and Geophysics, University of Adelaide, Australia.

Geochemical investigations on the widely dispersed Late Proterozoic Acraman impact ejecta horizon and its host marine shales in the Adelaide Geosyncline provide strong evidence for low-temperature mobilization of the platinum group elements (PGE), including Ir. The ejecta horizon was formed when the middle Proterozoic dacitic volcanics in the Gawler Ranges, central South Australia, were impacted by a very large (ca. $4 \mathrm{~km}$ ) meteorite. The resulting structure, now represented by Lake Acraman, is Australia's largest meteorite impact structure. Debris from the impact was blasted for many hundreds of kilometers, some falling into the shallow sea of the Adelaide Geosyncline, some $300 \mathrm{~km}$ to the east of the impact site.

The Bunyeroo Formation ( 600 m.y.), which hosts the impact horizon, consists of monotonous deep-shelf maroon and green clay shales, with minor concretionary carbonates. The ejecta horizon is typically 0 to $40 \mathrm{~cm}$ thick and is composed of a basal clast layer that is poorly sorted, angular, and dominated by pebble-sized fragments. It is overlain by a thin shale layer that contains abundant coarse sand-sized clasts that is in turn overlain by a graded layer that fines up from coarse-medium sand to a fine muddy sand. The largest clast found to date is $\mathbf{4 0} \mathrm{cm}$ in diameter. All the clasts and most of the sand-sized grains appear to have been derived from a pink to red porphyritic volcanic rock, similar to that currently exposed at the Gawler Ranges impact site. The ejecta horizon is almost invariably enveloped by green shales that range in thickness from a few millimeters to several meters.

Metal concentration along the horizon is anomalously high though variable, with values up to 300 times greater than average red shale background values [1]. Where the green shale envelope is most narrow, metal enrichment is lowest and the PGEs exhibit chondritic ratios. Sections of the ejecta horizon with a significantly wider green alteration envelope are variably enriched in $\mathrm{Cu}$ and frequently in Au. In these situations, both the ejecta horizon and the green shales that envelope it have strong PGE enrichments with Ir up to 100 times enriched and Pt up to $\mathbf{3 0 0}$ times enriched relative to the host red shales. Copper and Pt are well correlated with each other and the PGEs exhibit strong nonchondritic ratios.

Thin green shale layers that show no evidence of meteoritic contribution and occur at stratigraphic positions above and below the ejecta horizon in the red shale sequence are similarly enriched in Ir and $\mathrm{Pt}$ as well as $\mathrm{Cu}, \mathrm{V}, \mathrm{Zn}$, and $\mathrm{Ni}$. Isolated green reduction spots in the red shales also have PGE enrichments. All thin green shale horizons and green reduction spots analyzed have relatively high levels of $K$ and other PGE regardless of their stratigraphic position.

The similar chemistries of the ejecta-associated green shales and green shales at other stratigraphic levels suggest a similarity in the enrichment process. The very high $\mathrm{Pd} / \mathrm{I}, \mathrm{Pt} / \mathrm{Ir}$, and $\mathrm{Au} / \mathrm{Ir}$ ratios of the green shale and the $\mathrm{Cu}$-enriched ejecta sample, together with the $\mathrm{Cu}-\mathrm{PGE}$ correlation, are not totally consistent with an extraterrestrial origin. The ejecta horizon clearly has a meteoritic component as do the other thin green shale horizons and green reduction spots, which suggests that the elevated values are due to low-temperature transport.

The element associations and distribution are consistent with a PGE redox entrapment process. It is suggested that the ejecta horizon was an aquifer for low Eh fluids derived from deeper in the sedimentary basin. These fluids reduced ferric iron in the red shales to ferrous iron that was removed in solution, leaving the shales with their green color. Mixing of the reduced fluids flowing along the aquifer with oxidized fluids circulating in the red shales, from which they had leached $\mathrm{Au}, \mathrm{Cu}, \mathrm{PGE}$, and other elements, caused metal deposition.

The discovery of significant PGE mobility by low-temperature oxidized fluids has several important implications: Ir, PGE, and Au anomalies may be associated with postdepositional processes, which is particularly significant given the $\mathrm{K} / \mathrm{T}$ boundary Ir controversy. Further, it indicates that economically important accumulations of the metals might be anticipated in environments in which such solutions entered low redox environments. Examples of such environments include red-bed $\mathrm{Cu}$ and roll-type $\mathrm{U}$ deposits.

Reference: [1] Wallace M. W. et al. (1990) Geology, 18. 132-135.

DOES THE BUSHVELD-VREDEFORT SYSTEM (SOUTH AFRICA) RECORD THE LARGEST KNOWN TERRESTRIAL IMPACT CATASTROPHE? W. E. Elston, Department of Geology, University of New Mexico, Albuquerque NM 871311116, USA.

The unique 2.05-Ga Bushveld and Vredefort complexes cover $100,000 \mathrm{~km}^{2}$ (diameter $400 \mathrm{~km}$ ) on the otherwise stable Kaapvaal craton. Since the 1920 s, workers have recognized that they are bracketed by the same units and were probably formed by related processes. Modern field studies and radiometric dates have provided nocompelling evidence for different ages. Hall and Molengraaff [1] and Daly [2] invoked magmatic upthrust. Daly [3] later attributed Vredefort to impact, but never applied his concept to the 
Bushveld. Subsequently, Vredefort yielded shatter cones [4], coesite and stishovite [5], and planar features [6]; pseudotachylite (indistinguishable from Sudbury) had long been known [7]. Dietz [8], Hamilton [9], and Rhodes [10] concluded that at least four simultaneous impacts caused the Bushveld-Vredefort system. Three impacts formed overlapping Bushveld basins; the fourth made the Vredefort dome. If so, why has the Bushveld yielded no unequivocal shock phenomena? The nature of intra-Bushveld "fragments" and the properties of Rooiberg Felsite offer clues.

Cratering of this magnitude would intersect the ambient-pressure liquidus isotherms of both granite and gabbro. As a result, the Bushveld Complex generated successively the most voluminous siliceous flows, the greatest accumulation of layered gabbro, and the largest masses of A-type granite on Earth, in a setting of complex and long-continued structural adjustments. Gabbroic sills (Rustenburg Layered Suite, RLS), collectively up to $9 \mathrm{~km}$ thick, outline the Bushveld basins. Up to $4.5 \mathrm{~km}$ of earlier Rooiberg Felsite forms its intruded roof and locally (as Dullstroom Formation) its floor [11], analogous to the Onaping-sublayer relationship at Sudbury. Latestage Lebowa Granite occupies interiors of Bushveld basins and invades the RLS-Rooiberg contact as sills up to $2 \mathrm{~km}$ thick.

This simple scheme is disturbed by deformation of pre-Bushveld rocks around the periphery of the complex [12] and, especially, in 50-km "fragments" within the westem and eastern basins [13]. Deformation occurred prior toemplacement of Rooiberg Felsite and its equivalent "bronzite granophyre" dikes [14] at Vredefort. Hamilton [8] and Rhodes [9] interpreted "fragments" as central uplifts, which led to fruitless searches for shock phenomena $[15,16]$. Based on seismic [17] and field [12] evidence, I interpret the "fragments" as part of a zone between the central initial (transient) cavities (rebounded into Vredefort-type domes) and the present rim of the Bushveld basins. It is suggested that the Bushveld basins became enlarged beyond the initial cavities by collapse, in response to withdrawal of subsurface magma. Today, the central domes are totally obscured by Lebowa granite or covered by younger sediments. All exposures of RLS and Rooiberg Felsite are on the perimeters of the enlarged collapse basins, too distant from inferred central domes for shock phenomena.

In the eastern "fragment," the central (Marble Hall) segment exposes pre-Bushveld rocks that are intensely folded, faulted, metamorphosed, and boudinaged or brecciated. They are interpreted as part of the deformed collar around a transient cavity. In the northern (Stavoren) segment, basal Rooiberg-Dullstroom Felsite, conformable on unfolded pre-Bushveld quartzite, is interpreted as outflow that slid into the expanding collapse basin, probably during emplacement of Lebowa Granite (in the manner of collapse megabreccias of ignimbrite calderas [18]). The pre-Bushveld granitoid core of the southem (Dennilton dome) segment remains enigmatic. In the western "fragment," the southern deformed (Crocodile River) segment and the northem undeformed (Rooiberg) segment play roles similar to the Marble Hall and Stavoren segments respectively.

No source is known for Rooiberg Felsite, interpreted as several lithospheric melts [19]. Chemically and physically it differs profoundly from all known volcanic rocks. As a result of quenching from extraordinary temperatures, its feathery textures are more appropriate for komatiite than rhyodacite. It incorporates large amounts of sedimentary material, from relict quartz grains to large (up to $50 \mathrm{~m}$ ) quartzite blocks, commonly brecciated before engulfment by "felsite" melts. The basal high-temperature RooibergDullstroom flows grade into high-energy debris avalanches. Quartz grains in partly digested sandstone clasts were recrystallized to tridymite needles at temperatures $21175^{\circ}-1200^{\circ} \mathrm{C}[20,21]$ and inverted back to quartz $-1100^{\circ} \mathrm{C}$ [22]. Recrystallization at these temperatures would destroy all shock phenomena. $U_{p}$ to $30 \mathrm{~m}$ of quartzite beneath Rooiberg-Dullstroom flows also inverted to quartz needles and laths, paramorphs after tridymite [23]. Similar extridymite quartz needles occur in the transition from micropegmatite to basal Onaping quartzite breccia at Sudbury [24].

The Bushveld lacks "smoking gun" shock phenomena because all in situ exposures are peripheral and all ejecta is recrystallized or melted. In Bushveld-sized impacts, heat effects overwhelm shock effects. A deeply eroded shocked core is exposed only in the smaller and nearly amagmatic Vredefort dome. The Bushveld-Vredefort event probably was the largest known multiple impact on Earth. The alternative would be an as-yet-unknown and unique endogenic catastrophe. The event may have had global effects. It coincides with the biogenic transition from reducing to oxidizing atmosphere [25] and may correlate with a worldwide $8^{13} \mathrm{C}$ anomaly [26-28], greater than those at the Proterozoic-Cambrian, Permian-Triassic, and K-T boundaries [29-33].

Acknowledgments: David Twist, Joachim Schweitzer (then University of Pretoria), and Frikkie Hartzer (Geological Survey of South Africa) were my guides during field work in 1985, 1987, and 1991. The facts are theirs, the interpretations are mine.

References: [1] Hall A. L. and Molengraaf G. A. F. (1925) Verh. Koninkl. Akad. Wetensch. Amsterdam, Sect. 2, Vol. 24, No. 3. [2] Daly R. A. (1928) GSA Bull.,39, 125-152. [3] Daly R. A. (1947) J. Geol., 55, 125-152. [4] Hargraves R. B. (1961) Geol. Soc. S. Africa Trans., 64, 147-161. [5] Martini J. E. J. (1978) Nature, 272, 715-717; (1991) EPSL, 103, 285-300. [6] Grieve R. A. F. et al. (1990) Tectonophysics, 171, 185-200. [7] Shand S. J. (1916) Quart. J.Geol. Soc. London, 72, 198-217. [8] Dietz R. S. (1963) GSA Spec. Pap. 73, 35. [9] Hamilton W. (1970) Geol. Soc.S.Africa Spec.Publ. 1, 367-379. [10] Rhodes R. C. (1975) Geology, 3, 549-554. [11] Schweitzer J. K., personal communication; (1987) Unpublished draft, Ph.D. dissertation, Univ. Pretoria. [12] Sharpe M. R. and Chadwick B. (1982) Geol. Soc. S. Africa Trans. 85, $29-41$. [13] Hartzer F. J. (1991) personal communication; (1987) Unpublished M.S. thesis, Rand Afrikaans Univ. [14] French B. M. and Nielsen R. L. (1990) Tectonophysics, 171, 119-138. [15] French B. M. and Hargraves R.B. (1971)J.Geol.,79,616-620. [16] French B. M. (1990) Tectonophysics, 171, 287-301 . [17] DuPlessis A., personal communication; DuPlessis A. and Levitt J. G. (1987) Indaba, Geol. Soc. S. Africa, Progr. w. Abs., 14-15. [18] Lipman P. W. (1976) GSA Bull., 87, 1397-1410. [19] Twist D. (1985) Econ. Geol., 80, 1153-1165. [20] Eales H. V. (1974) Geol. Soc. S. Africa Trans., 77, 37-51. [21] Schneider H. and Florke O. W. (1982) N. Jahrb. f. Mineral. Abh., 145, 280-290. [22] Hirota K. and Ono A. (1977) Naturwissensch., 64, 39-40. [23] Elston W. E. and Sadow J. (1991) GSA Abs. w. Progr. 23, No. 5, A402. [24] Stevenson J. S. (1963) Can. Mineral., 7,413-419. [25] Twist D. and Cheney E. S. (1986) Precambrian Res., 33, 255-264. [26] Schidlowski et al. (1976) GCA, 40, 449-455. [27] Master S. et al., Geocongress (S. Africa) '90, 3 pp. [28] Baker A. J. and Fallick A. E. (1989) Nature, 337, 759-762. [29] Kirschvink J. L. et al. (1991) GSA Today, 1, 69-71. [30] Margaritz M. (1989) Geology. 17, 337-340. [31] Margaritz M. et al. (1986) Nature, 320, 258-259; (1988) Nature, 331, 337-339; (1985) Newsletter onStratigraphy, 15, 100-113. [32] Holser W. T. and Margaritz M. (1986) Mod. Geol., 11, 155-180. [33] Tucker M. E. (1986) Nature, 319, 48-50. 
RUTHENIUM/IRIDIUM RATIOS IN THE CRETACEOUSTERTIARY BOUNDARY CLAY: IMPLICATIONS FOR GLOBAL DISPERSAL AND FRACTIONATION WITHIN THE EJECTA CLOUD. Noreen Joyce Evans', W. D. Goodfellow' ${ }^{2}$, D.C. Gregoire', and J. Veizer, ', Division of Geological and Planetary Science, CaliforniaInstitute of Technology, Pasadena CA 91125, USA, ${ }^{2}$ Geological Survey of Canada, Ottawa, Ontaria, Canada K1 A 0E8, 3Ottawa-Carleton Geoscience Center, University of Ottawa, Ottawa, Ontario, Canada K1N 6N5.

Ruthenium (Ru) and iridium (Ir) are the least mobile platinum group elements (PGEs) within the Cretaceous-Tertiary (K-T) boundary clay (BC). The Ru/Ir ratio is, therefore, the most useful PGE interelement ratio for distinguishing terrestrial and extraterrestrial contributions to the BC. The Ru/Ir ratio of marine K-T sections $(1.77 \pm 0.53)$ is statistically different from that of the continental sections $(0.92 \pm 0.28)$. The marine $\mathrm{Ru} / \mathrm{Ir}$ ratios are chondritic $(\mathrm{Cl}=$ $1.48 \pm 0.09$ ), but the continental ratios are not. We discovered an inverse correlation of shocked quartz size (or distance from the impact site) and Ru/Ir ratio (see Fig. 1). This correlation may arise from the difference in $R u$ and Ir vaporization temperature and/or fractionation during condensation from the ejecta cloud.

Postsedimentary alteration, remobilization, or terrestrial PGE input may be responsible for the $R u / / r$ ratio variations within the groups of marine and continental sites studied. The marine ratios could also be attained if $\approx 15 \%$ of the boundary metals were contributed by Deccan Trap emissions. However, volcanic emissions could not have been the principal source of the PGEs in the BC because mantle PGE ratios and abundances are inconsistent with those measured in the clay. The Ru/lr values for pristine Tertiary mantle xenoliths $(2.6 \pm 0.48)$, picrites $(4.1 \pm 1.8)$, and Deccan Trap basalt $(3.42 \pm 1.96)$ are all statistically distinct from those measured in the K-T BC.

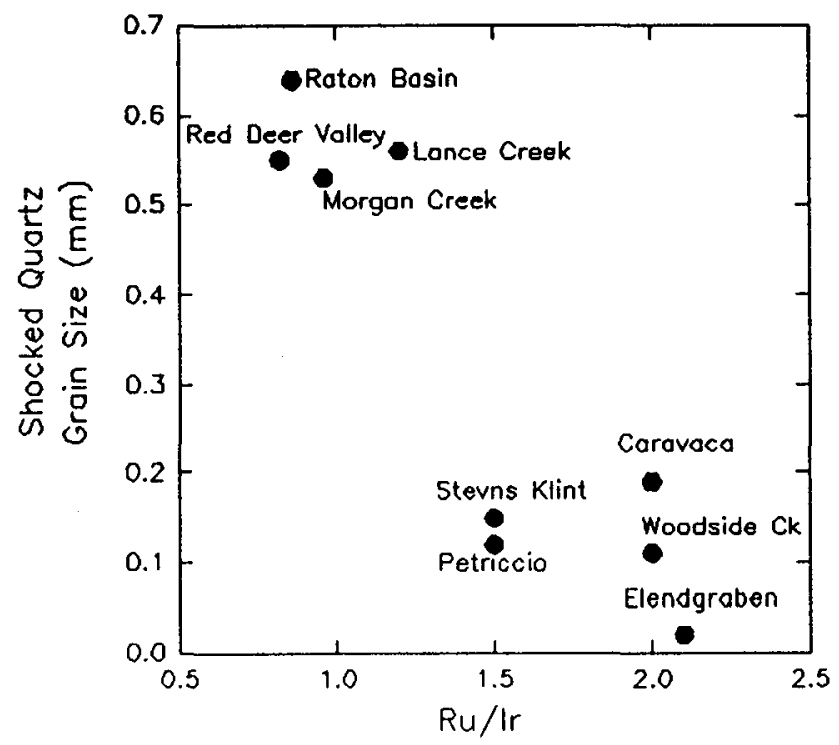

Fig. 1.
DIAPLECTIC TRANSFORMATION OF MINERALS: VOROTILOV DRILL CORE, PUCHEZH-KATUNKI IMPACT CRATER, RUSSIA. V. I. Feldman, Geological Department, Moscow University, Moscow, Russia, 119899.

Vorotilov core has been drilled in the central uplift of the Puchezh-Katunki astrobleme to a depth of $5.1 \mathrm{~km}$. Impactites are revealed in the rocks of the core beginning from a depth of $366 \mathrm{~m}$ : suevites $(66 \mathrm{~m})$, allogenic breccias (112 $\mathrm{m})$, and autogenic breccias (deeper than $544 \mathrm{~m}$ ). These rocks are represented by shockedmetamorphic gneisses, schists, amphibolites of Archean age, and magmatic rocks (dolerites, olivines, and peridotites) that lie between them.

According to the preliminary data, the intensity of the diaplectic mineral transformation in the crystalline rocks is decreased from $45-50 \mathrm{GPa}$ at the top to $15-20 \mathrm{GPa}$ at a depth of 4 to $4.5 \mathrm{~km}$. The rocks at the upper part of the section are transformed more uniformly. In contrast, one may observe unchanged plagioclase and maskelynite in the same thin section of the rocks from the lower part of the section. Sometimes the thermal metamorphism is superimposed on the shock metamorphism. Due to this superposition, impact glasses and diaplectic minerals are recrystallized to finegrained granoblastic aggregates (often monomineralic). The data obtained with SEM (Camscan with energy-dispersive analyzer AN$10,000)$ show the nonisochemical character of the element migration process, which often accompanies intensive diaplectic transformation. The result is formation of the aggregated pseudomorphs. They contain components missing from the original minerals. For example, the shocked, thermally decomposed biotite is transformed to a plagioclase-titanomagnetite-pyroxene-glass aggregate; amphibole is decomposed to a andesite-magnetiteclinopyroxene-amphibole aggregate; garnet is decomposed to a titanomagnetite-plagioclase-orthopyroxene aggregate.

The process of diaplectic feldspar and diaplectic feldspar glasses formation is also nonisochemical; K-rich, Na-poor diaplectic plagioclases and maskelynites, and $\mathrm{Ca}$-rich, $\mathrm{K}$-poor diaplectic orthoclases (in comparison with the initial feldspars) are revealed. The final product of this process is a melt glass that is composed of a mixture of both feldspars. Different grains of plagioclases (and different parts of some grains) appear to be variously transformed because of the nonuniform distribution of the shock load in the rock. In polysynthetically twinned plagioclases, transformations always begin more intensively in one system of the twinning, which is revealed under a pressure of $20 \mathrm{GPa}$. Very often one system of the twinning is completely isotropic, i.e., it is transformed into a diaplectic glass, while the other is not yet transformed. In a more transformed system a $\mathrm{Na}$ deficit is observed, i.e., $\mathrm{Na}$ is carried out. As a result, anorthite component enrichment and decrease of the sum of cations in the plagioclase formula is observed. Potassium enrichment of plagioclase in a more transformed twinning system is observed for samples containing $\mathbf{K}$-rich minerals. At a load of more than $30 \mathrm{GPa}$, plagioclase is partially or completely transformed into impact melt glass. Impact melt plagioclase glasses are often recrystallized into fine-grained secondary plagioclase aggregate. Sodium decrease and more intensive decrease of the sum of cations in the plagioclase formula is observed in the recrystallized impact glasses in comparison with the slightly transformed diaplectic plagioclases. This effect may be observed even in a single grain.

The investigation of diaplectic transformation of rock minerals in the Vorotilov drill core is continuing. 
BRECCIA DIKES FROM THE BEAVERHEAD IMPACT STRUCTURE, SOUTHWEST MONTANA. P. S. Fiske ${ }^{1}$, S. B.

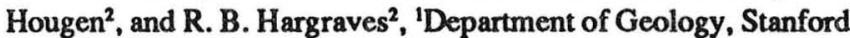
University, Stanford CA 94305-2115, USA, 'Department of Geological and Geophysical Science, Princeton University, Princeton NJ 08544, USA.

While shatter cones are generally accepted as indicators of meteorite impact, other petrologic features are not widely recognized in the geologic community. Breccia dikes are one such feature: They are found in many large impact structures occurring over an area at least as extensively as shatter cones [1]. Breccia dikes will survive moderate degrees of metamorphism and tectonism, unlike many other microscopic features (shocked quartz grains, high-pressure polymorphs, etc.) and even large-scale features such as annular or bowl-shaped topographic features. Thus, they are important diagnostic criteria, especially for large, poorly preserved impact structures.

The Beaverhead Impact structure is a recently discovered, deeply eroded impact structure in southwestern Montana [2]. The remains of the structure are delineated by the occurrence of shatter cones, found in an area $>200 \mathrm{~km}^{2}$, occurring within the Cabin thrust plate, part of the Cretaceous Sevier fold and thrust system. The distribution of shatter cones is further truncated by Tertiary normal faults (Fig. 1). The present remains represent an allochthonous fragment of a larger structure.

Enigmatic, fluidal-textured breccia dikes have been found in three localities in the area containing shatter cones. These rocks are characterized by rounded, highly deformed clasts of wall rock, suspended in a cryptocrystalline, flow-banded matrix. Two of these outcrops occur in sandstone (Proterozoic Gunsight Formation or Cambrian Wilbert Formation?) and the third is found in basement gneiss (Fig. 1). Breccia dikes of a different nature have been found $15 \mathrm{~km}$ south of the region containing shatter cones. Those breccia

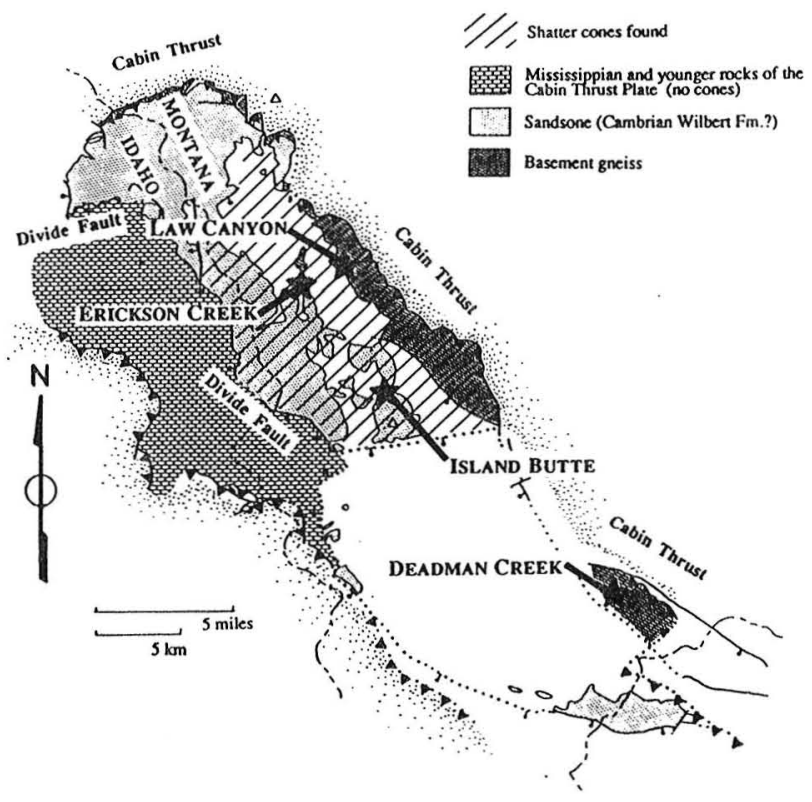

Fig. 1. Simplified map of the area of the Beaverhead Impact Structure, showing the distribution of shatter cones and the location of breccia dikes. Geologic map base is modified from [2]. dikes consist of angular, slightly deformed clasts in a fine matrix that lacks a fluidal texture.

Type A Breceis Dikes: The breccia dikes found in the northern three localities are all similar in texture and resemble type A breccia dikes described at Sudbury and elsewhere by Lambert [1]. The matrix of the dikes is greenish-gray at Island Butte, red to brown at Erickson Creek, and brown to black at Law Canyon, reflecting different compositions of the protolith and different degrees of postimpact alteration. Clasts in all samples are rounded, highly deformed, and represent local material only. In some clasts the deformation is most intense at the rims. In the central portion of these clasts, deformation is localized along small shear zones that contain an ultramylonitic material similar in texture to the dike matrix. Other clasts are completely pulverized and strung out into sinuous schlierenlike bands that fade into the matrix. Some of the material from Law Canyon contains vesicles, now filled with secondary quartz and calcite. Quartz, calcite, and chlorite also occur as secondary minerals in veins and in rims around some clasts. No unambiguous examples of shock lamellae (i.e., multiple sets of planar deformation features) have been found in any samples so far.

XRF and microprobe studies of the breccias of Island Butte show that the matrix is of similar composition to the wall rock, confirming previous studies [2], but depleted in $\mathrm{Na}$ by a factor of 5 and enriched in $\mathrm{K}, \mathrm{Fe}$, and $\mathrm{Al}$. INAA analyses of the same pairs of samples also showed the matrix to be enriched in $\mathrm{Sc}, \mathrm{Co}, \mathrm{Rb}$, and $\mathrm{REE}$, indicating alteration of the fine-grained matrix material, possibly by postimpact hydrothermal activity [3]. ICP atomic emission analyses of clast and matrix samples from Law Canyon show a similar depletion in $\mathrm{Na}$ and enrichment in $\mathrm{K}$. This trend is seen in impact melts from other impact structures [4]. In some samples from Law Canyon clasts have $\mathrm{K}$-rich halos. XRF, INAA, and microprobe analyses are currently underway on samples from the other localities.

Despite the presence of vesicles in the samples from Law Canyon and the fluidal texture of the matrix and the schlierenlike deformation of the clasts, there is little textural evidence to suggest that these rocks were molten! The intense deformation of the clasts, the absence of any melt zones at dike borders, the cataclastic texture of the matrix, and the lack of any igneous textures in even the largest dikes suggests that these dikes were primarily the product of extreme cataclasis. Furthermore, cathodoluminescence studies of the material from Island Butte failed to reveal any evidence for melting [5].

Type B (?) Breccia Dikes: The breccia dikes in the south are very different in texture and composition from those in the north. The matrix is cryptocrystalline but does not show any fluidal texture. Clasts within the matrix are angular, slightly deformed, and represent the local lithologies in which these dikes are found, including pieces of brecciated material. Single sets of planar deformation features have been found in quartz grains from these breccia dikes.

These breccia dikes bear many similarities to type B breccia dikes of Lambert [1]. Their location near the Cabin Thrust fault has led regional geologists to conclude that these dikes are related to thrusting. Further work is needed to establish the age and origin of these breccia dikes. Confirmation of the impact nature of these breccias would double the size of the known Beaverhead impact structure.

References: [1] Lambert P. (1981) Multi-Ring Basins (P. H. Schultz and R. B. Merrill, eds.), 59-78. [2] Hargraves R. B. et al. (1990) Geology, 18, 832-834. [3] Koeberl C. and Fiske P. S. (1991) Meteoritics, 26, in press. [4] Dence M.R.(1971)JGR, 76, 5552-5565. [5] Ramseyer K., personal communication. 
NEW PERSPECTIVES ON THE POPIGAI IMPACT STRUCTURE. J. B. Garvin ${ }^{1}$ and A. L. Deino' ${ }^{2}$ 'NASA/Goddand, Geodynamics, Code 921, Greenbelt, MD 20771, USA, ${ }^{2}$ Geochronology Center of the Institute of Human Origins, 2453 Ridge Road, Berkeley CA 94709, USA.

The record of large-scale cratering on Earth is scant, and the only currently "proven" 100-km-class impact structure known to have formed within the Cenozoic is Popigai, located in the Siberian Arctic at $71.5^{\circ} \mathrm{N}, 111^{\circ} \mathrm{E}$ (Masaitis et al., 1975). Popigai is clearly a multiringed impact basin formed within the crystalline shield rocks (Anabar) and platform sediments of the Siberian taiga, and estimates of the volume of preserved impact melt (i.e., Masaitis and Mashchak, 1986) typically exceed $1700 \mathrm{~km}^{3}$, which is within a factor of 2-3 of what would be predicted using scaling relationships (Melosh, 1989; Grieve and Pesonen, 1992). In this report, we present the preliminary results of an analysis of the present-day topography of the Popigai structure, together with refined absolute age estimates, in order to reconstruct the pre-erosional morphology of the basin, as well as to quantify the crosion or sediment infill rates in the Popigai region.

We have assembled an $\sim 90$-m-resolution digital elevation model (DEM) data for the Popigai region (see Fig. 1 for cross sections derived from the 2-D DEM), and are in the process of attempting to reconcile absolute age discrepancies that have resulted from ${ }^{10} \mathrm{Ar} /$ ${ }^{30}$ Ar radiometric analyses of glass samples provided to U.S. and Canadian investigators over the past five years by Russian impact crater specialists such as V. Masaitis (VSEGEI/St. Petersburg). In 1991 (see LPSC XXII, pp. 297-298), we reported on ${ }^{10} \mathrm{Ar} /{ }^{\prime}$ Ar laser step-heating ages of glass fragments removed from suevite (melt breccia) from the interior cavity of Popigai (provided by V.Masaitis), and obtained ages in the $\sim 70-60-\mathrm{Ma}$ range. We now have preliminary results from the ${ }^{10} \mathrm{Ar} /{ }^{\circ 9} \mathrm{Ar}$ step-heating of six additional glass samples from suevite and allogenic breccia from Popigai (again

TABLE 1. Volumetric analysis of craters.

\begin{tabular}{|c|c|c|c|c|c|c|c|c|}
\hline Crater Name & $\begin{array}{c}\text { Diameter } \\
\text { (km) }\end{array}$ & $\begin{array}{l}\text { Age } \\
(\mathrm{Ma})\end{array}$ & $\begin{array}{l}\text { Model } \\
\text { Interior } \\
\text { Volume } \\
\left(\mathrm{km}^{3}\right)\end{array}$ & $\begin{array}{c}\text { Volume } \\
\text { of Excavation } \\
\left(\mathrm{cm}^{3}\right)\end{array}$ & $\begin{array}{c}\text { Model } \\
\text { Melt } \\
\text { Volume } \\
\left(\mathrm{km}^{3}\right)\end{array}$ & $\begin{array}{l}\text { Observed } \\
\text { Interior } \\
\text { Volume } \\
\left(\mathrm{km}^{3}\right)\end{array}$ & $\begin{array}{c}\text { Max Depth } \\
\text { w Melting } \\
\left(\mathrm{km}^{3}\right)\end{array}$ & $\begin{array}{c}\text { Model } \\
\text { Kinetic } \\
\text { Energy } \\
\text { (Megatone) }\end{array}$ \\
\hline Henbury & 0.20 & 0.0040 & 4.00E-04 & $2.40 \mathrm{E}-04$ & $3.00 \mathrm{E}-08$ & $?$ & 0.011 & $1.00 \mathrm{E}-02$ \\
\hline Woif Croek & 0.94 & 0.1000 & $4.20 \mathrm{E}-02$ & $2.50 \mathrm{E}-02$ & $6.00 \mathrm{E}-04$ & $?$ & 0.065 & $1.90 E+\infty 0$ \\
\hline Darwin & 1.00 & 0.7300 & $5.10 \mathrm{E}-02$ & $3.00 \mathrm{E}-02$ & $7.00 \mathrm{E}-04$ & $?$ & 0.070 & $2.40 \mathrm{~B}+00$ \\
\hline Bosumtwi & 10.50 & 1.3000 & $2.28 \mathrm{E}+01$ & $4.91 \mathrm{E}+01$ & $2.08 E+00$ & 16.100 & 1.000 & $7.20 \mathrm{E}+03$ \\
\hline Zhamanahin & 14.40 & 0.8700 & $4.71 E+01$ & $1.08 \mathrm{E}+02$ & $6.07 \mathrm{E}+00$ & 20.100 & 1.400 & $2.10 \mathrm{E}+04$ \\
\hline Gosser Bluff & 22.00 & 142.0000 & $1.25 \mathrm{E}+02$ & $3.18 \mathrm{E}+02$ & $2.57 \mathrm{E}+01$ & $?$ & 2.300 & $8.90 \mathrm{E}+04$ \\
\hline Popiga** & 100.00 & 34.0000 & $4.06 \mathrm{E}+03$ & $1.51 \mathrm{E}+04$ & $4.42 \mathrm{E}+03$ & 1300.000 & 12.700 & $1.53 \mathrm{E}+07$ \\
\hline
\end{tabular}

*Age discrepancy: other age is $66 \mathrm{Ma}(\mathrm{K} / \mathrm{I})$.

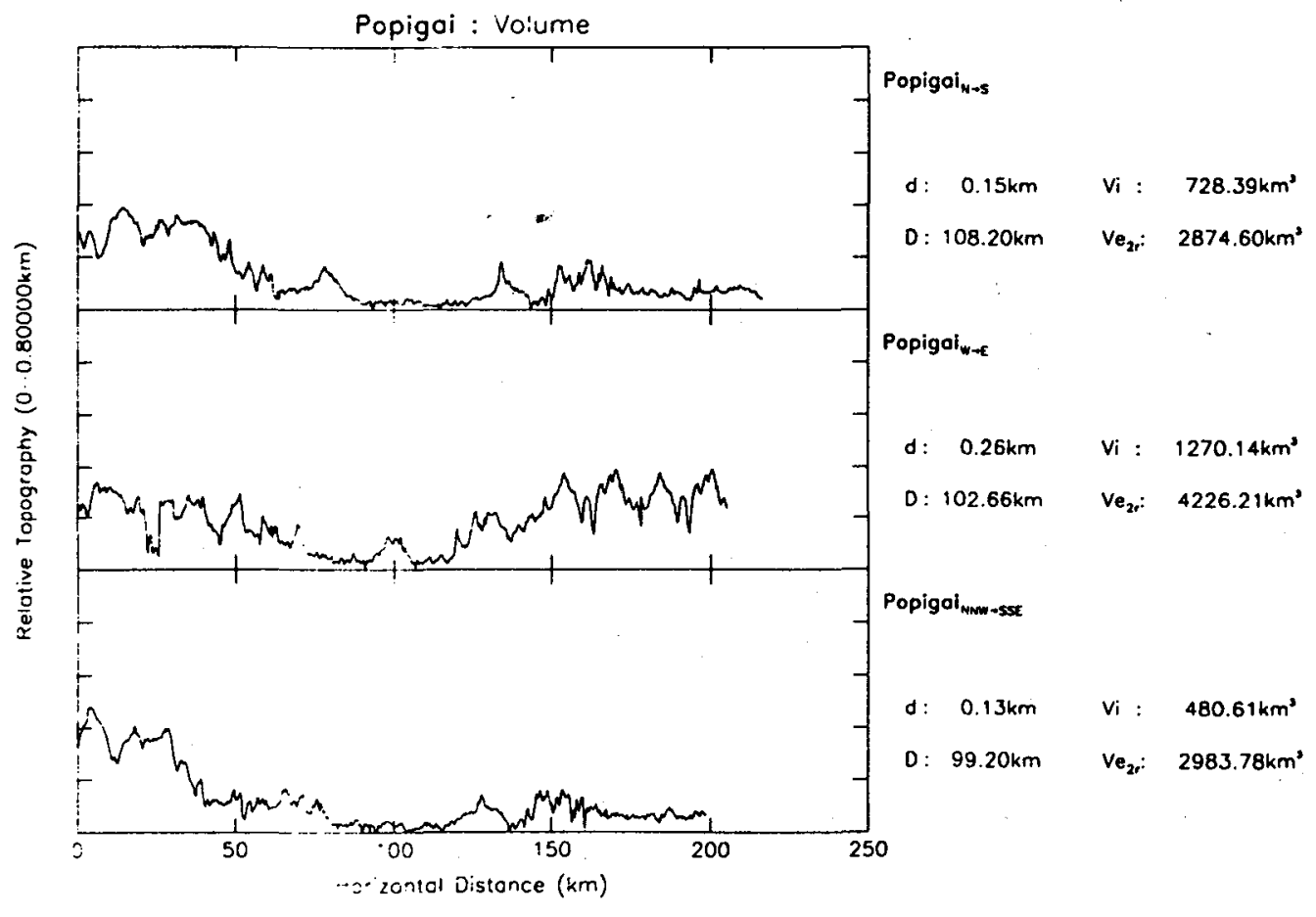

Fig. 1. 
provided courtesy of V. Masaitis). Data analysis is still underway, but it is evident that none of the new samples are as well-behaved in age release patterns as was the original sample, due most likely to alteration and the presence of old target-rock mineral inclusions. Predominant ages in these spectra are commonly between $\sim 60$ and $40 \mathrm{Ma}$, but portions of the gas release in the $-40-30$ range are also observed. We draw no conclusions as to the age of the Popigai impact event from these data at this early stage. Planned chemical, hydrogen, and oxygen isotopic analyses may help us sort out the effect alteration has had on the Ar age systematics. It is curious to note that independent results of ${ }^{40} \mathrm{Ar} /{ }^{9} \mathrm{Ar}$ laser step-heating of other samples conducted by Bottomley, Grieve, and York (R. Grieve, personal communication, 1992) indicate well-behaved release pattems that suggest an age in the vicinity of $\sim 34 \mathrm{Ma}$ (EoceneOligocene boundary). At this point, our impression is that a combination of analyses of pristine melt glasses and unaltered mineral phases is recommended in order to resolve the age disparity that apparently exists with respect to the absolute age of the Popigai impact.

Using the high-resolution topography data illustrated in Fig. 1, we can attempt to reconstruct the initial crater geometry by means of standard dimensional scaling relationships, such as those summarized in Melosh (1989) and by Grieve and Pesonen (1992). Table 1 highlights some of the parameter values derived for Popigai in comparison with a small set of representative smaller terrestrial features. The maximum degree of original relief at the crater (floor to rim crest) is between 520 and $960 \mathrm{~m}$ (depending on the model chosen), while the present-day dynamicrange of relief is $260-408 \mathrm{~m}$. This suggests that between 260 and $552 \mathrm{~m}$ of relief has been lost due to slumping, erosion, and other processes (interior cavity sediment infill). If we adopt typical erosion models for high-latiude shield terrains (see Garvin and Schnetzler, this volume), we find that up to $0.0052 \mathrm{~mm} / \mathrm{yr}$ could be eroded at Popigai, which translates into $\sim 176 \mathrm{~m}$ over a 34-Ma lifetime, or $350 \mathrm{~m}$ over a 66-Ma lifetime. Clearly, a refined absolute age for the structure is needed to refine these erosion estimates; however, the suggestion is that Popigai has experienced up to a factor of 5 more erosional infill than the much smaller equatorial shield crater Bosumtwi. (We acknowledge the cooperation of V. Masaitis at the VSEGEI in St. Petersburg for providing us with Popigai glass samples on several occasions).

THE ZHAMANSHIN IMPACT FEATURE: A NEW CLASS OF COMPLEX CRATER? J. B. Garvin' and C.C. Schnetzler', 'NASA/GSFC, Geodynamics Branch, Code 921, Greenbelt MD 20771, USA, 'Department of Geography, University of Maryland, College Park MD 20742, USA.

The record of 10-km-scale impact events of Quatemary age includes only two "proven" impact structures: the Zhamanshin Impact Feature (ZIF) and the Bosumtwi Impact Crater (BIC). What makes these impact landforms interesting from the standpoint of recent Earth history is their almost total lack of morphologic similarity, in spite of similar absolute ages and dimensions. The BIC resembles pristine complex craters on the Moon to first order (i.e., "U"-shaped topographic cross section with preserved rim), while the ZIF displays virtually none of the typical morphologic elements of a 13- to 14-km-diameter complex crater. Indeed, this apparent lack of a craterlike surficial topographic expression initially led Soviet geologists [1] to conclude that the structure was only 5.5 to
TABLE 1. Observed and model parameters for the ZIF and the BIC as derived from analysis of topography and scaling relationships.

\begin{tabular}{|c|c|c|c|}
\hline Parameter & Zhemanshin & Bosumtwi & Ref. \\
\hline Age $(\mathrm{Ma}=10 \mathrm{yr})$ & 0.87 & 1.3 & {$[2,14]$} \\
\hline Apparent diam. Da (km) & 14.4 & 10.5 & Mens. \\
\hline Apparent depth da (km) & 0.182 & 0.300 & $\omega$ \\
\hline Observed aspect da/Da & 0.013 & 0.030 & $\cdots$ \\
\hline Obs. Ht. Rim Ejecta hej (m) & 30.3 & 83.0 & 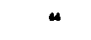 \\
\hline Obs. Vol. Cavity Vcav (km³) & 20.1 (max) & 16.05 & 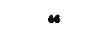 \\
\hline Obs. Vcav/SAcav (km) & 0.018 & 0.201 & $\cdots$ \\
\hline Obs. Vol. Ejecta Vej (km) & 16.7 & 11.6 & “ \\
\hline Obs. Tej = VejSAcj (cm) & 0.041 & 0.049 & 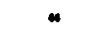 \\
\hline$\Delta V_{\text {lost }}=V_{c a v}-V_{e j}\left(\mathrm{~cm}^{3}\right)$ & 3.4 & 4.45 & $\omega$ \\
\hline Tejloxt $=\Delta V$ lousSAej $(m)$ & 8.3 & 18.6 & $*$ \\
\hline EJER = Tejlost/Age $(\mathrm{mm} / \mathrm{yr})$ & 0.0095 & 0.014 & $\cdots$ \\
\hline Model Vol. Init. Vi (km) & 47.1 & 22.8 & Comp. \\
\hline Model Vol. Excav. Vex (km) & 107.9 & 48.2 & 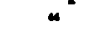 \\
\hline Model init. depth di (km) & 0.436 & 0.384 & 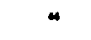 \\
\hline Model Aspect di/Da & 0.030 & 0.037 & $n$ \\
\hline Model Vi/SAi (km) & 0.289 & 0.263 & $\omega$ \\
\hline Model hoj* (m) & 360.0 & 263.0 & $\omega$ \\
\hline her $=$ hej ${ }^{*}$ hej (m) & 329.7 & 180.0 & n \\
\hline ERIM = her/Age $(\mathrm{mm} / \mathrm{yr})$ & 0.38 & 0.14 & “ \\
\hline$\Delta Z=$ di-da $(\mathrm{km})$ & 0.254 & 0.084 & * \\
\hline$\Delta$ Vol. $=\left|V_{i}-V_{c a v}\right|\left(\mathrm{km}^{3}\right)$ & 27.0 & 6.75 & $\omega$ \\
\hline Ter $=\Delta$ Vol.SSA (cm) & 0.166 & 0.078 & " \\
\hline CER $=\Delta V / S A / A g e(m m / y r)$ & 0.19 & 0.060 & $*$ \\
\hline$\Delta \mathbf{Z} / \mathrm{A}_{\mathbf{g}}(\mathrm{mm} / \mathrm{yr})$ & 0.29 & 0.065 & “ \\
\hline Erosion Model for Target & $x \Delta z^{a g n}$ & $x \Delta Z^{13 x}$ & [3] \\
\hline$K$ in Erosion Model & $1.05 E-4$ & 4.25E-7 & [3] \\
\hline Erosion $(m m / y r) @ \Delta Z$ in $m$ & 0.019 & 0.00016 & Comp. \\
\hline Erosion (m) for Cruter Age & 16.5 & 0.21 & 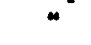 \\
\hline Max. Vol. Eroded ( $\left.\mathrm{km}^{2}\right)$ & 2.7 & 0.018 & $\cdots$ \\
\hline
\end{tabular}

$6 \mathrm{~km}$ in diameter and at least $4.5 \mathrm{Ma}$ in age $[1,10]$. However, more recent drilling and geophysical observations at the ZIF have indicated that its pre-erosional diameter is at least $13.5 \mathrm{~km}$, and that its age is most probably $0.87 \mathrm{Ma}[2,3,7,9,15]$. Why the present topographic expression of a 13.5-km complex impact crater less than 1 m.y. old most closely resembles heavily degraded Mesozoic shield craters such as Lappajarvi is question of considerable debate [6,7,9-11]. Hypotheses for the lack of a clearly defined craterlike form at the ZIF include a highly oblique impact, a low-strength "cometary" projectile, weak or water-saturated target materials, and anomalous erosion patterns $[1,2,6,7,9]$. The problem remains unresolved because typical erosion rates within the arid sedimentary platform environment [3] of central Kazakhstan in which the ZIF is located are typically low (see Table 1); it would require at least a factor of 10 greater erosion at the ZIF in order to degrade the nearrim ejecta typical of a 13.5-km complex crater by hundreds of meters in only $0.87 \mathrm{Ma}$, and to partially infill an inner cavity with $27 \mathrm{~km}^{3}$ (an equivalent uniform thickness of infill of $166 \mathrm{~m}$ ). Our analysis of the degree of erosion and infill at the ZIF calls for rates in the 0.19 to $0.38 \mathrm{~mm} / \mathrm{yr}$ range over the lifetime of the landform, which are a factor of $\mathbf{1 0}$ to 20 in excess of typical rates for the Kazakhstan semidesert [3]. If we apply similar erosional models to the BIC, which is located in an equatorial crystalline shield region 
and subject to tropical weathering processes [14], we find that the amount of erosion and infill needed to explain its current topographic expression is between $0.06 \mathrm{~mm} / \mathrm{yr}$ (infill) to $0.13 \mathrm{~mm} / \mathrm{year}$ (erosion of rim and near-rim ejecta). Of course, the degree of observed erosion at both the ZIF and the BIC assumes that the preerosional morphology of these impact structures can be reconstructed using established dimensional scaling relationships, such as those summarized by Ivanov [4] and Melosh 15]. Table 1 summarizes the available observational data on the dimensions of the two structures and all our estimates of parameters that can be derived on the basis of high-resolution topographic data. Model values are listed for comparison on the basis of simple scaling laws [4,5]. A model for terrestrial erosion as a function of geologic environment, rock type, and local to regional relief $(\Delta Z)$ is used to compute the expected erosion/infill rates for the regions associated with the ZIF and the BIC [3]. These model erosion rates are integrated throughout geologic time, and as such are upper bounds on the rates that would be operational over a time period as short as $\sim 1$ Ma. Thus, the $0.019 \mathrm{~mm} / \mathrm{yr}$ that would be predicted for the ZIF does not take into account that this region of the central Kazakhstan semidesert has apparently experienced much lower erosion during the Quaternary [2]. Indeed, the geomorphic record of erosion in the ZIF general region has been dominated by eolian redistribution and deposition of loess, with probable maximum accumulation levels in the range of $20-70 \mathrm{~m}$ within the interior cavity of the ZIF, based upon unpublished drilling results described by Masaitis and Boiko 12]. Thus, our impression is that it is impossible to reconcile typical erosion rates at the ZIF (in the range of 0.019 to $0.080 \mathrm{~mm} / \mathrm{yr}$ ) with what would be predicted $(0.19$ to $0.38 \mathrm{~mm} / \mathrm{yr})$ given erosion of a typical 10- to $15-\mathrm{km}$-diameter complex impact crater. While the observed erosion at the BIC appears to be within a factor of 2 of what would be predicted using terrestrial erosion models and pre-erosional crater dimension scaling laws, that for the ZIF disagrees by up to a factor of 20 . We believe that the pre-erosional morphology of the initial ZIF cannot be approximated using traditional complex crater scaling relationships, and that the ZIF represents a new class of complex crater form on the Earth that may help to explain the current deficiency of observed craters in the 8- to $16-\mathrm{km}$-diameter range. Furthermore, we believe that it is possible that there are perhaps tens of ZIF-style complex craters preserved, albeit poorly, within the sedimentary platforms of the continents [13]. Thus, it is important to develop methods for reconstructing ZIF-style cratering events, and for understanding why such events produce crater forms with anomalously mundane topographic expressions $[11,12]$.

References: [1] Florensky P. V. and Dabizha A. (1980) Zhamanshin Impact Crater,Nauka, Moscow, 127 pp. [2] Boiko Ya.et al.(1991)Impact Crater Zhamanshin,Zapkazgeologiya, 28 pp. (guidebook, V. Masaitis, ed.). [3] Masaitis V.L. et al. (1985)/zvestia Acad. Nauk SSSR, Seriya Geol., No. 2, 109-114. [4] Ivanov B. A. (1986) Cratering Mechanics, NASA TM-88977,97pp. [5] MeloshH.J.(1989) Impact Cratering, Oxford, New York, 245 pp. [6] McHone J. and Greeley R. (1981) In NASA TM-84211, 78-80. [7] Masaitis V. L. (1987)Meteoritika, 46,119-123. [8] GrieveR. and PesonenL.(1992) Tectonophysics, in press. [9] Masaitis V.L. etal.(1986)Meteoritika, 45, 142-149. [10] Zotkin I. and Dabizha A. (1982) Meteoritika, 40, 82-90. [11] Garvin J. B. et al. (1992) Tectonophysics, in press. [12] Garvin J. B. and Schnetzler C. C. (1988) Eos, 69, 1290. [13] Feldman V.(1991)The Petrology of Impactites,NASA TT-20925, 399pp. [14] Jones W. B. et al. (1981) GSA Bull., 92, 342-349. [15] Deino A. and Garvin J. (1990) LPSC XXI, 671-672.
ASTEROIDS AND ARCHAEAN CRUSTAL EVOLUTION: TESTS OF POSSIBLE GENETIC LINKS BETWEEN MAJOR MANTLE/CRUST MELTING EVENTS AND CLUSTERED EXTRATERRESTRIAL BOMBARDMENTS. A. Y. Glikson, BMR, P.O. Box 378, Canberra, A.C.T., Australia.

Since the oldest intact terrestrial rocks of ca. $4.0 \mathrm{Ga}$ and oldest zircon xenocrysts of ca. $4.3 \mathrm{Ga}$ measured to date overlap with the lunar late heavy bombardment, the early Precambrian record requires close reexamination vis a vis the effects of megaimpacts. This includes modeling of early megaimpact events [1], examination of the nature and origin of early volcanic activity [2-4], examination of Precambrian structures $[5,6]$, and close examination of the isotopic age evidence [7]. The identification of microtektitebearing horizons containing spinels of chondritic chemistry and Ir anomalies in 3.5-3.4-Ga greenstone belts [8.9] provides the first direct evidence for large-scale Archaean impacts. The Archaean crustal record contains evidence for several major greenstonegranite-forming episodes where deep upwelling and adiabatic fusion of the mantle was accompanied by contemporaneous crustal anatexis. Isotopic age studies suggest evidence for principal age clusters about 3.5, 3.0, and 2.7 ( \pm 0.8$) \mathrm{Ga}$, relics of a ca. 3.8-Ga event, and several less well defined episodes. These peak events were accompanied and followed by protracted thermal fluctuations in intracrustal high-grade metamorphic zones. Interpretations of these events in terms of internal dynamics of the Earth are difficult to reconcile with the thermal behaviour of silicate rheologies in a continuously convecting mantle regime. A triggering of these episodes by mantle rebound response to intermittent extraterrestrial asteroid impacts is supported by (1) identification of major Archaean impacts from microtektite and distal ejecta horizons marked by Ir anomalies; (2) geochemical and experimental evidence for mantle upwelling - possibly from levels as deep as the transition zone; and (3) catastrophic adiabatic melting required to generate peridotitic komatiites. Episodic differentiation/accretion growth of sial conse-
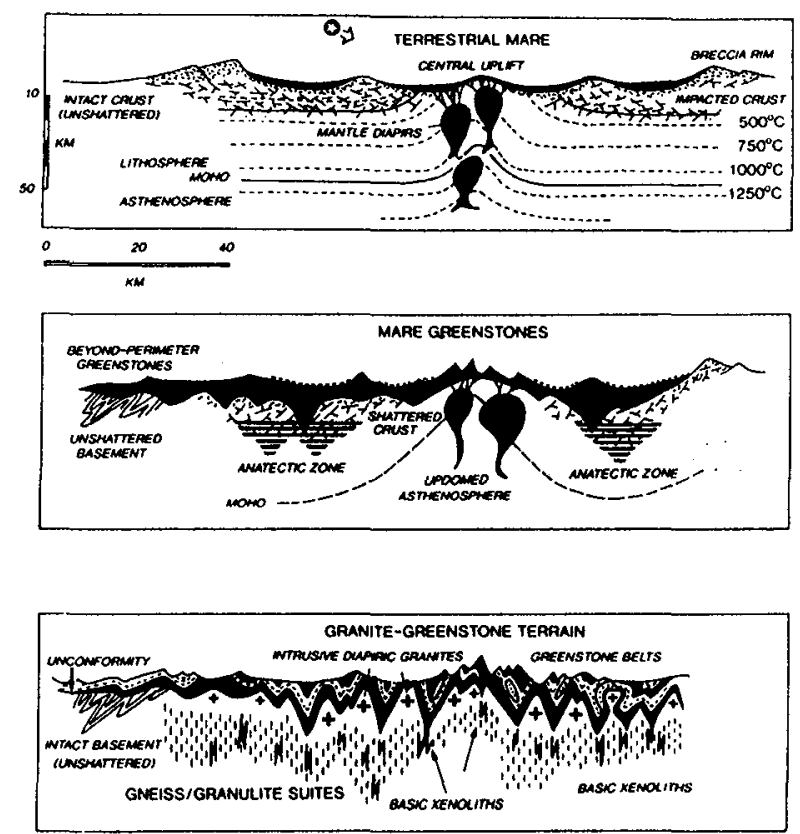

Fig. 1. Schematic model portraying the concept of evolution from terrestrial impact basins to greenstone/granite terranes. 
quent on these events is capable of resolving the volume problem that arises from comparisons between modern continental crust and the estimated sial produced by continuous two-stage mantle melting processes. The volume problem is exacerbated by projected high accretion rates under high Archaean geotherms. In accord with the model portrayed in Fig. 1 , it is suggested that impact shock effects have been largely obscured by (1) outpouring of voluminous basic/ ultrabasic lavas, inundating shock-deformed crust and extending beyond the perimeters of impact excavated basins; (2) gravity subsidence and downfaulting of terrestrial maria, accounting for the burial and anatexis of subgreenstone basement; and (3) extensive shearing and recrystallization at elevated temperatures of impact structures, breccias, and mineral deformation features beneath impact-excavated basins, relics of which may be retained in structural windows in high-grade metamorphic terranes. Isostatic subsidence and anatexis of thick maria-type piles and underlying impacted crust resulted in formation of intracrustal comagmatic plutonic and volcanic suites within periods in the order of 15-30X $10^{6} \mathrm{yr}$, limited by postimpact mantle convection cooling. Repeated posttectonic thermal/magmatic fluctuations reflect existence of long-term anomalous mantle regions beneath excavated impact basins, and possibly thermal perturbations related to younger distal impacts. The broad age zonation of some Archaean terranes suggests lateral accretion of the maria piles in a convection-driven plate tectonic regime.

References: [1] Grieve R. A. F (1980) Precambrian Res., 10, 217-248. [2] Green D. H. (1972) EPSL, 15, 263-270. [3] Glikson A. Y. (1976) Geology, 4, 202-205. [4] Glikson A. Y. (1990) LPI Contrib. No. 746, 13-15. [5] Goodwin A. M. (1976) In (B. F. Windley, ed.), 77-98, Wiley. [6] Weiblen P. W. and Schultz K. J. (1978) Proc. LPSC 9ih, 2749-2773. [7] Compston W. (1990) Third Intl. Archaean Symp., 5-6, Perth. [8] Lowe D. R. and Byerly G. R., Geology, 14, 83-86. [9] Lowe D. R. et al. (1989) Science, 245, 959-962.

THE ACRAMANIMPACT ANDITSWIDESPREADEJECTA, SOUTH AUSTRALIA. V. A. Gostin'1, R. R. Keays ${ }^{2}$, and M. W. Wallace2, 'Department of Geology and Geophysics, University of Adelaide, GPO Box 498, Adelaide, 5001, Australia, '2Department of Geology, University of Melbourne, Parkville, Victoria 3052, Australia.

Discovery of a widespread horizon of shock-deformed volcaniclastic ejecta preserved in Late Proterozoic ( $600 \mathrm{Ma}$ ) shales in South Australia [2-4,7] and its probable link to the Acraman impact structure in the Middle Proterozoic Gawler Range Volcanics $[2,8,9]$ provide a rare opportunity to study the effects of a major terrestrial impact, including the sedimentology and distribution of an ejecta blanket and its precious-metal signature.

The ejecta horizon occurs in the Bunyeroo Formation at many localities within the Adelaide Geosyncline $[2,3]$, including the Wearing Hills, which are $-350 \mathrm{~km}$ northeast of the Acraman impact site. Following a search at the same stratigraphic level in other basins in South Australia, the ejecta has been located within the Lower Rodda beds of the Officer Basin, extending the limits of the ejecta to $470 \mathrm{~km}$ northwest of the Acraman impact structure $[4,7]$. The ejecta is therefore widely dispersed, and provides an important chronostratigraphic marker enabling precise correlation of Late Proterozoic sequences in southern Australia.
The $\sim 600-\mathrm{MaB}$ Bnyeroo Formation consists of maroon and green shales, with minor concretionary carbonates, deposited in an outer marine-shelf setting. The ejecta horizon comprises mainly angular clasts of acid volcanics ranging from boulder (up to $30 \mathrm{~cm}$ diameter) to fine sand size. All large fragments and most sand-grade material were derived from a pink to red porphyritic volcanic rock like that at the Acraman impact site. The ejecta sequence varies in thickness from 0 to $40 \mathrm{~cm}$, and is commonly (from base upward) breccia, sandy mudstone, and graded sand. Such a sequence probably represents the primary ejecta fallout since it (1) is very widespread, (2) displays virtually perfect sorting and normal grading, resulting from its settling through a marine water column, and (3) invariably contains a sandy mudstone layer that directly overlies the basal breccia. Clast size analysis of the primary fallout sequence indicates that two distinct grain size populations are present (gravel and sand sized). These populations may be products of sorting by transport through the atmosphere or fragmentation processes during impact or subsequent transport.

Mass flow and storm reworking processes have been commonly superimposed on, and in places obliterated this primary sequence. To account for various sedimentological features, the following sequence of events probably took place: (1) Initial impact occurs, debris is ejected into the atmosphere, and a massive seismic event takes place with resulting disruption and slumping of muds in adjacent marine basins. (2) Ejecta entered the water column, with gravel-sized material deposited first. (3) Deposition of suspended host muds, together with continued settling of coarse sand, produced the sandy mudstone. (4)Continued hydrodynamic settling of sand-sized material produced the graded sand unit. This occurred several hours after ejecta entered the water column, assuming a 200 $\mathrm{m}$ water depth. Storm waves created during massive atmospheric disruption reached the depositional site during latter stages of sand deposition and resulted in hummocky and trough cross-stratification.

Evidence supporting an impact origin for the horizon includes the abundance of shattered mineral grains, the presence of multiple sets of shock lamellae in quartz grains, the presence of small shatter cones on large clasts, the local abundance of altered, tektitelike spherules [6], and anomalous Ir and other PGE values [3]. The correlation of the Bunyeroo ejecta with the Acraman impact structure is further supported by U-Pb ages obtained from severely shocked, euhedral zircons within the ejecta [1]; the dominant age of $1575 \pm 11 \mathrm{Ma}$ for the ejecta is consistent with derivation from the Gawler Range Volcanics, which has a U-Pb zircon age of $1592 \pm$ $3 \mathrm{Ma}$. The geographic distribution of the ejecta and the lateral variation of clast size within the horizon also are consistent with the Acraman impact site as the source.

The Bunyeroo ejecta is enveloped in green shales that are several centimeters thick [2]. These shales and the sandy layers of the ejecta horizon are enriched in $\mathrm{Cu}$ carbonates, barites, and Fe oxides, minerals that are widespread in sediments of the Adelaide Geosyncline. Geochemical profiles of the ejecta horizon indicate anomalously high $\mathrm{Ir}, \mathrm{Au}, \mathrm{Pt}, \mathrm{Pd}, \mathrm{Ru}$, and $\mathrm{Cr}$ relative to the host shales of the Bunyeroo Formation (Ir up to $2.0 \mathrm{ppb}$. Pt up to $270 \mathrm{ppb}$ ). Iridium enrichment up to 100 times the background value for the host shales has been recorded. As Ir values for the volcanic rocks that crop out at the Acraman impact site are $<0.005 \mathrm{ppb}$, the high values for Ir and for other PGEs and $\mathrm{Cr}$ in the ejecta horizon strongly suggest derivation from the impactor itself. The marked enrichment in Ir in the Bunyeroo ejecta is similar to that in sediments at the Cretaceous- 
Tertiary boundary, which has been attributed to a major impact event. The strong evidence for an impact origin of the Bunyeroo ejecta also points to a cosmic source for its PGE signature.

The shales above and below the Bunyeroo ejecta horizon also show Ir and Pt enrichments (0.073-0.45 ppb Ir, 3.1-313 ppb Pt), suggesting postdepositional mobilization of Ir and Pt. Interelement ratios of the PGEs within the ejecta horizon from different sites are also quite variable, again suggesting postdepositional, low-temperature mobilization of these elements. Indeed, all green shale horizons in the Bunyeroo Formation that were analyzed, regardless of their stratigraphic position, have relatively high levels of $I r$ and other PGEs. The diagenetic origin of these anomalies is indicated by their association with enrichments in $\mathrm{Cu}-\mathrm{V}-\mathrm{Zn}-\mathrm{Co}-\mathrm{Ni}$ in thin, permeable green-colored reduced beds in a predominantly red bed sequence. A redox precipitation model similar to that invoked for red bed $\mathrm{Cu}-\mathrm{U}-\mathrm{V}$ deposits has been proposed to explain the PGE anomalies in the green shales [5].

In summary, the Bunyeroo ejecta is unique as the only known example of a widely dispersed, coarse-grained ejecta blanket that is, moreover, strongly linked to a known major impact structure. The marked Ir-PGE anomalies in the ejecta horizon provide support for the hypothesis that meteorite impact events can produce Ir anomalies in terrestrial sediments. The findings also indicate that Ir can be mobilized and concentrated in sediments by low-temperature diagenetic processes. The identification of ejecta horizons in sedimentary rocks therefore should be based on the coincidence of shockmetamorphic features in the detritus and clear Ir anomalies.

References: [1] Compston W. et al. (1987) Aust. J. Earth Sciences, 34, 435-445. [2] Gostin V. A. et al. (1986) Science, 233, 189-200. [3] Gostin V. A. ot al. (1989) Nature, 340, 542-544. [4] Wallace M. W. et al. (1989) Aust. J. Earth Sciences, 36, 585-587. [5] Wallace M. W. et al. (1990) Geology. 18, 132-135. [6] Wallace M. W. et al. (1990) Meteoritics, 25, 161-165. [7] Wallace M. W. et al. (1990) Mines and Energy Review, South Australia, 157, 29-35. [8] Williams G. E. (1986) Science, 233, 200-203. [9] Williams G. E. (1987) Search, 18, 143-145.

OPTICAL AND TEM STUDY OF SHOCK METAMORPHISM FROM THE SEDAN TEST SITE. A. J. Gratz, Lawrence Livermore National Laboratory, Livermore CA 94550, USA.

Thus far, detailed petrologic studies of shock metamorphism have been performed on samples recovered from laboratory experiments and on a few natural impactites. The loading history of these samples is quite different: In particular, laboratory experiments spend only a short time $(<1 \mu s)$ at peak pressure, whereas natural impactites may have stress pulses from $0.1-1 \mathrm{~ms}$. On the other hand, laboratory experiments have known stress histories; natural impactites do not. Natural samples are also subjected to thousands or millions of years of postshock annealing and/or weathering. A useful intermediate case is that of nuclear detonation. Stress pulses for these events can reach $0.1 \mathrm{~ms}$ or higher, and samples are obtained in pristine condition. All three types of loading produce stresses of hundreds of kilobars.

Samples studied were taken from the Sedan nuclear test site, and consist of a coarse-grained granodiorite containing quartz, $\mathrm{K}$ feldspar, cordierite, and homblende. Samples were studied optically in thin section, then were thinned with an ion mill and studied by transmission electron microscopy (TEM).
Optically, quartz and K-feldspar displayed numerous sets of planar deformation features (PDFs) identical to the nondecorated PDFs seen in laboratory samples and many natural impactites. Other minerals showed less distinct shock damage, with some fracturing visible in cordierite and homblende.

TEM study showed that the PDFs in quartz and feldspar corresponded to densely packed wide transformation lamellac identical to those described in laboratory studies. The transformation lamellac in both minerals were amorphous, with no sign of high-pressure phases. In the case of K-feldspar only, narrow sublamellac extended outwand from some wide lamellac. Quartz, which was more abundant and studied more extensively, contained no shock-induced dislocations. Some planar features were also seen in cordierite, but could not be identified due to rapid beam damage. No shock defects were seen in homblende in TEM.

The shock-induced defects present at the Sedan site are very similar to those seen in shock recovery experiments, and also to those present at certain natural events (e.g., Meteor Crater). This suggests that shock deformation in quartz is not strongly dependent on shock pulse duration, and that laboratory recovery experiments are useful simulations of natural impact events. The lack of evidence for high-pressure phases along transformation lamellae is in agreement with past studies, and supports the idea that direct, solid-state amorphization occurs along transformation lamellae. Finally, no evidence was seen for decorated PDFs. Presumably decoration is due to postshock annealing or weathering. Further work should focus on processes that lead to decoration of transformation lamellac.

SIMULATED METEORITE IMPACTS AND VOLCANIC EXPLOSIONS: EJECTA ANALYSES AND PLANETARY IMPLICATIONS. A. J. Gratz and W. J. Nellis, Lawrence Livermore National Laboratory, Livermore CA 94550, USA.

Past cratering studies have focused primarily on crater morphology. However, important questions remain about the nature of crater deposits. Phenomena that need to be studied include the distribution of shock effects in crater deposits and crater walls; the origin of mono- and polymict breccias; differences between local and distal ejecta; deformation induced by explosive volcanism; and the production of unshocked, high-speed ejecta that could form the lunar and martian meteorites found on the Earth. To study these phenomena, one must characterize ejecta and crater wall materials from impacts produced under controlled conditions.

New efforts at LLNL simulate impacts and volcanism and study resultant deformation. All experiments use the two-stage light-gas gun facility at LLNL to accelerate projectiles to velocities of 0.2 to $4.3 \mathrm{~km} / \mathrm{s}$, inducing shock pressures of 0.9 to $50 \mathrm{GPa}$. We use granite targets and novel experimental geometries to unravel cratering processes in crystalline rocks.

We have thus far conducted three types of simulations: soft recovery of ejecta, "frozen crater" experiments, and an "artificial volcano." In the first case, a projectile impacts a granite disk, jetting ejecta, which is gently recovered in a soft-foam fixture to minimize postejection deformation. In "frozen crater" experiments, a granite block is snugly embedded in a large Al block with a narrow entry tunnel for the projectile. The projectile, which deforms on impact, seals most of the ejecta in place, minimizing postimpact material movement and allowing study of the shocked material close to its 
preshock location. Volcanic simulations use impact projectiles on the back surface of preheated targets, producing stress waves that release at the front, unloading rapidly in much the same manner as a decompressing magma chamber.

Our ejecta recovery experiments produced a useful separation of impactites. Material originally below the projectile remained trapped there, embedded in the soft metal of the flyer plate. In contrast, material directly adjacent to the projectile was jetted away from the impact, producing an ejecta cone that was trapped in the foam recovery fixture. The high-speed ejecta showed no signs of shock metamorphism, only intense fracturing, including close intergranular fractures and some planar fracturing in feldspars. These effects are consistent with shock pressures of $5-10 \mathrm{GPa}$ in the most damaged fragments while other fragments showed no significant internal damage. Material trapped in the flyer plate, in contrast, was highly shocked (10-40 GPa), with abundant planar deformation features (PDFs), amorphization, and micrometer-scale fracturing. Thus, we find that a significant component of crater ejecta shows no signs of strong shock; this material comes from the near-surface "interference zone" surrounding the impact site. This phenomenon explains the existence of unshocked meteorites on the Earth of lunar and martian origin. Impact of a large bolide on neighboring planets will produce high-speed, weakly shocked ejecta, which may be trapped by the Earth's gravitational field.

"Frozen crater" experiments show that the interference zone is highly localized; indeed, disaggregation does not extend beyond $\sim 1.5$ crater radii. A cone-shaped region extending downward from the impact site is completely disaggregated, including powdered rock (grain size $<5 \mu \mathrm{m}$ ) that escaped into the projectile tube. Petrographic analysis of crater ejecta and wall material will be presented.

Finally, study of ejecta from 0.9- and 1.3-GPa simulations of volcanic explosions reveal a complete lack of shock metamorphism. The ejecta shows no evidence of PDFs, amorphization, highpressure phases, or mosaicism. Instead, all deformation was brittle, with fractures irregular (not planar) and mostly intergranular. The extent of fracturing was remarkable, with the entire sample reduced to fragments of gravel size and smaller. Because the experimental shock stresses match those of the most energetic volcanic explosions, we conclude that explosive volcanism cannot produce shock features such as those seen at the $\mathrm{K} / \mathrm{T}$ boundary. Instead, these features-similar to those seen in many meteor craters-must be the result of a large meteorite impact.

\section{MELT PRODUCTIONINLARGE-SCALEIMPACTEVENTS:} IMPLICATIONS AND OBSERVATIONS AT TERRESTRIAL CRATERS. Richard A. F. Grieve ${ }^{1}$ and Mark J. Cintala2, 1 Geophysics Division, Geological Survey of Canada, Ottawa, Ontario K1A OY3, 2Code SN4, NASA Johnson Space Center, Houston TX 77058, USA.

The volume of impact melt relative to the volume of the transient cavity increases with the size of the impact event [1-3]. Here, we use the impact of chondrite into granite at 15,25 , and $50 \mathrm{~km} \mathrm{~s}^{-1}$ to model impact-melt volumes at terrestrial craters in crystalline targets and explore the implications for terrestrial craters; details of the model are given elsewhere [4,5].

Figure 1 illustrates the relationships between melt volume and final crater diameter $D_{R}$ (i.e., after transient-cavity adjustments [5,6]) for observed terrestrial craters in crystalline targets; also included are model curves for the three different impact velocities.

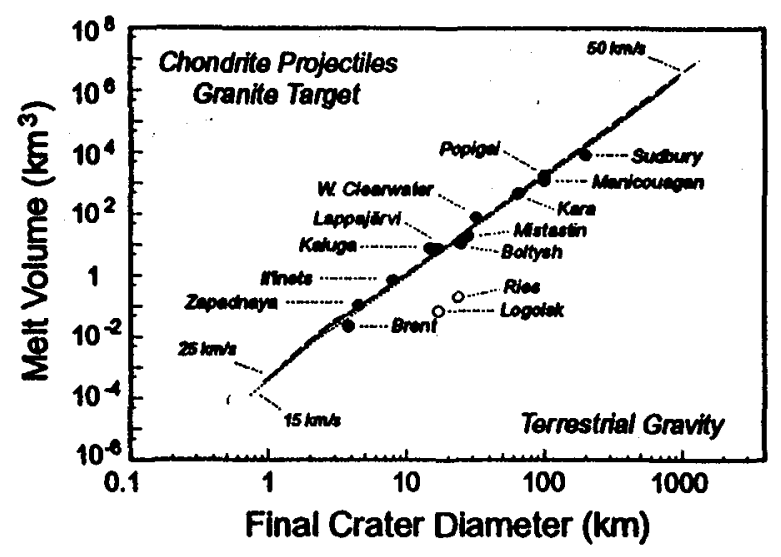

Fig. 1. Impact melt volumes as a function of final crater diameter for observed terrestrial craters and model curves. The slight breaks in slope at $3.1 \mathrm{~km}$ are due to application of the modification model of Croft [15].

One implication of the increase in melt volumes with increasing crater size (Fig. 1) is that the depth of melting will also increase (Fig. 2 and Fig. 5 in [6]). This requires that shock effects occurring at the base of the cavity in simple craters and in the uplifted peaks of central structures at complex craters record progressively higher pressures with increasing crater size, up to a maximum of partial melting ( $-45 \mathrm{GPa})$. Higher pressures cannot be reconded in the parautochthonous rocks of the cavity floor as they will be represented by impact melt, which will not remain in place. We have estimated maximum recorded pressures from a review of the literature [e.g., 7,8], using such observations as planar features in quartz and feldspar, diaplectic glasses of feldspar and quartz, and partial fusion and vesiculation, as calibrated with estimates of the pressures required for their formation (Table 1). Erosion complicates the picture by removing the surficial (most highly shocked) rocks in uplifted structures, thereby reducing the maximum shock pressures observed. In addition, the range of pressures that can be recorded is limited. Nevertheless, the data define a trend to higher recorded pressures with crater diameter (Table 1), which is consistent with the implications of the model.

TABLE 1. Estimates of maximum recorded shock pressures in the center of craters formed in crystalline targets.

\begin{tabular}{|c|c|c|c|}
\hline Crater & $\frac{D_{R}}{(\mathrm{~km})}$ & $\begin{array}{c}\text { Pressure } \\
\text { (GPa) }\end{array}$ & Notes \\
\hline Rotmistrovka & 2.5 & $\%$ & \\
\hline Brent* & 3.8 & 叒 & \\
\hline Logoisk & 20 & $x$ & \\
\hline Boltysh & 25 & \% & \\
\hline Mistastin & 28 & $>30-35$ & Eroded \\
\hline Slate Islands & 30 & $>20$ & Eroded \\
\hline W. Clearwater & 32 & $>30-35$ & Eroded \\
\hline Aragusinha & 40 & $>32$ & Eroded \\
\hline Charlevoix & 54 & $>25$ & Eroded \\
\hline Kara & 60 & $>35-40$ & Eroded \\
\hline Puchezh-Katunki & 80 & so & \\
\hline Manicoungan & 100 & $40-45$ & Eroded \\
\hline Popigai & 100 & g & \\
\hline
\end{tabular}

Better constrained estimates are shaded.

- Simple cravera; all othera are complex. 


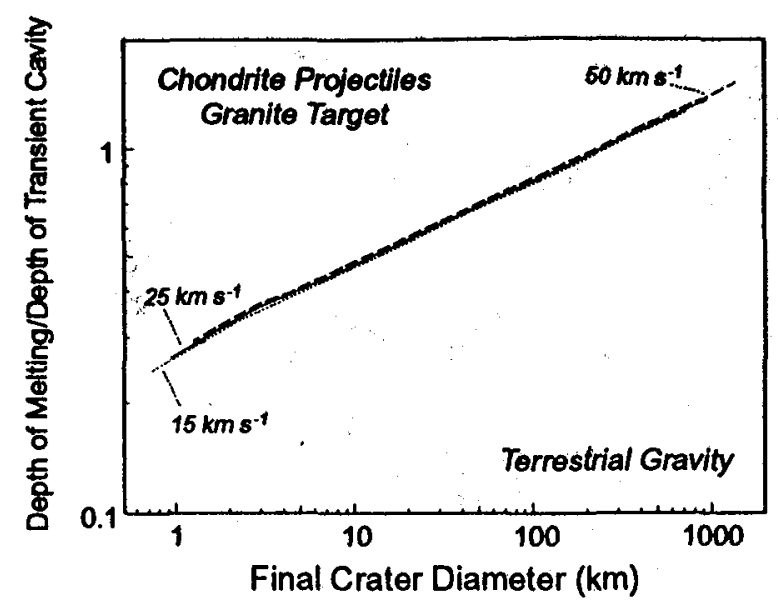

Fig. 2. Depth of melting along the axis of penetration relative to the depth of the transient cavity, plotted as a function of final crater diamater. Note that, regardless of the impact velocity, melting will approach the "base" of the cavity even at relatively small diameters.

A second implication is that, as the limit of melting intersects the base of the cavity (Fig. 2), central topographic peaks will be modified in appearance and ultimately will not occur. That is, the peak will first develop a central depression, due to the flow of lowstrength melted materials, when the melt volume begins to intersect the transient-cavity base. As the melt volume intersects an increasing portion of the transient cavity base, the peak will be replaced upon uplift by a ring. Some of the implications of this mechanism for ring formation and observations on other terrestrial planets is given elsewhere in this volume [9]. The morphology of central structures at complex terrestrial craters was also compiled from the literature [6]; again, erosion is a complicating factor as it can both destroy and create topography. Nevertheless, the general trend is what would be expected with central depressions at values of $D_{R} \geq$ $40 \mathrm{~km}$, and finally rings appearing at $D_{R} \geq 100 \mathrm{~km}$. The latter is equivalent to $d_{m} / d_{t c}$ values of $0.8-0.9$ (Fig. 2), and the diameter at which rings consistently appear in the terrestrial record is also where shock pressures in central-uplift structures record partial melting at $D_{R} \geq 80 \mathrm{~km}$ (Table 1).

As crater size increases, the volume of impact melt occupies a greater percentage of the volume of the transient cavity (Fig. 3). This implies that less clastic debris is available for incorporation into impact-melt sheets at larger craters. This argument has been used to explain, in part, the general lack of clasts in the bulk of the impactmelt sheet (the Igneous Complex) at Sudbury [10]. There are few detailed studies of clast-content variation in impact-melt rocks. The preserved melt sheets at Mistastin $\left(D_{R}=28 \mathrm{~km}\right)$ and $W$. Clearwater $\left(D_{R}=32 \mathrm{~km}\right)$ are $\sim 100 \mathrm{~m}$ thick and have clasts throughout $[11,12]$. At Manicouagan $\left(D_{R}=100 \mathrm{~km}\right)$, however, the melt sheet is essentially free of clasts $\sim 30 \mathrm{~m}$ above its base [13]. While this is consistent with the implications of the model, it could result from complete resorption of clasts in the thicker $(\sim 200 \mathrm{~m}$ preserved thickness) melt sheet at Manicouagan. Ultimately, the volume of melt could equal or exceed the volume of the transient cavity (Fig. 3). In this case $\left(D_{R} \sim 1000 \mathrm{~km}\right)$ and at larger diameters, the resulting final landform would not resemble a classic crater. We venture that terrestrial basins in the $1000-\mathrm{km}$ size range might have resembled palimpsests, a suggestion made for very large basins on the Moon and Mercury by Croft [1]. Thus, even if preserved, very

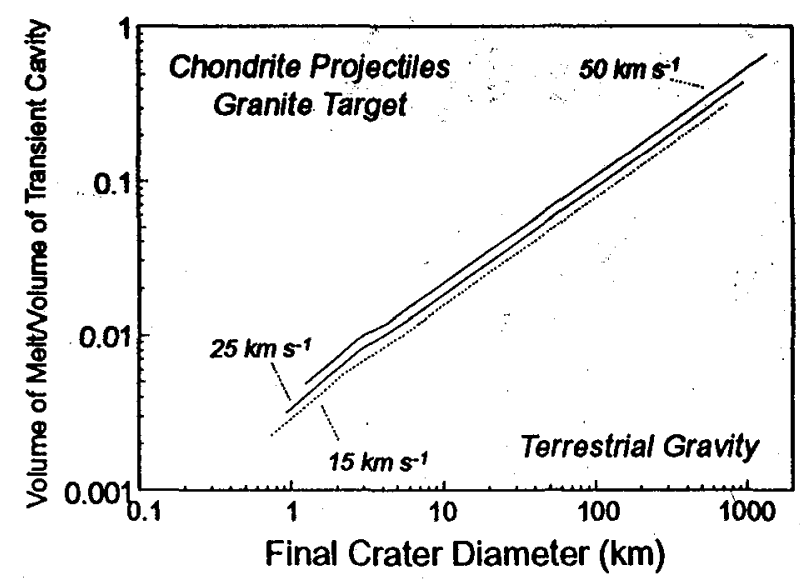

Fig. 3. Volume of melt relative to the volume of the transient cavity as a function of final crater diameter. The melt volume approaches that of the cavity at crater diameters above about $1000 \mathrm{~km}$.

large and ancient impact structures, such as those suggested to explain meter-thick, areally large spherule beds in the Archean [14] may be unrecognizable in the context of a classic crater form and its impact deposits. At these sizes, terrestrial impact structures might have appeared as low-relief pools of impact melt rocks $\left(10^{7} \mathrm{~km}^{3}\right.$; Fig. 1) with little clastic debris and no obvious associated crater structure. Accompanying subsolidus shock effects would be buried beneath a massive melt sheet and would also tend to anneal out. It would seem, therefore, that such ancient, large structures might not be recognizable as impact features according to common criteria.

References: [1] Croft S. K. (1983) Proc. LPSC 14th, in JGR, 88, B71. [2] Cintala M. J. and Grieve R. A. F. (1984) LPSCXV, 156. [3] Melosh H. J. (1989) Impact Cratering: A Geologic Process, Oxford, 245 pp. [4] Cintala M. J. (1992) JGR, 97, 947. [5] Cintala M. J. and Grieve R. A. F., this volume. [6] Grieve R. A. F. and Cintala M. J. (1992) Meteoritics, submitted. [7] Robertson P. B. (1975) Bull. GSA , 86, 1630 . [8] Dressler B. (1990) Tectonophysics, 171,229 . [9] Cintala M. J. and Grieve R. A. F., this volume. [10] Grieve R. A. F. et al. (1991) JGR, 96, 753. [11] Grieve R. A. F. (1975) Bull. GSA, 86, 1617. [12] Phinney W. C. et al. (1978) Proc. LPSC 9th, 2659. [13] Floran R. J. et al. (1978) JGR, 83, 2737. [14] Lowe D. R. et al. (1990) Science, 245, 959. [15] Croft S. K. (1985) Proc. LPSC 15th, in JGR, 88, 828.

\section{VENUSIAN IMPACT BASINS AND CRATERED TERRAINS.}

Warren B. Hamilton, Mail Stop 964, U.S. Geological Survey, Denver CO 80225, USA.

The consensus regarding interpretation of Magellan radar imagery assigns Venus a young volcanic surface subjected in many areas to moderate crustal shortening [1-3]. I infer that, on the contrary, ancient densely cratered terrain and large impact basins may be preserved over more than half the planet and that crustal shortening has been much overestimated. I see wind erosion and deposition as far more effective than do others in modifying old structures. Integration with lunar chronology suggests that most of the surface of Venus may be older than $3.0 \mathrm{Ga}$ and much may be older than $3.8 \mathrm{Ga}$. 


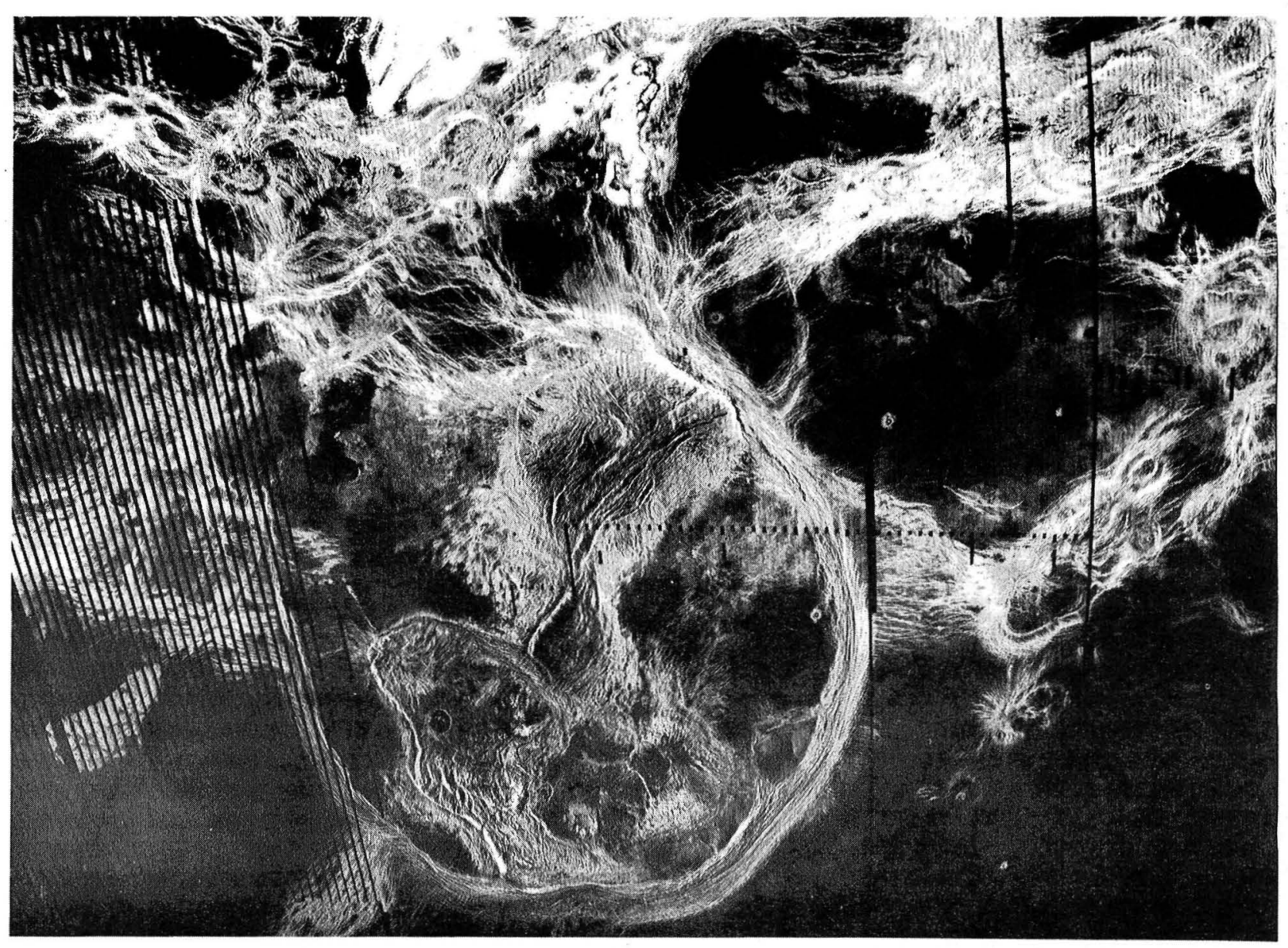

Fig. 1. The nearly circular Artemis structure, $2000 \mathrm{~km}$ in diameter and centered at $133^{\circ} \mathrm{E}, 35^{\circ} \mathrm{S}$, may be the largest impact structure on Venus. The scoured-bedrock ring consists of an inner rim, steepest on the inside, and an outer basin inside a broad, dark outer rim. Other large and small subcircular structures may be the eroded and partly deformed roots of other impact structures. C2-MIDRP.30S129;1, by JPL.

Broad volcanos, huge volcanic domes, plains preserving lobate flow patterns, and numerous lesser volcanic features, pocked sparsely by impact craters, are indeed obvious on Magellan imagery [4]. Some of these postvolcanic impact craters have been slightly extended, but only a small proportion has been flooded by still younger lavas [5]. Relative ages of the young craters are indicated by the varying eolian removal of their forms and ejecta blankets and flow lobes, and the oldest are much subdued [6]. If these young impact craters, maximum diameter $275 \mathrm{~km}$, include all preserved impact structures, then their quantity and distribution indicate that Venus was largely resurfaced by volcanism $\sim 0.5 \mathrm{Ga}$, subsequent eruptions having been at a much reduced rate [5].

Away from the $\sim 0.5-\mathrm{Ga}$ volcanic features, much of Venus is, however, dominated by circular and subcircular features, 50 $2000 \mathrm{~km}$ in diameter, many of them multiring, that may be mostly older impact and impact-melt structures substantially modified by wind action. Eolian erosion scoured to bedrock old ridges and uplands, including those that may be cratered terrains and the rims and outer-ring depressions of large impact basins, and removed all surficial deposits to the limits of resolution of the imagery. The complementary eolian deposits form not only dunes, wind streaks, and small plains $[6,7]$ but also broad radar-dark plains, commonly assumed to be volcanic although lacking flow morphology, whose materials appear to be thick because they are smoothly compacted into buried craters. Plains and erosional features are displayed on
Magellan stereo-image pairs. For example, a blowout, longitude $073^{\circ}$ to $076^{\circ} \mathrm{E}$, latitude $2^{\circ} \mathrm{N}$ to $2^{\circ} \mathrm{S}$, stripped deep into the bedrock of large superimposed craters, is surrounded by a vast swirl of connecting erosional canyons, wind streaks, and linear dunes atop an eolian plain.

Numerous possible large magma-flooded impact basins are also preserved. These include many coronae and have nearly circular rims, $300-2000 \mathrm{~km}$ in diameter, steeper on the inside than the outside. Many are multiring, the inner rims encircled by peripheral basins (some chasmata), outer broad, subdued rims, and concentric and radial fracture systems [8-10]. The interior volcanic plains are commonly higher than plains beyond the rings but lower than the inner rims. Some large circular basins are superimposed on older ones. Scaling considerations require that impacts on Venus produce larger craters and much more melt than on the Moon [11], and venusian basins, like some lunar maria, may be found to have positive gravity anomalies because they are underlain by thick lopoliths fractionated from impact-melt lakes. The large basins have mostly been regarded as formed by magma welling upward and outward atop giant plumes but they lack the lobate or irregular forms to be expected of such origins and their abrupt circular or subcircular rims have yet to be explained in terms of plumes.

The inferred heavily cratered terrains consist of arrays of separate or overlapping circular to subcircular rims and multiring complexes $50-1000 \mathrm{~km}$ in diameter. Many rims form radar-bright 
stripped-bedrockridges enclosing radar-dark eolian(?) plains. Other tracts are now eroded to almost continuous bedrock distinguished by numerous much-subdued, large, subcircular rims and basins. The prevailing interpretation of these diverse ring complexes as produced by crustal shortening and magma upwelling cannot account for their superimposed circular patterns.

Misunderstanding of visual illusions in radar imagery detracts from some interpretations. The scale of imagery in the sidelook direction is not horizontal distance but rather is proportional to slant distance. Slopes facing the spacecraft are foreshortened because their tops and bottoms plot close together, whereas slopes facing away are lengthened, an effect opposite to that of optical imagery. Symmetrical ridges appear to be hogbacks dipping gently in the direction of radar look, and such illusions have been misinterpreted to be thrust-imbricated sheets [2,12]; straight ridges of varying heights can mimic contorted and faulted structures.

References: [1] Head J.W.et al.(1991)Science, 252,276-288. [2] Solomon S. C. et al. (1991) Science, 252, 297-312. [3] Bindschadler D. L. et al. (1992) JGR, 97, in press. [4] Head J. W. et al. (1992) JGR, 97, in press. [5] Schaber G. G. et al. (1992) JGR, 97, in press. [6] Arvidson R. E. et al. (1992) JGR, 97, in press. [7] Greeley R. et al. (1992) JGR, 97, in press. [8] Squyres S. W. et al. (1992) JGR, 97, in press. [9] Stofan E. R. et al. (1992) JGR, 97 , in press. [10] Sandwell D. T. and Schubert G. (1992) JGR, 97, in press. [11] Cintala M. J. and Grieve R. A. F. (1991) LPSC XXII, 213-216. [12] Suppe J. and Connors C. (1992) LPSC XXIII, 1389-1390.

WHERE'S THE BEAVERHEAD BEEF? R. B. Hargraves, Department of Geological and Geophysical Sciences, Princeton University, Princeton NJ 08544, USA.

Only rare quartz grains with single-set planar (1013) deformation features (PDFs) are present in breccia dikes found in association with uniformly oriented shatter cones that occur over an area $8 \times$ $25 \mathrm{~km}$ (see Fiske et al., this volume). This suggests that the

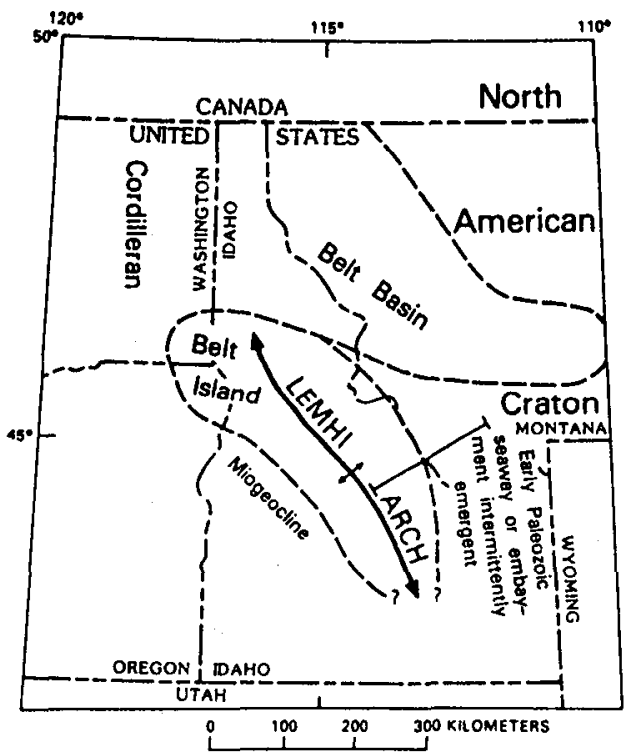

Fig. 1. Location of Lemhi Arch (from [3]).

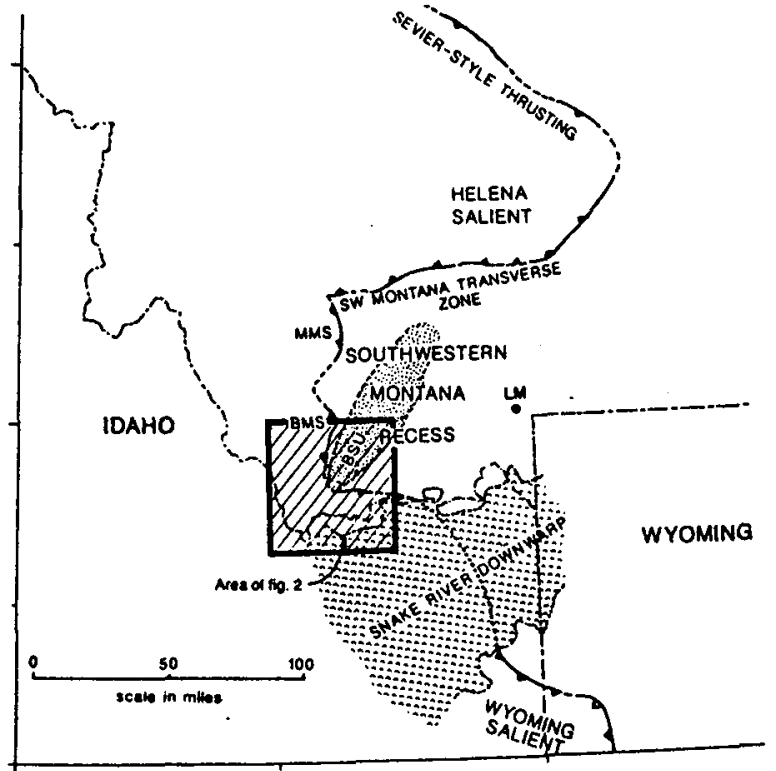

Fig. 2. Southwestem Montana Recess in Sevier Front (from [4]).

Beaverhead shocked rocks come from only the outer part of the central uplift of what must have been a large ( $>100 \mathrm{~km}$ diameter) complex impact structure. These rocks are allochthonous. They are present in the Cabin thrust plate (one of many in the Cordilleran belt), and are considered to have been tectonically transported 50 to $150 \mathrm{~km}$ east-northeast from a source in east central Idaho during the Laramide orogeny $[1,2]$.

An impact event of this magnitude on continental crust (thought to have occurred in late Precambrian or early Paleozoic time) could be expected to punctuate local geologic history. Furthermore, although it may now be covered, its scar should remain despite all the considerable subsequent erosion/deposition and tectonism since the impact. The following are three large-scale singularities or anomalies that may reflect the event and mark its source.

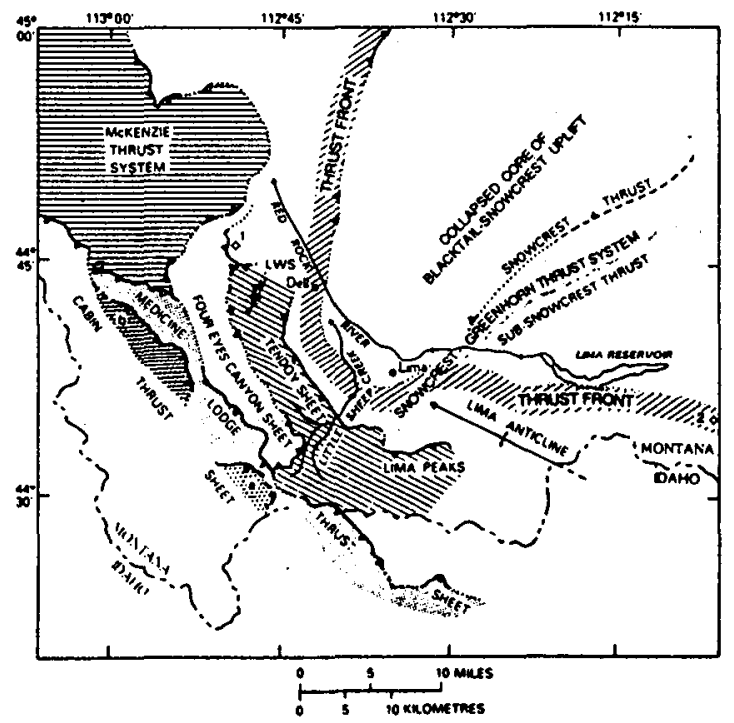

Fig. 3. Detail of apex of Southwestem Montana Recess (from [4]). 


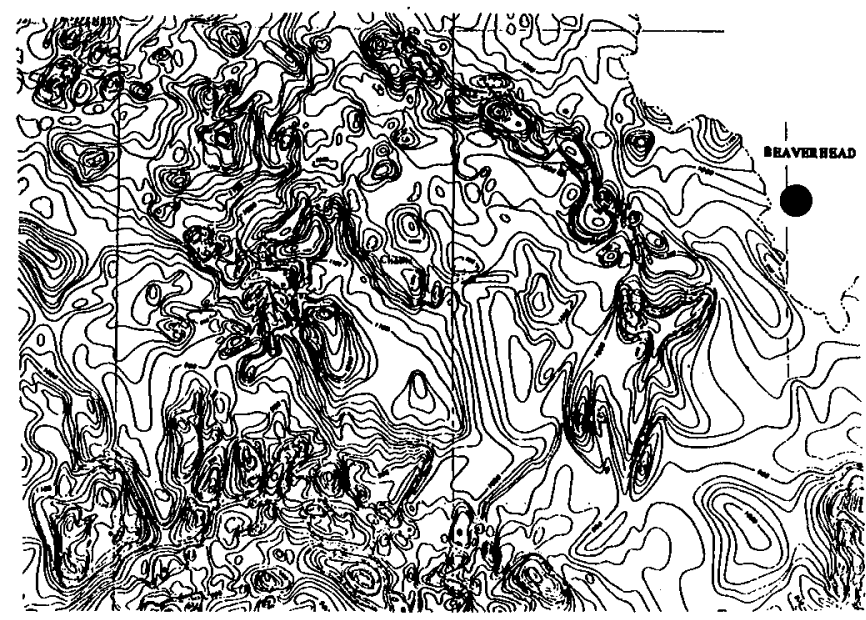

Fig. 4. Eastern segment of Aeromagnetic Map of Idaho [5].

1. The Lemhi Arch (Fig. 1) is a major structural uplift that occurred in late Proterozoic-early Paleozoic time in East Central Idaho and caused the erosion of at least $4 \mathrm{~km}$ of sedimentary cover [3]. This may be directly related to the impact.

2. Of the many thrust sheets comprising the Cordilleran belt, the Cabin plate that carries the shocked rocks is unique in that it alone intersected the crystalline basement [2]. It also now marks the apex of the Southwest Montana Recess in the Sevier front [4] (Figs. 2 and 3). The basement uplift remaining from the impact may have constituted a mechanical obstacle to the advancing thrust sheets in Cretaceous time, causing the recess. Perhaps a piece from the western edge of this uplift was sliced off and transported by the Cabin thrust.

3. What could be interpreted as a roughly circular aeromagnetic anomaly $\sim 70 \mathrm{~km}$ in diameter can be discerned in the state aeromagnetic map [5] centered about $20 \mathrm{~km}$ southeast of Challis, Idaho, in the Lost River range (Fig. 4). It is in approximately the right place, and ignoring the possibility that the anomalies have diverse causes and the circular pattern is coincidental, it may mark what remains of the buried central uplift structure!

The relevance of these speculations in the search for the source of the Beaverhead shocked rocks will be explored this summer and reported at the meeting.

References: [1] Ruppel E. T. and Lopez D. A. (1988) U.S. Geol.Surv. Prof. Paper 180, 122. [2] Skipp B. (1988) Interaction of the Rocky Mountain Foreland and the Cordilleran Thrust Belt (C. J. Schmidt and W. J. Perry, eds.), 237-266, GSA Mem. 171. [3] Ruppel E. T. (1986) Paleotectonics and Sedimentation in the Rocky Mountain Region, United States (J. A. Peterson, ed.), 119-130, A.A.P.G. Mem. 41. [4] Perry W. J. et al. (1989) Geol. Resources of Montana (D. E. French and R. F. Crabb, eds.), Montana Geol. Soc. 1989 Field Conf. Guidebook. [5] U.S. Geological Survey (1978) Aeromagnetic Map of Idaho.
REPORT ON THE INTERNATIONAL CAMBODIAN CRATER EXPEDITION-1992. J. Hartung1, C. Koeberl'2, P. Lee $^{3}$, Kuhn Pagnacith4, and Touch Sambath4, 1600 East Fifth Street, Des Moines IA 50309, USA, 2Institute of Geochemistry, University of Vienna, A-1010 Vienna, Austria, 3404 Space Sciences Building, Cornell University, Ithaca NY 14853, USA, ${ }^{2}$ Department of Geology and Mines, Ministry of Industry, Phnom Penh, Cambodia.

It has been proposed that Tonle Sap, a lake in Cambodia, $100 \mathrm{~km}$ long and $30 \mathrm{~km}$ wide, marks the location of an elongate basin formed by the oblique impact of a comet or asteroid [1]. The impact is considered to have produced melted ejecta found now as tektites over much of southeast Asia and Australia. The location of the lake, its approximate age, its size, and the orientation of its long axis (toward Australia) are consistent with this hypothesis.

After learning about the hypothesis, five individuals volunteered to participate in an expedition to Cambodia: Jack Hartung, Christian Koeberl, Charles Harper, Burkhard Dressler, and Pascal Lee. We agreed that a proper expedition could not be undertaken without a local host or "contact." After a year without progress Hartung decided to arrange travel to Phnom Penh, Cambodia, in January 1992. The primary objective of this trip was simply to identify a local contact. A secondary objective was to collect a variety of representative rock samples. In spite of the uncertainty related to getting into the field in Cambodia, Lee and Koeberl also decided to make the trip. Early in December 1991, John McAuliff, Director of the U.S.-Indochina Reconciliation Project, informed us that he had arranged for us to be received in Phnom Penh by officials of the Ministry of Industry. Although still uncertain regarding their status, Hartung and Lee arrived in Phnom Penh on January 5, 1992, and were greeted by Kuhn Pagnacith and Touch Sambath, who did all that was possible to make the expedition scientifically profitable and personally satisfying. Because we were not from Cambodia, travel into the countryside had to be approved by officials of the

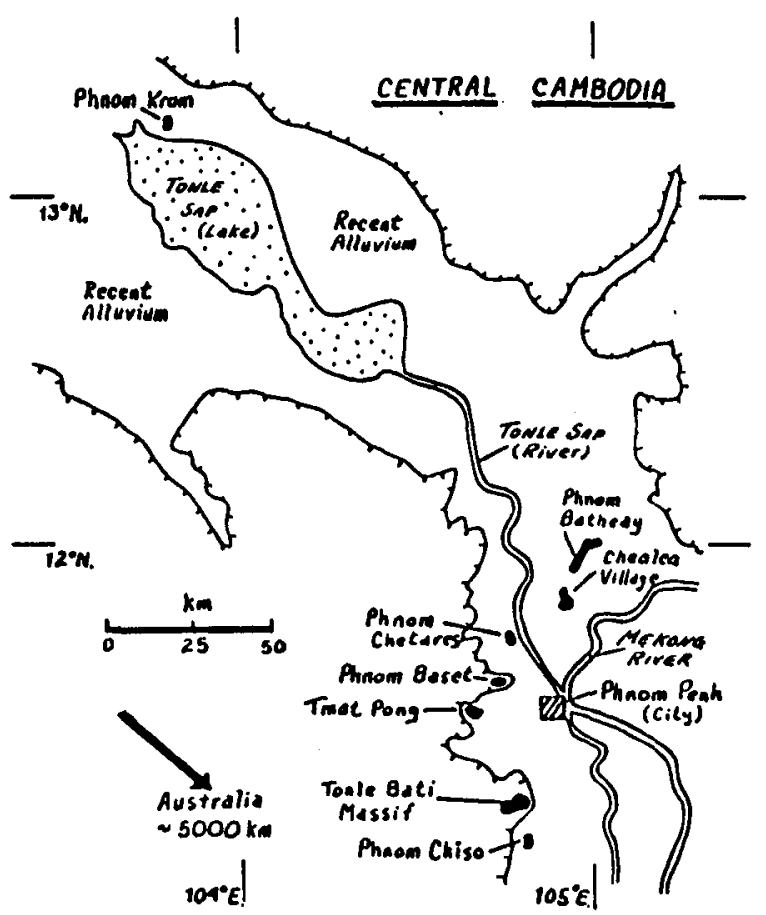

Fig. 1. Map of Central Cambodia, modified from [3]. 
TABLE 1. Locations of sites where samples were collected and a brief description of the materials collected.

\begin{tabular}{|c|c|c|}
\hline Site Name & Location & Rocks Reported \\
\hline $\begin{array}{l}\text { Phnom Krom (Quarry) } \\
\text { (8 samples) }\end{array}$ & $\begin{array}{l}10 \mathrm{~km} \text { SSW } \\
\text { of Siem Reap } \\
\text { (Angkor Wat) }\end{array}$ & $\begin{array}{l}\text { Compact cinerites, ferngenous scoria, } \\
\text { pink thyolitic lavas, dark cinerous sandstones, } \\
\text { and various volcanic conglomerates }\end{array}$ \\
\hline $\begin{array}{l}\text { Phnom Baset (Quarry) } \\
\text { (2 samples) }\end{array}$ & $\begin{array}{l}22 \mathrm{~km} \text { WNW } \\
\text { of Phnom Penh }\end{array}$ & $\begin{array}{l}\text { Granite, fine-grained, leucocratic, } \\
\text { white quartz vein }\end{array}$ \\
\hline $\begin{array}{l}\text { Phnom Chetares } \\
\text { (1 sample) }\end{array}$ & $\begin{array}{l}30 \mathrm{~km} \mathrm{NW} \\
\text { of Phnom Penh }\end{array}$ & $\begin{array}{l}\text { Jointed polychrome jasperites, } \\
\text { subvertical schists }\end{array}$ \\
\hline $\begin{array}{l}\text { Chealea Village Group } \\
\text { (7 samples) }\end{array}$ & $\begin{array}{l}38 \mathrm{~km} \mathrm{~N} \\
\text { of Phnom Penh }\end{array}$ & $\begin{array}{l}\text { Devitrified pyromeride, thyolite, white fluidal } \\
\text { thyolite, thyolitic breccias, siliceous dark decite }\end{array}$ \\
\hline $\begin{array}{l}\text { Phnom Batheay } \\
\text { (2 asmples) }\end{array}$ & $\begin{array}{l}46 \mathrm{~km} \mathrm{~N} \\
\text { of Phnom Penh }\end{array}$ & $\begin{array}{l}\text { Upper Indosinias sundatone, vein of } \\
\text { acidic thyolitic rock }\end{array}$ \\
\hline $\begin{array}{l}\text { Tmat Pong Group (Quarry) } \\
\text { (2 samples) }\end{array}$ & $\begin{array}{l}26 \mathrm{~km} \mathrm{~W} \\
\text { of Phnom Penh }\end{array}$ & $\begin{array}{l}\text { Rhyolitic, weathered whitish, sometimes } \\
\text { fluidal }\end{array}$ \\
\hline $\begin{array}{l}\text { Phnom Chiso (Quarry) } \\
\text { (3 samples) }\end{array}$ & $\begin{array}{l}45 \mathrm{~km} \mathrm{~S} \\
\text { of Phnom Penh }\end{array}$ & $\begin{array}{l}\text { Massive crystalline sandstone, intensely } \\
\text { eroded black schist }\end{array}$ \\
\hline $\begin{array}{l}\text { Tonle Bati Massif } \\
\text { (1 sample) }\end{array}$ & $\begin{array}{l}33 \mathrm{~km} \text { SSW } \\
\text { of Phnom Penh }\end{array}$ & $\begin{array}{l}\text { Granite, fine-to-medium grained, pseudo- } \\
\text { vortical biotite flames, black slaty schists }\end{array}$ \\
\hline
\end{tabular}

Cambodian equivalents of the U.S. Departments of Commerce, Interior, State, and Defense. For support in achieving this "diplomatic" objective we are indebted to Thach Xoval Say, ViceDirector, Dept. of Mines and Geology, Sov Chivkun, Director, Dept. of Geology and Mines, and Ith Praing, Vice Minister, Ministry of Industry. We were restricted from visiting sites that were "off limits" due either to unknown locations of land mines or known locations of military bases.

Our scientific objectives were to find impact or shock metamorphosed rocks unambiguously related to the Tonle Sap basin, to collect samples of rocks that may represent those melted to produce Australasian tektites, and to learn as much as possible about Cambodian geology. Using 1:200,000-scale geologic maps with fairly detailed descriptions of the rock units shown [2], we selected a number of acceptable "phnoms" (hills that rise abruptly out of the surrounding plain) that may contain rocks affected by the postulated Tonle Sap impact. A map of central Cambodia is shown in Fig. 1, and the locations of sites where samples were collected are indicated. A list of those sites, together with a description of the rocks reported to be present at each site [2], is given in Table 1. No obviously shock-metamorphosed or suevite-like rocks were observed. Recent alluvium surrounding Tonle Sap is judged to be lake sediment deposited when the lake surface was at a higher elevation.

Acknowledgment: Support provided by the Barringer Crater Company is gratefully acknowledged.

References: [1] Hartung J. B. (1990)Meteoritics, 25, 369-370. [2] Dottin O. (1972) Carte Geologique de Reconnaissance a 1 I 200,000, Republique Khmere, Phnom Penh, 41 pp., and Siemreap, 16 pp., Editions du Bureau de Recherches Geologiques Minieres, Paris. [3] Rasmussen W. C. and Bradford G. M. (1977) GroundWater Resources of Cambodia. Geological Survey Water-Supply Paper 1608-P, 122 pp., 3 plates.
THE DISTRIBUTION AND MODES OF OCCURRENCE OF IMPACT MELT AT LUNAR CRATERS. B. Ray Hawke ${ }^{1}$ and J. W. Head 2, 'Planetary Geosciences, SOEST, University of Hawaii, Honolulu HI 96822, USA, 2Department of Geological Sciences, Brown University, Providence RI 02912, USA.

Introduction: Numerous studies of the retumed lunar samples [1-4] as well as geologic and remote-sensing investigations $[5,6]$ have emphasized the importance of impact melts on the surface of the Moon. Information concerning the distribution and relative volumes is important for (1) an improved understanding of cratering processes, (2) kinetic energy estimates and energy partitioning studies, (3) the proper interpretation of melt-bearing lunar samples, and (4) comparative planetology studies. The identification of major flows of fluidized material associated with impact craters on the surface of Venus has increased interest in impact melt flows on the other terrestrial planets. For a number of years, we have been investigating the distribution, modes of occurrence, and relative and absolute amounts of impact melt associated with lunar craters as well as the manner in which melt volumes vary as a function of crater size, morphology, and target characteristics. The purpose of this paper is to present the results of this effort.

Method: Impact melt deposits were identified using the criteria established by Howard and Wilshire [5] and Hawke and Head [6-8]. Qualitative estimates were made and trends were established utilizing a population of over 100 fresh impact craters that was characterized in a previous paper [6], plus additional lunar craters for which adequate Lunar Orbiter and Apollo photography exists. Quantitative determinations of impact melt volumes were made for those craters for which high-quality topographic data are available from Lunar Topographic Orthophotomaps. 
Results and Discussion:

Melt occurrence as a function of crater size and morphology. Impact melt is more common at fresh simple craters $(D<\sim 15 \mathrm{~km})$ than has previously been thought. The smallest extensively studied crater with interior melt is $750 \mathrm{~m}$ in diameter, but we have noted the occurrence of even smaller melt-containing craters. At very small craters (D $<2 \mathrm{~km}$ ), impact melts typically occur as narrow ponds of low-albedo material on crater floors, less common dark streaks on walls, and very thin discontinuous veneers around the rim crests. The melt deposits associated with slightly larger simple craters $(D=$ 2-7 km) are similar but more abundant than those at smaller craters. Shallow ponds often occur among the small floor hummocks, and hard-rock veneers cover much of the crater floors. It appears that some of the melt flowed onto the floor from the lower portions of the crater walls and embayed clastic debris emplaced by mass wasting from the crater walls. Though some minor wall failure has occurred at craters in this size range, the positions of these craters on depthdiameter plots indicate that there has been very little, if any, reduction in depth [8-10].

Interior melt volumes are quite variable in fresh craters from 7 to $12 \mathrm{~km}$ in diameter. These deposits range from unobserved or present in only trace amounts to quite abundant. Extensive deposits of exterior melt are first observed around craters near the upper limit of this size range $[6,8]$.

Numerous workers have documented the changes in lunar crater morphology and morphometry, which start at a diameter of about $15 \mathrm{~km}$ as smaller, simple craters undergo a transition to larger, complex craters that exhibit central peaks and wall terraces [e.g., $9,10]$. It appears that the crater modification processes operative at craters between 15 and $25 \mathrm{~km}$ in diameter influence melt deposit morphologies and abundances. While most fresh primary craters in this diameter range for which adequate photography exists do contain at least some melt, the amounts are extremely variable. Dawes $(D=17 \mathrm{~km})$ is typical of craters in this size range. Significant accumulations of impact melt are restricted to a small area immediately east of the central peak [7]. Additional melt was probably present initially but was buried by scallop material slumped onto the crater floor during the modification stage of the impact cratering event. Fresh craters in this size range that exhibit little or no interior melt are generally characterized by the presence of extensively scalloped walls and/or swirl-textured floors, features indicative of pervasive wall failure $[7,8]$. The results of our analysis of the interior morphologies of these craters indicate that much of the interior melt was totally buried by scallop material. We conclude that the variable amounts of interior melt associated with craters in this size range can best be explained by differences in the degree and style of wall failure.

Fresh impact craters over $25-30 \mathrm{~km}$ in diameter are extensively modified and exhibit terraced walls, central peaks, and flat floors with abundant deposits of impact melt. Wall failure has been more extensive and deep-seated at the larger terraced-walled craters, and little melt appears to have been buried during the modification stage. The results of detailed mapping of interior and exterior melt distributions indicate that ponded material becomes relatively more abundant on the floors and rims of these larger craters [8].

Exteriormelt volumes as a function of crater diameter. Previous work has emphasized the role of oblique impact and preexisting topography in controlling the distribution and amounts of exterior melts $[5,6,8]$. While it is clear that these factors do cause variable amounts of melt to be emplaced on crater rims, a variety of evidence indicates that relatively greater quantities of melt are present on the rims of larger craters: (1) the dominance of large exterior melt ponds over flows and hard-rock veneer at craters over $50 \mathrm{~km}$ in diameter $[6,8]$; (2) the tendency for melts to occur at greater distances from the parent craters as a function of crater size; (3) the observation that exterior melt ponds are larger and more widespread at larger craters; and (4) quantitative estimates of melt volumes, which indicate that relatively more melt is present on the rims of larger structures. Even so, this may not imply that a greater percentage of the total melt has been ejected since the total amount of melt generated was also relatively greater at larger structures [8].

Interior melt volumes as a function of crater diameter. There also appears to be a systematic variation in the amounts of molten material in crater interiors. Since the extent and thicknesses of the ponded material on crater floors tend to increase as a function of crater size, more melt may be present in the interiors of larger craters. Support is provided by quantitative estimates of interior melt volumes for specific craters where detailed topographic data exist [11,12]. A similar trend has been noted for the impact melt volumes associated with terrestrial impact structures [13,14].

Influence of substrate on melt generation. Numerous cratering studies have demonstrated the importance of target characteristics in determining the morphology of lunar craters $[e . g ., 15,16]$. Therefore, we made an attempt to determine the influence of substrate on the relative amounts of impact melt associated with craters in highland vs. mare terrains. A comparison of the mapped interior melt deposits in similar-sized craters $(D<50 \mathrm{~km})$ suggests that highland craters contain melts in amounts either equal to or less than the amounts present in mare craters. This observation does not necessarily indicate that more melt was generated by impact into mare targets. The observation could be explained by one or more of the following: (1) for a given impact energy, larger craters may be formed in the highlands relative to the mare; (2) the style and degree of wall failure is known to be dependent on terrain, topography, and substrate [15]; and (3) a limited amount of evidence suggests that more melt was ejected from highland craters.

References: [1] Simonds C. et al. (1976) Am. Mineral., 61, 569. [2] Simonds C. et al. (1977) Proc. LSC 8th, 1869. [3] Taylor S. R. (1982) Planetary Science: A Lunar Perspective, 481 pp. [4] Spudis P. et al. (1991) Proc. LPSC, Vol. 21, 151. [5] Howard K. and Wilshire H. (1975) J. Res. US. Geol. Survey, 3, 237. [6] Hawke B. and Head J.(1977) Impact and Explosion Cratering, 815. [7] Hawke B. and Head J. (1977) LSC VIII, 415. [8] Hawke B. and Head J. (1979) LPSC X, 510. [9] Wood C. and Andersson L. (1978) Proc. LPSC 9th, 3669. [10] Pike R. (1977) Impact and Explosion Cratering, 489. [11] Lange M. and Hawke B. (1979) Conf. Lunar Highlands Crust, 99. [12] Lange M. and Hawke B. (1980) Proc. LPSC 10th, 599. [13] Dence M. et al. (1977) Impact and Explosion Cratering. 247. [14] Grieve R. et al. (1977) Impact and Explosion Cratering. 791. [15] Cintala M. et al. (1977) Proc. LSC 8th, 3409. [16] Head J. (1976) Proc. LSC 7th, 2913.

\section{LARGE IMPACTSIN THE BALTIC SHIELDWITH SPECIAL} ATTENTION TO THE UPPLAND STRUCTURE. H. Henkel and R. Lilljequist, Institute for Fotogrammetry, KTH, S-10044 Stockholm and Department of Geology, University of Stockholm, S-106 91, Stockholm, Sweden.

Within the Baltic Shield several very large structures have been identified and are suspected to be of meteorite impact origin (Fig. 1 and Table 1). Some of these deeply eroded circular features will be 


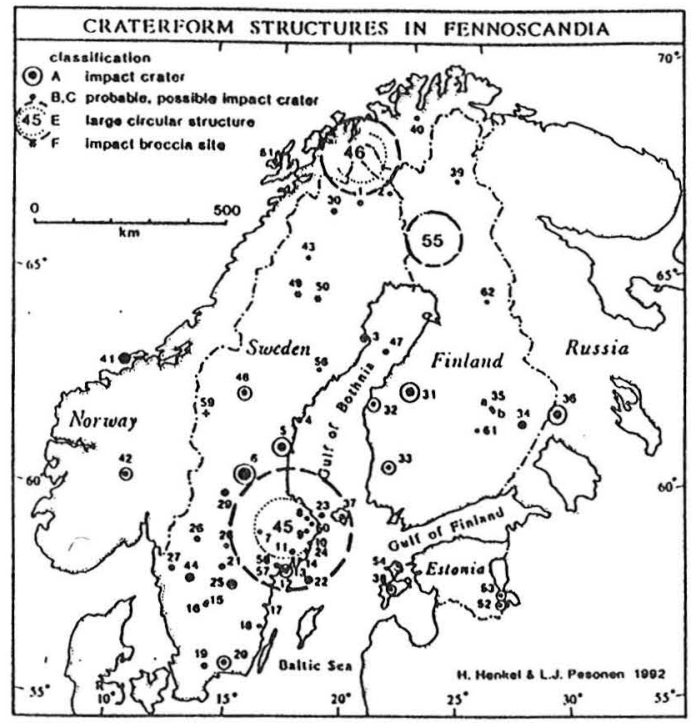

Fig. 1. Craterform structures in Fennoscandia. Numbers 45, 46, and 55 are large suspected impact structures.

TABLE 1. Location and indication features of large circular structures in Fennoscandia (compare Fig. 1).

\begin{tabular}{lllllcc}
\hline No & Name & Lat/N & Lat/E & Indication & Diameter & Age \\
\hline 45 & Uppland & 60.0 & 17.0 & Top., Grav. & 320 & Proterozoic \\
46 & Nunjes & 69.2 & 20.5 & Grav, Magn. & 200 & Proterozoic \\
55 & Marras & 66.9 & 25.2 & Top., Grav., Magn & 160 & Proterozoic \\
\hline
\end{tabular}

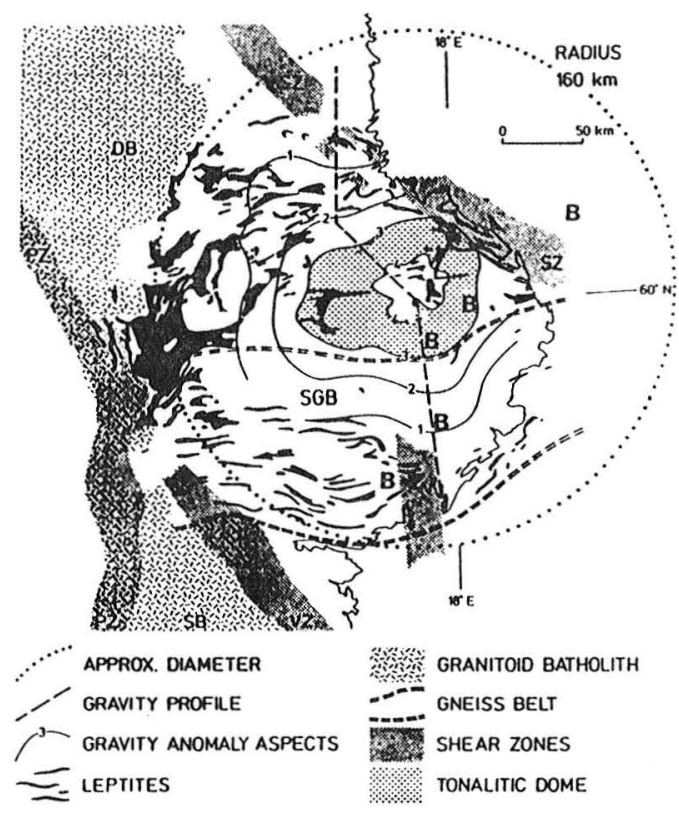

Fig. 2. Uppland structure. SGB = Sormland Gneiss Belt; SZ = Singö Shear Zone; $\mathrm{PZ}$ = Protogin Zone; VZ = Västerås Shear Zone; DB = Dala Batholiths; SB = Småland Batholiths; $\mathrm{B}=$ breccia dyke occurrences.

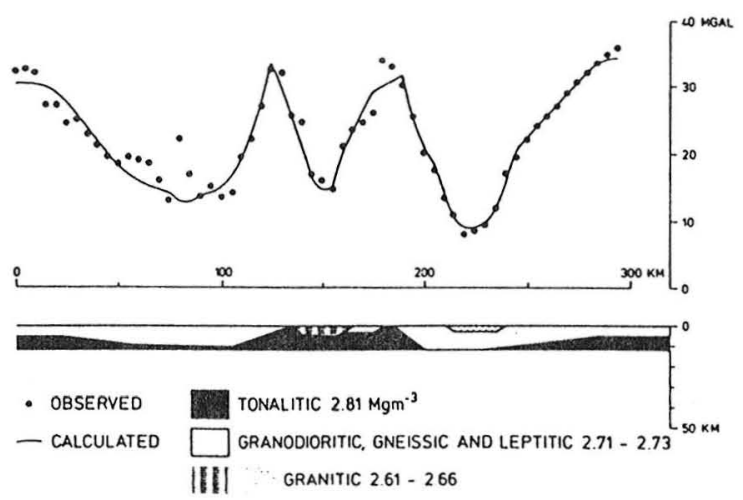

Fig. 3. Gravity profile of the Uppland structure.

presented with special attention to the Uppland structure, where several indications point toward an impact origin in the midProterozoic. The structures exceed $100 \mathrm{~km}$ in diameter and the topographic expression is inferior or absent. An arcuate arrangement of lithologies occurs around the margin of the structures and the central regions show conform magnetic and positive gravity anomalies.

The Uppland structure (Fig. 2) is approximately $320 \mathrm{~km}$ in diameter as expressed by morphological, geological, and geophysical concentric patterns. The central part is topographically remarkably flat and is characterized by an unusual irregular fracture pattern. A subcircular central tonalite with density of $2.81 \mathrm{Mg}^{-3}$ gives a positive gravity anomaly of $35 \mathrm{mgal}$ and the gravimetric profile is very similar to that of Manicouagan and Vredefort. The tonalite constitutes a huge antiform, $80 \mathrm{~km}$ in diameter, probably representing a 12-km structural uplift of infracrustal rocks (Fig. 3). The flancs of the tonalite are characterized by recrystallized pseudotachylitic breccia dykes and breccia zones. Around the central parts amphibolite-grade metamorphic rocks appear as large fragments within a fine-grained granite interpreted as a thermally annealed melt rock. Several occurrences of breccia dykes and breccia-bearing melts have been identified about $100 \mathrm{~km}$ from the gravimetric center of the structure. Outside the melt ring, downslided and eroded crater wall rocks of high metamorphic grade (garnetbearing gneisses and migmatites) occupy most of the terrain. The northwestern quadrant has later been downfaulted and preserves less metamorphic rocks of mainly sedimentary origin and a large quantity of iron deposits and $\mathrm{Zn}$-bearing sulphide mineralizations within huge hydrothermal fields. The northeastern quadrant is affected by a broad shear zone (the Singö Zone) and Rapakivi-type intrusives. The southem sector is overprinted by an east-west striking shear zone (the Sormland Gneiss Zone).

Impact-related ore deposits are located around the margin of the structure and are interpreted as preexisting downfaulted iron formations, and deposits formed from remobilization of these preimpact occurrences. The so-called ball ores are interpreted to have formed by fluid injection similar to the formation of breccia dykes. The extensive hydrothermal alteration along the outer margin of the structure have created extreme soda and K-enriched rocks ("leptites") from preexisting gneiss granites and supracrustal sedimentary gneisses. As an example, magnetite-skarn deposits are formed within gneiss granites in hydrothermal cells created during the postimpact phase. 
The other two suspected large impact structures (Fig. 1) have central gravity highs and conformally arranged occurrences of metasupracrustal rocks (greenstones) along parts of their periphery, here interpreted as parts of a subsided ring basin. No candidate for a melt rock has so far been identified in those structures.

THE PANTHER MOUNTAIN CIRCULAR STRUCTURE, A POSSIBLEBURIEDMETEORITECRATER. Y.W.Isachsen', S. F. Wright ${ }^{2}$, F. A. Revetta ${ }^{3}$, and R. J. Dineen ${ }^{4}$, ${ }^{1}$ New York State Geological Survey, ${ }^{2}$ University of Vermont, ${ }^{3}$ SUNY College at Potsdam, ${ }^{1}$ Roy F. Weston Company.

Panther Mountain, located near Phoenicia, New York, is part of the Catskill Mountains, which form the eastern end of the Allegheny Plateau in New York. It is a circular mass defined physiographically by an anomalous circular drainage pattern produced by Esopus Creek and its tributary Woodland Creek. The mountain is $10 \mathrm{~km}$ in diameter and has a maximum relief of $860 \mathrm{~m}$. It is well displayed on Landsat images and aerial photographs. Pervasive fluvial crossbedding made it impossible to determine whether the structure is slightly domical, slightly basinal, or unw arped. The circular valley that rings the mountain is fracture-controlled; where bedrock is exposed, it shows a joint density 5 to 10 times greater than that on either side of the valley. Where obscured by alluvial valley fill, the bedrock's low seismic velocity suggests that this anomalous fracturing is continuous in the bedrock underlying the rim valley.

North-south and east-west gravity and magnetic profiles were made across the structure. Terrane-corrected, residual gravity profiles show an 18-mgal negative anomaly, and very steep gradients indicate a near-surface source. Several possible explanations of the gravity data were modeled. Only one of the computed profiles matched the measured values, namely that of a shallowly buried meteorite crater with a diameter of $10 \mathrm{~km}$ and a breccia lens 3 to $4 \mathrm{~km}$ deep, which would pass through the entire Paleozoic section and perhaps into the crystalline basement. The closely spaced joints in the rim valley are interpreted as the result of differential compaction over the inferred crater rim, leading to bending and dense fracturing of the bedrock. The magnetic profiles show only small variations in intensity over the Panther Mountain area. This is not surprising in view of the significant depth to basement rocks $(\sim 3 \mathrm{~km})$ and the low content of ferromagnetic minerals in the overlying Paleozoic section. Regional fracture-controlled linear valleys north and south of Panther Mountain terminate at the rim valley. This is consistent with the inferred breccia lens beneath the structure, which would absorb rather than transmit stresses propagated upward from the basement.

We conclude that the Panther Mountain circular structure is probably a buried meteorite crater that formed contemporaneously with marine or fluvial sedimentation during Silurian or Devonian time. An examination of drill core and cuttings in the region is now underway to search for ejecta deposits and possible seismic and tsunami effects in the sedimentary section. Success would result in both dating the impact and furnishing a chronostratigraphic marker horizon.
GEOMECHANICAL MODELS OF MMPACT CRATERING: PUCHEZH-KATUNKI STRUCTURE. B. A. Ivanov, Institute for Dynamics of Geospheres, Russian Academy of Science, Leninsky Prospect, 38, corp.6, Moscow 117979, Russia.

Impact cratering is a complex natural phenomenon that involves various physical and mechanical processes [1]. Simulating these processes may be improved using the data obtained during the deep drilling at the central mound of the Puchezh-Katunki impact structure [2].

A research deep drillhole (named Vorotilovskaya) has been drilled in the Puchezh-Katunki impact structure (European Russia, $57^{\circ} 06{ }^{\prime} \mathrm{N}, 43^{\circ} 35^{\prime} \mathrm{E}$ ). The age of the structure is estimated at about 180 to $200 \mathrm{~m} . y$. [1]. The initial rim crater diameter is estimated at about $40 \mathrm{~km}$. The central uplift is composed of large blocks of crystalline basement rocks. Preliminary study of the core shows that crystalline rocks are shock metamorphosed by shock pressures from $45 \mathrm{GPa}$ near the surface to $15-20 \mathrm{GPa}$ at a depth of about $5 \mathrm{~km}$ [2]. The drill core allows the possibility of investigating many previously poorly studied cratering processes in the central part of the impact structure.

As a first step one can use the estimates of energy for the homogeneous rock target. The diameter of the crater rim may be estimated as $40 \mathrm{~km}$. The models elaborated carlier [cf. 3] show that such a crater may be formed after collapse of a transient cavity with a radius of $10 \mathrm{~km}$. The most probable range of impact velocities from 11.2 to $30 \mathrm{~km} / \mathrm{s}$ may be inferred for the asteroidal impactor. For the density of a projectile of $2 \mathrm{~g} / \mathrm{cm}^{3}$ the energy of impact is estimated as $1 \mathrm{E} 28$ to $3 \mathrm{E} 28 \mathrm{erg}$ (or about 500,000 Mton TNT).

In the case of vertical impact, the diameter of an asteroidal projectile is from 1.5 to $3 \mathrm{~km}$ for the velocity range from 11 to $30 \mathrm{~km} / \mathrm{s}$. For the most probable impact angle of $45^{\circ}$, the estimated diameter of an asteroid is slightly larger: from 2 to $4 \mathrm{~km}$.

For the homogeneous rock target one may expect $40 \mathrm{cubic} \mathrm{km}$ of impact melt. The depth of such a melt zone is about $3 \mathrm{~km}$, so twothirds of the probable depth of a melt zone seems to be situated in the limit of the sedimentary layer. Shock heating of the watersaturated sedimentary rocks typically does not produce a continuous melt sheet. We need to recalculate the shock attenuation for the specific geology of the Puchezh-Katunki structure to estimate the possible melting in the basement rocks.

One of the most interesting problems relates to the rock deformation history during complex crater formation. In the case of the Puchezh-Katunki structure one can use the level of shock metamotphism of target rocks as a "label" that marks specific points of the target. For an estimated projectile energy, the pressure attenuation curve gives the initial length of a vertical column (of $3 \mathrm{~km}$ at the symmetry axis) bounded by the shock pressure $45 \mathrm{GPa}$ and $10 \mathrm{GPa}$ When the transient cavity reaches a maximum depth, the column seems to be shortened to approximately $1 \mathrm{~km}$.

Numerical simulation of the transient crater collapse has been done using several models of rock rheology during collapse. Results show that the column at the final position beneath the central mound is about $5 \mathrm{~km}$ in length. This value is close to the shock-pressure decay observed along the drill core. Further improvement of the model needs to take into account the blocky structure of target rocks revealed by drilling.

The model of collapse allows the estimation of the final position of variously shocked and heated target rocks and the construction of a thermal model of the subcrater space. The comparison of observed 
thermal metamorphic features with the thermal model may improve our knowledge of the geologic process connected with impact cratering.

References: [1] Melosh H. J. (1990) Impact Cratering: A Geological Process, 245 pp. [2] Pevzner L. A. et al. (1992) LPSC XXIII. [3] Ivanov B. A. (1988) LPSC XIX, 531-532.

THERMOBAROMETRIC STUDIES ON THE LEVACK GNEISSES-FOOTWALL ROCKS TO THE SUDBURY IGNEOUS COMPLEX. R. S. James', W. Peredery'2, and J. M. Sweeny', 'Geology Department, Laurentian University, Sudbury, Ontario P3E 2C6, Canada, 2 INCO E.T.S., Copper Cliff, Ontario POM 1NO, Canada, and ${ }^{3}$ Falconbridge Limited (Exploration), Falconbridge, Ontario POM 1SO, Canada.

Granulite and amphibolite facies gneisses and migmatites of the Levack Gneiss Complex occupy a zone up to $8 \mathrm{~km}$ wide around the northern part of the Sudbury Igneous Complex (SIC). Orthopyroxeneand gamet-bearing tonalitic and semipelitic assemblages of granulite facies grade occur within $3 \mathrm{~km}$ of the SIC together with lenses of mafic and pyroxenitic rock compositions normally represented by an amphibole \pm cpx-rich assemblage; amphibolite facies assemblages dominate elsewhere in this terrain. These 2.711-Ga gneisses were intruded by (1) the Cartier Granite Batholith during late Archean to early Proterozoic time and (2) the SIC, at $1.85 \mathrm{Ga}$, which produced a contact aureole $1-1.5 \mathrm{~km}$ wide in which pyroxene hornfelses are common within $200-300 \mathrm{~m}$ of the contact.

A suite of 12 samples including both the opx-gt and amphibolerich rock compositions have been studied; typical mineral compositions are $\mathrm{OpxXmg}=0.55-0.60, \mathrm{GxXyr}=0.12-0.32, \mathrm{PlgAn}=$ 0.25-0.40 in the felsic and pelitic rocks; in the mafic gneisses Cpx has Xdi $=0.65-0.77$ and Al-Tsch $=0.036-0.043$ and amphibole compositions are Edenite with $(\mathrm{Na}+\mathrm{k})=0.52-0.77$ and $\mathrm{Si}(\mathrm{iv})=$ 6.4-6.9. Garnets in the semipelitic gneisses are variably replaced by a plg-bio assemblage. Thermobarometric calculations using a variety of barometers and thermometers reported in the literature suggest that the granulite facies assemblages formed at depths in the 21-28-km range (6-8 kbar). Textures and mineral chemistry in the garnet-bearing semipelitic rocks indicate that this terrain underwent a second metamorphic event during uplift to depths in the $5-11-\mathrm{km}$ range (2-3 kbar) and at temperatures as low as $500^{\circ}-550^{\circ} \mathrm{C}$. This latter event is distinct from thermal recrystallization caused by the emplacement of the SIC; it probably represents metamorphism attributable to intrusion of the Cartier Granite Batholith. These data allow two interpretations for the crustal uplift of the Levack Gneisses: (1) The gneisses were tectonically uplifted prior to the Sudbury Event (due to intrusion of the Cartier Batholith); or (2) the gneisses were raised to epizonal levels as a result of meteorite impact at $1.85 \mathrm{Ga}$.

THE CRETACEOUS-TERTIARY (K/T) IMPACT: ONE OR MORE SOURCE CRATERS? Christian Koeberl, Institute of Geochemistry, University of Vienna, Dr.-Karl-Lueger-Ring 1, A1010 Vienna, Austria.

The Cretaceous-Tertiary $(K / T)$ boundary is marked by signs of a worldwide catastrophe, marking the demise of more than $50 \%$ of all living species. Ever since Alvarez et al. [1] found an enrichment of Ir and other siderophile elements in rocks marking the $\mathrm{K} / \mathrm{T}$ boundary and interpreted it as the mark of a giant asteroid (or comet) impact, scientists have tried to understand the complexities of the K/T boundary event. The impact theory received a critical boost by the discovery of shocked minerals that have so far been found only in association with impact craters [2]. One of the problems of the $\mathrm{K} / \mathrm{T}$ impact theory was, and still is, the lack of an adequate large crater that is close to the maximum abundance of shocked grains in $\mathrm{K} / \mathrm{T}$ boundary sections, which was found to occur in sections in Northem America. The recent discovery of impact glasses from a $\mathrm{K} / \mathrm{T}$ section in Haiti $[3,4]$ has been crucial in establishing a connection with documented impact processes. The location of the impactglass findings and the continental nature of detritus found in all $\mathrm{K} / \mathrm{T}$ sections supports at least one impact site on or near the North American continent.

The Manson Impact Structure is the largest recognized in the United States, $35 \mathrm{~km}$ in diameter, and has a radiometric age indistinguishable from that of the Cretaceous-Tertiary (K/T) boundary [5]. Although the Manson structure may be too small, it may be considered at least one element of the events that led to the catastrophic loss of life and extinction of many species at that time. The Manson crater is completely covered by Quatemary glacial sedimentary deposits that are underlain by flat-lying carbonate sediments of Phanerozoic age as well as Proterozoic red clastic, metamorphic, volcanic, and plutonic rock sequences. In the $35-\mathrm{km}$ diameter zone that marks the extension of the crater the normal rock sequence is disturbed due to the impact, and at the center of the structure granitic basement rocks are present that have been uplifted from about $4 \mathrm{~km}$ depth. The Manson structure was established as an impact crater on the basis of its geomorphology (circular shape, central uplift), the presence of shock metamorphic features in minerals (e.g., multiple sets of planar lamellae in quartz), Bouguer gravity data, aeromagnetic and ground magnetic data, as well as seismic surveys [6].

Detailed studies of the geochemistry of Manson target rocks (approximated by the drill core samples of the Eischeid\#1 well,near the crater) and impact melt rocks and breccia samples [7] have shown that it is possible to reproduce the chemistry of the melt rocks and breccias by mixing various basement rocks. The elemental abundances in the black glasses found at the Haiti $\mathrm{K} / \mathrm{T}$ boundary section are not incompatible with the ranges observed for target rocks and some impact glasses found at the Manson crater [7]. Most elemental abundances measured in the black glasses are within the range for the Manson rocks, and elemental ratios such as Th/U and $\mathrm{La} / \mathrm{Th}$ are also compatible. The Rb-Sr and $\mathrm{Sm}-\mathrm{Nd}$ isotopic signatures of the black glass are compatible with a continental crustal source [3]. In principle, this would apply for Manson rocks, but no definite conclusion can be made as the isotopic characteristics of the Manson rocks are not yet known. The yellow glasses, on the other hand, may require a different source material, as no rocks with such high St or S content have been observed in sufficient quantities in the Manson target rock stratigraphy. However, the target rock stratigraphy at Eischeid indicates abundant carbonates. I suggest that a more definitive answer can be obtained in the near future, when the samples from the newly drilled cores at the Manson structure are analyzed in more detail. These cores are just now becoming available for studies.

A second candidate for the $\mathrm{K} / \mathrm{T}$ boundary crater is the Chicxulub structure, which was first suggested to be an impact crater more than a decade ago. Only recently, geophysical studies and petrological 
(as well as limited chemical) analyses have indicated that this buried structure may in fact be of impact origin [8]. The impact origin was recently confirmed by the discovery of unambiguous evidence for shock metamorphism, e.8., shocked quartz and feldspar [9]. The stratigraphy of the crater and the exact succession and age of rocks are not entirely clear at this time, largely because the structure is now buried under about $1 \mathrm{~km}$ of Tertiary sediments, mainly limestone, and because of limited sample availability due to the destruction of core samples in a fire. The sedimentary sequence (composed mainly of carbonates and evaporites) overlies a basement at $3-6 \mathrm{~km}$ depth that is inferred to be composed of metamorphic rocks. If Chicxulub w as formed by impact at a time at or before the end of the Cretaceous, the preimpact surface consisted largely of rocks for the carbonate-evaporite sedimentary sequence, probably releasing large quantities of $\mathrm{CO}_{2}$ and $\mathrm{SO}_{2}$ into the atmosphere.

Chicxulub contains abundant carbonate, limestone, and evaporite rocks, and the presence of andesitic rocks has been reported (which would make it a candidate for the source of the Haiti glasses), although it is not clear if the "andesite" is a real andesitic bedrock, or makes up the proposed melt sheet. There are some problems with Chicxulub being the source for the Haiti impact glasses (and therefore for parts of the claystones at some $\mathrm{K} / \mathrm{T}$ boundaries). For this discussion, we need to review the origin of tektites and impact glasses. Rb-Sr and Sm-Nd isotopic systematics of tektites show that the source material was Precambrian crustal terrane (from Nd model ages), and that the sediments that were later melted to form tektites were weathered and deposited at (for the Australasian tektites, for example) about $167 \mathrm{Ma}$ ago and probably comprised Jurassic sediments. Further evidence for a sedimentary precursor comes from the study of cosmogenic radionuclides. Pal et al. [10] first reported that the ${ }^{10} \mathrm{Be}$ content of Australasian tektites cannot have originated from direct cosmic ray irradiation in space or on Earth, but can only have been introduced from sediments that have absorbed ${ }^{10} \mathrm{Be}$ that was produced in the terrestrial atmosphere. This is an extremely important observation. The recent discovery of Glass and Wu [11], that impact debris is present in the same deep sea core layers as microtektites, gives further proof of an impact event leading to the production of tektites.

For Chicxulub, a major problem is the production of impact glasses (or "tektite-like" glasses), which originate, as I have just mentioned, from the surface layers of the target area. However, any "andesitic" rock or other basement rocks at Chicxulub were obviously covered by carbonates and evaporites of up to several kilometers thickness. We therefore cannot conclude, at least not with the data presently available, that Chicxulub is the most logical source for the Haiti glasses. Although the "andesite" present at Chicxulub is similar in composition to the black glasses [8], other rocks that will be mixed in upon impact have trace-element signatures that are not compatible with any glass composition. Another problem is the obvious lack of quartz-bearing rocks at Chicxulub, which poses problems for the explanation of the abundance of shocked quartz at almost all $\mathrm{K} / \mathrm{T}$ boundaries. This has led some researchers [e.g., 12] to propose that two impacts, involving Chicxulub and Manson, might be responsible for the $\mathrm{K} / \mathrm{T}$ event. In view of the preliminary nature of some data we refrain from speculating on such an origin. Other proposed impact locations, such as near Kara Crater, which was suggested by Russian scientists to be of $\mathrm{K} / \mathrm{T}$ age, have not been confirmed. Precise Ar-Ar ages of Kara show that it is most probably too old to be associated with the $K / T$ boundary, and it is also situated on the wrong side of the Earth, as it was inferred (see above) that the impact crater(s) are most likely near the North American continent.
At present we can conclude that the Manson crater is the only confirmed crater of $\mathrm{K} / \mathrm{T}$ age, but Chicxulub is becoming a strong contender; however, detailed geochemical, geochronological, and isotopic data are necessary to provide definitive evidence.

Acknowledgments: I thank J. Hartung, R. R. Anderson, and V. L. Sharpton for Manson and Chicxulub samples and valuable discussions. Work supported by Austrian "Fonds zur Forderung der wissenschaftlichen Forschung," Project P8794-GEO.

References: [1] Alvarez L. W. et al. (1980) Science, 208, 1095-1108. [2] Bohor B. F. et al. (1984) Science, 224, 867-869. [3] Sigurdsson H. (1991) Nature, 353, 839-842. [4] Koeberl C. and Sigurdsson H. (1992) GCA, S6, in press. [5] Kunk M. J. et al. (1989) Science, 244, 1565-1568. [6] Hartung J. B. and Anderson R. R. (1988) LPI Tech. Rept. 88-08, Lunar and Planetary Institute, Houston, 32 pp. [7] Koeberl C. and Hartung J. B. (1992) Proc. LPS, Vol. 22, 111-126. [8] Hildebrand A. et al. (1991) Geology, 19. 867-871. [9] Marin L. E. (1992) Science, submitted. [10] Pal D.K. (1982) Science, 218, 787-789. [11] Glass B. P. and Wu J. (1992) LPSC XXIII, 415-416. [12] Izett G. A. (1991) Eos, 72, 279.

TEKTITE ORIGIN BY HYPERVELOCITY ASTEROIDAL OR COMETARY MMACT: THEQUEST FOR THE SOURCE CRATERS. Christian Koeberl, Institute of Geochemistry, University of Vienna, Dr.-Karl-Lueger-Ring 1, A-1010 Vienna, Austria.

Impact Origin of Tektites: Tektites are natural glasses that are chemically homogeneous, often spherically symmetrical objects several centimeters in size, and occur in four known strewn fields on the surface of the Earth: the North American, moldavite (or Central European), Ivory Coast, and Australasian strewn fields. Tektites found within such strewn fields are related to each other with respect to their petrological, physical, and chemical properties as well as their age. A theory of tektite origin needs to explain the similarity of tektites in respect to age and certain aspects of isotopic and chemical composition within one strewn field, as well as the variety of tektite materials present in each strewn field.

In addition to tektites on land, microtektites (which are generally less than $1 \mathrm{~mm}$ in diameter) have been found in deep-sea cores. Tektites are classified into three groups: (1) normal or splash-form tektites, (2) aerodynamically shaped tektites, and (3) Muong Nongtype tektites (sometimes also called layered tektites). The aerodynamic ablation results from partial remelting of glass during atmospheric passage after it was ejected outside the terrestrial atmosphere and quenched from a hot liquid. Aerodynamically shaped tektites are known mainly from the Australasian strewn field where they occur as flanged-button australites. The shapes of splash-form tektites (spheres, droplets, teardrops, dumbbells, etc., or fragments thereof) are the result of the solidification of rotating liquids in the air or vacuum.

Mainly due to chemical studies, it is now commonly accepted that tektites are the product of melting and quenching of terrestrial rocks during hypervelocity impact on the Earth. The chemistry of tektites is in many respects identical to the composition of upper crustal material [1,2]. Trace elements are very useful for source rock comparisons: the ratios of, e.g., Ba/Rb, K/U, Th/Sm, Sm/Sc, Th/Sc, $\mathrm{K}$ vs. $\mathrm{K} / \mathrm{U}$ in tektites are indistinguishable from upper crustal rocks. The chondrite-normalized REE patterns of tektites are very similar to shales or loess, and have the characteristic shape and total 
abundances of the post-Archean upper crust. The determination of the exact source rocks of tektites is complicated because a variety of inhomogeneous target rocks were sampled by the impact. Muong Nong-type tektites are similar to impact glasses and because of their size and shape it is assumed that they have not traveled far from their location of origin, and may therefore provide information about the crater location.

The discovery of the tektite locations at Barbados and DSDP Site 612 in the North American strewn field is important because microtektites and tektites (tektite fragments) as well as shocked minerals are found in the same layer. A very important observation has recently been made by Glass and Wu [3], who showed that several microtektite-bearing layers in cores from the Australasian and North American strewn field contain shocked minerals (quartz and feldspar), vesicular impact glass, coesite, and possibly even stishovite. This discovery provides an immediate link of tektites with an impact event.

Shaw and Wasserburg [4] have shown that the crustal material that weathered to form the parent sediments for the Australasian tektites have $\mathrm{Nd}$ model ages of about $1.15 \mathrm{Ga}$, and that $\mathrm{Rb}$-Sr data point to a final sedimentation of their parent material around $250 \mathrm{Ma}$ ago. Recently, Blum et al. [5] have studied the Rb-Sr and Sm-Nd isotopic systematic of Muong Nong-type and splash-form tektites. and found that the source material was Precambrian crustal terrane (from Nd model ages), and that the sediments that were later melted to form tektites were weathered and deposited about $167 \mathrm{Ma}$ ago and probably comprised Jurassic sediments, which are not uncommon throughout Indochina. Further evidence for a sedimentary precursor comes from the study of cosmogenic radionuclides. Pal et al. [6] first reported that the ${ }^{10} \mathrm{Be}$ content of Australasian tektites cannot have originated from direct cosmic ray irradiation in space or on Earth, but can only have been introduced from sediments that have absorbed ${ }^{10} \mathrm{Be}$ that was produced in the terrestrial atmosphere.

Where are the Source Craters? During the past half-century, numerous suggestions and educated guesses have been made regarding the location of the possible source craters for the tektite strewn fields. Relatively reliable links between a crater and the respective tektite strewn field have been established between the Bosumtwi (Ghana) and the Ries (Germany) Craters and the Ivory Coast and the Central European (moldavite) fields, respectively. However, no large crater of the required ages are known for the Australasian and North American strewn fields. For the Australasian field, many proposals for possible craters were made and later discounted (including source craters in Antarctica, or the Elgygytgyn or Zhamanshin Craters).

Wasson [7] suggests that the tektites in the Australasian field may have originated in a multitude of small craters scattered over all of Indochina. There are numerous objections, including (1) small craters produce small to negligible quantities of relatively inhomogeneous impact glasses, as is well known from many impact craters; (2) small impact events are unable to provide the energy to launch the (associated) splash-form and aerodynamically shaped tektites; (3) the isotopic data do not seem to be in agreement with the multitude of different source rocks that are required by a multiple impact theory; (4) the crater problem has been multiplied-instead of one missing crater, there is a multitude of missing craters. In agreement with most other studies I therefore prefer a single large impact crater.
Stauffer [8] analyzed the distribution of Australasian tektites and microtektites and found that they do not show a homogeneous distribution. There are radial and concentric patterns and zones that do not contain microtektite-bearing deep sea cores. Stauffer suggested a crater that may be concealed beneath alluvial deposits of the lower Mekong Valley area. A similar analysis was done by Koeberl [9] for the North American strewn field, where I suggested that tektites show a raylike distribution, not unlike lunar crater ejecta. A possible off-shore impact location (about $175 \mathrm{~km}$ to the east of the Vietnam seashore) was suggested by Schnetzler et al. [10] from satellite gravity data. Underwater craters must exist on Earth but, with one exception, have not yet been found. Hartung [11] proposed that the lake Tonle Sap (100 km long and up to $35 \mathrm{~km}$ wide) in Cambodia is the result of the Australasian tektite source crater. The dimensions are probably minimum values as the structure is almost completely filled with alluvium. Tonle Sap would be in agreement with chemical and isotopic data for tektites, but more detailed studies are necessary. The new discovery [3] of impact debris (shocked minerals) in deep-sea cores near the Indochina coast, as well as the fact that the quantity of both impact debris and microtektites in the cores increases toward Indochina, is in support of a crater in this area. Similarly, Koeberl [9] suggested that the North American tektite source crater is in the area of eastern coast of the North American continent, maybe underwater. This was also supported by the findings of Glass and Wu [3].

The exact mechanism of tektite production during the impact is still not known in detail, but obviously the production of tektites requires special conditions because otherwise more than just four tektite strewn fields would be associated with the known impact craters. Oblique impact seems a possibility because of the asymmetric distribution of tektites within a strewn field. Furthermore, in the two cases where craters are known to be associated with tektite fields, the craters are never in the center of the strewn field. Jetting might contribute to impact melts, but it seems that material originating from jetting may be composed predominantly of projectile material, and projectile signatures in tektites are not well pronounced, excluding a major projectile component. An initial melting phase during the compression stage, before the formation of the crater in the excavation stage, is most likely responsible for the tektite production. Tektites have to originate from target rock layers close to the surface because otherwise it is not possible to explain their ${ }^{10} \mathrm{Be}$ content. The expanding vapor plume after the impact may be important in distributing the tektite material (which is on the order of $10^{9} \mathrm{t}$ for the two larger strewn fields).

References: [1]TaylorS.R.(1973)EarthSci.Rev.,9, 101-123. [2] Koeberl C. (1986) Annu. Rev. Earth Planet Sci., 14, 323-350. [3] Glass B. P. and Wu J. (1992) LPSC XXIII, 415-416. [4] Shaw H. F. and Wasserburg G. J. (1982) Earth Planet. Sci. Lett., 60 , 155-177. [5] Blum J. D. et al. (1992) GCA, 56, 483-492. [6] Pal D. K. et al. (1982) Science, 218, 787-789. [7] Wasson J. T. (1991) EPSL, 102, 95-109. [8] Stauffer P. H. (1978) 3rd Regional Conf. on Geology and Mineral Resources of Sourheast Asia, Bangkok, 285-289. [9] Koeberl C. (1989) Proc. LPSC 19th, 745-751. [10] Schnetzler C. C. (1988) GLR, 15, 357-360. [11] Hartung J. B. (1990) Meteoritics, 25, 369-370. 
EARLY ARCHEAN SPHERULE BEDS OF POSSIBLE IMPACT ORIGIN FROM BARBERTON, SOUTH AFRICA: A DETAILED MINERALOGICAL AND GEOCHEMICAL STUDY. Christian Koeberl'1, Wolf Uwe Reimold2', and Rudolf H. Boer', 'Institute of Geochemistry, University of Vienna, Dr.-KarlLueger-Ring 1, A-1010 Vienna, Austria, 2Economic Geology Research Unit, University of the Witwatersrand, P.O. Wits, Johannesburg 2050, South Africa.

The Barberton Greenstone belt is a 3.5- to 3.2-Ga-old formation situated in the Swaziland Supergroup near Barberton, northeast Transvaal, South Africa. The belt includes a lower, predominantly volcanic sequence, and an upper sedimentary sequence (e.g., the Fig Tree Group). Within this upper sedimentary sequence, Lowe and Byerly [1] identified a series of different beds of spherules with diameters of around 0.5-2 mm. Lowe and Byerly [1] and Lowe et al. [2] have interpreted these spherules to be condensates of rock vapor produced by large meteorite impacts in the early Archean. This interesting hypothesis is based mainly on the structure of the spherules, which is reported to be similar to quench structures, and on the discovery of Ir anomalies of up to several hundred ppb in some of the spherule beds [2]. Although Lowe et al. [2] reported the abundances of the platinum group elements (PGEs) to be of roughly chondritic proportions, a more detailed study by Kyte et al. [3] showed that the PGEs are fractionated relative to the chondritic abundances. They interpreted this to be due to later hydrothermal alterations.

The study of impacts early in the history of the Earth is of great importance and interest; we feel that therefore a more detailed investigation of the Barberton spherule beds is warranted, especially because no detailed mineralogical study of the spherules (and of all secondary mineralizations such as abundant sulfide mineralization) and no detailed geochemical stratigraphy (including, e.g., the rare earth elements) is available so far. The host phase of the Ir (and PGE) anomaly is also unknown.

We have collected a series of samples from drill cores from the Mt. Morgan and Princeton sections near Barberton, as well as samples taken from underground exposures in the Sheba and Agnes mines. These samples seem much better preserved than the surface samples described by Lowe and Byerly [1] and Lowe et al. [2]. Over a scale of just under $30 \mathrm{~cm}$, several well-defined spherule beds are visible, interspaced with shales and/or layers of banded iron formation. Some spherules have clearly been deposited on top of a sedimentary unit because the shale layer shows indentions from the overlying spherules. Although fresher than the surface samples (e.g., spherule bed S-2), there is abundant evidence for extensive alteration, presumably by hydrothermal processes. In some sections of the cores sulfide mineralization is common.

For our mineralogical and petrographical studies we have prepared detailed thin sections of all core and underground samples (as well as some surface samples from the S-2 layer for comparison). For geochemical work, layers with thicknesses in the order of 1-5 mm were separated from selected core and underground samples. The chemical analyses are being performed using neutron activation analysis in order to obtain data for about 35 trace elements in each sample. Major elements are being determined by XRF and plasma spectrometry. To clarify the history of the sulfide mineralization, sulfur isotopic compositions are being determined. We hope to be able to identify the host phase of the platinum metal anomaly by separating spherules and matrix. At the time of the conference we will report on the first geochemical and mineralogical results and their bearing on the impact hypothesis.
Acknowledgment: We gratefully acknowledge the support from Eastem Transvaal Consolidated (Anglovaal Pty. Ltd.), particularly Mr. Mauritz van den Berq (Chief Geologist).

References: [1] Lowe D.R. and Byerly G. R. (1986) Geology, 14, 83-86. [2] Lowe D. R. (1989) Science, 245, 959-962. [3] Kyte F. T. et al. (1992) GCA, 56, in press.

U-Pb ISOTOPIC RESULTS FOR SINGLE SHOCKED AND POLYCRYSTALLINE ZIRCONS RECORD 550-65.5-Ma AGES FOR A K-T TARGET SITE AND 2700-1850-Mn AGES FOR THE SUDBURY IMPACT EVENT. T. E. Krogh' ${ }^{1}$, S. L. Kamo', and B. F. Bohor ${ }^{2}$, 'Jack Satterly Geochronology Department, Royal Ontario Museum, 100 Queen's Park, Toronto, Ontario, M5S 2C6, Canada, 2U.S. Geological Survey, Box 26046, MS972, Denver CO 80225, USA.

The refractory mineral zircon develops distinct morphological features during shock metamorphism and retains these features under conditions that would anneal them in other minerals. In addition, weakly shocked zircon grains give primary ages for the impact site, while highly reconstituted (polycrystalline) single grains give ages that approach the age of the impact event. Data for a series of originally coeval grains will define a mixing line that gives both of these ages providing that no subsequent geological disturbances have overprinted the isotopic systematics. In this study, we have shown that the three zircon grain types described by Bohor (this session), from both K-T distal ejecta (Fireball layer, Raton Basin, Colorado) and the Onaping Formation, represent a progressive increase in impact-related morphological change that coincides with a progressive increase in isotopic resetting in zircons from the ejecta and basement rocks. Unshocked grains are least affected by isotopic resetting while polycrystalline grains are most affected.

$\mathrm{U}-\mathrm{Pb}$ isotopic results for 12 of 14 single zircon grains from the Fireball layer (Fig. 1) plot on or close to a line recording a primary age of $550 \pm 10 \mathrm{Ma}$ and a secondary age of $65.5 \pm 3 \mathrm{Ma}$. Data for the least and most shocked grains plot closest to the primary and secondary ages respectively. The two other grains each give ages between 300 and $350 \mathrm{Ma}$. This implies that the target ejecta was

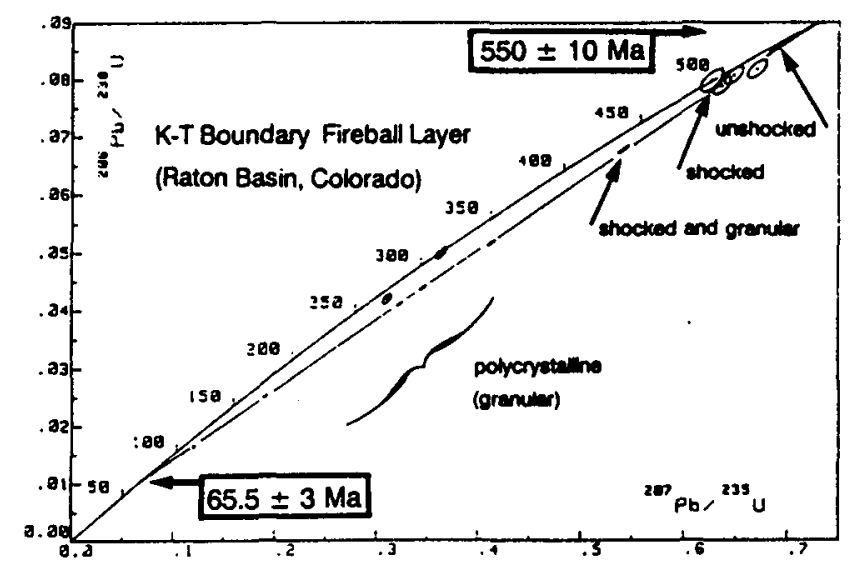

Fig. 1. U-Pb data for single zircons from the K-T boundary fireball Layer, Raton Basin, Colorado. 


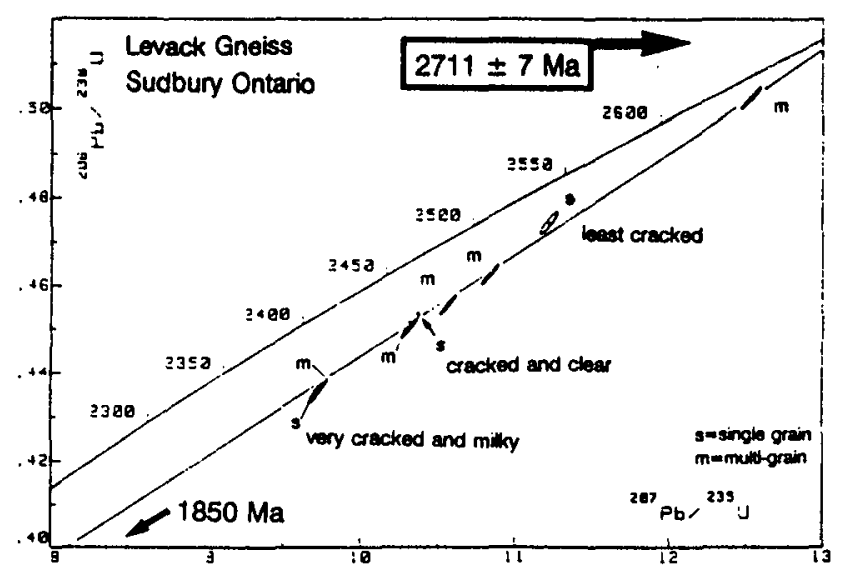

Fig. 2. U-Pb data for single zircons and multiple zircon fractions from the Levack gneiss, Sudbury, Ontario.

dominated by 550-Ma rocks and that the recrystallization features of the zircon were superimposed during the impact event at $65.5 \mathrm{Ma}$.

Data for four of the five polycrystalline grains are colinear (33\% probability of fit), with data displaced $49 \%, 58 \%, 62 \%$, and $82 \%$ from $559 \pm 5 \mathrm{Ma}$ toward the younger event and provide the best age estimate for the impact event $(65.5 \pm 3 \mathrm{Ma})$. Data for three colinear points (66\% probability of fit), which are represented by an unshocked, a shocked, and a shocked and granular grain, are displaced by only $3 \%, 12 \%$, and $26 \%$ respectively toward the younger event, thus providing the best estimate for a primary age of $544 \pm 5 \mathrm{Mr}$. Since there is no reason to assume that single unrelated grains should form colinear arrays within our small ( \pm 4 m.y.) uncertainty, this coincidence implies that these grains share the same primary and secondary ages. The two different upper intercept ages indicate that the most and least shocked grains may have come from different parts of the impact site. Considering a possible 180$\mathrm{km}$ impact site, ejecta from a local focused area may be inferred.

A predominant age of $550 \mathrm{Ma}$ for zircons from the Fireball layer provides an excellent opportunity to identify the impact site and to test the hypothesis that multiple impacts occurred at this time. A volcanic origin for the Fireball layer is ruled out by shock-related morphological changes in zircon and the fact that the least shocked grains are old.

Basement Levack gneisses north of the Sudbury structure have a primary age of $2711 \mathrm{Ma}$. Data for three single zircons from this rock (Fig. 2), which record a progressive increase in shock features, are displaced 24\%, 36\%, and 45\% along a Pb-loss line toward the $1850 \pm 1 \mathrm{Ma}$ minimum age for the impact as defined by the age of the norite. Southeast of the structure three shocked grains from the Murray granite record a primary age of $2468 \mathrm{Ma}$ and are displaced $24 \%, 41 \%$, and $56 \%$ tow ard the $1853 \pm 4 \mathrm{Ma}$ event as defined by coexisting titanite. The coincidence of titanite and norite ages, however, is consistent with near coeval impact and intrusion. The correlation of discordance with the intensity of shock-related features implies that the impact caused the observed discordance, but the precise age of impact is not evident from zircon data since some recent lead loss has occurred.

Data for five of six single unshocked zircons from a fluidal glass sample from the North Range Gray On aping Formation plot directly on the concordia curve and give ages of $2719 \mathrm{Ma}, 2708 \mathrm{Ma}$, $2696 \mathrm{Ma}, 2686 \mathrm{Ma}$, and $2678 \mathrm{Ma}$; the sixth data point is $2679 \mathrm{Ma}$
(2.2\% discordant). These ages reflect the age spectra of the nearby Archean basement. A volcanic origin at $1850 \mathrm{Ma}$ is impossible since the zircons would have to be $100 \%$ xenocrystic in origin and this has never been observed in volcanic rocks.

INFLUENCE OF THE PRESHOCK TEMPERATURE ON SHOCK EFFECTS IN QUARTZ. F. Langenhorst and A. Deutsch, Institut für Planetologic, Wilhelm-Klemm-Str. 10, D 4400 Muinster, Germany.

Shock metamorphic features are the prime indicators for recognizing impact phenomena on Earth and other planetary bodies $[1,2]$. In the past, many shock-loading experiments were performed at room temperature [3-5] in order to artificially reproduce shock effects occurring in nature. Results of such experiments have been extensively used as a database for shock wave barometry of impactmetamorphosed terrestrial and extraterrestrial rocks. Although the pressure dependence of shock features is well known, information about the influence of the preshock temperature is almost lacking (except [6-8]). Especially in the case of large-scale impacts like Sudbury, it is expected that deep-seated crustal rocks were subjected to shock at elevated temperatures.

Therefore, we continued to perform shock experiments at elevated temperatures on $<0.5-\mathrm{mm}$ thin disks of single crystal quartz cut parallel to the $\{1010\}$ face [8]. These specimens were shocked at pressures from 20 to $50 \mathrm{GPa}$ (precision $< \pm 3 \%$ ) and preshock temperatures of $20^{\circ} \mathrm{C}, 540^{\circ} \mathrm{C}$, and $630^{\circ} \mathrm{C} \pm 5^{\circ} \mathrm{C}$ using a previously described high-explosive device [9]. The preshock temperature of $630^{\circ} \mathrm{C}$ clearly exceeds $573^{\circ} \mathrm{C}$, the $\alpha / \beta$-transition temperature, whereas the preshock temperature of $540^{\circ} \mathrm{C}$ is just below the transition temperature. All recovered quartz samples were investigated by universal stage, spindle stage, and a newly developed density gradient technique. Errors of refractive index and density measurements are \pm 0.0005 and $\pm 0.002 \mathrm{~g} / \mathrm{cm}^{3}$ respectively.

Orientation of Planar Deformation Features (PDF) (Figs. 1a,b): The frequency distribution of PDF in quartz shocked at $20 \mathrm{GPa}$ and $540^{\circ} \mathrm{C}$ displays two maxima at $\{1013\}$ and $\{1011\}$, which are quite typical for this pressure as already known from naturally $[10,11]$ and experimentally [4] shocked quartz. In contrast, PDF in quartz shocked at $20 \mathrm{GPa}$ and $630^{\circ} \mathrm{C}$ show a broad distribution of crystallographic orientations with indistinct maxima that are difficult to index. In particular, the total absence of $\{1013\}$ orientations is most characteristic for this preshock temperature. This difference in orientation of PDF in quartz heated to $540^{\circ} \mathrm{C}$ and $630^{\circ} \mathrm{C}$ and both shocked to the same peak pressure may reflect the slight difference in the lattices of $\alpha$ and $\beta$ quartz.

Refractive Index Data (Fig. 2): Drastic differences of the optical parameters of quartz shocked at the three different preshock temperatures appear between $25 \mathrm{GPa}$ and $40 \mathrm{GPa}$. Refractive indices of quartz shocked at $540^{\circ} \mathrm{C}$ and $630^{\circ} \mathrm{C}$ decrease drastically and discontinuously in the pressure range from 25 to $26 \mathrm{GPa}$ and from 25 to $27.5 \mathrm{GPa}$ respectively, whereas refractive indices of cold shocked quartz change smoothly and continuously from 25 to $35 \mathrm{GPa}[12,13]$.

Density Data (Fig. 3): The densities determined with a socalled density gradient column confirm the results of the refractivity measurements. An abrupt decrease of densities for quartz shocked at $540^{\circ} \mathrm{C}$ and $630^{\circ} \mathrm{C}$ takes place between 25 and $26 \mathrm{GPa}$, whereas quartz shocked at room temperature shows the equivalent change in the pressure range from 25 to $>34 \mathrm{GPa}$. 


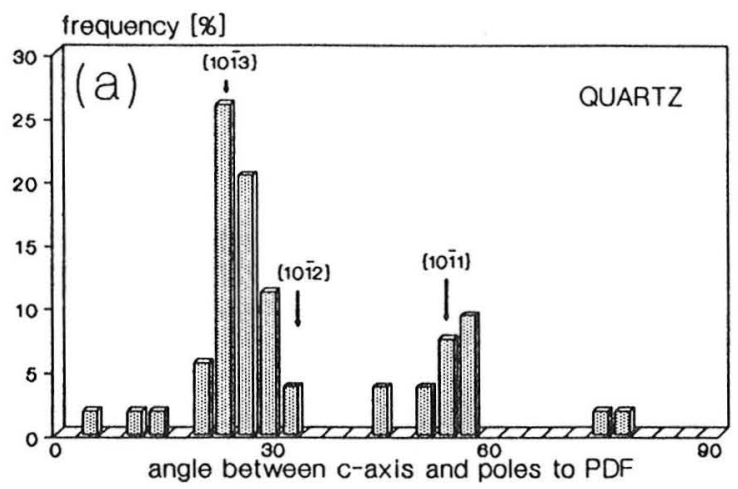

$20 \mathrm{GPa} / 540^{\circ} \mathrm{C}$

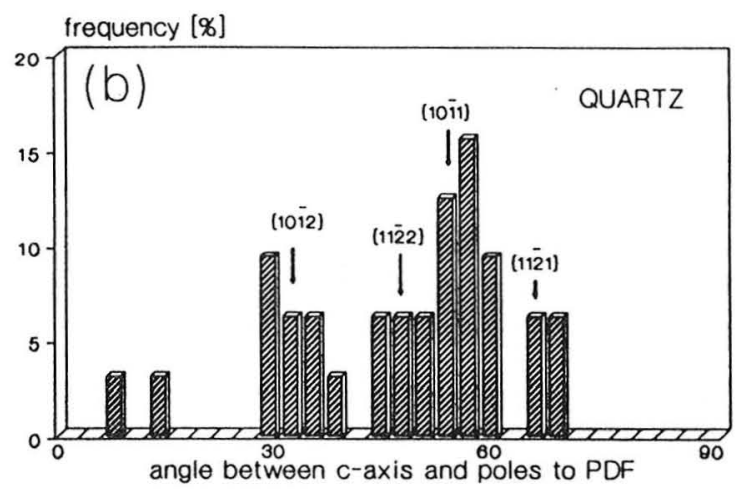

पIII $20 \mathrm{GP} / 630^{\circ} \mathrm{C}$

Fig. 1. Orientations of planar deformation features in quartz experimentally shocked at a pressure of $20 \mathrm{GPa}$ and at preshock temperatures of (a) $540^{\circ} \mathrm{C}$ and (b) $630^{\circ} \mathrm{C}$.

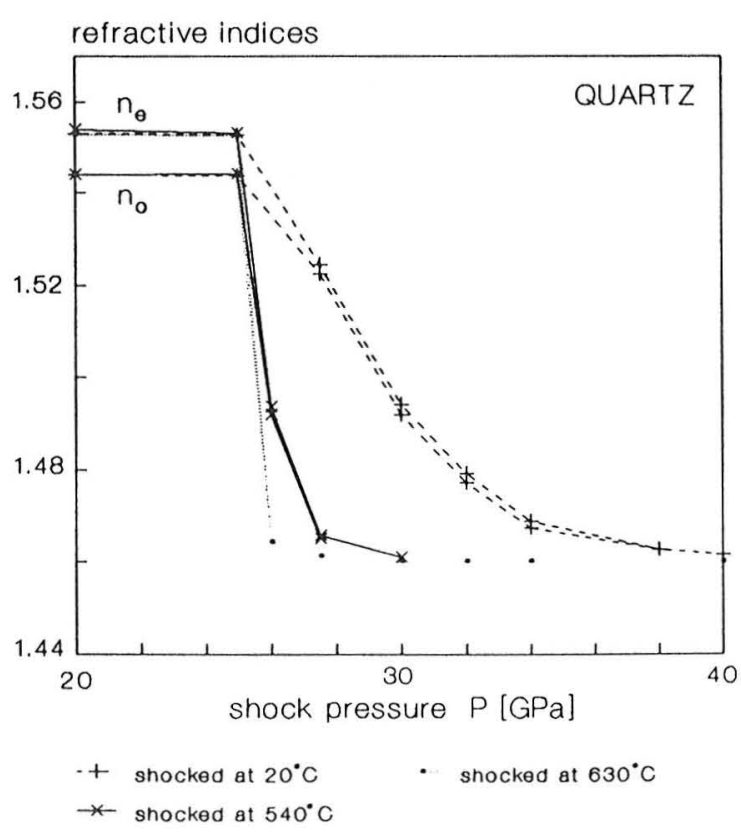

Fig. 2. Variation of refractive indices $n_{e}$ and $n_{0}$ as function of shock pressure for preshock temperatures of $20^{\circ} \mathrm{C}, 540^{\circ} \mathrm{C}$, and $630^{\circ} \mathrm{C}$.

Our investigations indicate that shock metamorphic features are strongly dependent on the preshock temperature. This statement has far-reaching implications with respect to shock wave barometry that is based on data from recovery experiments at room temperature. These datasets might be applicable only to low-temperature target rocks. Moreover, this study demonstrates that shock recovery experiments are definitely required for understanding the complete pressure-temperature regime of shock metamorphism on planetary bodies.

References: [1] Roddy et al., eds. (1977) Impact Explosion Cratering, Pergamon, New York. [2] Stöffler D. et al. (1991) GCA, 55, 3845-3867. [3] Stöffler D. (1972) Fortschr. Mineral., 49, 50113. [4] Hörz F. (1968) In Shock Metamorphism of Natural Mate-

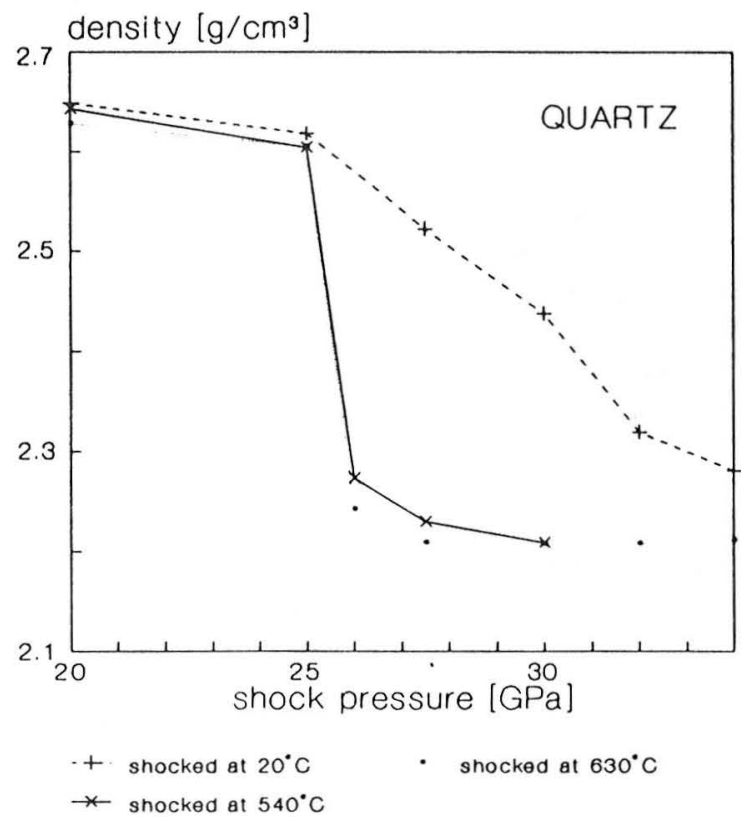

Fig. 3. Densities of quartz shocked at $20^{\circ} \mathrm{C}, 540^{\circ} \mathrm{C}$, and $630^{\circ} \mathrm{C}$ vs. shock pressure.

rials (B. M. French and N. M. Short, eds.), 243-253, Mono, Baltimore. [5] Reimold W. U. and Hörz F. (1986) LPSC XVII, 703-704. [6] Reimold W. U. (1990) LPSCI XIX, 970-971. [7] Huffman A. R. et al. (1989) In Shock Compression of Condensed Matter ( S. C. Schmidt et al., eds.), Elsevier. [8] Langenhorst F. et al. (1992) Nature, in press. [9] Schneider H. and Hornemann U. (1974)N.Jb.Miner. Mh., 149-162. [10] Robertson P. B. and Grieve R. A. F. (1977) In Impact and Explosion Cratering (Roddy et al., eds.), 687-702, Pergamon. [11] Engelhardt W. von and Bertsch W. (1969) Consrib. Mineral. Petrol., 20, 203-234. [12] RehfeldtOskierski A. and Stöffler D. (1986) LPSCI XVII, 697-698. [13] Grothues J. et al. (1989) LPSCI XX, 365-366. 
SEARCH FOR A METEORITIC COMPONENT AT THE BEAVERHEAD IMPACT STRUCTURE, MONTANA. Pascal Lee' and Robert W. Kay², 'Department of Astronomy, Cornell University, Ithaca NY 14853, USA, 2Department of Geological Sciences, Comell University, Ithaca NY 14853, USA.

The Beaverhead impact structure, in southwestern Montana $\left(44^{\circ} 36^{\prime} \mathrm{N} ; 112^{\circ} 58^{\prime} \mathrm{W}\right)$, was identified recently by the presence of shatter cones and impactites in outcrops of Proterozoic sandstones of the Belt Supergroup [1]. The cones occur over an area $>100 \mathrm{~km}^{2}$. Because the geologic and tectonic history of this region is long and complex, the outline of the original impact crater is no longer identifiable. The extent of the area over which shatter cones occur suggests, however, that the feature may have been at least $60 \mathrm{~km}$ in diameter. The absence of shatter cones in younger sedimentary units suggests that the impact event occurred in late Precambrian or early Paleozoic time.

We have collected samples of shocked sandstone from the socalled "Main Site" of dark-matrix breccias, and of impact breccias and melts from the south end of Island Butte. The melts, occurring often as veins through brecciated sandstone, exhibit a distinctive fluidal texture, a greenish color, and a cryptocry stalline matrix, with small inclusions of deformed sandstone. Samples of the same type, along with country rock, were analyzed previously for major- and trace-element abundances [2]. It was found that, although the majorelement composition was relatively uniform, the trace-element composition showed variations between the melt material and the adjacent sandstone. These variations were attributed to extensive weathering and hydrothermal alteration.

In a more specific search for a possible meteoritic signature in the breccia and the melt material we have conducted a new series of trace-element analyses on powders of our own samples by thermal neutron activation analysis. Our results indicate that Ir abundances in the breccia, the melts, and the adjacent sandstone clasts are no greater than about $0.1 \mathrm{ppb}$, suggesting no Ir enrichment of the breccia or the melts relative to the country rock. However, both the breccia and the melt material exhibit notable enrichments in $\mathrm{Cr}$ (8and 10-fold), in $U$ (9- and 5-fold), and in the heavy REEs (1.5- and 3-fold), respectively (normalization carried out relative to La) (see Table 1). Such enhancements relative to the country sandstone suggest that weathering and hydrothermal alteration alone might not be sufficient to account for the observed variations in traceelement abundances, and that the incorporation of a $\mathrm{Cr}, \mathrm{U}$, and HREE-rich component in the breccia and the melts is likely. Because both the breccia and the melts show noIr or Ni enrichments

TABLE 1. Trace-element concentrations in ppm (" \pm " indicates 2-sigma measurement error).

\begin{tabular}{lccc}
\hline & BHSS & BHM & BHB \\
\hline $\mathrm{Cr}$ & $17.76 \pm 0.6$ & $127.88 \pm 0.5$ & $71.94 \pm 0.4$ \\
$\mathrm{Ni}$ & $14.50 \pm 2.5$ & $15.65 \pm 1.0$ & $7.68 \pm 0.9$ \\
$\mathrm{U}$ & $1.48 \pm 0.1$ & $5.54 \pm 0.2$ & $6.99 \pm 0.3$ \\
$\mathrm{Yb}$ & $1.38 \pm 0.1$ & $3.23 \pm 0.1$ & $1.13 \pm 0.1$ \\
$\mathrm{Ta}$ & $0.39 \pm 0.1$ & $1.66 \pm 0.1$ & $1.33 \pm 0.1$ \\
La & $52.49 \pm 0.5$ & $39.04 \pm 0.3$ & $26.49 \pm 0.2$ \\
It & $<0.1 \mathrm{ppb}$ & $<0.1 \mathrm{ppb}$ & $<0.1 \mathrm{ppb}$ \\
\hline
\end{tabular}

BHSS = Beaverhead sandstone (country rock). BHM = Beaverhead impact melt. BHB $=$ Beavertead dark-matrix breccia. relative to the sandstone, the invoked additional component is unlikely to be chondritic or iron-rich meteoritic material. Instead, the low $\mathrm{Ni} / \mathrm{Cr}$ ratio in the breccia and the melts points either to an achondritic impactor or to some other (terrestrial) source of $\mathbf{C r}$ enrichment.

Meteoritic geochemical signatures at large and/or ancient terrestrial impact craters are difficult to find [3]. Possible reasons for this include the high impact velocities and energies involved in large impacts, the possibility of chemically inconspicuous (achondritic) projectiles, weathering and hydrothermal alteration of impactites and their associated country rock, and inadequate sampling. Our search for a meteoritic component in samples from the Beaverhead impact structure will be discussed in the context of this general problem.

References: [1] Hargraves R. B. et al. (1990) Geology, 18, 832-834. [2] Koeberl C. and Fiske P. S. (1991) Meteoritics, 26, 358-359. [3] Palme H. et al. (1978) GCA, 42, 313-323.

ORDOVICIAN IMPACTS AT SEA IN BALTOSCANDIA. M. Lindström'1, V. Puura2, T. Floden', and A. Bruun', 'University of Stockholm, Sweden, 'Estonian Academy of Sciences, Estonia, 3Swedish Geological Survey, Sweden.

Northern Europe has an assemblage of Ordovician probable impacts that is exceptional because the structures involved are relatively old yet well preserved because they formed at sea and because they formed within a restricted geological time in a relatively small area. The Tvaren, Kardla, and Lockne structures might not be strictly contemporaneous but all formed near the beginning of the Caradoc Age (about $460 \mathrm{Ma}$ ), whereas the Granby structure is about $20 \mathrm{Ma}$ older. The range of diameters is from about $2 \mathrm{~km}$ (Tvaren, Granby) to $8 \mathrm{~km}$ (Lockne). The stratigraphic succession formed on impact at sea, as uniformly documented by these structures, begins with a breccia lens consisting of basement rocks that are intensely crushed. Owing to expulsion of sea water by the impact, this breccia formed under essentially dry conditions. Later on this breccia was in part hydrothermally altered. It is overlain by backsurge turbidite that formed from fragments of local sedimentary bedrock and crystalline basement when the sea water returned to the crater site. Either the turbidite is simply a Bouma sequence (although quite thick - as much as over $50 \mathrm{~m}$ ) from very coarse rubble to mud, or it is more complex.

After deposition of the backsurge turbidite, or turbidite complex, the craters still remained as 150-200-m-deep holes in the sea bed. Together with the presence of relatively shallow water over the rim wall, this situation created predictable hydrologic conditions for extended histories of sedimentation and biological development at the crater as well as within it. For instance, hypoxia frequently developed in the bottom water before depth had been appreciably reduced by sedimentation. The insights acquired at these craters make it possible to improve paleoecological reconstructions applied to Ordovician sea beds.

The presence of a concentration of craters within a limited area of well-preserved and accessible Ordovician deposits raises a question about the Ordovician, especially its middle portion, as potentially an age of relatively intense impact activity even in wider areas. In this connection it may be apposite to mention that the only fossil stony meteorites so far reconded in rocks are from the late Early and the Middle Ordovician. 
DOES THE SEDIMENTOLOGY OF THE CHELMSFORD FORMATION PROVIDE EVIDENCE FOR A METEORITE IMPACT ORIGIN OF THE SUDBURY STRUCTURE? D. G. F. Long, Department of Geology, Laurentian University, Sudbury, Ontario P3E 2C6, Canada.

The post -"event" fill of the Paleoproterozoic Sudbury Basin consists of at least $600 \mathrm{~m}$ of deep-water mudrocks of the Onwatin Formation, overlain by $850 \mathrm{~m}$ of lithic-arkosic muddy sandstones in the Chelmsford Formation. While mudstones of the Onwatin reflect deposition in a deep-water, anoxic setting, there is no clear evidence of local breccias, conglomerates, or sand bodies to support the concept that the basin was protected by the steep walls of an impact crater. Carbonates in the basal, Vermillion Member are of sedimentary exhalitive origin and were not derived from a shallow marine shelf. Turbidites in the Chelmsford Formation show no evidence of centripetal fill as might be expected from a restricted, circular basin. They appear to have been emplaced by predominantly southwesterly flowing turbidity currents, which showed little to no deflection along the depositional axis of an elongate foreland basin that developed in front of the rising Penokean mountain chain.

While the presence of minor sandstone-filled fractures in parts of the Chelmsford Formation suggests the presence of north- or south-directed paleoslopes, no evidence is seen to support the existence of subbasins or a central uplift within the Sudbury Basin. While tilt-corrected paleocurrent orientations are ambiguous, due to postdepositional shortening of strata during cleavage development, strain correction of the observations makes little difference to the net, south-southwest-directed paleoflow.

IMPACT ORIGIN OF THE SUDBURY STRUCTURE: EVOLUTION OF A THEORY. Paul D. Lowman Jr., Goddard Space Flight Center, Code 921, Greenbelt MD 20771, USA.

This paper reviews the origin, development, and present status of the widely accepted theory, proposed by Robert S. Dietz in 1962 [1], that the Sudbury structure was formed by meteoritic or asteroidal impact. The first publication leading to Dietz's proposal was the suggestion by Hamilton [2] that the Sudbury Igneous Complex (SIC) was an extrusive lopolith, covered by its own silicic differentiates (the Onaping Formation, then considered a welded tuff). Hamilton's interpretation was applied by Lowman [3] to the problem of how parent rocks similar to tektites in composition could be formed on the Moon, tektites assumed to be of lunar origin. Lowman proposed that the lunar maria were extrusive lopoliths, analogous to the Bushveld, Sudbury, and Duluth Complexes, and that tektites were derived by impact from rhyolites surfacing the maria, analogous to the silicic differentiates of lopoliths. The lopolith-mare analogy was interpreted by Dietz to imply that the terrestrial lopoliths, like the circular maria, were large impact craters, and should have associated shatter cones. Dietz then searched for, and found, shatter cones in Huronian metasediments on the south side of the Sudbury structure. It is stressed that this was a predictive discovery, not a chance one. Dietz then proposed that Sudbury was a small terrestrial mare basin. It was shown, however, by B. $\mathbf{M}$. French [4] that the Onaping Formation was a metamorphosed fallback breccia rather than a welded tuff. Although contradicting Dietz's impact-triggered extrusive lopolith hypothesis, French's convincing demonstration of shock metamorphism put the impact mechanism on firm ground. Detailed field and laboratory studies in following years by Peredery, Dressler, Guy-Bray, Dence, and many others greatly strengthened the impact theory, which is today widely though not universally accepted by geologists familiar with the Sudbury area.

Following publication of the monumental The Geology and Ore Deposits of the Sudbury Structure [5], several lines of study have clarified the origin and evolution of the structure and the intrusive complex. Isotopic analyses by Faggart et al. supported the carlier proposal by Dence that much of the SIC might be impact melt rather than internally derived igneous rock. Impact modeling by Grieve et al. [6] also supports this mechanism, showing that the SIC average composition is close to that of local granite-greenstone terrain with a small proportion of Huronian cover rock. The size and shape of the original impact crater remain open to debate. An imaging radar and field study by Lowman [7] supported the interpretation by Rousell that the original crater had been elliptical, though made more so, since its formation, by the Penokean orogeny. However, primary elliptical impact craters do exist on the Moon and Mars, and ellipticity should not be considered an argument against impact. The predeformation shape of the crater was reconstructed by Shanks and Schwerdtner using finite-element modeling methods, which indicate that the predeformation structure was 2 to 3 times wider (northwest-southeast), i.e., nearly circular. A LITHOPROBE survey carried out in 1991 [8] supported the ShanksSchwerdtner interpretation to the extent that the South Range Shear Zone, in which the deformation was concentrated, was traced at depth by reflection profiling.

The impact theory for the origin of the Sudbury structure seems supported by a nearly conclusive body of evidence. However, even assuming an impact origin to be correct, at least three major questions require further study: (1) the original size and shape of the crater, before tectonic deformation and erosion, (2) the source of the melt now forming the Sudbury Igneous Complex, and (3) the degree, if any, to which the $\mathrm{Ni}$-Cu-platinum group elements are meteoritic.

The history of the impact theory illustrates several underappreciated aspects of scientific research: (1) the importance of cross-fertilization between space research and terrestrial geology, (2) the role of the outsider in stimulating thinking by insiders. (3) the value of small science, at least in the initial stages of an investigation, Dietz's first field work having been at his own expense, and (4) the value of analogies (here, between the Sudbury Igneous Complex and the maria), which, although incorrect in major aspects, may trigger research on totally new lines. Finally, the Sudbury story illustrates the totally unpredictable and, by implication, unplannable nature of basic research, in that insight to the origin of the world's then-greatest $\mathrm{Ni}$ deposit came from the study of tektites and the Moon.

References: [1] Dietz R. S. (1962) Program, AGU, Western National Meeting, 445-446. [2] Hamilton W. (1960) Rept. Int. Geol. Cong., XXI, 59-67. [3] Lowman P. D. Jr. (1962) JGR, 67, 1646, and (1963) Icarus, 2, 35-48. [4] French B. M. (1967) Science, 156, 1094-1098. [5] Pye E. G. et al. (1984) The Geology and Ore Deposits of the Sudbury Structure, Ontario Geological Survey. [6] Grieve R. A. F. et al. (1992) JGR, 96, 753-764. [7] Lowman P. D. Jr. (1991) Can.J.Remote Sens., 17, 152-161. [8] Milkereit B. et al. (1992) Geology, submitted. 
IMAGING RADAR INVESTIGATIONS OF THE SUDBURY STRUCTURE. P. D. Lowman ${ }^{1}$, V. H. Singhroy ${ }^{2}$, and V. R.

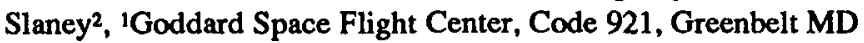
20771, USA, ${ }^{2}$ Canada Centre for Remote Sensing, 1547 Merivale Road, Ottawa, Ontario K1A 0Y7, Canada.

This paper reports preliminary results of airborne imaging radar studies of the Sudbury structure carried out in preparation for a CCRS European Remote Sensing Satellite (ERS-1) investigation. The data used were synthetic aperture radar (SAR)C-band $(5.66 \mathrm{~cm})$ images acquired from about $6 \mathrm{~km}$ altitude in 1987 . They cover the Sudbury area in both wide and narrow swath modes, with east-west flight paths and north-south illumination directions. Narrow swath resolution is $6 \mathrm{~m}$ in range and azimuth; wide swath resolution is $20 \mathrm{~m}$ in range and $10 \mathrm{~m}$ in azimuth.

The SAR imagery has proven highly effective for field use, providing excellent rendition of topography and topographically expressed structure. Reasons for this include the illumination geometry, notably the look azimuth normal to the long axis of the Sudbury structure and Penokean fold axes, the good spatial resolution, and the short wavelength. Forested areas in the Sudbury area tend to be uniformly rough at $\mathrm{C}$-band wavelength, with backscatter dominated by local incidence angle (i.e., topography). Dielectric properties have relatively little effect on backscatter, except for targets such as metal or water.

Field work using the SAR imagery has to date been concentrated in the North Range and Superior Province as far north as the Benny greenstone belt. This area was chosen for initial investigation of the original size and shape of the Sudbury structure because the effects of the Penokean Orogeny were minimal there. Field work using SAR indicates that there has been little postimpact deformation of the North Range or adjacent Superior Province rock [1]. There appears to be no evidence for an outer ring concentric with the North Range as indicated by early Landsat imagery $[2,3]$. The apparent ring shown by Landsat is visible on the SAR imagery as the intersection of two regional fracture patterns not related to the Sudbury structure [4]. There is no outer ring visible southwest of the structure. This can reasonably be explained by Penokean deformation, but there is also no outer ring to the northeast cutting the relatively undeformed Huronian sediments of the Cobalt Embayment. Further study of these problems is planned with ERS-1 imagery.

References: [1] Lowman P. D. Jr. (1991) Can. J. Remote Sens., 17, 152-161. [2] Dressler B. O. (1984) In The Geology and Ore Deposits of the Sudbury Structure (E. G. Pye et al., eds.), Ontario Geological Survey. [3] Grieve R. A. F. et al. (1991)JGR,96, 753-764. [4] Lowman P. D. Jr. (1992) Rev. Geophys., in press.

PHASE TRANSFORMATIONS IN 40-60-GPa SHOCKED GNEISSES FROM THE HAUGHTON CRATER (CANADA): AN ANALYTICAL TRANSMISSION ELECTRON MICROSCOPE (ATEM) STUDY. I. Martinez, F. Guyot, and U. Schärer, Université Paris7 et IPG Paris, 2 place Jussieu, 75251 Paris cedex 05, France.

In order to better understand phase transformations, chemical migration, and isotopic disequilibrium in highly shocked rocks [1], we have performed a microprobe and an ATEM study on gneisses shocked up to $60 \mathrm{GPa}$ from the Haughton Crater.
The Haughton impact structure, Devon Island, is a crater of $24 \mathrm{~km}$ in diameter formed in a target of about $1700 \mathrm{~m}$ of sedimentary rocks (limestones and dolomites) on top of a crystalline Precambrian gneiss. Samples were all crystalline fragments from the alloch honous polymict breccia [2], which cover the central area of the crater. Optical microscopy on thin sections does not allow identification of minerals by classical criteria: Birefringence of most of the phases (actually all but sillimanite) is largely lost, documenting their essentially amorphous character. Nevertheless, conservation of primary foliation suggests that total rock melting did not occur. These crystalline fragments also show large degrees of porosity, lying roughly at $40 \%$. Electron microprobe analyses reveal five compositional domains: (1) numerous $\mathrm{SiO}_{2}$ dominant zones, (2) areas with a biotitelike composition, (3) layers with feldsparlike composition, (4) areas characterized by Al/Si close to 1 , and (5) fracturated sillimanites.

Strong chemical heterogeneities were observed within most of the compositional domains. To decipher the origin of such heterogeneities, an ATEM study was performed, yielding a spatial resolution of $0.5 \mathrm{~nm}$ in image mode and of $200 \mathrm{~nm}$ for the energy dispersive X-ray microanalyses (EDS). This study reveals the following chemical and structural characteristics:

1. $\mathrm{SiO}_{2}$ dominant areas are formed by a mixture of pure $\mathrm{SiO}_{2}$ polycrystalline quartz identified by electron diffraction pattern and chemical analysis (Fig. 1a) and a silica-rich amorphous phase containing minor amounts of aluminium, potassium, and iron (Fig. 1b).

2. Areas with biotitelike composition are formed by $<200-\mathrm{nm}$ grains of iron-rich spinels (Fig. 2a) embedded in a silica-rich amorphous phase (Fig. 2b) that is very similar to the one described above.

3. Layers with feldsparlike composition are constituted by 100-200-nm-sized alumina-rich grains (the indexation of the crystalline structure is under progress) and the silica-rich amorphous phase.

4. Zones characterized by the unusual $\mathrm{Al} / \mathrm{Si}$ ratio close to 1 are formed by spinel grains (200-nm-sized) embedded in the same silica-rich amorphous phase.

5. The fracturated sillimanites contain domains with a lamellar structure, defined by the intercalation of 100 -nm-wide lamellae of mullite crystals and of a silica-rich amorphous phase (Fig. 3a). Figure $3 \mathrm{~b}$ shows an individual 500 -nm-sized crystal of mullite. These crystals preserved the crystallographical orientation of the preshock sillimanite.

All compositional domains, identified at the microprobe scale, can thus be explained by a mixture in different proportion between the following phases: (1) a silica-rich amorphous phase, with minor $\mathrm{Al}$ and $\mathrm{K}$; (2) quartz crystals; (3) spinel crystals and alumina-rich crystals; (4) sillimanite; and (5) mullite. Such mixtures of amorphous phases and crystals in different proportions explain disturbed isotope systems in these rocks and chemical heterogeneities observed on the microprobe.

References: [1] Schärer U. and Deutsch A. (1990) GCA, 54, 3435-3447. [2] Metzler A. et al. (1988) Meteoritics, 23, 197-207. 
PHASE TRANSFORMATIONS IN 40-60-GPa SHOCKED GNEISSES FROM THE HAUGHTON CRATER (CANADA): Martinez I. et al.
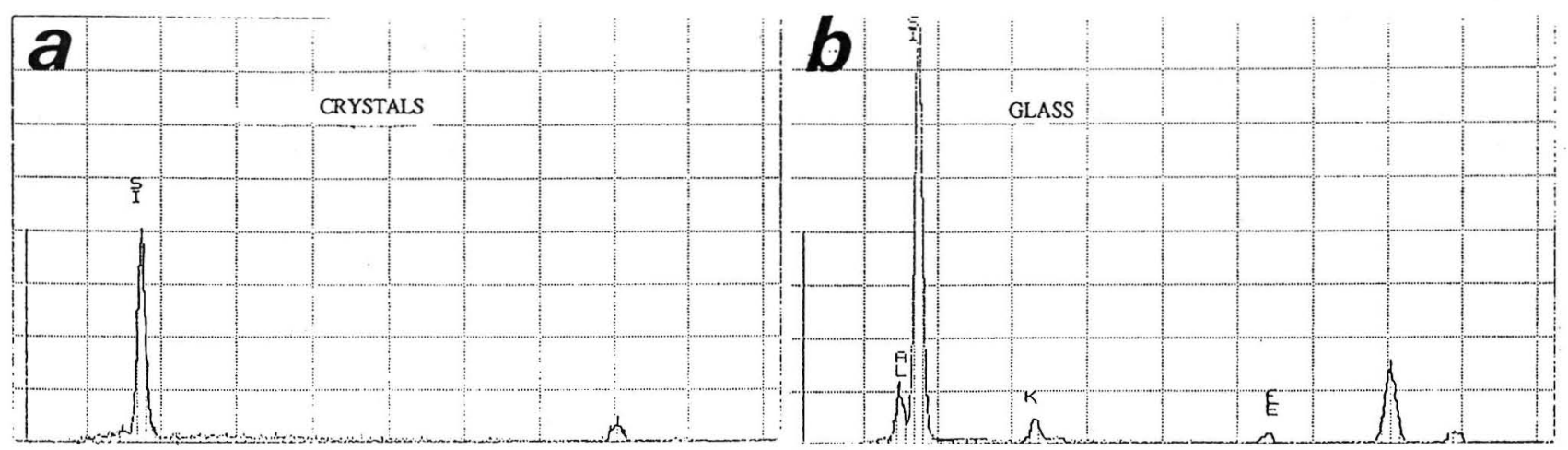

Fig. 1. (a) EDS microanalysis of polycrystalline quartz. Oxygen is not detectable with this EDS configuration and some contamination by the copper of the sample support occurs; (b) EDS microanalysis of the silica-rich amorphous phase.
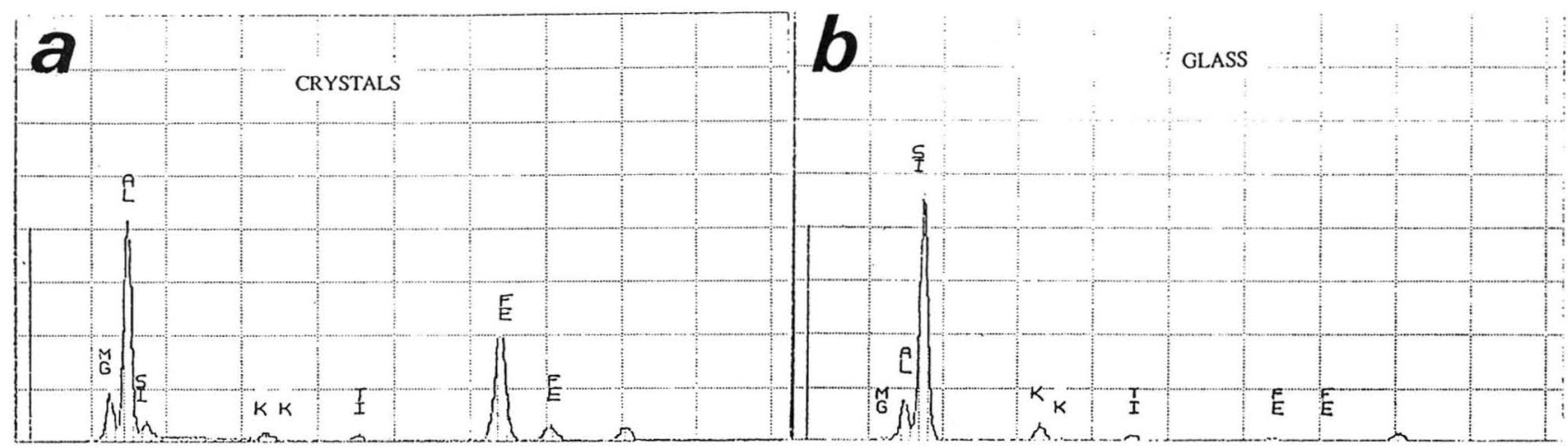

Fig. 2. (a) EDS microanalysis of an iron-rich spinel crystal. The composition is approximately $\left(\mathrm{Mg}_{0.5} \mathrm{Fe}_{0.5}\right) \mathrm{Al}_{2} \mathrm{O}_{4}$, although Fe ${ }^{3+}$ could not be determined; (b) EDS microanalysis of the silica-rich amorphous phase. Notice the similarity with Fig. $1 \mathrm{~b}$.
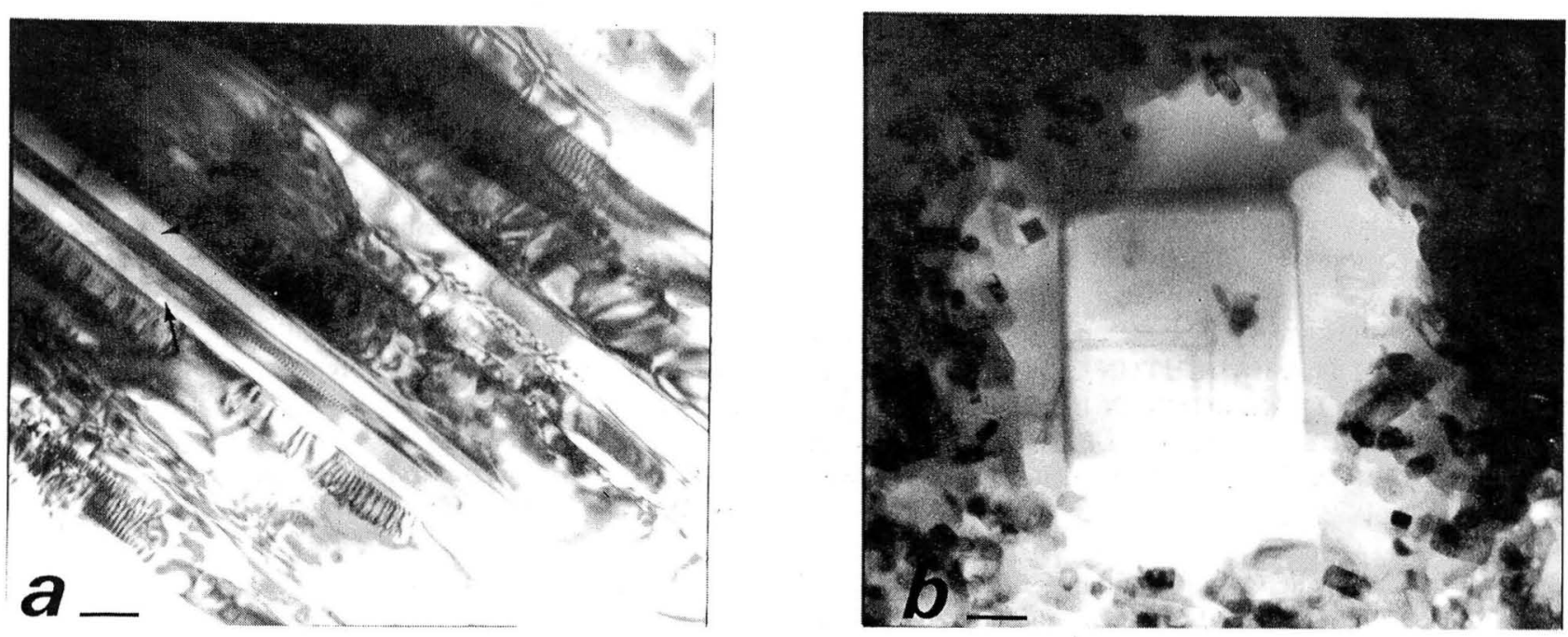

Fig. 3. (a) TEM image of the lamellar structure of intercalated mullite and silica-rich (+Al, $\mathrm{K})$ amorphous phase (see arrows). Scale bar is $200 \mathrm{~nm}$. (b) In some areas, mullite appears as small euhedral crystals surrounded by the amorphous phase. TEM, scale bar $200 \mathrm{~nm}$. 
IMPACTITES FROM POPIGAI CRATER. V. L. Masaitis, Karpinsky Geological Research Institute, St. Petersburg, Russia.

Impactites (tagamites and suevites) from Popigai impact crater, whose diameter is about $100 \mathrm{~km}$, are distributed over an area of $5000 \mathrm{~km}^{2}[1,2]$. The continuous sheet of suevite overlies the allogenic polymict breccia and partly authogenic breccia, and may also be observed in lenses or irregular bodies. The thickness of suevites in the central part of the crater is more than $100 \mathrm{~m}$. Suevites may be distinguished by content of vitroclasts, lithoclasts, and crystalloclasts, by their dimensions, and by type of cementation, which reflects the facial settings of ejection of crushed and molten material, its sedimentation and lithification. Tagamites (impact melt rocks) are distributed on the surface predominantly in the westem sector of the crater. The most characteristic are thick sheetlike bodies overlying the allogenic breccia and occurring in suevites where minor irregular bodies are widespread. The maximal thickness of separate tagamite sheets is up to $600 \mathrm{~m}$. Tagamites, whose matrix is crystallized to a different degree, include fragments of minerals and gneiss blocks, among them shocked and thermally metamorphosed ones. Tagamite sheets have a complex inner structure; separate horizontal zones distinguish in crystallinity and fragment saturation. Differentiation in the impact melt in situ was not observed.

The average chemical compositions of tagamites and suevites are similar, and correspond to the composition of biotite-garnet gneisses of the basement [3]. According to the content of supplied $\mathrm{Ir}, \mathrm{Ni}$, and other siderophiles, impact melt was contaminated by $5 \%$ cosmic matter of collided body, probably ordinary chondrite [4]. The total volume of remaining products of chilled impact melt is about $1750 \mathrm{~km}^{3}$. Half this amount is represented by tagamite bodies. Though impact melt was in general well homogenized, the trend analysis showed that the concentric zonation in distribution of $\mathrm{SiO}_{2}$, $\mathrm{MgO}$, and $\mathrm{Na}_{2} \mathrm{O}$ and the bandlike distribution of $\mathrm{FeO}$ and $\mathrm{Al}_{2} \mathrm{O}_{3}$ content [5] testifies to a certain inheritance and heterogeneity in country rock composition laterally and vertically in the melting zone. The radial ray inhomogeneities of content of newly formed high-pressure phases determined in impactites also reflect the peculiarities of melt transportation during excavation. On the other hand, the irregularity of distribution of supplied siderophile elements in impactites shows that contamination by cosmic matter was probably associated with the condensation from vapor on cold fragments engulfed by melt after its homogenization.

References (all in Russian): [1] Nedra L. (1980) Geology of Astroblemes, 231 pp. [2] Masaitis V. L. (1984) In Modern Ideas of Theoretical Geology (L. Nedra, ed.), 151-179. [3] Raikhlin A.I. and Mashchak M. S. (1977) Meteoritika, 36, 140-145. [4] Masaitis V. L. and Raikchlin A.I.(1989)Meteoritika, 48, 161-169. [5] Masaitis V. L. et al. (1980) In Cosmochemistry of Meteorites, Moon and Planets, 176-191, Naukova dumka, Kiev.

SUDBURY BRECCIA AND SUEVITE AS GLACIAL INDICATORS TRANSPORTED $800 \mathrm{KM}$ TO KENTLAND ASTROBLEME, INDIANA. John F.McHone', Robert S. Dietz', and Walter V. Peredery', 'Geology Department, Arizona State University, Tempe AZ 85287-1404, USA, ${ }^{2}$ INCO Exploration and Technical Services Inc, Copper Cliff, Ontario POM 1N0, Canada.

A glacial erratic whose place of origin is known by direct comparison with bedrock is known as an indicator [1]. In 1971, while visiting the known astrobleme at Kentland, Indiana, one of us

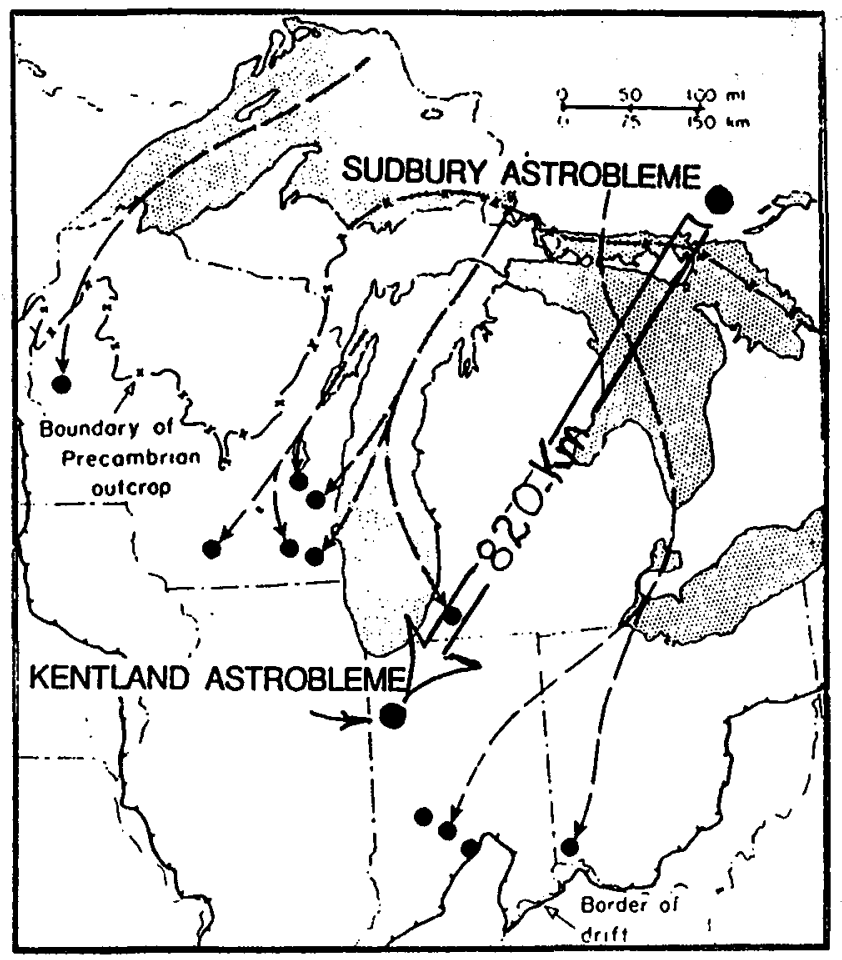

Fig. 1. Map showing Wisconsin epoch glacial transport of two indicator rocks (Onaping black suevite and Sudbury breccia) from the Sudbury astrobleme, Ontario, some $820 \mathrm{~km}$ to the Kentland, Indiana, astrobleme. Dashed lines indicate presumed glacial transport of diamond erratics to the midwest till plain. After [1].

(Peredery) recognized and sampled in the overlying glacial drift deposits a distinctive boulder of Sudbury suevite (black member, Onaping Formation) that normally occurs within the Sudbury Basin as an impact fall-back or wash-in deposit. The rock was sampled (but later mislaid) from a farmer's caim next to a cleared field. Informal reports of this discovery prompted the other authors to recently reconnoiter the Kentland locality in an attempt to relocate the original boulder. Several breccia blocks were sampled but laboratory examination proved most of these probably to be diamictites (tillites?) [2] from the Precambrian Gowganda Formation, which outcrops extensively in southem Ontario [3]. However, one sample was confirmed as typical Sudbury Breccia, which outcrops in the country rock surrounding the Sudbury Basin. Thus two glacial indicators were transported by Pleistocene continental glaciers about $820 \mathrm{~km}$ over a tightly proscribed path and, curiously. from one astrobleme to another.

Brecciated boulders in the Illinois/Indiana till plain are usually ascribed to the Gowganda or Mississagi formations in Ontario. But impact-generated rocks need not be confused. The carbonaceous matrix of the suevite, for example, was sufficiently distinctive to assign it to the upper portion of the black Onaping. The unique and restricted source area of these indicators provide an accurate and reliable control for estimating Pleistocene ice movement.

References: [1] Flint R. F. (1957) Glacial and Pleistocene Geology, Wiley, 553 pp. [2] Harker and Giegengack (1989) Geology, 17, 123-126. [3] Young G. M. (1981) In Earth's Pre-Pleistocene Glacial Record International Geological Correlation Programme Project 38: Pre-Pleistocene Tillites (M. J. Hambrey and W. B. Harland, eds.), 807-812. 
WHAT CAN WE LEARN ABOUT IMPACT MECHANICS FROM LARGE CRATERS ON VENUS? William B. McKinnon and J. S. Alexopoulos, Department of Earth and Planetary Sciences and McDonnell Center for the Space Sciences, Washington University, St. Louis MO 63130, USA.

More than 50 unequivocal peak-ring craters and multiringed impact basins have been identified on Venus from Earth-based Arecibo, Venera 15/16, and Magellan radar images. These ringed craters are relatively pristine, and so serve as an important new dataset that will further understanding of the structural and rheological properties of the venusian surface and of impact mechanics in general. They are also the most direct analogues for craters formed on the Earth in Phanerozoic time [1].

The inner rings and crater rims of venusian peak-ring craters (or basins) are morphologically similar to inner rings and crater rims, respectively, of peak-ring craters on the Moon, Mars, and Mercury. As is observed for mercurian ringed basins, ring diameter ratios decrease from $z 3.5$ to 2 (or less) with increasing crater diameter. On Venus, the transition from central-peak crater to peak-ring crater is well defined at around $40 \mathrm{~km}$ diameter. Decreasing ring diameter ratios with increasing peak-ring crater diameter are consistent with a hydrodynamic origin for peak rings, i.e., collapse and expansion of the uplifted central peak. The large but finite ring ratios at the transition and, on other terrestrial planets, the simultaneous presence of central peaks and rings in many of these transitional structures imply that central rings rise from the collapsing shoulders of central peaks, i.e., that they are a wave-breaking phenomena in oversteepened and unstable central peaks (cf. photographs in [2]). The viscosities of fluidized crater material implied by central-peak to peak-ring transition diameters on the terrestrial planets are more or less proportional to crater diameter, $D$, indicating that the scale dependence of viscosity, $\eta$, may dominate gravity in the formation of peak-ring craters. This approximately linear dependence, $\eta \approx$ $9(\mathrm{D} / \mathrm{km}) \mathrm{GPa}-\mathrm{s}$, is compatible with fluidization by strong acoustic or seismic vibrations. It implies a nearly constant ratio $\lambda_{d} / \mathrm{D} \approx 1 / 80$ to $1 / 20$, where $\lambda_{d}$ is the dominant wavelength of the acoustic field, depending on the sound speed in agitated rubble adopted (0.5$2 \mathrm{~km} / \mathrm{s}$ ). In terms of scaling, the originally generated $\lambda / \mathrm{D}$ spectrum may be expected to be roughly invariant with respect to final crater size. For lower sound speeds, the dominant wavelength $\lambda_{d}$ could be a large fraction of the crater depth, which may imply leakage of lower frequencies and damping of higher ones [3]. Impactor diameter and $\lambda_{d}$ would also be comparable for the lower sound speed above, given presently accepted crater scaling relations.

Important interplanetary differences remain; martian crust in particular appears to be more easily fluidized by impact. We also do not consider the shock melt hypothesis of [4] here, but note that the increasing amount of melt compared to ejected mass in larger structures might be expected to result in decreasing effective viscosity with size. The interiors of most of the peak-ring craters appear generally smooth (similar to the surrounding plains), as evidenced by the radar-dark returns in Arecibo and Magellan images. This may be attributed to the presence of impact melt deposits or to postimpact volcanism. The increasing incidence of bright floors among the youngest craters (i.e., those with dark parabolic deposits [5]) suggests that volcanism may be the more correct choice, but postimpact differentiation and eruption from a large melt sheet should also be considered.

Of the four largest ringed structures identified on Venus so far. Klenova (144 km diameter), Lise Meitner $(148 \mathrm{~km})$, and Mead $(270 \mathrm{~km})$ exhibit what we interpret to be major asymmetric inner (intermediate for Klenova) and outer mountain rings, possibly representing fault scarps similar to the Outer Rook and, especially, the Cordilleraring of Orientale, respectively. Furthermore, Klenova exhibits an inner peak ring analogous to Orientale's Inner Rook. whereas Meitner exhibits a possible additional, exterior, scarplike partial or transitional ring. A recent Magellan image of Meitner does not equivocally show this outer segment as a scarp, but the radar geometry was poor for determining this. Mead exhibits no inner peak ring, but may be the structurally clearest example of "megaterrace" collapse yet observed on the terrestrial planets. Adjacent ring diameter ratios for the three multiringed basins range from $\sim 1.6$ between the most prominent rings of Klenova and Meitner to $~ 1.4$ for Klenova's peak ring, Meitner's partial ring, and Mead. These ratios are similar to those observed for Orientale and other lunar multiringed basins. Thus we interpret all three venusian structures to represent Orientale-type multiringed impact basins. Isabella $(\sim 170 \mathrm{~km}$ diameter) is also a ringed basin, but it is severely volcanically flooded; much of the intermediate ring and all of the inner ring are defined by isolated but concentrically arranged, massifs.

Although multiringed basins on Venus occur at much smaller diameters than on the other terrestrial planets (except perhaps the Earth), effective viscosities are low enough at depth to allow inward asthenospheric flow, which in the model of [6] can cause radial extensional stress and circumferential faulting in the overlying lithosphere, block rotation, and ring formation. The differing rheologies of Venus crust and mantle may play a role in the creation of Cordilleran-style ring faulting. The large differential stresses associated with the deep transient crater precursors to Klenova, Meitner, and Mead are sufficient to have driven solid-state power-law flow of venusian upper mantle rock at low effective viscosity (not only low enough to define an asthenosphere on the collapse timescale. but a lower viscosity than that of overlying shock-fluidized lithosphere). For the two smaller multiringed basins, sufficiently low viscosities may have only been possible if accessible mantle temperatures were close to or at the peridotite solidus. This is not geologically implausible, as the abundant widespread basaltic volcanism on Venus implies that its mantie temperature profiles exceed the solidus at numerous locations and the asthenosphere may in fact be defined by pressure-release partial melting, but altemative possibilities include enhanced flow rates in mantle rocks due to plasticity or viscous flow in a weaker crustal asthenosphere. Analogous arguments can be made with respect to multiple ring formation on the Moon. Effective viscosity estimates imply that ring tectonics on the terrestrial planets may in fact work most readily within a sufficiently thick, soft crustal layer.

Finite-element simulations of basin collapse and ring formation along the lines of [7] were undertaken in collaboration with V. J. Hillgren (University of Arizona). These calculations, summarized in [1], used an axisymmetric version of the viscoelastic finite element code TECTON, modeled structures on the scale of Klenova or Meitner, and demonstrated two major points. First, viscous flow and ring formation are possible on the timescale of crater collapse for the sizes of multiringed basins seen on Venus and heat flows appropriate to the planet. Second, an elastic lithosphere overlying a Newtonian viscous asthenosphere results mainly in uplift beneath the crater. Inward asthenospheric flow mainly occurs at deeper levels. Lithospheric response is dominantly vertical and flexural. Tensional stress maxima occur and ring formation by normal faulting is predicted in some cases, but these predicted rings occur too far out to explain observed ring spacings on Venus (or on the Moon). Similar distant tensional stress maxima were reported by 
[7], who found that in order to generate a ring fault at a distance of $\sim 1.4$ crater radii, it was necessary to restrict asthenospheric flow to a channel at depth, one overlying a stiffer mesosphere. It is tempting to assign this asthenospheric channel to a ductile lower crust, as discussed above. Alternatively, an effectively stiffer mesosphere may be a natural consequence of truly non-Newtonian rebound. Much work remains to be done on this problem.

Overall, these estimates and models suggest that multiringed basin formation is indeed possible at the scales observed on Venus. Furthermore, due to the strong inverse dependence of solid-state viscosity on stress, the absence of Condilleran-style ring faulting in craters smaller than Meitner or Klenova makes sense. The (1) apparent increase in viscosity of shock-fluidized rock with crater diameter, (2) greater interior temperatures accessed by larger, deeper craters, and (3) decreased non-Newtonian viscosity associated with larger craters may conspire to make the transition with diameter from peak-ring crater to Orientale-type multiringed basin rather abrupt.

References: [1] Alexopoulos J. S. and McKinnon W. B. (1992) JGR, submitted. [2] Gault D. E. and Sonett C. P. (1982) GSA Spec. Pap., 190, 69-102. [3] Melosh H. J. and Gaffney E. S. (1983) Proc. LPSC 13th, in JGR, 88, A830-A834. [4] Cintala M. J. and Grieve R. A. F. (1991) LPSC XXII, 213-214. [5] Campbell D. B. et al. (1991) JGR, in press. [6] Melosh H. J. and McKinnon W. B. (1978) GRL, 5, 985-988. [7] Melosh H. J. and Hillgren V.J. (1987) LPSC XVIII, 639-640.

SUDBURY PROJECT (UNIVERSITY OF MŨNSTERONTARIO GEOLOGICAL SURVEY): (5) NEW INVESTIGATIONS ON SUDBURY BRECCIA. V. Müller-Mohr, Institute of Planetology, University of Münster, Wilhelm-Klemm-Str. 10, W-4400 Milnster, Germany.

Sudbury breccias occur as discordant dike breccias within the footwall rocks of the Sudbury structure, which is regarded as the possible remnant of a multiring basin [1]. Exposures of Sudbury breccias in the North Range are known up to a radial distance of $60-80 \mathrm{~km}$ from the Sudbury Igneous Complex (SIC). The breccias appear more frequent within a zone of $10 \mathrm{~km}$ adjacent to the SIC and a further zone located about $20-33 \mathrm{~km}$ north of the structure.

From differences in the structure of the breccias, as for example the size of the breccia dikes, contact relationships between breccia and country rock as well as between different breccia dikes, fragment content, and fabric of the ground mass, as seen in thin section, the Sudbury Breccias have been classified into four different types.

A. Early breccias with a clastic/crystalline matrix comprise small dikes ranging in size from $1 \mathrm{~cm}$ to $\max .20 \mathrm{~cm}$. Characteristic features of these breccias are sharp contacts to country rock. low fragment content (20-30\%), local origin of fragments, and an aphanitic, homogenous matrix, which can be related to country rock. Locally corrosional contacts to feldspar minerals and small vesicles filled with secondary minerals are observed.

B. Polymict breccias with a clastic matrix represent the most common type of Sudbury breccia. The thickness of the dikes varies from several tens of centimeters to a few meters but can also extend to more than $100 \mathrm{~m}$ in the case of the largest known breccia dike. Contacts with country rock are sharp or gradational. Fragment content (60-75\%) is usually of local origin but especially in large dikes allochthonous fragments have been observed. Inclusions of type A breccias reveal the later formation of this type of breccia. The heterogenous matrix consisting of a fine-grained rock flour displays nonoriented textures as well as extreme flow lines. Chemical analysis substantiates at least some mixing with allochthonous material.

C. Breccias with a crystalline matrix are a subordinate type of Sudbury breccia. According to petrographical and chemical differences, three subtypes have been separated. The local origin of the fragments and the close chemical relationship to the country rock point to an autochthonous generation probably through in situ frictional processes. For two subtypes the geometry of the dikes and the texture of the matrix indicates that at least some transport of breccia material has occurred. Breccias with a crystalline matrix have never been observed in contact with the other types of breccias.

D. Late breccias with a clastic matrix are believed to represent the latest phase of brecciation. Two subtypes have been distinguished due to differences in the fragment content. Breccias with a low fragment content show a weak lamination and sharp or gradational contacts to country rock. Inclusions of type A breccias are observed. Breccias with a high fragment content are characterized by gradational contacts and are only known from the outermost parts of the structure. Fragments of these breccias are of local origin. A possible correlation of the relative timescale of breccia formation with the phases of crater formation will be discussed.

Shock deformation features, which have been recorded within breccia fragments up to a radial distance of $9 \mathrm{~km}$ from the SIC, represent the shock stage I of the basement rocks. Inclusions exhibiting a higher shock stage, such as melt particles or suevitic fragments, which are known from dike breccias of,e.g., the Carswell impact structure, are lacking. This means that the dike breccias of Sudbury as presently exposed are from a deeper level of the subcrater basement than their counterparts of Carswell.

References: [1] Stöffler et al. (1989) Meteoritics, 24, 328.

A HISTORY OF THE LONAR CRATER, INDIA-AN OVERVIEW. V. K. Nayak, Department of Applied Geology, Indian School of Mines, Dhanbad, India.

The origin of the circular structure at Lonar, India (19 $\left.9^{\circ} 8^{\circ} \mathrm{N}: 76^{\circ} 31^{\prime} \mathrm{E}\right)$, described variously as cauldron, pit, hollow, depression, and crater, has been a controversial subject since the early nineteenth century. A history of its origin and other aspects from 1823 to 1990 are overviewed. The structure in the Deccan Trap Basalt is nearly circular with a breach in the northeast, $1830 \mathrm{~m}$ in diameter, $150 \mathrm{~m}$ deep, with a saline lake in the crater floor.

Since time immemorial, mythological stories prevailed to explain in some way the formation of the Lonar structure, which has been held in great veneration with several temples within and outside the depression. Various hypotheses proposed to understand its origin are critically examined and grouped into four categories as (1) volcanic, (2) subsidence, (3) cryptovolcanic, and (4) meteorite impact. In the past, interpretations based on geological, morphological, and structural data were rather subjective and dominated by volcanic, subsidence, and, to some extent, cryptovolcanic explanations [1]. In 1960, experience of the Canadian craters led Beals et al. [2] to first suggest the possibility of a meteorite impact origin of the Lonar crater, and thus began a new era of meteorite impact in the history of the Indian crater.

The last three decades (1960 to 1990) reflect a period of great excitement and activity of the Lonar crater, perhaps owing to an upsurge of interest in exploration of the Moon and other planets. 
Application of principles of hypervelocity impact cratering has provided overwhelming evidence for an impact origin of the Indian crater. Among others, shock metamorphic characteristics of basalt, impact glasses, mineralogy, chemistry, geochemistry, and comparison with the Moon's rocks have clearly demonstrated its formation by impact of a meteorite [3-6].

Over the years, the origin of the Lonar structure has risen from volcanism, subsidence, and cryptovolcanism to an authentic meteorite impact crater. Lonar is unique because it is probably the only terrestrial crater in basalt and is the closest analog with the Moon's craters. Some unresolved questions are suggested. The proposal is made that the young Lonar impact crater, which is less than 50,000 years old, should be considered as the best crater laboratory analogous to those of the Moon, be treated as a global monument. and preserved for scientists to comprehend more about the mysteries of nature and impact cratering, which is now emerging as a fundamental ubiquitous geological process in the evolution of the planets [7].

References: [1] La Touche T. H. D. and Christie W. A. K. (1912) Rec. Geol. Surv. India, 41, 266-285. [2] Beals C. S. et al. (1960) Current Science, India, 29, 205-218. [3] Nayak V. K. (1972) EPSL, 14, 1-6. [4] Fredriksson K. et al. (1973) Science, 180, 862-864. [5] Fredriksson K. et al. (1979) Smithson. Contrib. Earth Sci., 22, 1-13. [6] Kieffer S. W. et al. (1976) Proc. LSC 7th, 1391-1412. [7] Grieve R. A. F. and Head J. W. (1981) Episodes, 4, 3-9.

SUDBURY IGNEOUS COMPLEX: IMPACT MELT OR IGNEOUS ROCK? IMPLCATIONS FOR LUNAR MAGMATISM. MarcD.Norman, Planetary Geosciences, Department of Geology and Geophysics, SOEST, University of Hawaii, Honolulu HI 96822, USA.

The recent suggestion that the Sudbury Igneous Complex (SIC) is a fractionated impactmelt [1] may have profound implications for understanding the lunar crust and the magmatic history of the Moon. A comerstone of much current thought on the Moon is that the development of the lunar crust can be traced through the lineage of "pristine" igneous rocks [2]. However, if rocks closely resembling those from layered igneous intrusions can be produced by differentiation of a large impact melt sheet, then much of what is thought to be known about the Moon may be called into question. This paper presents a brief evaluation of the SIC as a differentiated impact melt vs. endogenous igneous magma and possible implications for the magmatic history of the lunar crust.

Petrologic and geochemical studies of terrestrial impact melts have shown that most of these occurrences cooled quickly, creating homogeneous crystalline rocks with compositions approximating those of the average target stratigraphy $[3,4]$. Impact melts typically, but not always, have elevated concentrations of siderophile elements relative to the country rock, indicating meteoritic contamination $[5,6,7]$. Application of these studies to lunar samples has lead to various criteria thought to be useful for distinguishing primary igneous rocks of the lunar highlands crust from the mixtures created by impact melting $[2,8,9]$. Among these criteria are mineral compositions suggesting plutonic conditions, non-KREEPy incompatible trace-element patterns, and low concentrations of meteoritic siderophile elements. Lunar breccias and impact melts identified as polymict on petrographic grounds usually have incom- patible- and siderophile-element signatures indicating KREEP and meteoritic components, so a lack of these components may be taken as evidence that a sample preserves its primary igneous composition, even though its texture may have been modified by cataclasis or annealing.

If the SIC represents melt formed during the impact event that created the Sudbury Basin, then ideas of how large melt sheets behave require revision. The SIC is a noritic-to-granophyric mass of crystallized silicate liquid with mineral and chemical compositions broadly consistent with closed-system fractional crystallization, although greenschist facies alteration has obscured much of the fine-scale recond [10]. Despite the Ni and PGE (platinum-groupclement) sulfide ores in the SIC, siderophile-element abundances in the silicates are comparable to those of the country rock [11]. PGE patterns in the ores are not chondritic, as they are in many impact melts, but are highly fractionated and similar to those of terrestrial basalts [12]. Osmium isotopic compositions in the ores suggest a significant component of continental crust and are difficult to reconcile with meteoritic contamination [11].

A lunar sample with mineralogic and geochemical characteristics analogous to those of the SIC probably would be judged as "pristine," hence a primary igneous rock. If large impact events can create melt rocks with characteristics indistinguishable from those of layered igneous intrusions and with no detectable metecritic contamination, then any or all of the pristine lunar highland rocks may not necessarily represent endogenous lunar magmatism but fractionated impact melts. Diverse components would still be required in the lunar crust and/or upper mantle to produce the impressive array of lunar highland rock types, but the connection to major mantle reservoirs that could constrain the planet's bulk composition would be lost. There may be economic implications as well: If the SIC is a fractionated impact melt, then large impact structures become potential exploration targets, both terrestrial and extraterrestrial.

Despite the somewhat unusual, silica-rich bulk composition of the SIC, several characteristics of the complex appear more consistent with endogenous magmatic processes vs. impact melting and in situ differentiation. Among these characteristics are (1) petrologic and geophysical evidence suggesting an unexposed mafic or ultramafic mass bencath the SIC, (2) contact relations within the SIC that suggest multiple intrusive events, and (3) possibly abundant water in the SIC magma. In addition, we argue that the silica-rich composition of the SIC does not require impact melting, but can be accounted for by endogenous magmatic processes although the impact event may have influenced the course of the magmatic evolution. These topics are discussed in more detail below.

Petrologic and geophysical evidence favoring an unexposed mafic or ultramafic mass beneath the SIC includes ultramafic xenoliths found in the SIC sublayer $[13,14]$ and gravity and magnetic data [15]. The xenoliths have mineral and trace-element compositions suggesting a petrogenetic connection to the SIC. A basal ultramafic zone would suggest that the SIC is not contained entirely within the impact structure and would create a bulk composition for the SIC unlike that of the proposed target stratigraphy. It would also seem to require a mantle-derived component in the SIC magma, which may be more supportive of an endogenous magmatic origin rather than incorporation of mantle material into the impact melt. If the excavation cavity of the Sudbury impact event was 100-150 km diameter [1], the depth of excavation was probably $\leq 20 \mathrm{~km}[16]$, which would be predominantly or exclusively within the continental crust. 
Contact relations between the sublayer and the SIC main mass norite appear to reflect multiple intrusive events although both units may have been mobile simultaneously [14]. Multiple intrusions would seem more consistent with pulses of endogenous magmatism rather than a one-shot impact event although the mechanics of largescale impact melting remain obscure. Amphibole is present in the SIC norite and may be primary [10]. The presence of water in the melt in amounts necessary to stabilize amphibole (2-5 wt\%) may be more consistent with an endogenous magma rather than a superheated impact melt. For example, tektites are among the driest of terrestrial rocks, but their small volume may not be directly analogous to the SIC. It may also be possible that a dry impact melt became hydrated through assimilation of country rock during crystallization.

The bulk composition of the SIC seems to be close to that of an average for the upper crustal target stratigraphy [1], which is a common characteristic of terrestrial impact melts. However, endogenous magmatic processes such as assimilation can incorporate significant amounts of continental crust into more mafic magmas without superheat $[17,18]$. Such processes can produce igneous rocks with compositional characteristics quite similar to that estimated for the bulk composition of the SIC. For example, many occurrences of Cenozoic volcanic rocks in western North America have bulk compositions close to that of the SIC [19-22].

Even if the SIC is not a direct impact melt, there does appear to be a close association in space and time between the SIC and a major impact event. Dietz [23] and French [24] described features in the Sudbury Basin that they attributed to shock. Their arguments that the Basin is an impact structure are persuasive because there are no known occurrences of similar shock features unequivocally associated with volcanic eruptions. If the Sudbury Basin is an impact structure, it is the largest such structure known on Earth. The noncircularity of the SB has been cited as evidence against an impact origin, although the original shape of the Basin is poorly constrained [25]. Although the original shapes of most impact craters generally are circular, considerable variation in crater outline and morphology can be found. Oblique impacts can produce craters with elongate outlines, as observed on the Moon and Mars [26-29]. An oblique, skipping impact event that created a series of elongated scars was discovered recently in Peru [30]. Fragmentation of the impactor can produce elongated, noncircular crater patterns or multiple events as shown by the Henbury cluster, the Cape York meteorite field, and the East-West Clearwater pair. Erosion and deformation can alter the original shape of an impact basin, e.g., Meteor Crater is somewhat rectangular. The apparent noncircularity of the Sudbury crater is not a strong argument against an impact origin when stacked against the host of shock features clearly associated with the Basin.

Even if the SIC is an endogenously produced magma and not an impact melt, the association of impact events and magmatism may nonetheless have important implications when considering the locus and style of planetary magmatism. The close correspondence in space and time between the impact event and the magmatism that produced the SIC suggests a broadly genetic connection, especially considering the overall paucity of magmatism of similar age (1850 $\mathrm{Ma}$ ) in the region $[31,32]$. In order to explain the compositional characteristics of the SIC, it appears necessary to invoke significant mixing of mantle-derived magmas with continental crust. Spatial variations in mineral compositions away from wall rock contacts suggest that the melt was actively assimilating wall rock [10]. Intracrater melt rocks or breccias may have been assimi- lated by more mafic magmas, which in turn may have been produced by local thermal perturbations or pressure-release melting associated with the impact.

Altematively, crustal material may have been injected into the mantle, producing a mixed source that melted to give the SIC parent magma. Nyquist and Shih [33] have proposed that regional heterogeneities in the lunar mantle may reflect large impact events that injected crustal material deep into the Moon's interior.

The SIC appears to represent endogenous magmatism although probably localized and influenced by a major impact event and structure. The role of pristine lunar highland rocks as products of endogenous magmatism is correspondingly secure for the moment but the effects of major impact events in localizing and influencing that magmatism remains poorly perceived and probably requires additional missions to the Moon to clarify. Regardless, study of impact events remains of fundamental importance for understanding the formation and evolution of the planets.

References: [1] Grieve et al. (1991)JGR,96, 22753. [2] Warren and Wasson (1977) Proc.LSC 8th, 2215;(1978)Proc.LPSC9th, 185. [3] Phinney and Simonds (1977) Impact and Explosion Cratering. 771. [4] Grieve et al. (1977) Impact and Explosion Cratering, 791. [5] Morgan et al. (1975) Proc. LSC 6th, 1609. [6] Palme et al. (1978) GCA, 42, 313. [7] Wolf et al. (1980) GCA, 44, 1015. [8] Warner and Bickle (1978) Am. Mineral., 63, 1010. [9] Ryder et al. (1980) Proc. LPSC 11th, 471. [10] Naldrett and Hewins (1984) Ontario Geol. Surv. Spec. Vol. 1, 235. [11] Walker et al. (1991) EPSL, 105, 416. [12] Naldrett (1984) Ontario Geol. Surv. Spec. Vol. 1, 309. [13] Scribbins et al. (1984) Can. Mineral., 22, 67. [14] Naldrett et al. (1984) Ontario Geol. Surv. Spec. Vol. I, 253. [15] Gupta et al. (1984) Ontario Geol. Surv. Spec. Vol. 1, 381. [16] Pike and Spudis (1987) Earth Moon Planets, 39, 129. [17] Leeman and Hawkesworth (1986) JGR, 91, 5901. [18] Moorbath and Hildreth (1988) CMP, 98, 455. [19] Gerlach and Grove (1982) CMP, 80, 147. [20] McMillan and Duncan (1988) J.Petrol., 29, 527. [21] Nixon (1988) J. Petrol., 29, 265. [22] Norman and Mertunan (1991) JGR 96, 13279. [23] Dietz (1964) J. Geol., 72, 412. [24] French (1970) Bull. Volcanol,. 34, 466. [25] Shanks and Schwerdiner (1991) Can. J. Earth. Sci., 28, 411. [26] Wilhelms (1987) U.S. Geol. Surv. Prof. Pap. 1348. [27] Schultz and LutzGarihan (1982) Proc. LPSC 13th, 84. [28] Nyquist (1983) Proc. LPSC 13th, 785; (1984) Proc. LPSC 14th, 631. [29] Mouginis-Mark et al. (1992) JGR, in press. [30] Schultz and Lianza (1992) Nature, 355, 234. [31] Sims et al. (1981) Geol. Surv. Can. Pap. 81-10, 379. [32] Krogh et al. (1984) Ontario Geol. Surv. Spec. Vol. 1, 431. [33] Nyquist L. E. and Shih C.-Y. (1992) LPSC XXIII, 1007-1008.

MELTING ANDITS RELATIONSHIP TOIMPACT CRATER MORPHOLOGY. John D. O'Keefe and Thomas J. Ahrens, Lindhurst Laboratory of Experimental Geophysics, Seismological Laboratory 252-21, Califomia Institute of Technology, Pasadena CA 91125, USA.

Shock-melting features occur on planets at scales that range from micrometers to megameters. It is the objective of this study to determine the extent of thickness, volume geometry of the melt, and relationship with crater morphology.

The variation in impact crater morphology on planets is influenced by a broad range of parameters: e.g.. planetary density ( $\rho$ ), thermal state, strength (Y), impact velocity (U), gravitational acceleration (g),... We modeled the normal impact of spherical 

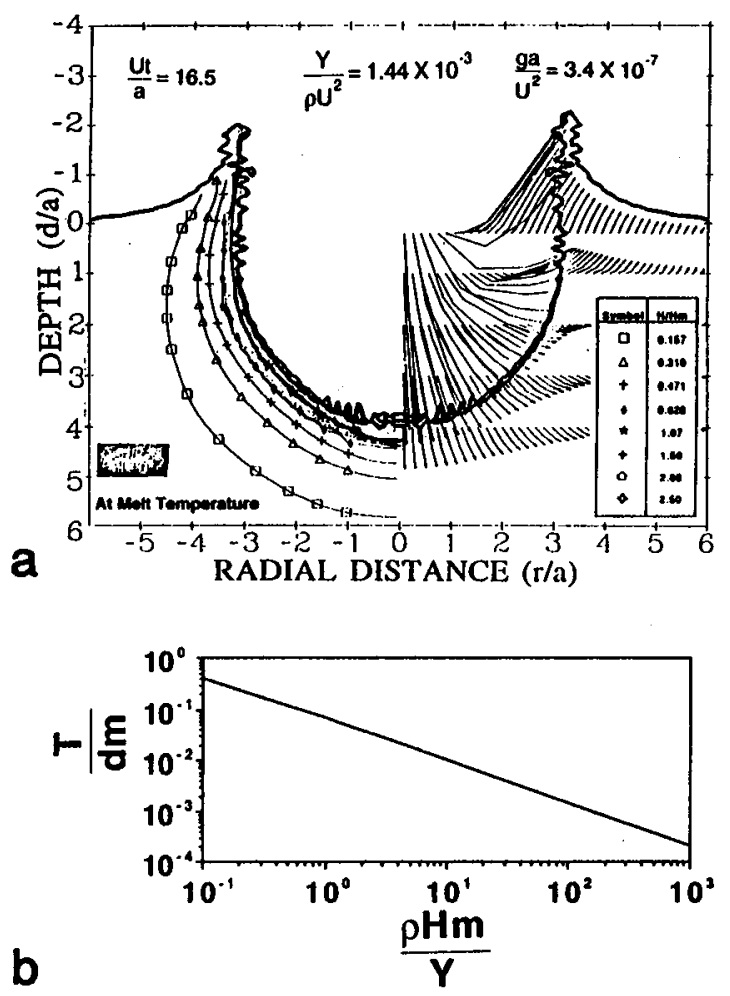

Fig. 1. (a) Melt layer morphology at time of maximum penetration for strength-dominated simple crater. (b) Melt layer thickness/ crater diameter at time of maximum penetration as a function of (Cauchy number) ${ }^{-1}$.
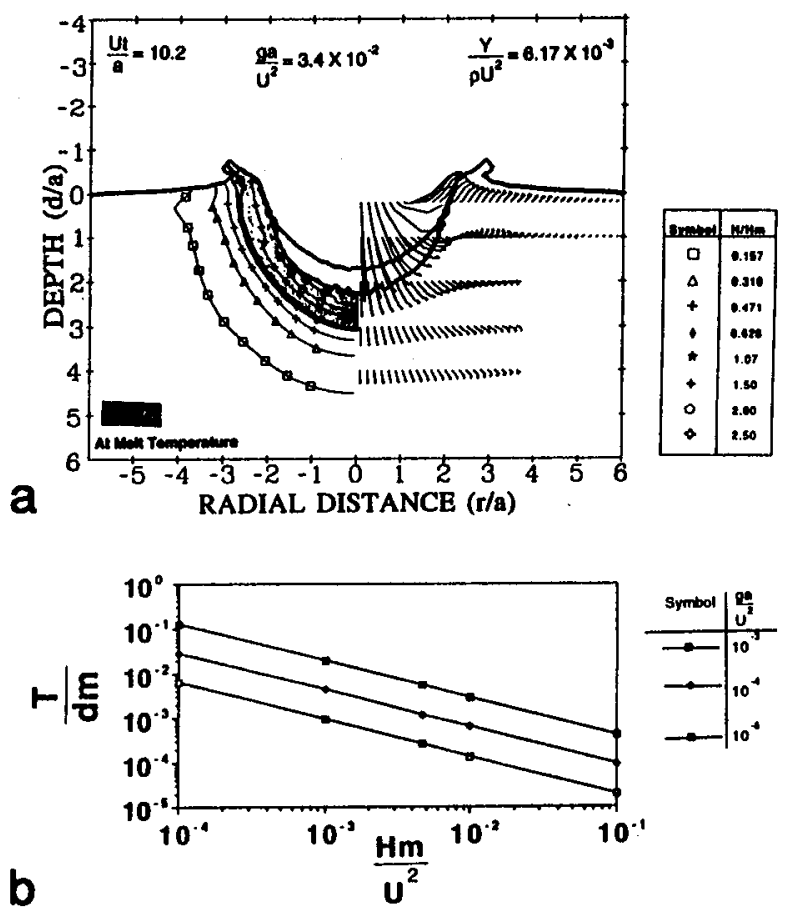

Fig.2. (a) Melt layer morphology at time of maximum penetration for a gravity-dominated complex crater. (b) Melt layer thickness/ crater diameter at time of maximum penetration as a function of (Froude number) ${ }^{-1}$.

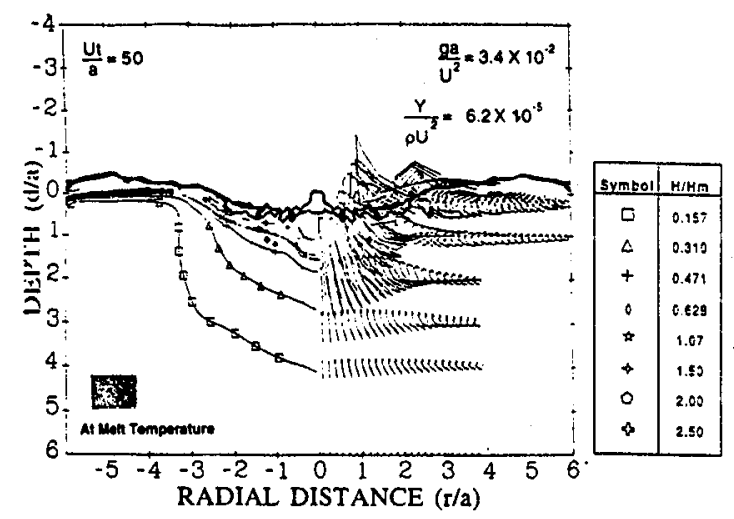

Fg.3. Melt layermorphology at later times for a gravity-dominated complex crater.

projectiles on a semi-infinite planet over a broad range of conditions using numerical techniques [1]. The scope of the calculations was defined so as to span the range of dimensionless parameters that characterize planetary impacts. These parameters are the inverse Froude number, ga/U2, inverse Cauchy number, $\mathrm{Y} /\left(\mathrm{pU}^{2}\right)$, melt number, $H_{m} / U^{2}$, and shock weakening number, $H_{g} / \mathrm{U}^{2}$. Here $H_{m}$ is the melt enthalpy $\left(-10^{10} \mathrm{erg} / \mathrm{g}\right)$, and $\mathrm{H}_{2 \mathrm{w}}$ is the enthalpy required to negate the planet's strength $\left(-10^{7}-10^{\circ} \mathrm{crg} / \mathrm{g}\right)$.

The crater morphological regimes have been described as simple bowl-shaped, flat-floored, multiple-ringed, central peak, and central pit [2]. In the case of simple bowl-shaped craters, the strength of the planet arrests the growth of the crater and is the dominant factor in its shape (Fig. 1). In all the other regimes, gravity arrests the growth and results in a rebounding of the depth and a collapse and propagation of the crater lip (Fig. 2). Multiple rings, peaks, and pits evolve after the rebounding and collapse and are a result of the interplay between the gravitational and strength forces (Fig. 3). The planetary strength is altered by the impact process. The strong shock wave melts, thermally weakens, and fractures the planetary material. We have modeled the melting and thermal weakening and Asphaung et al. [3] are addressing fracturing. We have determined the consequences of these effects on crater morphology scaling using the formalism of Holsapple and Schmidt [4]. Using the result of calculations, we determine the melt layer thickness/crater diameter $\left(T_{m} / d\right)$ for simple and complex bowl-shaped craters. From numerical calculations, we find for simple craters that the quantity $T_{m} / d$ is dependent only upon the material properties and scales as $\left[\mathrm{Y} /\left(\mathrm{pH}_{\mathrm{m}}\right)\right]^{-02 \mathrm{a}}$ (Fig. 1b). The relative melt layer thickness for craters that are dominated by a shock weakening scale as $\left(H_{m} / H_{m}\right)$-ars. For gravity-dominated craters and a given crater diameter, $T_{\mathrm{m}} / \mathrm{d} \propto\left(\mathrm{H}_{\mathrm{w}} /\right.$ $\mathrm{U}^{2}$ ) $-02 \mathrm{~s}$, so that the relative thickness increases with velocity (Fig. 2b). In addition to the melt layer thickness, we determined the scaling of the depth and total amount of melting for each of the cratering regimes. These results will be presented along with a comparison with terrestrial [e.g., 5] cratering field results.

References: [1] Thompson S. L. (1979) SAND-77-1339. Sandia National Labs., Albuquerque, New Mexico. [2] Melosh H. J. (1989) Impact Cratering, A Geologic Process, Oxford, New York, 245 pp. [3] Asphaung E. H. et al. (1991) LPSC XXII, 37-38. [4] Holsapple K. A. and Schmidt R.M. (1987) JGR, 92,6350-6376. [5] Grieve R. A. F. et al. (1991) JGR, 96, 22753-22764. 
IMPACT CRATERING RECORD OF FENNOSCANDIA. L. J. Pesonen' and H. Henkel' ${ }^{2}$ 'Laboratory for Paleomagnetism, Geophysics Department, Geological Survey of Finland, Espoo, Finland, 2Department of Photogrammetry, Royal Institute of Technology, Stockholm, Sweden.

A compilation (Fig. 1) of circular topographic, morphological, or geophysical structures in Fennoscandia and adjacent areas reveals 62 craterform structures of which 15 (class $A$ or a) appear to be of extraterrestrial origin due to meteorite impact. The majority of the structures are probable (class B, 9) and possible (class C, 34) impact craters for which there is not yet sufficient proof for impact origin.

Four of the proven impact craters (Lappajjarvi, No. 31, 77 Ma old; Dellen, No. 5, $990 \mathrm{Ma}$ old; Mien, No. 20, $\sim 120 \mathrm{Ma}$ old; and Jänisjärvi, No. 36, 700 Ma old) contain large volumes of impact melt and many other features of intense shock metamorphism. The age of the recognized impact craters vary from prehistoric ( 3500 B.C., No. 38, Kaali) to late Precambrian ( 1210 Ma, No.11, Björkö). The histogram of the ages (although the number of proven impact craters is still very small) shows two possible peaks (Fig. 1, inset): one group consisting of impact craters less than $150 \mathrm{Ma}$ old and the second one with ages between 350 and $600 \mathrm{Ma}$. There is so far a deficiency of impact craters in Fennoscandia with ages between 200 and $350 \mathrm{Ma}$. The majority of the proven impact craters have rim diameters between 5 and $20 \mathrm{~km}$; the largest meteorite impact crater in Fennoscandia, the Siljan (No. 6, age $\sim 360 \mathrm{Ma}$ ), has a diameter of

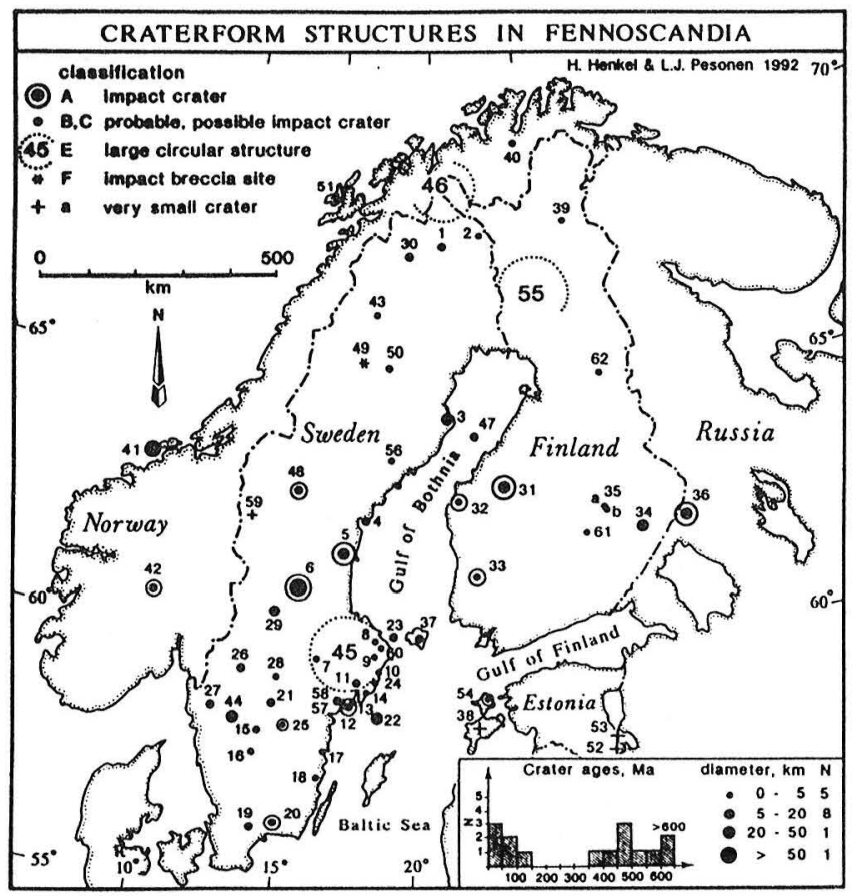

Fig. 1. Impact craters and other craterform structures in Fennoscandia and adjacent areas. Encircled structures refer to proven impact craters (class A); the others refer to class B (probable) and class $C$ (possible) impact craters respectively. The very large circular pattems refer to class $\mathrm{E}$ structures for which impact origin is not yet proven. The class F sites represent locations of breccia occurrences without known crater structure. The very small Quaternary craters (class a) are denoted with a plus sign. (Inset) Ages and diameters of the proven (classes A and a) impact craters.
$55 \mathrm{~km}$. The impact cratering rate for Fennoscandia in the region where craters occur is $2.4 \times 10^{-14} \mathrm{~km}^{-2} \mathrm{a}^{-1}$ and includes 12 proven impact craters with diameters from 3 to $55 \mathrm{~km}$. This amounts to 2 events per every $100 \mathrm{Ma}$ during the last $700 \mathrm{Ma}$.

There is increasing evidence that some ( 3 , class E) of the large circular geological, morphological, or geophysical features [the Uppland (No. 45), the Nunjes (No. 46), and the Marras (No. 55) structures, Fig. 1] represent deeply eroded scars of Early Proterozoic impact craters, but impact-generated rocks or fall-out ejecta layers have not yet been identified with these structures.

No craterform structures of Archean age have so far been discovered in Fennoscandia although, statistically, remnants of Archean cratering events should be found in the Fennoscandian Shield. New ways of searching for these craters are proposed and discussed. In addition to changes in the petrophysical properties of rocks, such as density, magnetization, and electrical conductivity, redistribution of large volumes of rocks are associated with large impacts. Such changes in structures and rock properties may be identified by integrated interpretations of regional high-resolution geophysical data.

The Siljan impact case shows, however, that the impact overprinting can be very slight in comparison to geophysical anomalies caused by preimpact lithological and structural variations.

We review the Fennoscandian impact cratering recond giving examples of geophysical signatures of impact craters.

BOHEMIAN CIRCULAR STRUCTURE, CZECHOSLOVAKIA: SEARCH FOR THE IMPACT EVIDENCE. Petr Rajlich, Geological Institute, Czechoslovak Academy of Sciences, Rozvojova 135,165 00 Prague 6, Czechoslovakia.

Test of the impact hypothesis [1] for the origin of the circular, 260-km-diameter structure of the Bohemian Massif (Fig. 1) led to the discovery of glasses and breccias in the Upper Proterozoic sequence that can be compared to autogeneous breccias [2] of larger craters. The black recrystallized glass contains small exsolution

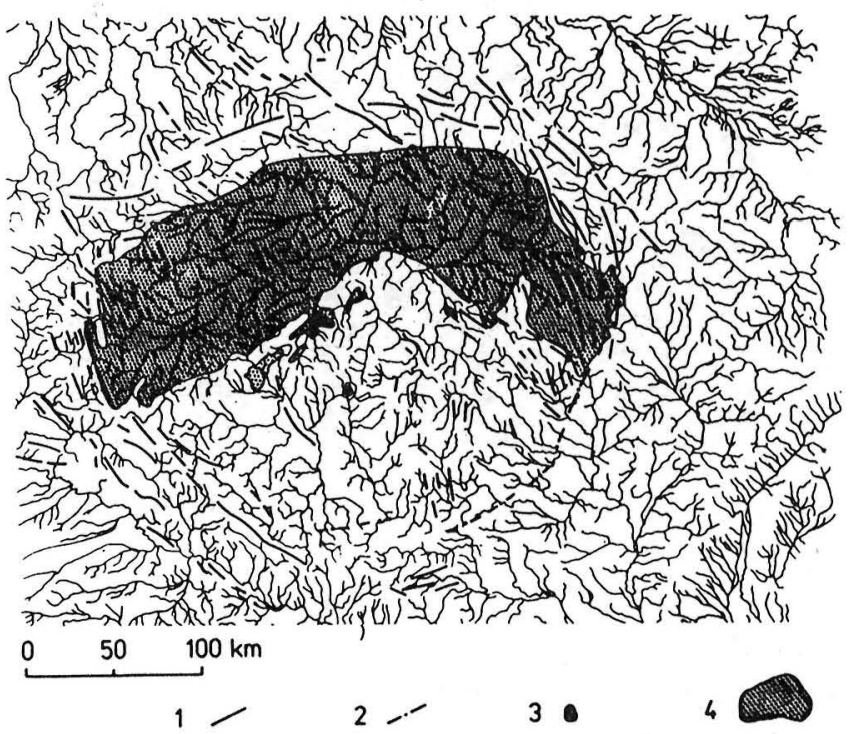

Fig. 1. Circular structure of the Bohemian Massif; 1-topographical features, 2-important faults with geological contacts of units differing in mobility in Variscan orogenesis, 3-outcrops of autogeneous breccias, 4 -extent of the Upper Proterozoic series. 
TABLE 1. Chemical composition of fragments and melt veins.

\begin{tabular}{|c|c|c|c|c|c|c|c|c|c|c|c|}
\hline$\%$ & $\mathrm{H}_{2} \mathrm{O}^{+}$ & $\mathrm{SiO}_{2}$ & $\mathrm{Al}_{2} \mathrm{O}_{3}$ & $\mathrm{Fe}_{2} \mathrm{O}_{3}$ & $\mathrm{TiO}_{2}$ & $\mathrm{CaO}$ & $\mathrm{MgO}$ & $\mathrm{Na}_{2} \mathrm{O}$ & $\mathrm{K}_{2} \mathrm{O}$ & $\mathrm{MnO}$ & $\mathrm{P}_{2} \mathrm{O}_{5}$ \\
\hline Melt & 1.11 & 59.53 & 21.52 & 8.64 & 1.15 & 0.62 & 1.98 & 0.95 & 4.07 & 0.053 & 0.13 \\
\hline $\mathrm{CR}$ & 1.45 & 57.76 & 23.60 & 8.41 & 1.19 & 0.21 & 1.86 & 0.61 & 4.47 & 0.050 & 0.12 \\
\hline Melt & 1.06 & 60.61 & 21.42 & 8.32 & 1.09 & 0.50 & 1.91 & 0.71 & 3.91 & 0.058 & 0.14 \\
\hline Melt & 0.99 & 60.92 & 21.34 & 8.37 & 1.08 & 0.46 & 1.89 & 0.62 & 3.89 & 0.053 & 0.14 \\
\hline$C * R$ & 1.36 & 60.73 & 18.84 & 8.34 & 0.84 & 1.20 & 3.04 & 2.54 & 2.40 & 0.310 & 0.11 \\
\hline ppm & Ba & Co & $\mathrm{Cr}$ & $\mathrm{Nb}$ & $\mathrm{Ni}$ & $\mathbf{R b}$ & Sr & $\mathrm{Y}$ & $\mathrm{Zn}$ & $Z_{\boldsymbol{r}}$ & \\
\hline Melt & 958 & 26 & 126 & 24 & 40 & 145 & 173 & 34 & 102 & 209 & \\
\hline CR & 938 & 26 & 153 & 26 & 51 & 132 & 153 & 36 & 99 & 190 & \\
\hline Melt & 877 & 25 & 117 & 22 & 43 & 150 & 150 & 33 & 92 & 194 & \\
\hline Melt & 874 & 24 & 163 & 21 & 56 & 148 & 146 & 34 & 94 & 193 & \\
\hline$C^{*} \mathbf{R}$ & 392 & 29 & 146 & 13 & 54 & 90 & 95 & 29 & 96 & 126 & \\
\hline
\end{tabular}

C* $\mathrm{R}$-country rock from place more distant than other samples.

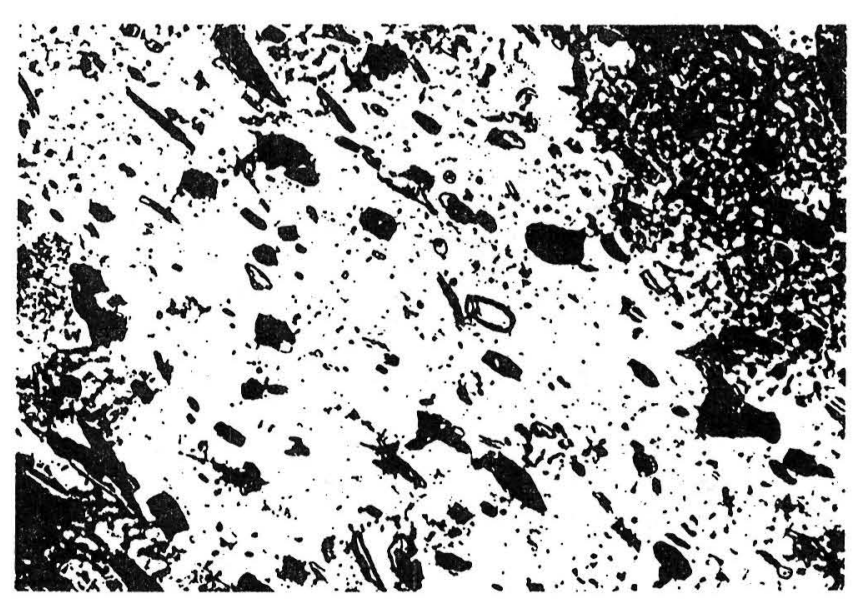

Fig. 2. Microphotograph of the recrystallized quartz glass with exsolutions of feldspar and biotite, $\times 100$.

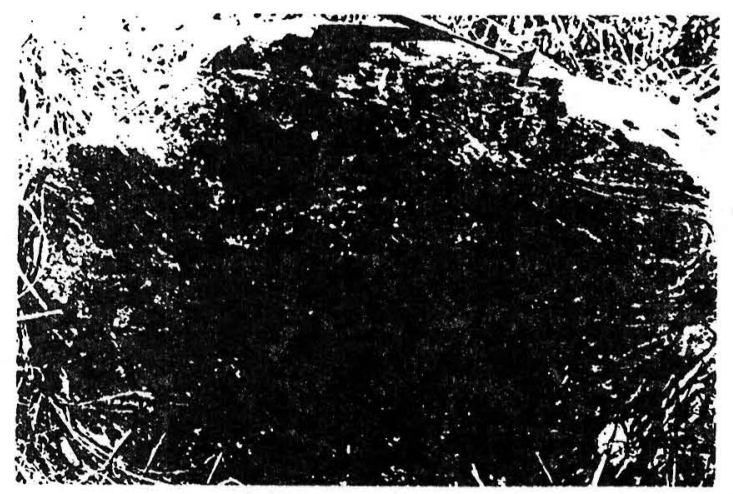

Fig. 3. Outcrops of the autogeneous breccia with rock fragments cemented by the melt.

crystals of albite-oligoclase and biotite, regularly dispersed in the matrix recrystallized to quartz (Fig. 2). The occurrence of these rocks is limited to a $1-\mathrm{km}^{2}$ area. It is directly underlain by the breccia (Fig. 3 ) of the pelitic and silty rocks cemented by the melted matrix, found on several tens of square kilometers. The melt has the same chemistry as rock fragments (Table 1, Fig. 4) in major and in trace

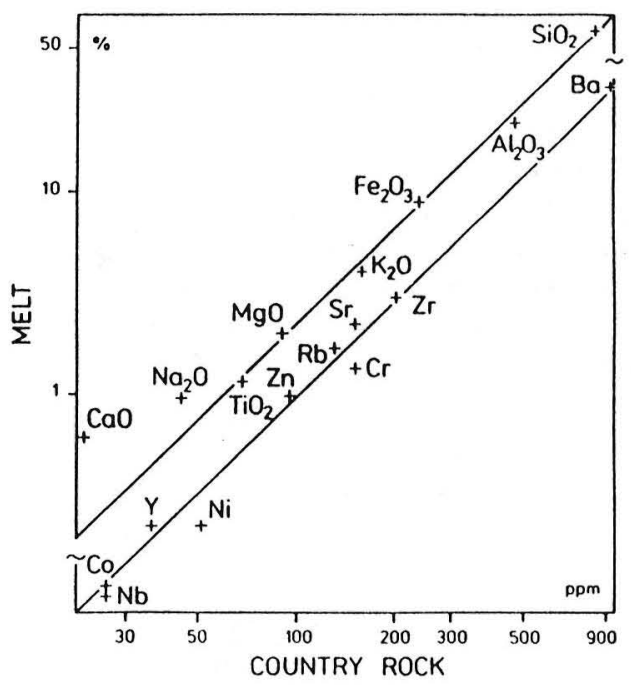

Fig. 4. Correlation graph of the chemical composition of country rock and melt.

elements. It is slightly impoverished in water. The proportion of melted rocks to fragments varies from 1:5 to 10:1 (Fig. 2). The mineralogy of melt veins is the function of later, mostly contact metamorphism. On the contact of granitic plutons it abounds on sillimanite, cordierite, and small bullets of ilmenite. Immediately on the contact with syenodiorites it contains garnets. The metamorphism of the impact rock melt seems the most probable explanation of the mineralogy and the dry total fusion of rocks accompanied by the strong fragmentation. The next rocks in the top of the sequence are larger bodies of tchermakitic metamelagabbros and conglomerates with the volcanic matrix. Crystalline rock fragments are frequently found here. Structurally they resemble orthogneisses and granites, but with a glassy appearance especially of feldspars. The very-fine-grained texture of rocks is explained tentatively as recrystallized shocked rocks. Some parts of the conglomerates can be suevites as well. The breccia formation and conglomerates are intercalated between the Moldanubian gneisses that transgrade the circular structure and between the Upper Proterozoic sequence, which on the map is crescent shaped, contouring the northern half of the circular structure (Fig. 1). The lower part of the Upper 
Proterozoic sequence begins with pillow lavas and is terminated by the sedimentary sequence with shallow water fossils (from $<10 \mathrm{~m}$ depth; Vavrdova, oral communication), indicating the successive filling of the hole. The total thickness of this formation is not known, though geophysical models indicate several kilometers. The restriction of breccias to the base of this formation provides age constraints that would indicate the age of the impact is 1.8-1.2 m.y.

The circular structure is defined by the topography, water courses, and geological contacts in the Tertiary through Upper Proterozoic sequences. It is visible also on the fault geometries in the brittle and in the ductile stages from later orogenies as featured by the half circular Permian and Cretaceous sedimentary basins. The rigid conservation of the circular form is tentatively explained by the later cooling of the upper mantle rocks under the structure after the impact, enabling them to behave rigidly. Several shearing phenomena encountered in crystalline rocks of the Moldanubian can be attributed to the excavation stage.

References: [1] Bouska V. (1990) Vesmir, 69, 9, 487-492 (in Czech). [2] Masaytis V. L. et al. (1980) Geology of Astroblemes, Nyedra, Moscow, 1-231.

THE VREDEFORT DOME-REVIEW OF GEOLOGY AND DEFORMATION PHENOMENA ANDSTATUS REPORT ON CURRENT KNOWLEDGE AND REMAINING PROBLEMATICS (FIVE YEARS AFTER THE CRYPTOEXPLOSION WORKSHOP). W. U. Reimold, Econ. Geological Res. Unit at the Department of Geology, University of the Witwatersrand, P.O. Wits 2050, Johannesburg, R.S.A.

The Vredefort Structure located in the center of the Witwatersrand basin in South Africa and the Sudbury structure in Canada are widely considered the two oldest and largest impact structures still evident on Earth. Both structures are very similar in a number of geological aspects (e.g., association with major economic ore deposits, similar ages of ca. $2 \mathrm{Ga}$, abundant pseudotachylite as well as shatter cone occurrences, overturned collar), as summarized by [1]. However, whereas the geological community generally accepts an impact origin for the Sudbury structure, a number of researchers are still reluctant to accept this for the Vredefort Dome.

Five years ago an intemational workshop focusing on the Vredefort structure [2] scrutinized the evidence and attempted to resolve the differences between impact supporters and protagonists of internal genetic processes. Clearly, this goal was not achieved, but at least a number of important areas of further research were defined. Research in the Vredefort structure gained new momentum in 1991, partially in anticipation of the Sudbury '92 Conference, and because several mining houses realized how important full understanding of the structure and evolution of the Vredefort Dome is with regard to exploration and mining activities in the surrounding Witwatersrand basin.

Besides the long-established impact and gas explosion hypotheses, several other genetic processes have been discussed in recent years: rapid updoming, thrusting, combinations of several tectonic processes, and an impact event at $2 \mathrm{Ga}$ ago followed by tectonic modification. Reviews of the geology and geophysics of the Vredefort structure were repeatedly presented in recent years (e.8., $[3,4]$ and several papers in [2]). Therefore the aim of this review is to present new data, to highlight the most obvious shortcomings in the current database, and to summarize the major arguments in the genetic controversy.
Since 1987 important new results were provided by Hart et al. [3, and refs. therein] dealing with the geochemistry of the granitic core and aspects of dynamic metamorphism. Reimold [4] evaluated the geochemical database for Vredefort pseudotachylite, and new chronological data were contributed by [5] and [6]. Continued structural work had been demanded by the participants of the 1987 workshop. Colliston and Reimold [7] presented the results of a first detailed structural study in the southern part of the Dome and in areas of the northwestern sector. Minnitt et al. [8] mapped the Archean greenstone terrane in the southeastem quadrant and completed structural analysis of the granite-gneiss exposures in the southem part. Both studies resulted in similar findings, suggesting that deformation in the basement is mainly of Archean age and related to a stress field, in which the principal stresses operated in a near-horizontal plane (cf. Colliston and Reimold, this volume). Later macroscopic deformation is mainly restricted to local subvertical shear zones scattered throughout the granitic core. In the central part of the core deforma-

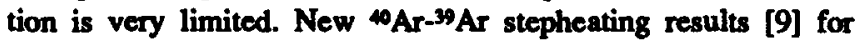
mineral separates from host rocks to two pseudotachylite samples that were dated by [6] at ca. $1.4 \mathrm{Ga}$ further supported the conclusion that these breccias were formed at post-2-Ga times.

Currently several structural projects in the collar are in progress, with preliminary reports indicating that several deformation events since deposition of the Witwatersrand Supergroup (ca. 2.75-3.05 Ga ago) could be recognized. Consequently, one aspect of utmost importance for future research must be to establish a complete chronological framework for the geological evolution in this region. The igneous rocks that intruded core and collar of the Dome at various times since Ventersdorp volcanism (ca. $2.7 \mathrm{Ga}$ ago) are currently being studied as possible candidates for radiometric dating. ${ }^{10} \mathrm{Ar}-{ }^{39} \mathrm{Ar}$ stepheating and laser $\mathrm{Ar}$ dating of the various generations of pseudotachylite identified in both the structure and the Witwatersrand basin should be continued as well. A detailed metamorphic project, comparing the rocks of different metamorphic grades in the northwest/west (high) and northeast (low) sectors respectively with the metamorphic record for the whole Witwatersrand basin, has just been initiated. It is also still uncertain at what times the major metamorphic events took place and whether the enhanced metamorphism in the northwest/west is the result of contact metamorphism in the vicinity of alkali granitic intrusions or of regional metamorphism. The nature of the pseudotachylite-rich and chamockite-bearing transition zone between Outer Granite gneiss and Inlandsee Leucogranofels is still controversial: Does it represent a pre-Vredefort intracrustal lithological boundary, a thrust plane, or a decollement zone possibly linked to major pre-Vredefort gravity slides in the northern Witwatersrand basin? What is the significance of the chamockite occurrences that to date have not been studied in detail? New quarry exposures in and near this zone are being studied and could reveal the three-dimensional geometry of pseudotachylite breccia zones. Finally, (sub)planar microdeformations in Vredefort quartz have now become the object of TEM investigations.

At this point in time, the main arguments in favor and against an impact origin for the Vredefort structure can be summarized as follows.

Pro Impact: (1) The structure is regarded as being circular and (2) surrounded by ring faults. (3) The dome itself is considered to be the central uplift of a gigantic impact structure with (4) a "crust-onedge" configuration of the structure, involving both overtumed collar and basement. (5) The presence of shatter cones. (6) Pseudotachylite is regarded as an equivalent of impact breccia and (7) the 
granophyre as melt rock. (8) Shock metamorphism occurs in the form of shock-characteristic planar microdeformation features (PDFs) in quartz.

Contra Impact: (1) The structure is asymmetrical and polygonal. (2) The southem equivalent to the collar in other sectors shows subhorizontal stratigraphy. (3) The "crust-on-edge" model is only valid for the northem part of the dome. (4) There is only limited structural evidence for 2-Gadeformation. (5) Deformation intensity does not increase toward the center, and deformation in the central area is generally poorly developed. (6) Deformation is magnified along northeast-southwest-trending lineaments. (7) Several phases of deformation have been identified. (8) Vredefort deformation phenomena are also observed in the northem Witwatersrand basin. (9) Temporal relationships between MSJS/shatter cones and pseudotachylite are complex and multiple. (10) Microdeformation is restricted to controversial "features" in quartz and kinkbanding of mica and occasionally hornblende. No other characteristic shock effects have been described from other minerals. (11) Temporal relationships between the various deformation and structural/magmatic events are complex and as yet not sufficiently resolved.

References: [1] Dressler B. O. and Reimold W. U. (1988) Snowbird II, 42-43, LPI Contr. 673. [2] Nicolaysen L. O. and Reimold W.U.(1990) Tectonophysics, 171, 422. [3] Hart R. J. et al. (1991) Tectonophysics, 192, 313-331. [4] Reimold W. U. (1991)N. Jhrb. Miner. Abh., 161, 151-184. [5] Allsopp H. L. et al. (1991) S. Afr. J. Sci., 87, 431-442. [6] Reimold W. U. et al. (1990a) Tectonophysics, 171, 139-152. [7] Colliston W. P. and Reimold W. U. (1990) Econ. Geol. Res. Unit. Inf. Circ., 229, 31. [8] Minnitt R. C.A. et al. (1992) LPSC XXIII. [9] Reimold W. U. et al. (1990b) Geol. Soc. Austral. Abstr., 27, 82.

\section{THE PSEUDOTACHYLITES FROM THE VREDEFORT} STRUCTURE AND THE WTWATERSRANDBASIN. W.U.

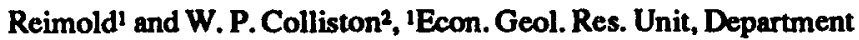
of Geology, University of the Witwatersrand, P.O. Wits 2050, Johannesburg, R.S.A., '2Department of Geology, University of the Orange Free State, P.O. Box 339, Bloomfontein 9300, R.S.A.

Pseudotachylite (pt) from both the Sudbury structure in Ontario and the Vredefort Dome in South Africa have been widely cited as the result of shock(impact)-induced brecciation. In the scientific [e.g., 1] and popular [2] literature pt has been described as "shock melt" or even as "impact melt rock" [2, p. 22]. In contrast, others have for years requested that a clarification of the definitions for "pseudotachylite" and "impact melt rock" be pursued [e.g., 3]. We have suggested that, until that time when well-defined criteria for genetically different melt rock types (e.g., generated by impact or tectonic processes) will have been established, the term "pseudotachylite" should only be used as a descriptive one and that, wherever genetic implications are discussed, other terms, such as impact melt (rock) or friction melt, should be applied. It is obvious that these suggestions are not only of value for the discussion of terrestrial melt rocks of controversial origin, but also apply to the characterization of melt veins in extraterrestrial materials [1,4].

The majority of planetologists currently support the impact hypothesis for the origin of the Vredefort Dome. However, those workers that have actively pursued research in the structure still feel uncomfortable about the severe limitations of the Vredefort database and the widely held belief that a few particular observations should hold the key to the understanding of the origin of the Dome. When the whole database is considered, there is a lot of (mainly structural or pt-related) evidence that is not readily explained by the impact hypothesis. Unfortunately, in recent years these workers have been ridiculed in a quite unscientific way, c.g., as "academic dinosaurs" or "reactionary dichards."

In this paper important observations on Vredefort and Witwatersrand pseudotachylite are summarized (for more detail, cf. [5]).

Distribution and Styles of Development: Major pt occurrences on the Dome are concentrated along the transition zone between Outer Granite gneiss and Inlandsce Leucogranofels, as well as along a northeast-southwest-trending zone just south of the Inlandsee. Brecciation in the central core region is extremely limited. Within the collar strata, pt mainly occurs in the form of $<30$ $\mathrm{cm}$-wide veins along bedding faults, but up to several-meter-wide zones comprised of intercalated networks of narnow veinlets and more massive melt breccia have recently been observed in mafic intrusives in the collar. Throughout the Dome and the northem part of the Witwatersrand basin pt is also found as thin melt films on slickenside and shatter cone (MSJS) surfaces. In the granitic core one finds either massive development (network breccia) or up to 50 cm-wide veins. Network breccias are occasionally seen to be delimited at one side by a thick, straight vein that possibly represents the initial generation vein. Several new quarry exposures indicate subhorizontal intemal structures within major breccia developments, but individual large-scale breccia zones appear to have overall vertical attitude. Thin veins generally resemble tectonic pt occurrences. Displacement is usually variable in $\mathrm{dm}$ to $\mathrm{m}$ intervals and ranges normally from $<1 \mathrm{~mm}$ to $>50 \mathrm{~cm}$ (but $<1 \mathrm{~m}$ ). Sense of movement is found to be equally variable along a given vein (but only rarely can three-dimensional geometries be studied). Frequently orthogonal pairs of veins-at $90^{\circ}$ angles-are observed. Most veins trend parallel to the main orientations (northwestsoutheast and northeast-southwest) defined by the pervasive Archean fabric. Other veins are generally injection veins off master veins or network breccia.

$P t$ in the Witwatersrand basin has been described from the north and northwest portions-the remainder is barren. Most pt here is bound to important bedding faults (dipping generally at low angles to the south) and to a few north-south-trending normal faults. Drilling has revealed several up to 40 -m-wide breccia zones with up to $60 \%$ melt development. Steeper pt veins are thought to represent injection veins. As in the Vredefort case, several generations of fault rocks (including pt) have been recognized. Ages for Vredefort pt range from 2.2 to $1.1 \mathrm{Ga}$. Further support for some of the lower ages has recently been presented by [6,7]; for one occurrence of Witwatersrand pt, ages of $2.0 \mathrm{Ga}$ have been established (Trieloff et al., this volume). This could possibly mean that formation of at least some of the Witwatersrand pt could be linked with either Bushveld or Vredefort activity.

Mineralogical data are still scarce and no quantitative micropetrographic results are available yet. The limited data at hand have, however, shown that at least some of the Vredefort pt was formed by cataclasis prior to melting. Chemical results for Vredefort pt [8] show that most of the analyzed pt was formed locally and that lateral mixing, probably not exceeding distances of a few meters, is restricted to network breccias. Comparative analysis of host rock and pt pairs illustrated that the same melting processes apply to Vredefort pt and to tectonic occurrences. A discussion of Vredefort pt would be incomplete if Martini's [9] findings of $\mathrm{HP} \mathrm{SiO}_{2}$ polymorphs in narrow veinlets from the outer collar were to be ignored (discussion of this aspect is in press elsewhere). Also of importance is the debate about the nature of mineral deformation associated with host rock contact zones and clasts within pt: e.g., do 
the (sub)planar deformation structures in quartz represent PDFs or planar fractures? It is our contention that they generally resemble planar fractures rather than the shorter and closer-spaced PDFs (compare Figs. 7b,c of [4] with Vredefort microdeformation).

Other unresolved problematics regarding Vredefort pt are the nature and origin of the enigmatic granophyre that, besides being regionally homogeneous in composition, displays a number of characteristics similar to those of pt. Major shortcomings in the pt database are (1) absolute ages for the several phases of pt development and of structural deformation, (2) understanding of the geological structure in the zones of major pt development and (3) of the internal structures of pt-rich (fault?) zones, (4) P-T-x conditions at pt formation-also with regard to $\mathrm{HP} \mathrm{SiO}_{2}$ polymorph generation, and (5) the relationships between Vredefort and Witwatersrand $p t$ and Witwatersrand fault structure.

References: [1] Schwarzman E. C. et al. (1983) Bull.GSA, 94, 926-935. [2] Dietz R. S. (1992) Earth, 1, 22. [3] Reimold W. U. et al. (1987) JGR, 92, 747-758. [4] Stöffler D. et al. (1992) GCA, 55, 3845-3867. [5] Killick A. M. and Reimold W. U. (1990) S. Afr. J. Geol., 93, 350-365. [6] Reimold W. U. et al. (1990) Geol. Soc. Austral. Abstr., 27, 82. [7] Allsopp H. L. et al. (1991) S. Afr. J. Sci., 87, 431-442. [8] Reimold W. U. (1991) N. Jhrb. Miner. Abh., 162, 151-184. [9] Martini J.E. J. (1991) EPSL, 103, 285-300. [10] Reimold W. U. (1990) S. Afr. J. Geol., 93, 645-663.

COINCIDENCE IN TIME OF THE IMBRIUM BASIN IMPACT AND APOLLO 15 KREEP VOLCANIC SERIES: IMPACT-INDUCED MELTING? Graham Ryder, Lunar and Planetary Institute, 3600 Bay Area Boulevard, Houston TX 77058, USA.

On the Earth there may be no firm evidence that impacts can induce volcanic activity [1]. However, the Moon does provide a very likely example of volcanism induced by an immense impact: The Imbrium Basin-forming event was immediately succeeded by a crustal partial melting event that released KREEP lava flows over a wide area. These two events are at present indistinguishable in radiometric age. The sample record indicates that such KREEP volcanism had not occurred in the region prior to that time, and never occurred again. Such coincidence in time implies a genetic relationship between the two events, and impact-induced partial melting appears to be the only candidate process.

This conclusion rests essentially on the arguments that (1) the Imbrium Basin event took place $3.86 \pm 0.02 \mathrm{Ga}$ ago; (2) the Apennine Bench Formation postdates Imbrium; (3) the Apollo 15 KREEP basalts are $3.85 \pm 0.03 \mathrm{Ga}$ old; (4) the Apollo $15 \mathrm{KREEP}$ basalts are derived from the Apennine Bench Formation; and (5) the Apollo 15 KREEP basalts are volcanic. Thus the Apollo 15 KREEP basalts represent a unique volcanic unit that immediately postdates the Imbrium event (within $20 \mathrm{Ma}$, possibly much less).

This abstract sketches the evidence for the links in the argument, describes some implications for initial conditions, and briefly explores ramifications of the process for the early history of the Earth.

The Age of Imbrium: Samples collected at the Apennine Front must be dominantly isotopically reset either by the Imbrium event or by older events. Analyses by laser argon release methods $[3,4]$ of varied impact melts from the rubble that forms the Apennines constrains the basin to be probably no older than $3.836 \mathrm{Ga}$, and extremely unlikely to be older than $3.870 \mathrm{Ga}$. Imbrium must also be younger than Serenitatis, reliably dated at $3.87 \mathrm{Ga}$. A younger limit set by the Apennine Bench Formation arguments is within uncertainty the same age.

The Stratigraphic Age of the Apennine Bench Formation: This extensive plains unit inside the Imbrium Basin underlies Imbrium-age craters and mare units (Fig. 1). However, it overlaps basin topography, hence is at least slightly younger than the basin itself $[5,6]$.

The Age of A pollo 15 KREEP Basalts: This distinct group of intersertal igneous fragments, widespread at the Apollo 15 landing site, gives $\mathrm{Ar}-\mathrm{Ar}$ and $\mathrm{Sm}-\mathrm{Nd}$ crystallization ages of $3.85 \pm 0.05 \mathrm{Ga}$

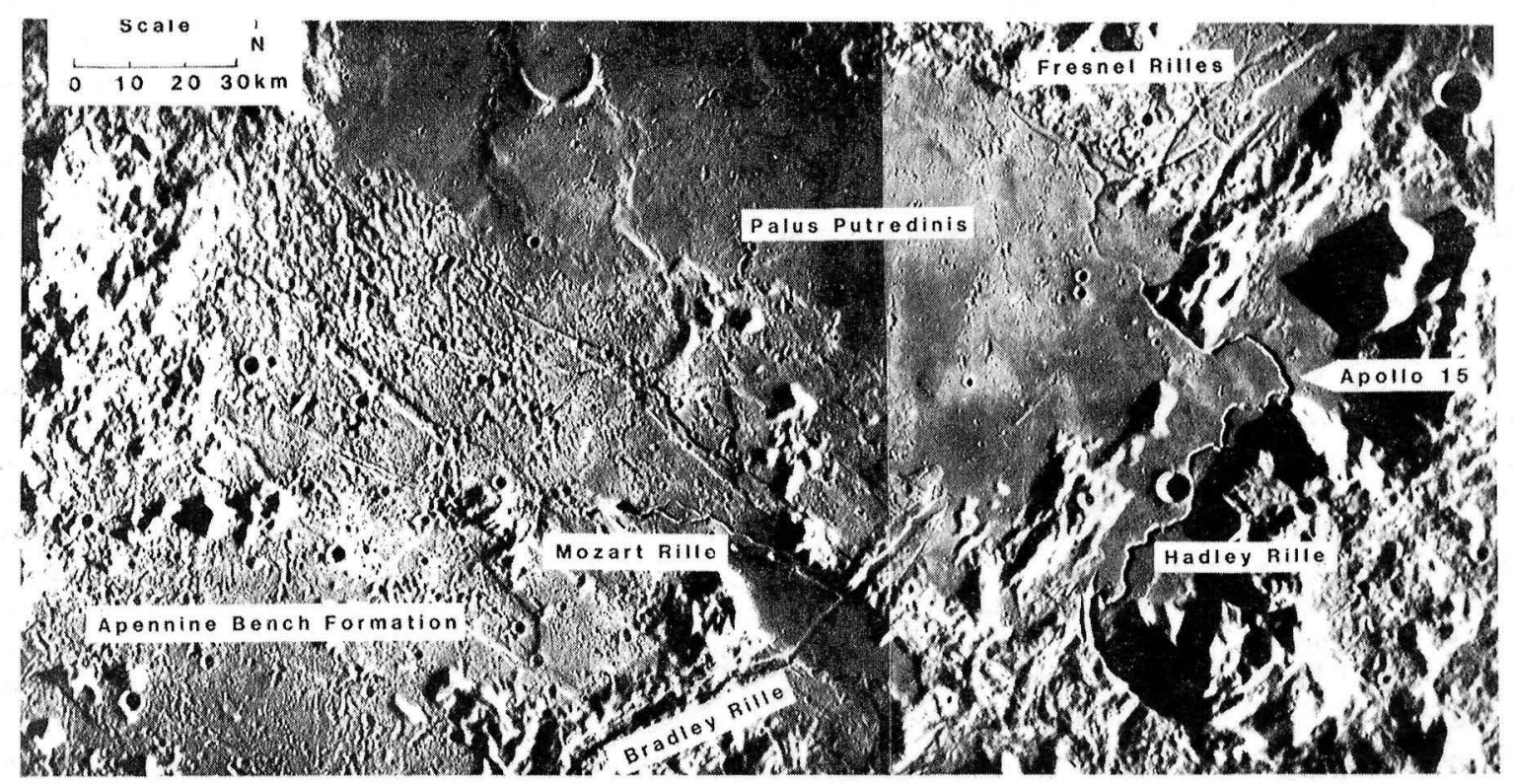

Fig. 1. Orbital photograph of the Apollo 15 landing site and relevant environs. Apart from the large area to the left of the picture, Apennine Bench Formation occurs at the area of the Fresnel Rilles. It probably also underlies the mare near the Apollo 15 landing site and may even be exposed at the North Complex (a dimple just to the north of the landing site) and elsewhere nearby. The mountains to the right are the Apennines, a prominent ring of Imbrium. 
[summary in 7], indistinguishable from the age of Imbrium. The RbSr ages are slightly older (slight Rb loss?) but within uncertainty of a 3.85-Ga age. KREEP basaltic material of other character or age has not been identified in the region, thus these basalts appear to represent a unique event in the region.

Apollo 15 KREEP = Apennine Bench Formation: The morphology of the Apennine Bench Formation indicates subsidence of a fluidlike material, consistent with volcanic flows $[5,6]$. The deconvolved orbital geochemistry shows the formation to be chemically very similar to the Apollo15 KREEP fragments. The formation occurs very close to the Apollo 15 landing site (Fig. 1), and is inferred to underlie the mare basalts near Hadley Rille; it may even be exposed at the North Complex, intended to be visited on the Apollo 15 mission but missed because of time delays. The Apollo 15 KREEP basalts are ubiquitous at the Apollo 15 site, and most must represent a local, not an exotic, component. The age of the KREEP fragments is consistent with requirements for the Apennine Bench. The correlation of the Apollo 15 KREEP basalts with the Apennine Bench Formation is almost inescapable.

Apollo 15 KREEP Basalts Are Volcanic: The basalts are free of clasts or meteoritic siderophile contamination, and have a range of compositions indicating crystal separation (unlike impact melts) and lying along the plagioclase-low Ca pyroxene cotectic [2]. Some demonstrate nonlinear cooling rates inconsistent with cooling of impact melts [8]. They cannot represent an average crustal composition such as would be represented by the Imbrium impact melt because they are so radiogenic.

With such a coincidence in age of a giant impact basin and a unique flood basalt eruption, the most reasonable conclusion is cause and effect: The unloading and heat input from the Imbrium Basin impact was directly responsible for the partial melting of a hot crust producing the Apollo 15 KREEP basalt floods. The chemical and isotopic evidence suggest that a large amount of partial melting of a crustal source is required to produce these basalts. The small gravity field on the Moon shows that the pressure relief of unloading even $100 \mathrm{~km}$ is only $0.5 \mathrm{GPa}$, and brings a mass of suitable rock only $60 \mathrm{~K}$ closer to its melting point [1]. The unloading of the lunar lower crust would have been less than that, and with latent heat of melting to take into account, not much melting can be expected. Thus, if impact-induced crustal melting is responsible for the Apollo 15 KREEP basalts, the source must have been at or very close to its melting temperature anyway, or melts induced by pressure release of the mantle added their heat to the source by upward movement without actually reaching the surface.

The oldest Earth rocks of any significant volume have an age similar to that of the lunar cataclysmic bombardment. Older crust either did not exist, or was essentially annihilated at that time. A hotter Earth at $3.86 \mathrm{Ga}$ ago was perhaps very susceptible to impactinduced partial melting, causing very extensive recycling even of nonsubductable granitic crust. Even larger planetesimals would have hit the Earth than the Moon, traveling even faster; the effects of pressure release would have been greater because of the stronger gravity field, and more material close to its melting temperature. Such melting could have had drastic effects in remixing and assimilating old crust into upper mantle material to add to an assumed plate-tectonic recycling that could not by itself be very efficient for granitic material.

References: [1] Melosh H. J. (1989) Impact Cratering, Oxford, 245 pp. [2] Ryder G. (1989) LPSC XX, 936. [3] Dalrymple G. E. and Ryder G. (1991) GRL, 18, 1163. [4] Dalrymple G. B. and Ryder G. (1992) Trans. AGU 14 Suppl., 362. [5] Spudis P. D., Proc.
LPSC 9th, 3379. [6] Wilhelms D. (1987) U.S. Geol.Surv.Prof.Pap. 1348, 302. [7] Shih C.-Y. et al. (1992) EPSL, 108, 203. [8] Ryder G. (1987) Proc. LPSC 17th, in JGR, 92, E331.

APOLLO 15 IMPACT MELTS, THE AGE OF IMBRIUM, AND THE EARTH-MOONIMPACTCATACLYSM. Graham Ryder' ${ }^{1}$ and G. Brent Dalrymple', 'Lunar and Planetary Institute, 3600 Bay Area Boulevard, Houston TX 77058-1113, USA, 2U.S. Geological Survey, 345 Middlefield Road, Menlo Park CA 94025, USA.

The early impact history of the lunar surface is of critical importance in understanding the evolution of both the primitive Moon and the Earth, as well as the corresponding populations of planetesimals in Earth-crossing orbits. Two endmember hypotheses call for greatly dissimilar impact dynamics. One is a heavy continuous (declining) bombardment from about $4.5 \mathrm{Ga}$ to $3.85 \mathrm{Ga}$. The other is that an intense but brief bombardment at about $3.85( \pm$ ? $) \mathrm{Ga}$ was responsible for producing the visible lunar landforms and for the common 3.8-3.9-Ga ages of highland rocks.

No impact melts among lunar samples have been found with an age greater than $3.9 \mathrm{Ga}$ [1]. A heavy continuous bombardment requires such melts to have once been common, and their absence requires either that they are present but have not been sampled, or that they have been reset continuously or terminally at dates later than $3.9 \mathrm{Ga}$. The chemical variety of dated impact melts suggests that at least several impacts have been dated, not just a limited sample reset by Imbrium and Serenitatis. Most ejecta in an impact is deposited cold and is not radiometrically reset even for Ar (although it can be disturbed), as shown by studies of both experimentally and naturally shocked materials [2-4]. Resetting should be accomplished only or nearly only by making a new impact melt, yet lunar samples clearly show that not all of the lunar crust has been so converted; old melt should remain if it once existed. Furthermore, the existence of old basalts and plutonic rocks suggests that old impact melts should have been preserved, had they existed. These arguments should be persuasive that no heavy bombardment in the period from at least 4.3 to $3.9 \mathrm{Ga}$ occurred [1]. Apparently, for various reasons they are not persuasive [e.g., 5]. Thus reliable ages for impact melt rocks of even more varied composition (hence potentially distinct origins) are needed to further test the various early impact hypotheses, and particularly to establish the relative abundance of old impact melts.

The Apennine Front, the main topographic ring of the Imbrium Basin, was sampled on the Apollo 15 mission. The rocks in the massif represent two main sources: (1) pre-Imbrium masses that have been uplifted by the event itself, and consist of pre-Imbrium rock units, and (2) ejecta from the Imbrium event, consisting of material melted in the Imbrium event and older material [6]. Either way, if impact melts existed in the region prior to the Imbrium event, they should now be part of the Front. Material formed in impacts younger than the Imbrium B asin must be minor, of very local origin, and from small craters (which tend to produce glassy melt products). The Apollo 15 impact melts show a diversity of chemical compositions, indicating their origin in at least several different impact events $[$ e.g., 7,8,9]. The few attempts at dating them have generally not produced convincing ages, despite their importance. Thus we chose to investigate the ages of melt rock samples from the Apennine Front, because of their stratigraphic importance yet lack of previous age definition. 
Using a continuouslaser system, we haveobtainedhigh-resolution ${ }^{10} \mathrm{Ar} \beta \mathrm{As}$ age spectra on single fragments of 12 melt rock samples from the Apennine Front. The melt rocks, all fine-grained, are essentially aluminous basalts, but with a variety of compositions, e.g., $\mathrm{MgO} 9$ to 21\%, Sm 2 to $25 \mathrm{ppm}$. We believe they must represent at least several different impact events. A few milligrams of each sample were crushed to submillimeter sizes and individual fragments, visibly free of clasts and weighing 62 to $620 \mathrm{mg}$, were irradiated. They were analyzed with a continuous Ar-ion laser extraction system and mass spectrometer [10,11]. Individual particles were incrementally heated, with temperature measured with an infrared radiometer. We have obtained 26 age spectra on the 12 melt samples. Some of these results have been previously published [11].

Of the 12 rocks analyzed, 7 have age spectrum plateaus that we interpret as crystallization (impact) ages. Individual plateaus have 2-sigma uncertainties of $\pm 16 \mathrm{Ma}$. The ${ }^{40} \mathrm{Ar} /{ }^{39} \mathrm{Ar}$ plateaus are generally well defined in the intermediate temperature range with $40 \%$ to $70 \%$ of the ${ }^{39} \mathrm{Ar}$ released. Six of these ages fall within the narrow range of $3879 \mathrm{Ma}$ and $3849 \mathrm{Ma}$, more or less within uncertainty of a common age. Spectra on five fragments of one sample gave a range from $3856 \mathrm{Ma}$ to $3879 \mathrm{Ma}$. The seventh sample gave a plateau age of $3836 \mathrm{Ma}$. The total span of ages is less than $1 \%$, a very narrow range. The remaining five samples show spectra that clearly indicate disturbance by post-3.8-Ga events, and lack plateaus. None of the 26 age spectra for the 12 melt rocks show any indication of older melt components. A conventional ${ }^{10} \mathrm{Ar} /{ }^{39} \mathrm{Ar}$ age of $3.85 \pm 0.05 \mathrm{Ga}$ for a different impact melt from the Apollo 15 landing site was reported by [12].

We believe that these data provide ages for a variety of impact melts that are coeval with or predate the Imbrium event. Thus a firstorder conclusion is that the Imbrium event is no older than about $3870 \mathrm{Ma}$, and probably no older than $3940 \mathrm{Ma}$. Independent evidence suggests strongly that Imbrium is not younger than this (because of the later KREEP basalts), hence is indeed very close to 3840 to $3850 \mathrm{Ma}$. In that our data show a variety of melts at or just before this time but not older melt, we believe it to be consistent with a very tightly constrained bombardment of the Moon. Serenitatis (about $3.87 \mathrm{Ga}$ ) falls in this same period. We have still no tangible evidence for significant bombardment prior to $3.9 \mathrm{Ga}$.

References: [1] Ryder G. (1990) Eos, 71, 313. [2] Jessberger E. and Ostertag R. (1982) GCA, 46, 1465. [3] Bogard D. et al. (1988) GCA, 52, 2639. [4] Stephan T. and Jessberger E. (1992) GCA, 56, 1591. [5] Schmitt H. (1991) Am. Mineral., 76, 773. [6] Apollo 15 Preliminary Science Report (1972) NASA SP-289. [7] Ryder G. and Spudis P. (1987) Proc. LPSC 17th, in JGR, 92, E432. [8] Laul J. C. et al. (1988) Proc. LPSC 18th, 203. [9] Lindstrom M. et al. (1990) Proc. LPSC 20th, 77. [10] Dalrymple G. B. (1989) U.S. Geol. Surv. Bull., 1890, 89. [11] Dalrymple G. B. and Ryder G. (1991) GRL, 18, 1163. [12] Bogard D. et al. (1991) LPSC XXII. 117.

SEARCH FOR THE 700,000-YEAR-OLD SOURCE CRATER OP THE AUSTRALASIAN TEKTITE STREWN FIELD. C. C. Schnetzler' and J. B. Garvin', 'Geography Department, University of Maryland, College Park MD 20742, USA, 2Geodynamic Branch, Code 921, Goddard Space Flight Center, Greenbelt MD 20771, USA.

Many tektite investigators have hypothesized that the impact crater that was the source of the extensive Australasian strewn field lies somewhere in or near Indochina. This is due to variations in abundance and size of tektites across the strewn field, variation of thickness of microtektite layers in ocean cores, nature of ablation characteristics across the field, and, above all, the occurrence of the lange, blocky, layered Muong Nong-type tektites in Indochina. A recent study of the location and chemistry of Muong Nong-type and splash-form tektites suggests that the source region can be further narrowed to a limited area in eastem Thailand and southem Laos [1].

There are four lines of evidence that point toward this area. The first is the observation that tektite sites in Indochina are nonrandomly distributed. Many sites seem to be located along linear trends or "rays" separated by areas relatively sparse or devoid of samples. These rays converge to a small area along the Thailand-Laos border between $15.5^{\circ} \mathrm{N}$ and $17^{\circ} \mathrm{N}$ latitude. Second, there is a somewhat larger region, enclosing the area delineated by the rays, where Muong Nong tektites predominate and/or there is no mention of splash-form-type tektites. Third, a high proportion of the reported sites containing super-sized (>1 kg) Muong Nong tektites are in this area. Lastly, Muong Nong tektites with this area show the largest chemical inhomogeneity in sites, and there is a high chemical gradient across the region; these are characteristics one would expect proximal to the source. The area defined by the above evidence is centered at $16^{\circ} \mathrm{N} / 105^{\circ} \mathrm{E}$, with a radius of approximately $125 \mathrm{~km}$.

Satellite multispectral imagery, a digital elevation dataset, and maps showing drainage patterns have been used to search within this area for possible anomalous features that may be large degraded impact craters. Four interesting structures have been identified from these datasets:

1. An approximately 30-km-diameter, quasicircular structure in Laos, resembling a partially infilled impact structure, centered at $16.35^{\circ} \mathrm{N} / 106.15^{\circ} \mathrm{E}$. It has a relatively flat floor surrounded by hills rising $70 \mathrm{~m}$ to several hundred meters above the floor, and a central elevated area rising about $100 \mathrm{~m}$ above the floor (Fig. 1). The structure is breached at approximately the cardinal points by rivers.

2. An approximately $25-\mathrm{km}$-diameter circular feature on the east side of the Mekong River, slightly east of Savannakhet, Laos $\left(16.55^{\circ} \mathrm{N} / 104.90^{\circ} \mathrm{E}\right)$. This feature is not an obvious depression or crater, but is an approximately circular area enclosing hummocky terrain of very low relief.

3. A $90-\mathrm{km}$-diameter area, centered at $16.6^{\circ} \mathrm{N} / 105.5^{\circ} \mathrm{E}$ (directly to the east of structure 2). This broad south-sloping feature is rimmed by high hills on the north and east, rising to $450 \mathrm{~m}$ above the floor, but only low lying hills to the west and south. The area is drained by two rivers flowing to the south.

4. An oblong depression on the west side and in a curve of the Mekong River, approximately $80 \mathrm{~km}$ northeast of Ubon Ratchathani, Thailand. It is approximately $30 \mathrm{~km}$ long northwest-southeast, and about $20 \mathrm{~km}$ wide southwest-northeast. Hills rise about $75 \mathrm{~m}$ in the southwest to over $300 \mathrm{~m}$ in the southeast above the flat floored plain.

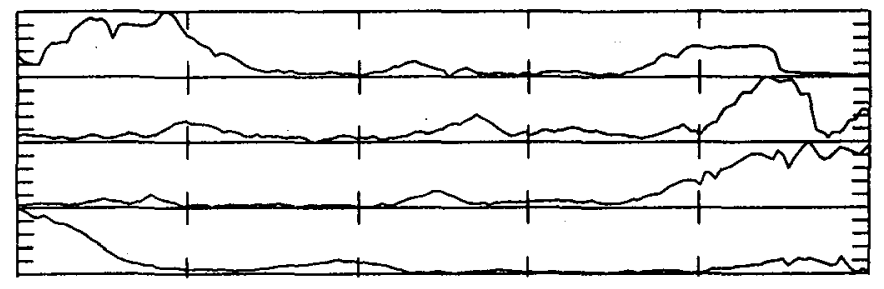

Fig. 1. Profiles across structure 1, centered at $16.35^{\circ} \mathrm{N} / 106.15^{\circ} \mathrm{E}$, in southern Laos. From top to bottom, southeast-northwest, southwest-northeast, west-east, south-north. 
All these features lie within a broad region of Mesozoic marine sedimentary rocks, the Indosinias formation, primarily sandstones interbedded with shales and limestones, which covers much of central Indochina. The age and composition of these sediments are broadly consistent with Australasian tektite composition and age [2]. Field work to examine these structures and collect country rocks for specific comparisons would seem warranted.

References: [1] Schnetzler C. C. (1992) Meteoritics, June. [2] Blum J. D. et al. (1992) GCA, 56, 483-492.

RECOGNIZINGIMPACTOR SIGNATURESIN THE PLANETARY RECORD. Peter H. Schultz ${ }^{1}$ and Donald E. Gault ${ }^{2}$, 'Department of Geological Sciences, Brown University, Providence RI, USA, ${ }^{2}$ Murphys Center of Planetology, Murphys CA, USA.

Crater size reflects the target response to the combined effects of impactor size, density, and velocity. Isolating the effect of each variable in the cratering record is generally considered masked, if not lost, during late stages of crater modification (e.g., floor uplift and rim collapse). Important clues, however, come from the distinctive signatures of the impactor created by oblique impacts.

In laboratory experiments, crater diameter exceeds impactor diameter by a factor of $\mathbf{4 0}$ for vertical impacts into gravitycontrolled particulate targets and reduces to 25 for oblique impacts at $15^{\circ}$ from the horizontal. Strength-controlled cratering in aluminum reduces these factors to 5 and 2 respectively. As scale increases, crater excavation is limited by gravity and cratering efficiency becomes progressively less efficient. A $100-\mathrm{km}$-diameter crater on Earth (rim-to-rim diameter with $25 \%$ enlargement due to slumping) is only a factor of 12 greater than the impactor diameter for a vertical impact and reduces to 6 for a $15^{\circ} \mathrm{impact}$ angle based on scaling relations given in [1]. The early compression stage [2] at planetary scales, therefore, comprises a significant fraction of the final crater size and approaches a value more typical of strengthcontrolled laboratory experiments, particularly for oblique impacts.

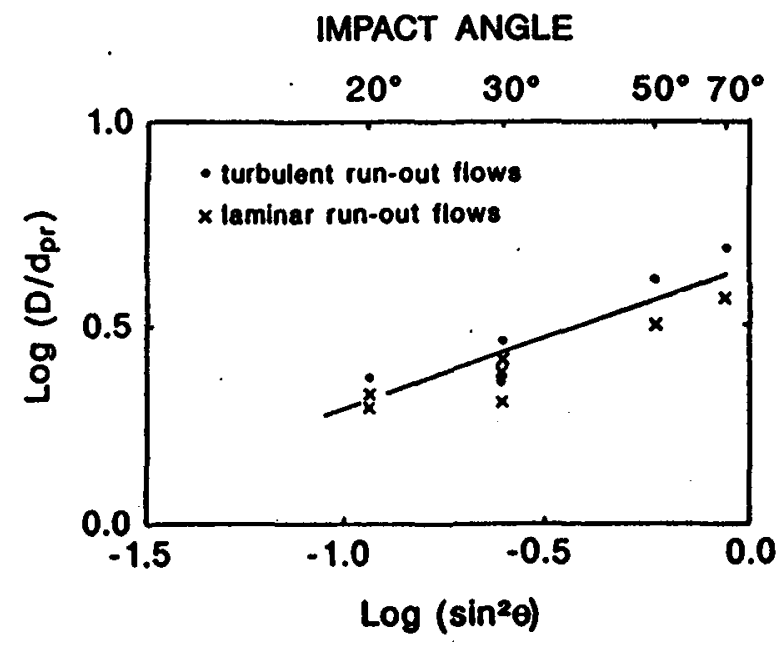

Fig. 1. Crater diameter (D) scaled to peak-ring diameter $\left(d_{w}\right)$ on Venus as a function of impact angle estimated from the degree of asymmetry in the ejecta deposits. If peak-ring diameter depends on impactor size (given velocity), $D / d_{p x}$ should decrease as impact angle decreases, as is shown. Different symbols correspond to different styles of long nun-out flows observed on Venus [6].
As a result, the distinctive signatures of early energy transfer may not be completely consumed by crater growth at planetary scales.

Two key diagnostic features of oblique impacts can be found in craters at both laboratory and planetary scales. First, oblique impacts create a distinctive asymmetric crater profile with the deepest penetration and steep inner wall uprange and a shallow, shelflike wall downrange [3]. Such a profile occurs for impact angles from $45^{\circ}$ to $15^{\circ}$ in strength-controlled craters (e.g., aluminum targets) but requires impact angles less than $5^{\circ}$ for gravity-

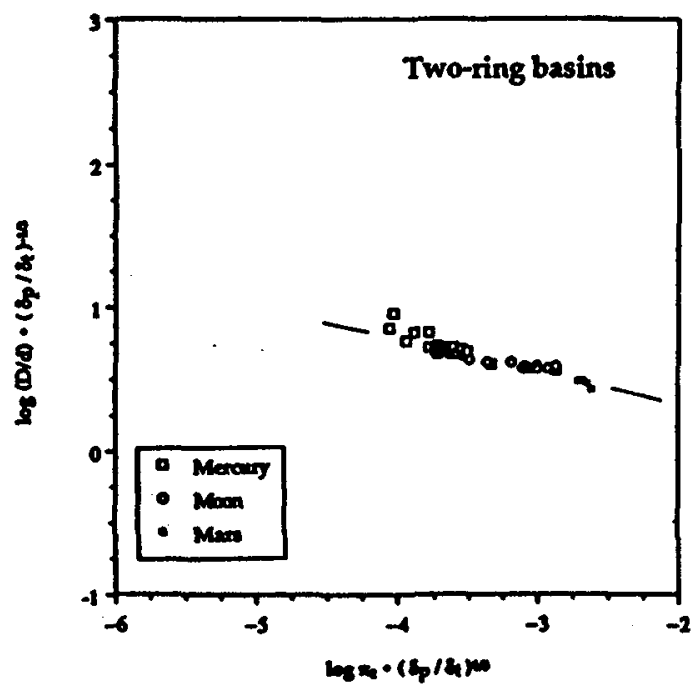

Fig. 2a. Crater diameter (D) scaled to impactor diameter (d) inferred from peak-ring diameter as a function of the dimensionless gravity-scaling parameter $\pi_{2}$ equal to $3.22 \mathrm{gr} / \mathrm{v}^{2}$ with radius ( $r$ ) again inferred from peak-ring diameter ( $g$ and $v$ refer to gravity and impact velocity respectively; $\delta_{p} / \delta$ t represents projectile/targetdensity ratio). Data for the Moon, Mercury, and Mars collapse onto a single relation for impact velocities 14,16 , and $32 \mathrm{~km} / \mathrm{s}$ respectively.

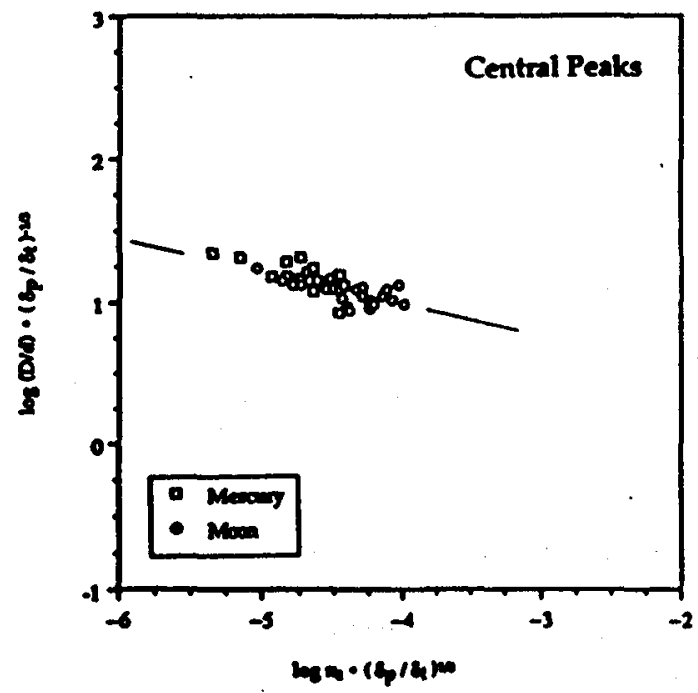

Fig. 2b. Crater diameter scaled to impactor diameter as in Fig. 2 a but referenced to the diameter of the central peak. Assumed impact velocities for the Moon and Mercury in this case are 16 and $40 \mathrm{~km} /$ s respectively. 
controlled targets (sand). Large simple craters on the Moon such as Messier exhibit the same profile. Larger complex craters, however, exhibit an indirect expression of this profile with more extensive $\mathrm{rim} / \mathrm{wall}$ collapse uprange in response to the oversteeped inner wall and an uprange offset of the central peak complex in response to the deepest point of penetration (e.g., Tycho and King Craters). Tworinged basins with other indications of an oblique trajectory also exhibit an uprange offset of the inner ring and enhanced uprange collapse (e.g., Moscoviense on the Moon and Bach on Mercury).

Second, interior pits created by hypervelocity impacts into strength-controlled targets become elongate and breached downrange as impact angle decreases from $45^{\circ}$ to $15^{\circ}$. The diameter of the interior pit $\left(\chi_{0}\right)$ perpendicular to the trajectory is found to depend simply on the impactor diameter (2r), target/impactor density ratio $\left(\delta_{i} / \delta_{p}\right)$, vertical component of impactor velocity $(v \sin \theta)$, and target sound speed (c)

$$
\left(\chi_{0} / 2 r\right)\left(\delta_{l} / \delta_{p}\right)^{1 / s} \sim(v \sin \theta / c)^{\mu}
$$

This relation can be directly derived from the pressure-decay law given in [4] where $\chi_{0}$ corresponds to a characteristic strength limit in the target.

Planet-scale craters also exhibit elongated and breached central peaks (e.g., King on the Moon) and peak rings (Bach on Mercury) as impact angle decreases $[5,6]$. If the central structures are large-scale analogs for the zones of maximum penetration in laboratory-scale hypervelocity impacts, then the diameter of the gravity-controlled crater diameter relative to the strength-controlled central structure should decrease with decreasing impact angle, as observed in craters on Venus (Fig. 1). In very-large-scale basins that undergo further enlargement by rim collapse or lithospheric failure, the distinctive impactor signature (e.g., breached downrange central ring) may persist even though its diameter relative to the diameter of the outer basin scarp no longer follows the same trend as smaller two-ringed basins (e.g., Orientale on the Moon).

If the central relief in impact structures simply corresponds to a zone of maximum compression during initial stages of penetration, then it may provide a measure of impactor size for a given impact velocity [6]. This hypothesis can be tested by referencing crater diameter to the central-ring diameter (in lieu of impactor size) and plotting this value against the dimensionless gravity-scaling parameter $\mathrm{gr} / \mathrm{v}^{2}$ where $\mathrm{r}$ again is replaced by the central ring dimension. The resulting power-law exponent (Fig. 2a) exhibits nearly the same value for different planets and can be brought into line by adopting reasonable average impact velocities for cach planet. Central peaks may be similar manifestations of the impactor compression zone but it is uplifted during decompression due to higher peak shock pressures and smaller size. Figure $2 b$ tests this hypothesis and reveals a very similar dependence.

In summary, oblique impacts allow identifying distinctive signatures of the impactor created during early penetration. Such signatures further may allow first-onder testing of scaling relations for late crater excavation from the planetary surface record.

References: [1] Schmidt R. M. and Housen K. R. (1987) Int. J. Impact Engng., S, 543-560. [2] Gault D. E. et al. (1968) In Shock Metamorphism of Natural Materials (B.M. French and N. M. Short, eds.), 87-100, Mono, Baltimore. [3] Gault D. E. and Wedekind J. A. (1978) Proc. LPSC 9th, 3843-3875. [4] Holsapple K. A. (1980) Proc. LPSC 1lth, 2379-2401. [5] Schultz P. H. and Gault D. E. (1991) Meteoritics, 26, No. 4. [6] Schultz P. H. (1992) LPSCXXIII, 1231-1232. [7] Schultz P. H. (1988) In Mercury (F. Vilas et al., eds.), 274-335, Univ. of Arizona, Tucson.
PARADIGM LOST: VENUS CRATER DEPTHS AND THE ROLEOF GRAVTYYINCRATERMODIFICATION. Virgil L. Sharpton, Lunar and Planetary Instiwute, 3600 Bay Area Boulevard, Houston TX 77058, USA.

Background: Previous to Magellan, a convincing case had been assembled that predicted that complex impact craters on Venus were considerably shallower that their counterparts on Mars, Mercury, the Moon, and perhaps even Earth. This was fueled primarily by the morphometric observation that, for a given diameter (D), crater depth (d) secms to scale inversely with surface gravity for the other planets in the inner solar system [e.g., 6]. Thus Venus, which is similar to Earth in its size and density, should yield a very low d$D$ trend, like that reconstructed from the terrestrial impact recond (Fig. 1). In addition, deceleration of ejecta through the dense venusian atmosphere [8] and viscous relaxation of crater topography [11] due to Venus' high surface temperatures were expected to contribute to craters perhaps even shallower that those on Earth. Indeed, altimetric data from Pioneer Venus [6] and the Venera orbiters [3] indicated low relief for presumed impact craters on Venus, although the large footprint of radar altimeters grossly undersampled the true topography for all impact features measured, and many of the large circular structures thought to be impact basins were not. Even the enhanced resolution provided by the Magellan radar altimeter probably undersamples the relief of all but a few of the largest impact basins on Venus [4].

Depth Measurements: Useful crater topography can be extracted from Magellan radar images using the distortions in the cross track direction imparted by the interaction of radar incidence angle $(\theta)$ with surface slope. In the general case, two images of the same feature, taken at different $\theta$, are required, but crater depths can be estimated by assuming the crater is symmetrical in the cross-track direction [4]. Using this technique, [9] have calculated crater depths for 73 craters out of a set of 102 large $(18 \mathrm{~km}>D>175 \mathrm{~km})$ complex craters identified in Magellan data then available to them, indicating a power law fit $\mathrm{d}=\mathbf{0 . 2 8} \mathrm{Dans}$. The large dispersion in this dataset $\left(R^{2}=0.21\right)$ probably reflects several effects including (1) crrors associated with locating the rim crest and the outer boundary of the floor; (2) errors associated with asymmetries in the actual crater topography; (3) inclusion of relatively modified craters, as well as fresh craters; and (4) true variations in crater morphometry. Nonetheless, it is clear that venusian craters fall considerably above the terrestrial d-D trend, with the freshest craters (distinguished by parabolic deposits of distal ejecta [1]) virtually indistinguishable from the martian fresh crater trend (Fig. 1).

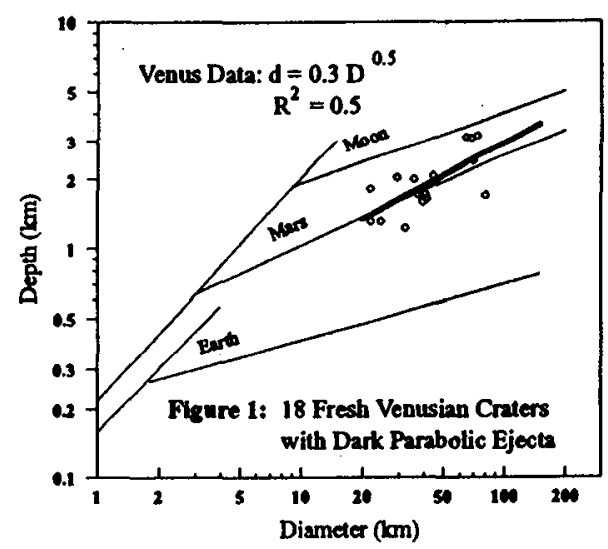

Fig. 1. Eighteen fresh venusian craters with dark parabolic ejecta. 

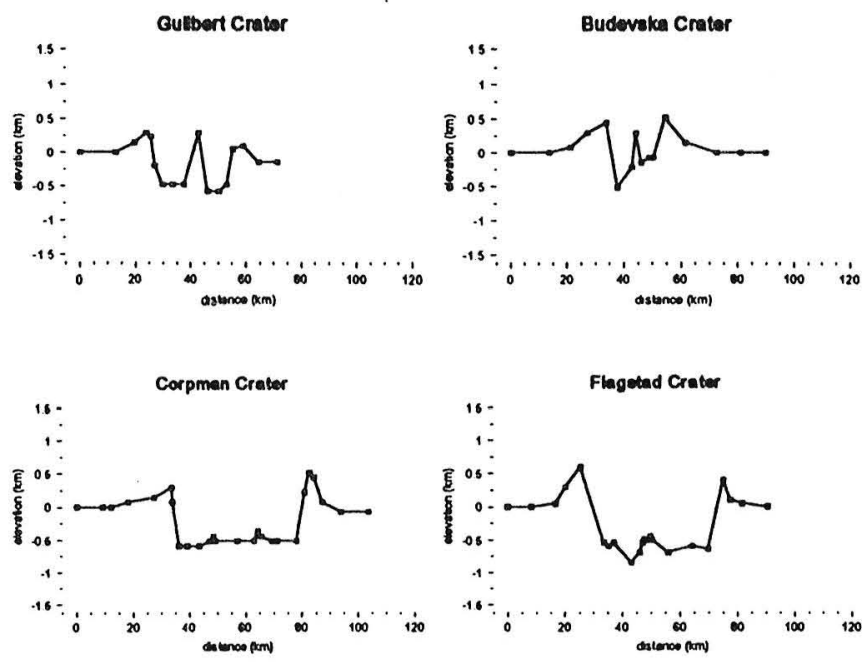

Fig. 2. Crater profiles constructed from Magellan image pairs.

Crater Proffles and Morphometry: The four crater profiles ( west-east, through the crater center) shown in Fig. 2 were produced using a nonstereo technique on Magellan cycle 1-cycle 2 image pairs. Guilbert and Budevska are central peak craters; Corpman and Flagstad are peak ring structures; Budevska is a fresh, brightfloored crater; the rest contain dark-floor deposits that may be indicative of volcanic or acolian infilling. Corpman contains the most areally extensive dark floor deposits. The depth estimates of these craters support the single-image estimates presented above. Furthermore, because this technique does not hinge upon symmetrical topography, morphometric information can be extended beyond simple depth constraints.

The rim height $\left(\mathrm{H}_{\mathrm{r}}\right)$ of these craters constitutes $\sim 0.3-0.5 \mathrm{~d}$ and there are slight variations $\left(<0.3 \mathrm{H}_{\mathrm{r}}\right)$ in the eastern and western $\mathrm{H}_{\mathrm{r}}$ for all craters measured. Crater flanks, mantled by bright, blocky ejecta, are typically narrow, ranging from $0.2-0.5 \mathrm{D}$. Assuming that ejecta constitutes $\sim 0.5 \mathrm{H}_{\mathrm{r}}$ [5], the continuous ejecta blanket around Budevska Crater contains $400 \mathrm{~km}^{3}$ of ejecta, equivalent to $300 \mathrm{~km}^{3}$ of unfragmented target rock.

Central peak heights vary considerably from $\sim 0.1$ to $1.0 \mathrm{~d}$. The lower extent of this range may be due in part to subsequent modification of Corpman by extensive dark floor deposits. The central peak of Guibert protrudes virtually to the level of the rim, and Budevska's central peak is only slightly shorter. Similar craters have been noted on other planets, e.g, the lunar farside crater, Icarus [7], and the terrestrial Marquez Dome crater [10]. Such craters, however, are relatively rare on other planets; having two such examples within a sample of four craters (Fig. 2) suggests that these anomalously tall central peaks might be more common on Venus. Crater floors are flat in all cases except Budevska, where the radar

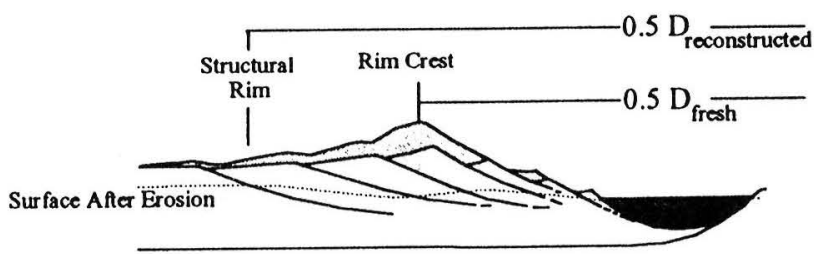

Fig. 3. Structure cross section of complex crater half-space. Crater center is on the right. image shows a narrow ridge, coinciding with topographic profile, extending eastward from the central peak, thus resulting in the shallow depth on the profile's east side.

Implications and Conclusions: The unpredicted depth of fresh impact craters on Venus argues against a simple inverse relationship between surface gravity and crater depth. Factors that could contribute to deep craters on Venus include (1) more efficient excavation on Venus, possibly reflecting rheological effects of the hot venusian environment, (2) more melting and efficient removal of melt from the crater cavity, and (3) enhanced ejection of material out of the crater, possibly as a result of entrainment in an atmosphere set in motion by the passage of the projectile.

The broader issue raised by the venusian crater depths is whether surface gravity is the predominant influence on crater depths on any planet. There is an apparent $\mathrm{d}-\mathrm{g}^{-1}$ trend in data from the Moon and Mercury, but these planets are all relatively small and, to the first order, of the same size. The surface properties and target characteristics of Mars are considerably different from those of the Moon and Mercury and could contribute to its somewhat lower d-D relationship. Although shallow depths, in accordance with $\mathbf{g}^{-1}$ scaling, are reported for terrestrial craters [6,2], there are no fresh complex craters on Earth from which to directly take these measurements. The Venus data in Fig. 2 indicate that $H_{r}$ is a significant portion of $\mathrm{d}$, and as all terrestrial complex structures are severely modified by erosion, d estimates may be up to a factor of 2 too low due to rim removal alone. In addition, when the crater rim and ejecta blanket have been removed, it becomes more difficult to determine the rim crest diameter. Reconstructions based on structural analysis may overestimate the true diameter if faulting extends beyond the rim as shown in Fig. 3. Thus while inverse gravity scaling of crater depths has been a useful paradigm in planetary cratering, the venusian data do not support this model and the terrestrial data are equivocal at best. The hypothesis that planetary gravity is the primary influence over crater depths and the paradigm that terrestrial craters are shallow should be reevaluated.

References: [1] Campbell D. B.et al. (1992) JGR, in press. [2] Grieve R. et al. (1981) Multi-Ring Basins, Proc.LPS 12A (P.Schultz and R. Merrill, eds.), 37, Pergamon, New York. [3] Ivanov M.N. et al. (1986) JGR, 91, 413. [4] Leberl F. et al. (1991) Photogram. Engrg. Remote Sens., 57, 1561. [5] Melosh H. J. (1990) Impact Cratering: A Geologic Process, Oxford, 245 pp. [6] Pike R. J. (1980) Icarus, 43, 1. [7] Schultz P. H. (1972) Moon Morphology. 626, Univ. of Texas. [8] Settle M.(1980) Icarus, 42, 1. [9] Sharpton V. L. and Edmunds M. S. (1992) GRL, in review. [10] Sharpton V. L. and Gibson J. W. (1990) LPSC XIX, 1136. [11] Solomon S. C. et al. (1982) JGR, 87, 7763.

K/T BOUNDARY STRATIGRAPHY: EVIDENCE FOR MULTIPLE IMPACTS AND A POSSIBLE COMETSTREAM. E. M. Shoemaker' ${ }^{1}$ and G. A. Izett ${ }^{2}$, 1U.S. Geological Survey, Flagstaff AZ 86001, USA, 2U.S. Geological Survey, Denver CO 80225, USA.

A critical set of observations be aring on the $\mathrm{K} / \mathrm{T}$ boundary events has been obtained from several dozen sites in western North America. Thin strata at and adjacent to the $\mathrm{K} / \mathrm{T}$ boundary are locally preserved in association with coal beds at these sites. The strata were laid down in local shallow basins that were either intermittently flooded or occupied by very shallow ponds. Detailed examination by [1] of the stratigraphy at numerous sites led to their recognition 
of two distinct strata at the boundary $[1-4]$. From the time that the two strata were first recognized, E. M. Shoemaker has maintained that they record two impact events. We report here some of the evidence that supports this conclusion.

The lower stratum, first recognized at localities in the Raton Basin of New Mexico and Colorado by $[4,5]$, is referred to as the $\mathrm{K} / \mathrm{T}$ boundary claystone. Microscopic study of polished slabs of the boundary claystone, which consists typically of $1-2 \mathrm{~cm}$ of white, gray, or tan kaolinite, reveals that it is speckled with small angular to rounded clasts and pellets of white to gray kalolinite and subparallel flakes of vitrinite. The claystone commonly appears to be a single massive bed, but is found in some places to be a complex unit when examined in detail. Generally it rests on dark, thinly laminated carbonaceous claystone or coal; the lower contact is gradational at most places but sharp at some. The lower part of the claystone bed generally is dark colored, evidently owing to reworking of dark carbonaceous material from the underlying bed. Up to four discrete depositional units, most of them bounded by sharp contacts, are locally present within the claystone. In an example illustrated by [3, Fig. 5], angular kaolinite clasts in one depositional unit are truncated by a sharp contact at the base of the next overlying unit. The occurrence of the kaolinite clasts, most of which contain relict vegetal remains in the form of vitrinite flakes, and the multiple depositional units that rest on sharp truncation surfaces show unequivocally that the boundary claystone has not been formed by a single event of deposition or fallout of impact ejecta. Many clasts are ripup clasts of previously deposited claystone [3], and the presence of multiple depositional units indicates multiple episodes of reworking.

A distinctive feature of the boundary claystone is the presence of very-smooth-surfaced (in some cases shiny) spherules that typically range from about 0.1 to $1 \mathrm{~mm}$ in diameter $[3,6-8]$. In the Raton $B$ asin the spherules are composed of gorceixite or kaolinite. At some localities in Wyoming the walls of the spherules are composed of gorceixite or another phosphate mineral, and the interiors are filled with kaolinite, gypsum, or, rarely, sulfides. Many spherules are hollow. Smooth-surfaced forms in the shape of teardrops, spindles, and dumbbells are also present $[3,9,10]$. These forms are nearly identical to but generally somewhat smaller than spherules, teardrops, spindles, and dumbbells found in the $\mathrm{K} / \mathrm{T}$ boundary claystone in Haiti [9], where remnants of tektite glass are preserved in the interiors of the larger forms [9,11-14]. It is now clear that the gorceixite spherules in the boundary claystone in western North America are pseudomorphs after glassy objects. The variety of these pseudomorphus forms is typical of those produced by disruption of a liquid. Traces of the intemal flow bands in the original liquid droplets are preserved on the surfaces of some of the pseudomorphs $[9,15]$. Spherules are fairly abundant at some localities in Wyoming, constituting up to several percent of the boundary claystone. Where they are composed entirely of kaolinite and embedded in a kaolinite matrix, they are often difficult to detect in hand specimen but easily detected in thin sections.

The upper stratum of the $\mathrm{K} / \mathrm{T}$ boundary in westem North America, referred to by [3] as the K/T boundary impact layer, generally consists of a few millimeters of thinly laminated claystone of mixed clay mineralogy and abundant flakes and laminae of vitrinite. Nearly everywhere it contains numerous ovoid pellets of claystone about 0.1 to $1 \mathrm{~mm}$ across, commonly referred to as graupen; in places it contains much larger rounded claystone clasts. Like the underlying boundary claystone, the upper stratum consists in some places of multiple depositional units bounded by sharp contacts. Hence the upper stratum also shows clear evidence of reworking. The interlaminated vitrinite shows that the upper stratum had a protracted history of deposition that produced the altemate laminae of vitrinite and clay.

The most diagnostic feature of the upper stratum is the presence of quartz grains and quartzose lithic fragments, about $30 \%$ of which exhibit shock lamellac [3]. About half the lithic fragments are chert and chalcedony and the other half are quartzite and metaquartzite. Rare shocked grains of oligoclase and microcline and granitoid lithic fragments are also present. The shocked grains tend to be concentrated near the base or in the lowest depositional unit of the upper stratum. No spherules are found in the upper stratum.

Of particular interest for the present discussion is the contact of the upper stratum on the boundary claystone. As noted by [16] and [3], this contact at some sites is a palcosurface that shows evidence of weathering and reworking or remobilization of the uppermost part of the boundary claystone. The uppermost 1 to few millimeters of the boundary claystone generally consists of irregular claystone clasts, mostly less than $1 \mathrm{~mm}$ across, embedded in a vitriniteenriched matrix. Following [3], we informally refer to this reworked zone as the billowy layer. Shocked grains of quartz derived from the upper stratum locally occur in the billowy layer.

Root casts occur in the boundary claystone at localities in Montana [16] and Colorado, notably at the Clear Creek North site near Trinidad. Most of the recognized root casts are confined to the boundary claystone stratum. Where the root casts can be traced in polished slabs, they open at the top of the boundary claystone and are filled by the billowy layer. A shallow dimple generally is present at the top of the billowy layer over each root cast. Abundant flakes of vitrinite occur in the root casts, and shocked quartz can be found in the billowy filling, commonly along the upper walls of the root casts. The base of the upper stratum is marked in places by a fairly pronounced lamina of vitrinite that rests on the billowy layer. The upper stratum overlies the billowy filling of the root casts and therefore postdates them. The stratigraphic evidence reveals quite unambiguously that plants took root in the boundary claystone prior to the deposition of the upper stratum.

The strata at the K/T boundary in westem North America thus record at least two impact events separated by a time interval long enough for small plants to grow on the $K / T$ boundary claystone. Neither the boundary claystone nor the upper stratum, however, were formed simply by airfall of impact ejecta, as each stratum locally consists of multiple depositional units and contains clasts of previously deposited material. The upper stratum, in particular, contains heavy minerals of local provenance [3]; the abundant vitrinite almost certainly represents locally derived plant material. The clay mineralogy of the upper stratum may also be indicative of mixing of materials from diverse sources.

We interpret the boundary claystone in westem North America as derived partly and perhaps chiefly from impact ejecta from the Chicxulub structure, Yucatan [17,9]. Following the suggestion of [3], we consider the Manson impact structure in lowa [18] the likely source of most or all the shocked grains in the upper stratum. Shocked quartz grains and quartzose lithic fragments are coarser and one to two orders of magnitude more abundant at the sites in western North America than they are at other sites around the world, with the possible exception of sites in Haiti. This global pattern and the continental affinity of the grains led to a search for a possible source crater in North America and the identification of the Manson structure as a candidate source. ${ }^{10} \mathrm{Ar} /{ }^{39} \mathrm{Ar}$ measurements on shocked microcline from the central uplift of Manson show that the Manson structure is synchronous with the $\mathrm{K} / \mathrm{T}$ boundary within the $\pm 1 \mathrm{Ma}$ precision of the age determination [19]. Not only is the Manson 
structure very close to the right age, but the rocks excavated at the crater appear to be a likely source for the shocked grains as well as most other grains lacking observable shock lamellae in the upper stratum.

The occurrence of two impacts separated in time by at least part of a growing season appears to be most readily explained if the Earth intercepted a compact comet stream at the end of the Cretaceous [20]. In repetitive passes through the stream, the Earth may have encountered more than two crater-forming projectiles and may have swept up substantial amounts of cometary material that did not produce craters. The peak Ir abundance, which occurs in the upper stratum, may reflect a somewhat protracted accumulation of cometary material. Iridium is relatively low in abundance in the boundary claystone, possibly as a consequence of blowoff and escape of the vaporized projectile that formed the great Chicxulub impact structure [cf. 21].

A comet stream is most likely to have been formed by breakup of a large Sun-grazing comet. Reexamination of the flux of active and extinct Earth-crossing comets suggests that collision of periodic comets accounts for about $25 \%$ of the terrestrial impact craters larger than $20 \mathrm{~km}$ in diameter. Periodic comets initially on orbits with inclinations near $90^{\circ}$ become Sun grazers [22]. More than onefifth of the Earth-crossing periodic comets probably become Sun grazers that are subject to tidal disruption.

References: [1] Izett G. A. and Pillmore C. L. (1985) GSA Abstr. with Progr., 17, 617. [2] Izett G. A. (1987) U.S. Geol. Surv. Open-File Rept.87-606, 125. [3] Izett G. A. (1990) GSA Spec. Pap. 249, 100. [4] Pillmore C. L. et al. (1984) Science, 233, 1180-1183. [5] Pillmore C. L. and Flores R. M. (1987) GSA Spec. Pap. 209. 111-130. [6] Pollastro R. M. and Pillmore C. L. (1987) J. Sed. Petrol., 57, 456-466. [7] Bohor B. F. and Triplehorn D. M. (1987) LPSC XVIII, 103-104. [8] Bohor B. F. (1990) GSA Spec. Pap. 247. 335-342. [9] Izett G. A. (1991) JGR, 96, 20879-20905. [10] Smit J. (1990) Geol. Mijnbouw, 69, 187-204. [11] Izett G. A. et al. (1990) U.S. Geol.Surv. Open File Rept. 90-635. 31. [12] Izett G. A. (1991) LPSC XXII, 625-626. [13] Sigurdsson H. et al. (1991) Nature, 349. 482-487. [14] Sigurdsson H. et al. (1991) Nature, 353, 839-842. [15] Izett G. A. (1991) Eos, 72, 278. [16] Fastovsky D. E. et al. (1989) J. Sed. Petrol., 59, 758-767. [17] Hildebrand A. R. et al. (1991) Geology, 19, 867-871 . [18] Hartung J. B. et al. (1990) GSA Spec.Pap. 247, 207-221. [19] Kunk M. J. et al. (1989) Science, 244, 1565-1568. [20] Shoemaker E. M. (1991) Abstracts for the International Conference on Asteroids, Comets, Meteors, 199. [21] Vickery A. M. and Melosh H. J. (1990) GSA Spec. Pap. 247, 289-300. [22] Bailey M. E. et al. (1992) Astron. Astrophys., in press.

GEOLOGICAL EVIDENCE FOR A 2.6-Ga STREWN FIELD OF IMPACT SPHERULES IN THE HAMERSLEY BASIN OF WESTERN AUSTRALIA. Bruce M. Simonson, Geology Department, Oberlin College, Oberlin OH 44074, USA.

Sand-sized spherules up to $1.7 \mathrm{~mm}$ across with spherulitic, vesicular, and other crystalline textures that consist mainly of $\mathbf{K}$ feldspar help define a unique horizon in the well-preserved $2.6-\mathrm{Ga}$ Wittenoom Formation in the Hamersley Basin of Westem Australia $[1,2]$. This layer, informally known as the spherule marker bed, is nowhere thicker than about $1.3 \mathrm{~m}$, yet it persists for more than $300 \mathrm{~km}$ across the basin, blanketing an area of at least $13,700 \mathrm{~km}^{2}$. Sedimentological evidence indicates the layer is a single turbidite, and the spherules are a minor constituent that are usually con- centrated along its base; locally, however, they are restricted to centimeter-thick lenses of pure spherules along a single horizon in the argillite close beneath the turbidite. The total volume of preserved spherules is estimated at $8 \times 10^{7} \mathrm{~m}^{3}$. Assuming an original specific gravity of 2.5, typical of silicate glass, the lower limit of the total original mass of spherules is about $1.7 \times 10^{14} \mathrm{~g}$.

In the northeastem part of the Hamersley Basin, similar spherules again occur at only one horizon, but here they are a minor constituent of a dolomitic debris-flow deposit 9.9 to $22.7 \mathrm{~m}$ thick known as the dolomixtite layer. The dolomixtite layer occurs in the Carawine Dolomite, which is stratigraphically equivalent to the Wittenoom Formation [3]. Moreover, paleocurrent data from closely associated carbonate [4,5] and volcaniclastic $[6,7]$ turbidites indicate the spherule marker bed was deposited in deeper-water palecenvironments than the dolomixtite layer. Therefore, the dolomixtite layer is believed to be a proximal equivalent of the spherule marker bed. In addition to spherules, the dolomixtite layer contains particles that also consist of $\mathbf{K}$-feldspar, but are larger than the spherules (up to $11 \mathrm{~mm}$ across) and have much more internal heterogeneity. Some display internal flow banding or schlieren, while others contain typical spherules as inclusions. These larger particles are in the size range of true tektites, but ablated forms have yet to be observed.

Based on their similarity to microtektites and microkrystites in shape, size, and internal textures, and their occurrence as a very thin layer over a large area, the spherules are interpreted as droplets of silicate melt that were generated and dispersed across the Hamersley Basin by a major bolide impact. The mass of the spherules preserved in the Hamersley Basin is of the same order of magnitude as the estimated masses of microtektite glass in major Cenozoic strewn fields, despite the fact that the spherules currently cover an area that is 2 to 3 orders of magnitude smaller. The layers that host the spherules are interpreted to be the deposits of a major sediment gravity flow that exhumed and redeposited most of the spherules after shallow burial, although the flow is not believed to have been a direct result of the proposed impact. The internal textures of the spherules suggests the target rocks were mafic in composition, but the presence of trace amounts of mictocline and quartz crystals in both the spherule marker bed and dolomixtite layer suggests some continental basement rocks were also present in the target area. Given this, plus the fact that the spherules and related particles are largest in the northeastem comer of the Hamersley Basin, the most likely site for the proposed impact would have been in the early Precambrian ocean close to the northeastern edge of the Pilbara Craton.

Another thin horizon in the overlying Brockman Iron Formation contains spherules that again consist largely of $\mathbf{K}$-feldspar and have internal textures strikingly similar to those of the Wittenoom Formation and Carawine Dolomite. They differ in being slightly larger on average (up to $1.8 \mathrm{~mm}$ ) and extensively replaced by ironrich minerals (particularly stilpnomelane) as they are hosted by iron formation rather than argillite. This horizon is about $250 \mathrm{~m}$ higher stratigraphically and persists laterally for at least $30 \mathrm{~km}$. The close resemblance of these spherules to those of the Wittenoom Formation and Carawine Dolomite suggests they also originated as impect melt droplets, even though they are admixed with volcaniclastic detritus. Using the sedimentation rate of $3-4 \mathrm{~m} / \mathrm{m}$.y. typical of the Hamersley Group [8], the stratigraphic separation between the two suggests that a second major impact occurred near the Hamersley Basin after a time interval of about 75 m.y. clapsed. This suggests the record of impacts in early Precambrian strata is richer than is generally appreciated. 
References: [1] Trendall A. F. (1983) In Iron-Formations: Facts and Problems (A. F. Trendall and R. C. Morris, eds.), 69-129, Elsevier, Amsterdam. [2] Simonson B. M. (1992) GSA Bull., 104. in press. [3] Goode A. D. T. (1981) In The Precambrian Geology of the Southern Hemisphere (D. R. Hunter, ed.), 105-203, Elsevier, Amsterdam. [4] Simonson B. M. and Goode A. D. T. (1989) Geology, 17, 269-272. [5] Simonson B. M. et al. (1992) Precambrian Res., in press. [6] Hassler S. W. (1991) Ph.D. dissertation, University of California, Santa Barbara. [7] Hassler S. W. (1992) Precambrian Res., in press. [8] Amdt N. T. et al. (1991) Australian J. Earth Sci., 38, 261-281.

SAR IN SUPPORT OF GEOLOGICAL INVESTIGATIONS OF THE SUDBURY STRUCTURE. V. Singhroy', R. Mussakowski2, B. O. Dressler ${ }^{3}$, N. F. Trowell'3, and Richard Grieve', 'Canada Centre for Remote Sensing Department of Energy, Mines and Resources of Energy, Mines and Resources, Canada, 2Provincial Remote Sensing Office, Ontario Ministry of Natural Resources, Canada, 3Ontario Geological Survey Ministry of Northem Development and Mines, Canada, "Geological Survey of Canada, Department of Energy, Mines and Resources, Canada.

Imaging radar is an important contributing source of information for a range of geological problems and environments. Airborne SAR and ERS-1 data integrated with other geoscience datasets are being used in an attempt to characterize the crustal fracturing associated with the Sudbury structure. This presentation highlights examples of integrated and composite images aimed at facilitating the interpretation of the Sudbury structure. This work is the result of an ongoing cooperative multidisciplinary SAR study of the basin carried out by the Canada Centre for Remote Sensing, Ontario's Provincial Remote Sensing Office, the Ontario Geological Survey, and the Geological Survey of Canada.

VISCOSITY DETERMINATIONS OF SOME FRICTIONALLY GENERATED SILICATE MELTS: IMPLICATIONS FOR SLIPZONERHEOLOGY DURING IMPACT-INDUCED FAULTING. John G. Spray, Department of Geology, University of New Brunswick, Fredericton, New Brunswick, Canada.

Analytical scanning electron microscopy, using combined energy dispersive and wavelength dispersive spectrometry, has been used to determine the major-element compositions of some natural and artificial silicate glasses and their crystalline equivalents derived by the frictional melting of acid to intermediate protoliths. The major-element compositions are used to calculate the viscosities of their melt precursors using the model of Shaw [1] at temperatures of $800^{\circ}-1400^{\circ} \mathrm{C}$, with $\mathrm{Fe}^{2+} / \mathrm{Fe}(\mathrm{tot})=0.5$ and for $1-3$ wt $\mathrm{H}_{2} \mathrm{O}$. These results are then modified to account for suspension effects (i.e., the presence of mineral and rock clasts) in order to determine effective viscosities.

The critical factors in controlling the viscosities of the silicate melts are $\mathrm{SiO}_{2}$ and $\mathrm{H}_{2} \mathrm{O}$ contents and temperature, as has been well established for silicate melts of magmatic origin. Additionally, for fault-generated melts, the effects of shear thinning can reduce the viscosity to a significant degree. At $1200^{\circ} \mathrm{C}$, the viscosities range from $7 \mathrm{p}$ for the more basic melt sample $\left(40 \mathrm{wt} \% \mathrm{SiO}_{2}\right)$ to $1 \times 10^{5} \mathrm{p}$ for the more acid melt sample (64 $\mathrm{wt}_{0} \mathrm{SiO}_{2}$ ). These viscosities are low and indicate that at least the friction melt derived from the more basic protolith would have been highly fluid within the slip zone during displacement. The effects of shear thinning at very high strain rates would reduce these viscosities even further.

Where friction melts are generated during coseismic slip (to form pseudotachylites) this implies that the melt may help to lubricate the sliding interface and dissipate stored strain energy. These results are contrary to the views of earlier workers, who suggested that any melts generated by frictional heating would possess high viscosities and so inhibit slip. Part of this inference was based on the erroneous assumption that pseudotachylite generation involved the bulk fusion of wallrocks. Although a pseudotachylite matrix plus clasts has a very similar chemistry to the wallrock lithology, the matrix typically possesses a more basic chemistry and hence, due to its lower $\mathrm{SiO}_{2}$ content, a significantly lower viscosity than that of its protolith. On the other hand, smaller entrained clasts ( $<1 \mathrm{~cm}$ diameter) are typically felsic and dominated by quartz.

These results have implications for the generation of pseudotachylitic breccias as seen in the basement lithologies of the Sudbury and Vredefort structures and possibly certain dimict lunar breccias. Many of these breccias show similarities with the more commonly developed pseudotachylite fault and injection veins seen in endogenic fault zones that typically occur in thicknesses of a few centimeters or less. The main difference is one of scale: Impactinduced pseudotachylite breccias can attain several meters in thickness. This would suggest that they were generated under exceptionally high slip rates and hence high strain rates and that the friction melts generated possessed extremely low viscosities.

Reference: [1] Shaw H. R. (1972) Am. J. Sci., 272, 870-893.

THE LARGE IMPACT PROCESS INFERRED FROM THE GEOLOGY OF LUNAR MULTIRING BASINS. Paul D. Spudis, Lunar and Planetary Institute, Houston TX 77058, USA.

The nature of the impact process has been inferred through the study of the geology of a wide variety of impact crater types and sizes. Some of the largest craters known are the multiring basins found in ancient terrains of the terrestrial planets [e.g., 1]. Of these features, those found on the Moon possess the most extensive and diverse data coverage, including morphological, geochemical, geophysical, and sample data. The study of the geology of lunar basins over the past 10 years $[2-4]$ has given us a rudimentary understanding of how these large structures have formed and evolved.

Basin Morphology: Basins on the Moon begin to form at diameters of about $300 \mathrm{~km}$, the $320-\mathrm{km}$-diameter Schrodinger being an example [5,6]. At these diameter ranges, only two distinct rings are apparent; the transition diameter at which multiple rings appear is uncertain, but appears to be between 400 and $500 \mathrm{~km}$ in diameter [6]. Above these diameters, basins possess multiple rings, as few as three and as many as seven $[1,5,6]$. In every basin, one ring appears to be very prominent and is believed to correspond structurally to the topographic rim of complex craters. This ring has various names (basin rim of [5], Ring IV of [6], MOR of [7]), but corresponds to the Cordillera ring of the Orientale Basin. Rings inside and outside this ring are recognized, each having distinct morphology. Basin inner rings tend to be clusters or aligned segments of massifs, arranged into a crudely concentric pattern; scarplike elements may or may not be present. Basin outer rings tend to be much more scarplike and massifs are rare to absent. Within a certain subset of basins on the Moon (e.g. Crisium [8], Humorum [9]), the main topo- 
graphic rim is not evident. These basins appear to have undergone a different style of postimpact modification, possibly related to rapidly changing thermal conditions within the Moon $3.9 \mathrm{Ga}$ ago $[8,9]$.

Basin Ejecta: Basins display textured ejecte deposits, extending roughly an apparent crater radius beyond the main topographic rim. Ejecta may display various morphologies, ranging from wormy to hummocky deposits (c.g., Hevelius Formation of Orientale, Fra Mauro Formation of Imbrium [5]) to knobby textured materia] (e.g.. Alpes Formation of Imbrium [5]). The cause of these variations in ejecta morphology are not known. At Orientale, knobby material is largely confined within the Cordillern scarp while hummocky materials appear to be mostly restricted beyond this boundary $[5,10]$. However, at Imbrium, both units are restricted beyond the topographic rim (Apennine ring) and display a curious "bilateral" double symmetry $[1,3]$; this relation remains unexplained. Outside the limits of the basin textured ejecta are found both fields of satellitic craters (secondaries [5,11]) and light plains deposits (Cayley Formation [5]). These materials contain both primary basin ejecta and local materials, the local materials being predominant [12].

Impact melt sheets are observed on the floors of relatively unflooded basins, such as Orientale [1,5,10]. A class of impactmelts in the Apollo sample collections possess basaltic major-element chemistry, have a KREEP trace-element pattem of varying concentration, and all have ages of about 3.8-3.9 $\mathrm{Ga}[1,13]$. These rocks, collectively called "low-K Fra Mauro" basalts, are probably related to basin impact melts [13-15]. Although the exact number is contentious, at least three major compositional subdivisions of the LKFM melt group can be recognized; each may correspond to a different multiring basin, the Imbrium [13,15], Serentitatis [15], and Nectaris Basins [16]. A curious fact about lunar LKFM melts is that they cannot be produced through the fusion of known lunar pristine rock types [13,14], suggesting the occurrence of unknown crustal lithologies on the Moon. The LKFM melts were probably generated at middle to lower crustal levels [13,15].

Basin Excavation: The preservation of preexisting topography within the main topographic rim provides some constraints on the size of the excavation cavity of multiring basins. At Orientale, pre-existing craters and basins can be mapped $[2,17,18]$ within the Cordillera scarp ( $950 \mathrm{~km}$ diameter) and some structures [17] may extend inside the outer Rook ring ( $620 \mathrm{~km}$ diameter). These observations suggest that the excavation cavity for Orientale must have been less than about $600 \mathrm{~km}$ in diameter [2]. The minimum size is difficult to constrain; the innermost ring ( $400 \mathrm{~km}$ diameter) may provide a lower limit to cavity size [2]. These constraints observed at the Orientale Basin are paralleled by similar relations of prebasin topography preserved within the Imbrium Basin (1160-km main rim diameter), where the prominence of the Apennine Bench indicates that the excavation cavity for the Imbrium Basin must be less than about $800 \mathrm{~km}$ in diameter [3]. These data indicate that the excavation cavity of multiring basins is between about 0.4 and 0.6 times the diameter of the apparent crater diameter $[2-4,17]$.

Basin depths of excavation can be inferred from the composition of basin ejecta. At Orientale, basin ejecta are very feldspathic, having normative composition of noritic anorthosite, and mafic (basaltic) components cannot be present in quantities greater than a few percent [2]. Because evidence from other basins [16,20] and impact melts from Imbrium and Serentitatis [15] suggest a more mafic crustal composition at depth, this basin ejecta composition strongly suggests that basin excavation was limited to upper crustal levels [2]. At Orientale, the crust may be as thick as $100 \pm 10 \mathrm{~km}$
[21]; thus, the maximum depth of excavation is on the order of about $50 \mathrm{~km}$, suggesting an effective depth of excavation of about $0.1 \pm$ 0.02 times the diameter of the excavation cavity [2-4]. Data from well-studied complex craters on the Earth suggest that the excavation cavity of complex craters is on the order of 0.5 to 0.65 times the diameter of the apparent crater [19]; the maximum depths of excavation are on the order of $0.09-0.12$ times the excavation cavity diameter [19]. These numbers compare favorably with the admittedly poorly resolved lunar values [1-3], a conclusion substantiated by certain analytical methods [22]. The relatively shallow effective depths of excavation predicted by these various models account for the relative paucity of very deep crustal or mantle materials within the retumed Apollo lunar samples $[5,23]$.

Basin Ring Formation: A wide variety of mechanisms has been proposed to account for the formation of basin rings (see review in [1,5,7]). In my opinion, none of them are entirely plausible and the formation of rings constitutes the last great unsolved puzzle of multiring basin formation. Ring-forming mechanisms can be divided into two broad groups (see [1,6]): (1) forcible uplift due to fluidization of the target [5,24]; (2) concentric, brittle fracturing and failure of the target on regional (megaterraces [25]) to global scales (lithospheric fracturing [27]). Geological evidence supports portions of all of these models, but none of them completely or unequivocally. One constraint that has emerged from the examination of a variety of basins on a number of terrestrial planets is that basin rings are spaced at a constant factor, namely the famous $\sqrt{2}$ relation observed between adjacent rings $[1,6,27]$. Originally proposed only for the Orientale Basin [27,28], it has been found to be valid for all of the terrestrial planets and some icy satellites $[1,6]$. Because geological evidence supports divergent ring-forming models, it may be that the ring-locating mechanism is different from the ring-forming mechanism [6]. Thus, large-scale crustal foundering (megaterracing) could occur along concentric zones of weakness created by some type of resonant wave mochanism (fluidization and uplift); such immediate crustal adjustment could then be followed by long-term adjustment due to lithospheric fracturing. If the conundrum of ring genesis can be resolved, we will possess a good understanding of all of the principal phases of formation of multiring basins.

References: [1] Spudis P. D., in press, The Geology of Multiring Impact Basins, Cambridge Univ. [2] Spudis P. D. et al. (1984) Proc. LPSC 15th, in JGR, 89, C197. [3] Spudis P. D. et al. (1988) Proc. LPSC 18th, 155. [4] Spudis P. D. et al. (1989) Proc. LPSC 19th, 51. [5] Wilhelms D. E. (1987) U.S. Geol. Surv. Prof. Pap. 1348. [6] Pike R. J. and Spudis P. D. (1987) EarthMoon Planets, 39, 129. [7] Croft S. K. (1981) In Multi-Ring Basins, Proc. LPS $12 A$ (P. Schultz and R. B. Merrill, eds.), 207, 227, Pergamon, New York. [8] Spudis P. D. et al. (1989) LPSCXX, 1042. [9] Spudis P. D. et al. (1992) LPSC XXIII, 1345. [10] McCauley J. F. (1977) PEPI, IS, 220. [11] Wilhelms D. E. (1976) Proc. LSC 7th, 2883. [12] Oberbeck V. R. (1975) Rev. Geophys. Space Phys., 13, 337 [13] Spudis P. D. et al. (1991) Proc. LPS, Vol. 21, 151. [14] McCormick K. et al. (1989) Proc. LPSC 19th, 691. [15] Ryder G. and Wood J. A. (1977) Proc. LSC 8th, 655. [16] Spudis P. D. (1984) Proc. LPSC 15th, in JGR, 89, C95. [17] Schultz P. H. and Spudis P. D. (1978) LPSC IX, 1033. [18] King J. S. and Scou D. H. (1978) NASA TM79729, 153. [19] Grieve R. A. F. et al. (1981) In Multi-Ring Basins, Proc. LPSC 12A (P. Schultz and R. Merrill, eds), 37, Pergamon, New York. [20] Spudis P. D. and Davis P. A. (1986) Proc. LPSC 17th, in JGR, 92, E188. [21] Bills B. and Ferrari A. J. (1976) Proc. LSC 7th, frontispiece. [22] Croft S. K. (1985) Proc. LPSC 15th, in JGR, 90, C828. [23] Taylor S. R. (1982) Planetary Science, LPI, 
Houston, 481 pp. [24] Baldwin R. B. (1981) In Multi-Ring Basins, Proc. LPSC 12A (P. Schultz and R. Merrill, eds.), 275, Pergamon, New York. [25] Head J. W. (1974) Moon, 11, 327. [26] Melosh H. J. (1988) Impact Crasering, Oxford. [27] Hartmann W. and Kuiper G. (1962) Comm. Lunar Planet. Lab., 1, 51. [28] Fielder G. (1963) Nature, 198, 1256.

\section{SUDBURY PROJECT (UNIVERSITY OF MÜNSTER- ONTARIO GEOLOGICAL SURVEY): (3) PETROLOGY, CHIEMISTRY, AND ORIGIN OF BRECCIA FORMATIONS. D. Stöffler', A. Deutsch', M. Avermann ${ }^{1,2}$, P. Brockmeyer ${ }^{1,2}$, R. Lakomy ${ }^{12}$, and V. Müller-Mohr ${ }^{12}$, 1Institut für Planetologie and ${ }^{2}$ Geologisch-Paläontologisches Institut, Universität Münster, Wilhelm-Klemm-Str. 10 and Correnstr. 24, W-4400 Münster, Germany.}

Within the Sudbury Project of the University of Münster and the Ontario Geological Survey [1] special emphasis has been put on the breccia formations exposed at the Sudbury structure (SS) because of their crucial role for the impact hypothesis [2]. They were mapped and sampled in selected areas of the North, East, and South Ranges of the SS ([3] and Fig. 1 of [2]). The relative stratigraphic positions of these units are summarized in Fig. 1. Selected samples were analyzed by optical microscopy, SEM, microprobe, XRF and INAA, $\mathrm{Rb}$-Sr and $\mathrm{Sm}-\mathrm{Nd}$-isotope geochemistry [4], and carbon isotope analysis.

This abstract summarizes the results of petrographic and chemical analyses for those stratigraphic units that were considered the main structural elements of a large impact basin (see [1]).

Basement and Related Brecclas (Fig. 1): The crystalline rocks underlying the Sudbury Igneous Complex (SIC), collectively called footwall rocks [5], display three types of impact-induced effects: (1) An 8-10-km-wide zone with planar deformation features in quartz immediately below the SIC indicating peak shock pressure up to about $20 \mathrm{GPa}$ [6]. (2) An irregular, mostly lensshaped, discontinuous heterolithic breccia zone along the contact of the SIC (Footwall Breccia = FB) that occasionally occurs in dikelike "intrusions" in the footwall rocks. The breccia matrix is crystalline with a dioritic composition and intersertal texture in an upper zone near to the SIC and a tonalitic-to-granitic composition and poikilitic to granular texture in a lower zone. The matrix texture is caused by thermal annealing and partial melting due to the overlying melt complex [7-9]. The clast lithologies in this breccia and its chemical

\section{THICKNESS}

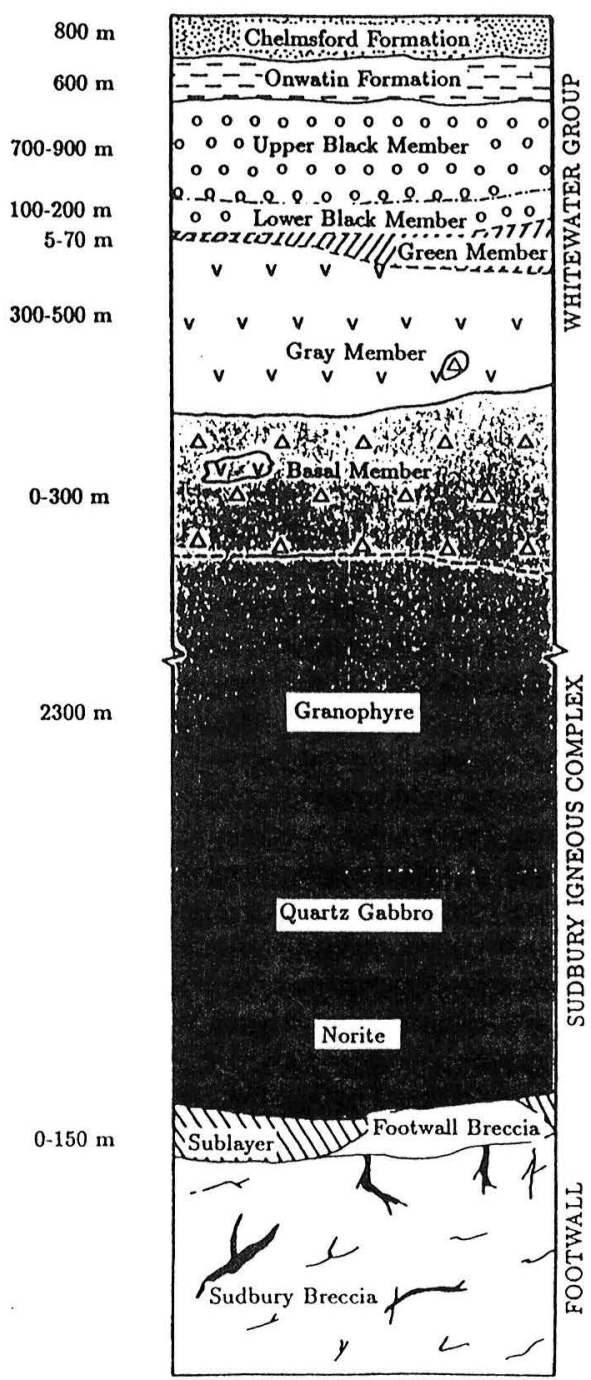

\section{INTERPRETATION}

\author{
post-impact \\ sedimentary fill \\ reworked breccia material \\ redeposited suevitic breccias \\ final fall-back \\ suevitic breccias \\ inclusions of melt-breccia \\ clast rich melt-breccia \\ inclusions of suevitic breccias
}

clast free

impact melt sheet

clast rich melt rock

thermally metamorphosed

clastic breccia

dike breccias

brecciated crater floor
Fig. 1. Stratigraphic sequence at the Sudbury structure with the present genetic interpretation of the lithological units (modified from [12]). 
characteristics indicate that it is derived almost exclusively from the local Levack gneisses $[7,8]$. (3) Breccia dikes, collectively named Sudbury Breccia, which are irregularly distributed in the basement up to a radial distance of at least $55 \mathrm{~km}$ from the SIC [6]. They have a random orientation and range in thickness from millimeters to some $300 \mathrm{~m}$. Four generations of dikes have been identified [6] that differ in matrix characteristics (crystalline to clastic), thickness, clast content, and contact relationships. The composition of the matrix typically resembles the composition of the country rock and the clasts are derived from the local rocks except for very large dikes where clasts were moved over distances of up to $800 \mathrm{~m}$. Shocked clasts (stage I) within the dikes occur only up to a radial distance of $10 \mathrm{~km}$ from the SIC.

SIC and Basal Member of Onaping (Fig. 1): The SIC has been studied only in its contact zones to the Basal Member and to the Footwall Breccia. The Sublayer is a heterolithic breccia with a crystalline melt matrix of mafic composition and abundant mafic to ultramafic lithic clasts. It contains also clasts of FB as the latter carries clasts of the norite and Sublayer. The contacts of the FB to the norite are sharp whereas to the Sublayer they are either sharp or gradational $[8,9]$. Similarly, the uppermost section of the SIC (granophyre) shows sharp and gradational transitions to the Basal Member, which is a clast-rich impact melt breccia. Abundant clasts (up to 80 vol\%), mainly from the Proterozoic Huronian metasediments, are embedded in a crystalline matrix with granophyric to variolitic texture [10]. There is a chemical similarity between the SIC, especially the granophyre, and the melt breccia of the Basal Member confirming that both units represent a whole rock melt of Precambrian target rocks. There is some indication for an increasing proportion of Proterozoic Huronian rocks tow ard the top of the melt system [4].

Gray, Green, and Black Members of Onaping (Fig. 1)[10,11]: The Gray Member is a polymict clastic matrix breccia composed of lithic clasts of variable degree of shock and irregularly shaped melt inclusions that have a fine-grained crystalline texture and show flow structures. Texturally, this breccia layer is similar to the suevitic breccias found in the crater fill of many complex impact craters. The clastic breccia constituents are derived predominantly from rocks of the Huronian Supergroup and, more rarely, from Archean basement rocks. The Gray Member is covered by a thin layer of a rather uniform, strongly chloritized breccia (Green Member, formerly called chloritized shard horizon). The contact varies from sharp to gradational. This breccia contains relatively fine-grained clastic material in a microcrystalline matrix characterized by concavely shaped vugs filled with chlorite. Green Member is topped by the clastic matrix breccia layer of the Black Member, which, as a whole, is characterized by a carbonaceous matrix. In its lower unit it shows similarities to the Gray Member. The upper unit displays textural features of reworking and sedimentation under aquatic conditions. A major fraction of the carbon is derived from organic matter and formed under euxinic conditions. The bulk chemical composition of the whole sequence of clastic matrix breccias (Gray Member to Black Member) is less siliceous and richer in $\mathrm{Fe}, \mathrm{Mg}, \mathrm{K}$, and $\mathrm{Nathan}$ the melt breccia of the Black Member [10,11]. It is not clear whether this is due to secondary alteration processes or whether it reflects a primary change in the composition of the source rocks of the clastic matrix breccias. The REE patterns of all breccia units of the Onaping Formation are quite similar and are well within the range of the potential source rocks from the Proterozoic and Archean basement.

The data obtained from the petrographic and chemical investigations of the breccia formations at the SS are compatible with the impact basin model summarized in (2). The interpretation of our results with regard to the origin and emplacement of these formations are therefore different from most of the previous views as expressed mainly in [5]. The present interpretation is as follows: The Sudbury Breccias (dike compression of the crater basement by in situ frictional melting and by shearing processes during the gravity-induced breccias) were formed during shock collapse of the transient cavity. The Footwall and Sublayer Breccias including the offset dikes were formed in the late stage of the transient cavity (TC) formation as crater floor breccias before the collapse of the cavity. This holds also for the impact melt system and the suevitic breccias of the Gray Member that covered the central part and the upper walls of the TC. As a consequence of its collapse the innermost, clast-free part of the melt layer within the TC pooled to a melt sheet filling the central depression as well as the depressions outside the now eroded peak ring and, immediately afterward, became covered by clast-rich melt slumping in from higher regions of the TC wall. Similarly, the suevitic material slumped into the depression from even higher portions of the TC wall. It was then covered by airbome fallback material (Green Member) deposited from the ejecta plume. The Black Member breccias are interpreted as material that was transported into the central depression by turbulent slumping from the walls of the peak ring and by aquatic sedimentation of ejecta material covering the ring region.

References: [1] Avermann M. et al., this volume. [2] Dressler B. O. et al. (1987) In Research in Terrestrial Impact Structures (J. Pohl, ed.), 39, Earth Evolution Series, F. Vieweg, Braunschweig. [3] Bischoff L. et al., this volume. [4] Deutsch A. et al., this volume. [5] Pye E. G. et al., eds. (1984) The Geology and Ore Deposits of the Sudbury Structure, 603, Ministry of Natural Resources, Toronto. [6] Muller-Mohr V., this volume. [7] Deutsch A. et al. (1989) EPSL, 93, 359. [8] Lakomy R. (1990) Meteoritics, 25, 195. [9] Dressler B. O. (1984) in [5] . [10] Muir T. L. and Peredery W. V. (1984) in [5]. [11] Avermann M., this volume. [12] Brockmeyer P. (1990) Doctoral dissertation, University of Munster, 228.

"BRONZITE" GRANOPHYRE: NEW INSIGHT ON VREDEFORT. A. M. Therriault and A. M Reid, University of Houston, Department of Geosciences, Houston TX 77204, USA.

The Vredefort Dome is located near the center of the Witwatersrand Basin, about $120 \mathrm{~km}$ southeast of Johannesburg. South Africa. Its origin is enigmatic, ranging from a major impact event [1-3] to endogenous processes, either igneous [4-6] or tectonic [7]. A unique melt rock, the "Bronzite" Granophyr, occurs in the Vredefort structure as vertical ring dikes along the contact between sedimentary collar and core of Archaean granites, and as vertical dikes extending north west-southeast and northeast-southwest in the granitic core. The granophyre rocks have an unusual composition and high content of recrystallized sedimentary inclusions compared to common intrusive igneous rocks with similar $\mathrm{SiO}_{2}$ content (61 to $70 \%$ by weight). The unique nature of the granophyre has been underlined in previous studies and origin hypotheses as an impact melt or as a highly contaminated intrusive mafic magma have also been discussed [e.g., 8-10]. We present new results obtained from a recent detailed petrographic and geochemical study of a very large and texturally diverse suite of "Bronzite" Granophyre, representing all dikes occurring at Vredefort.

Petrography: Themajor mineral phases observed in the granophyre are hypersthene, plagioclase, orthoclase, quartz, pigeonite, augite, biotite, magnetite, and ilmenite. Only rare bronzite grains 
are observed and they occur exclusively as xenoliths. None of the bronzite grains are in equilibrium with the granophyre melt.

Two major types of granophyre are observed: (1) fine-grained, clast-rich dikes, confined to the central core of the structure that are dominated by a spherulitic texture and textural heterogeneity occur over distances ranging from millimeters to tens of meters produced by four spherulitic subtypes and an ophitic subtype texture; and (2) medium- to fine-grained clast-rich granophyre core-collar dikes dominated by hypidiomorphic textures [11]. Grain size of the granophyre matrix minerals ranges up to $5 \mathrm{~mm}$. The mineralogy of all dikes is similar with the exception of the higher modal abundance of biotite in the core dikes relative to the core-collar dikes. The spherulitic texture with skeletal crystal morphologies observed in the core dikes is indicative of extreme undercooling conditions [12], while increased textural homogeneity characterizing the core-collar granophyre dikes indicates more uniform and slower cooling histories.

Numerous monomineralic and lithic fragments, up to $80 \mathrm{~cm}$ long. compose up to $20 \%$ of the rock volume [11]. All the major country rocks are represented as inclusions in every dike examined. Granite, gneiss, and quartzite are the most abundant, mafic rock fragments and metasediments other than quartzite are less abundant, and shale inclusions are rare $[10,11]$. These abundant inclusions show intense recrystallization, reactions with the granophyre melt, and melting. Rare shock features are observed in quartz grains and are restricted to remnants of decorated planar elements occurring as one set parallel to the $c$ axis of individual quartz grains.

Chemistry: Chemical homogeneity, on a regional scale, is a major characteristic of the granophyre dikes of the Vredefort structure. Homogenization was achieved early in the melt's history and was maintained as the melt intruded the fractured country rocks where it underwent cooling and crystallization under relatively undisturbed conditions.

Although no gross differences in major- and most trace-element compositions were detected that could be ascribed to regional position within the structure, minor chemical variations are present. The granophyre dikes of the central core have higher $\mathrm{SiO}_{2}, \mathrm{TiO}_{2}$, $\mathrm{Al}_{2} \mathrm{O}_{3}$, and $\mathrm{K}_{2} \mathrm{O}$ contents than the core-collar dike, while core-collar dikes have higher $\mathrm{FeO}+\mathrm{Fe}_{2} \mathrm{O}_{3}, \mathrm{MgO}, \mathrm{CaO}$, and $\mathrm{Na}_{2} \mathrm{O}$ contents. These differences are thought to be due to differences in the composition and amount of local materials assimilated. Although the granophyre melt is weakly differentiated, this is a minor factor in the evolution of the granophyre melt and differential assimilation is the major cause of the chemical variability observed.

Discusslon: Metasediments and shale inclusions, from lithologies occurring within units stratigraphically higher than the present emplacement level of the granophyre dikes, are regionally distributed within all these dikes. This observation is hard to reconcile with the processes involved in the intrusion of a magma from the mantle or upper crust and indicates that the granophyre melt must have been efficiently and dynamically mixed before being injected into major fractures. Highly heterogeneous clast populations from widely different stratigraphic levels, a complex thermal history, and injection of melt/clast mixtures into dikes are in agreement with processes related to impact melt formation. The first report of rare shock features in xenolithic quartz grains supports the melt origin by impact. Two reasons explain why shock planar features, observed in the source rocks [13], are rarely seen in inclusions of the granophyre: (1) they have been annealed [13,14] and (2) shocked fragments are preferentially assimilated in the melt because they attained a higher temperature during the initial shock event $[15,16]$.
Conclusions: The matrix textures, the variable thermal effects in the inclusions, and the chemical variations presented for the granophyre dikes of Vredefort are compatible with an impact melt $[15,16]$. Our observations and results indicate that the granophyre dikes best represent remnants of an impact melt that intruded fractures of the transient crater floor of Vredefort. We thus favor the Vredefort structure as a deeply eroded multiring impact basin.

References: [1] Dietz R. S. (1961) J. Geol., 69, 499-516. [2] Hart R. J. et al. (1991) Tectonophysics, 192, 313-331. [3] Martini J. E. J. (1991) EPSL, 103, 285-300. [4] Lilly P. A. (1981) JGR, 86, 10689-10700. [5] Schreyer W. and Medenbach O. (1981) Contrib. Mineral. Petrol., 77, 93-100. [6] Nicolaysen L. O. and Ferguson J. (1990) Tectonophysics, 171, 305-335. [7] Colliston W. P. (1990) Tectonophysics, 171, 115-118. [8] French B. M. et al. (1989) Proc. LPSC 19th, 733-744. [9] French B. M. and Nielsen R. L. (1990) Tectorophysics, 171, 119-138. [10] Reimold W. U. et al. (1990) Proc. LPSC 20th, 433-450. [11] Therriault A. M. and Reimold W. U. (1991) LPSC XXII, 1391-1392. [12] Lofgren G. (1971) Am. J. Sci., 274, 243-273. [13] Grieve R. A. F. et al. (1990) Tectonophysics, 171, 185-200. [14] Schreyer W. (1983) J. Petrol., 24, 2647. [15] Floran R. J. et al. (1978) JGR, 83, 2737-2759. [16] Phinney W. C. et al. (1978) Proc. LPSC 9th, 2659-2693.

A COMPARISON OF THE CHEMISTRY OF PSEUDOTACHYLYTE BRECCIAS IN THE ARCHEAN LEVACK GNEISSES OF THE SUDBURY STRUCTURE, ONTARIO. Lucy M. Thompson and John G. Spray, Department of Geology, University of New Brunswick, Fredericton, New Brunswick, Canada.

The Archean Levack Gneisses of the North Rangehostmillimeterthick veins and centimeter-thick lenses of pseudotachylyte, as well as substantially larger meter-wide, dykelike bodies of pseudotachylytic "breccia." The "breccia" occurs up to several tens of kilometers away from the Sudbury Igneous Complex and is commonly sited within or near joints and other natural weaknesses such as bedding, dyke contacts, and lithological boundaries.

The larger "breccia" dykes comprise a generally dark matrix containing rounded to subrounded and occasionally angular rock fragments derived predominantly from Levack Gneiss. The matrix may exhibit flow features and typically appears aphanitic, although in certain exposures it possesses a fine-grained crystalline texture. The "breccia" fragments can be as large as 2-3 $\mathrm{m}$ in their long dimension and are typically chaotically arranged within the matrix, showing evidence of both rotation and internal fracturing. More exotic rock fragments, such as amphibolite, also occur and these appear to have been transported for some distance (i.e., at least tens of meters). The origin of the so-called Sudbury Breccias is a subject of controversy, but is generally believed to be related to the $1.85-\mathrm{Ga}$ Sudbury event. Field evidence indicates that they are fault-related and frictionally induced and are therefore not the direct products of shock melting.

Selected samples of bulk Sudbury Breccia and Sudbury Breccia matrices have been chemically analyzed and compared to existing data on the Levack Gneisses and Sudbury Breccia. The matrices are apparently enriched in $\mathrm{Fe}$ and, to a lesser extent, $\mathrm{Mg}, \mathrm{Ti}$, and $\mathrm{Ca}$ compared to the wallrocks and the majority of clasts. This enrichment can be partly explained by the preferential cataclasis and/or frictional melting of hydrous ferromagnesian wallrock minerals, but also appears to require contamination by more basic exotic 
lithologies. This suggests that certaincomponents of pseudotachylitic Sudbury Breccia have undergone significant transport (?kilometers) during their formation.

"Ar-"Ar AGES OF THE LARGE IMPACT STRUCTURES KARA AND MANICOUAGAN AND THEIR RELEVANCE TO THE CRETACEOUS-TERTIARY AND THE TRIASSICJURASSIC BOUNDARY. M. Trieloff and E. K. Jessberger, Max-Planck-Institut fir Kemphysik, P.O. Box 103980, W-6900 Heidelberg, Germany.

Since the discovery of the Ir enrichment in Cretaceous-Tertiary boundary clays in 1980 by [1] the effects of a 10-km asteroid impacting on the Earth $65 \mathrm{Ma}$ ago are discussed as the possible reason for the mass extinction- including the extinction of the dinosaurs - at the end of the Cretaceous. But up to now no crater of this age that is large enough (ca. $200 \mathrm{~km}$ in diameter) has been found. The Manson Crater in north America is 65 Ma old [2], but too small-only $35 \mathrm{~km}$ in diameter. A recently discovered candidate is the Chicxulub structure in Yucatan, Mexico, but intensive investigations have to be done to identify it as the $K-T$ impact crater. Petrographic signs at the K-T boundary seem to point to an impact into the oceans as well as onto the continental crust; multiple impacts were considered [3].

Another candidate is the Kara Crater in northem Siberia. Kolesnikov et al. [4] determined a K-Ar isochron of $65.6 \pm 0.5 \mathrm{Ma}$. indistinguishable from the age of the $\mathrm{K}-\mathrm{T}$ boundary and interpreted

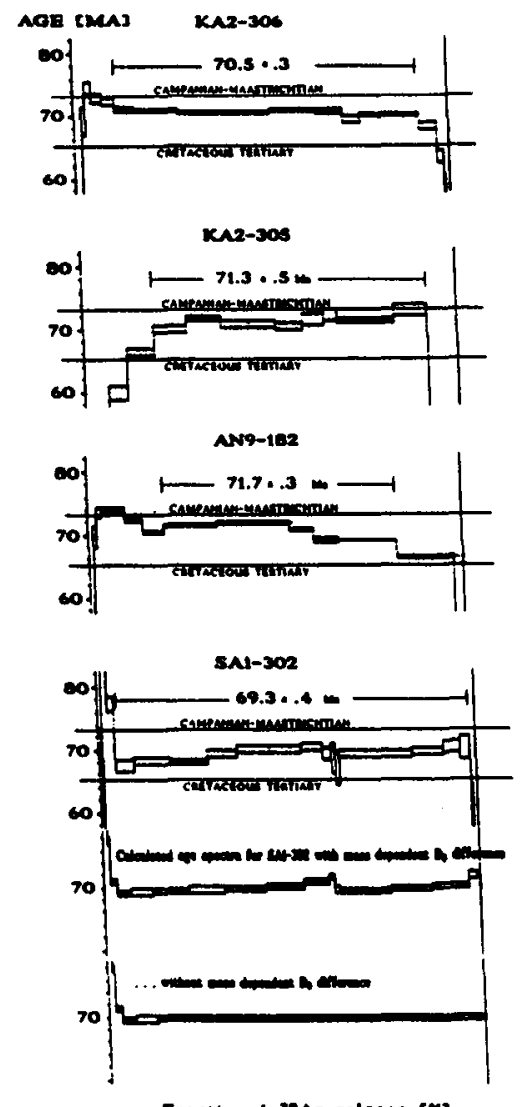

Frecelonal NAr roleane $(x)$

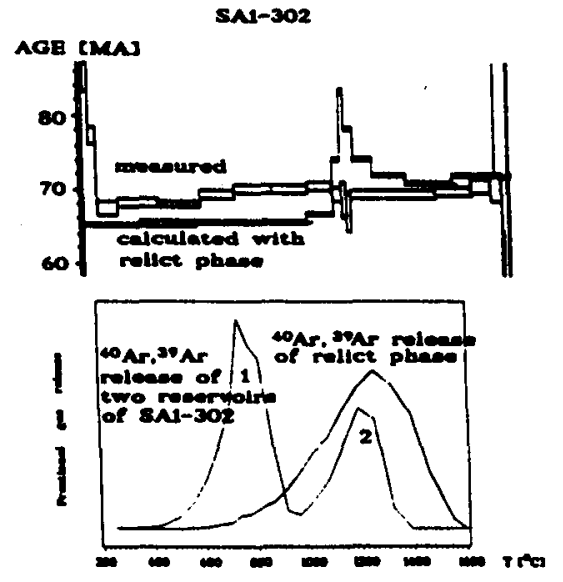

Fig. 2.

this as confirmation of earlier proposals that the Kara bolide would have been at least one of the K-T impactors. Koeberl et al. [5] determined ${ }^{20} \mathrm{Ar}-39 \mathrm{Ar}$ ages ranging from 70 to $82 \mathrm{Ma}$ and suggested an association to the Campanian-Masstrichtian boundary, another important extinction horizon $73 \mathrm{Ma}$ ago.

We dated four impact melts, KA2-306, KA2-305, SA1-302, and AN9-182. All spectra show well-defined plateaus. They are shown with a strong extended age scale (Figs. 1 and 2). Our ages range from 69.3 to $71.7 \mathrm{Ma}$, and it is clearly visible that our data suggest neither an association with the Cretaceous-Tertiary nor the CampanianMasstrichtian boundary. Errors are given as 10 errors computed of the deviation of the plateau fractions. The systematic error induced by the NL25 homblende standard is $0.6 \mathrm{Ma}$. It may be argued that our ages -old in comparison to the K-T boundary-could becaused by relict target rocks incorporated in the melt. At the first sight this seems to be possible:If only $1 \%$ of the sample's potassium is located in a relict phase of paleozoic age of $500 \mathrm{Ma}$, this is enough to lift the sample's K-Ar age from $65 \mathrm{Ma}$ to 70.S Ma. We consider SA1-302 to test whether the age pattern would then still show a plateau or if the relict phase would be recognizable. The degassing pattern shows two distinct reservoirs. We calculated the diffusion parameters, activation energy $Q$ and frequency factor $D_{0}$, by Arrhenius plots for each reservoir and simulated the gas release by two phases having different diffusion parameters. We assumed an age of $65 \mathrm{Ma}$ for the two phases and added an arbitrarily chosen relict phase having

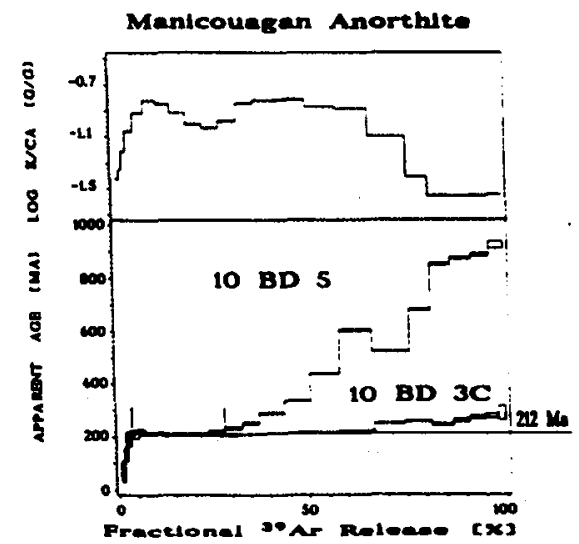

Fig. 3.

Nig. 1. 
diffusion parameters of a typical anorthite, with an age of $500 \mathrm{Ma}$ constituting $0.8 \%$ of the samples' potassium. The degassing peak of the relict phase coincides by and large with the second reservoir of SA1-302 but the degassing feature is broader (Fig. 3). The resulting calculated age pattem shows a low-temperature plateau of $65 \mathrm{Ma}$ and an irregular shape in the high-temperature steps. That means that the measured age pattem can only be interpreted as a result of 65-Ma age and a relict phase if the relict phase has exactly the same gas release pattern-but if this is the case, the relict phase should have been reset by the cratering event as well as the sample unless it would have been incorporated afterward, e.g., as contamination. A further condition that must be fulfilled to fit this scenario is that the $\mathrm{K}$ fraction of 500-Ma old relict phases in the different samples must be nearly the same $(1 \pm 0.2 \%)$, or another proper combination of age and $K$ content. We regard this as improbable.

Although the age spectra show well-defined plateaus, the plateau fractions still exhibit fine-scale structures that deviate from a theoretical calculated plateau (Fig. 2, bottom) as expected for a maximum precise measurement of an undisturbed sample. Normally the mass-dependent diffusion difference of ${ }^{40} \mathrm{Ar}$ and ${ }^{30} \mathrm{Ar}$ is considered as negligible, but if we induce it in our calculations in the case of SAl-302 we get an age spectra as shown in Fig. 2 with slightly increasing ages within each reservoir. This strengthens the assumption that these deviations are not of statistical, but of systematic nature, an artifact induced by the ${ }^{40} \mathrm{Ar}-$ "Ar stepheating technique. In this sense, the spectrum of SA1-302 seems to represent the "ideal" spectrum of an undisturbed sample. For the fine-scale deviations of the other three impact melts ${ }^{3}$ Ar recoil redistribution seems to play a major role, but this has to be investigated by further petrographic studies on grain size and potassium distribution.

We conclude an age of 69-71 Ma for the Kara impact structure. Hydrogen isotopic measurements by Nazarov et al. [6] show that the impact occurred on dry land and the authors concluded a maximum age of 69-70 Ma, the time of the end of the last regression within the crater's region before the end of the Cretaceous. Our data are consistent with an impact a short time after the regression.

Figure 4 shows the $\mathrm{K} / \mathrm{Ca}$ and the age spectra of two impact metamorphic anorthite samples (10BD5 and 10BD3C) of the Manicouagan Crater, Canada. As visible in the $\mathrm{K} / \mathrm{Ca}$ spectra (only 10BD5 is shown), the samples consists of two different phases, one degassing at low temperatures having an age plateau indistinguishable from the cratering event of $212 \mathrm{Ma}$ (7), the second one showing the signature of a partially degassed phase, having ages increasing up to. $950 \mathrm{Ma}$ (10BD5), the age of the target rocks [8]. 10BD3C suffered a more complete degassing, having ages ranging only up to $300 \mathrm{Ma}$. The low-temperature plateaus are in agreement with the crater age of $212 \mathrm{Ma}$ and do not improve the age of the impact structure. Anyway, while the crater age is quite accurate, the ages of the adjacent geologic boundaries seem not to be. The last revision [9] of the Triassic-Jurassic boundary in 1982 delivered an age of $213 \mathrm{Ma}$, while a later determination [10] gives a lower age of $208 \mathrm{Ma}$. We think so far as ages are concemed it is not possible to conclude or exclude an association of the two events until the age of the boundary is determined more precisely.

Our measurements enable us to estimate the intensity of the thermal event induced by the cratering event for the two Manicouagan samples. Our results are consistent with a time-temperature combination of $1 \mathrm{Ma}$ at $337^{\circ} \mathrm{C}$ or $12 \mathrm{hr}$ at $1100^{\circ} \mathrm{C}$ for 10BD5 and $1 \mathrm{Ma}$ at $361^{\circ} \mathrm{C}$ or $50 \mathrm{hr}$ at $1100^{\circ} \mathrm{C}$ for $10 \mathrm{BD} 3 \mathrm{C}$. Future investigations may allow us to infer a cooling model for the Manicouagan impact melt sheet.
References: [1] Alvarez L. W. et al. (1980) Science, 208, 1095. [2] Hartung J. B. and Anderson R. R. (1988) LPI Tech. Rept. 88-08. [3] Alvarez L. W. and Asaro F. (1990) Sci. Am., 362. [4] Kolesnikov E. M. et al. (1988) In LPI Contrib. No. 673. [5] Koeberl C. et al. (1990) Geology, 18, 50. [6] Nazarov M. A. et al. (1991) LPSC XXII, 961. [7] Grieve R. A. F. (1991) Meteoritics, 26, 175. [8] Wolfe S. H. (1971) JGR, 76, 5424. [9] Harland W. B. et al. (1982) A Geologic Time Scale, Cambridge Univ. [10] Palmer A. R. (1983) Geology, 11, 103.

"Ar-3Ar dATING OF PSEUdOTACHYLITES FROM THE WITWATERSRAND BASIN, SOUTH AFRICA, WITH IMPLICATIONS FOR THE FORMATION OF THE VREDEFORT DOME. M. Trieloff', J. Kunz', E. K. Jessberger!' W. U. Reimold2, R. H. Boer', and M. C. Jackson'2, 1Max-Planck Institut fir Kemphysik, P.O. Box 103980, W-6900 Heidelberg. Germany, ${ }^{2 E c o n o m i c ~ G e o l o g y ~ R e s e a r c h ~ U n i t, ~ U n i v e r s i t y ~ o f ~ t h e ~}$ Witwatersrand, P.O. Wits 2050, Johannesburg, RSA.

The formation of the Vredefort dome, a structure in excess of $100 \mathrm{~km}$ in diameter and located in the approximate center of the Witwatersrand basin, is still the subject of lively geological controversy. It is widely accepted that its formation seems to have taken place in a single sudden event, herein referred to as the Vredefort event, accompanied by the release of gigantic amounts of energy. It is debated, however, whether this central event was an internal one, i.e., a cryptoexplosion triggered by volcanic or tectonic processes, or the impact of an extraterrestrial body.

Ages obtained on rocks from the Vredefort structure cluster largely around $2.0 \mathrm{Ga}$ (e.g., review by [1]). Granophyre, an unusual melt rock forming dykes in the Vredefort Dome and thought to be related to the Vredefort event, yielded a $\mathrm{Pb}-\mathrm{Pb}$ zircon age of $2002 \pm$ $52 \mathrm{Ma}$ [2]. Pseudotachylite, a melt breccia first discovered and

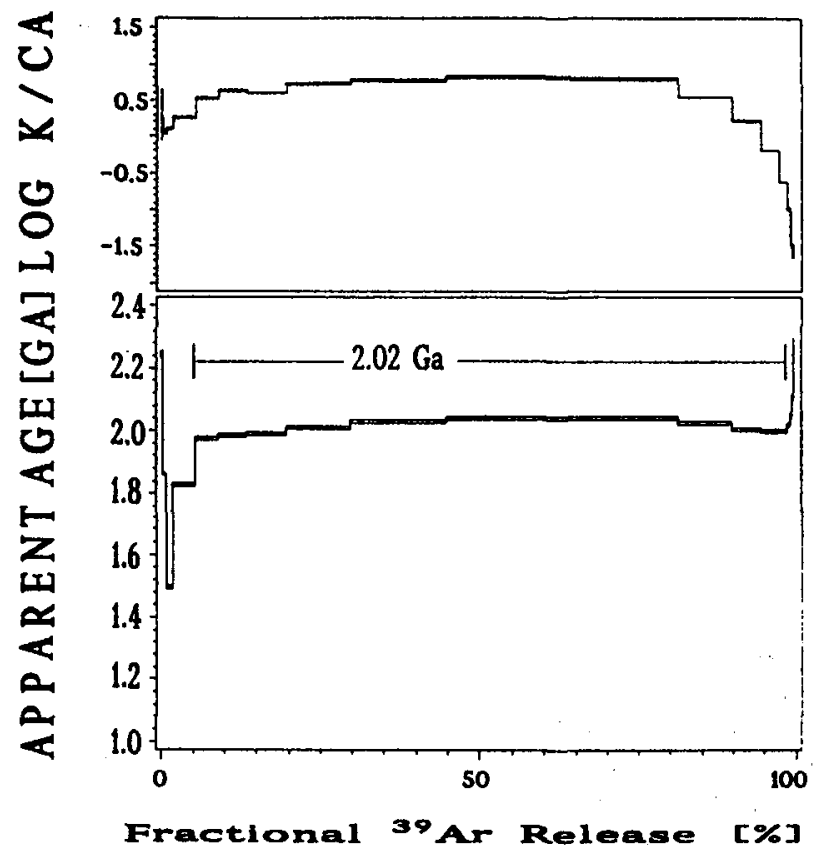

Fig. 1. Age spectrum for EL-28B. 
extremely abundant in the Vredefort structure, is, like the granophyre, widely regarded to be the direct result of the dome-forming process.

We dated eight pseudotachylite samples from a bedding-parallel fault zone across the north-central Witwatersrand basin with the ${ }^{40} \mathrm{Ar}-{ }^{39} \mathrm{Ar}$ step heating technique. All age results (Table 1) are indistinguishable from $2.00 \mathrm{Ga}$ within $1 \sigma$ errors, except for those obtained for two samples: 10D05 $(2.10 \mathrm{Ga})$ seems to be severely disturbed in the low-temperanure fractions; the other one, EL-30 has an extremely low $\mathrm{K}$ content of $20 \mathrm{ppm}$-compared to $\mathrm{K}$ contents of several percent in the other pseudotachylite samples. The relative fraction of excess argon is significant, which results in an unrealistic $\mathrm{K}$-Ar age of $4.7 \mathrm{Ga}$.

Figure 1 shows the exemplary spectrum of pseudotachylite sample EL28B with a plateau over $92 \%$ of the ${ }^{39}$ Ar release. In light of the appearance of the age spectra and the large number of samples analyzed to identical results, we donot believe that the 2-Ga ages are reset ages caused by thermal overprint. Our ages are consistent with the ${ }^{40} \mathrm{Ar}-{ }^{39} \mathrm{Ar}$ age of a Vredefort pseudotachylite (USA29, 2.00 Ga [3]). This indicates that the Vredefort event and the Witwatersrand pseudotachylite are related. Taking all our results into account, the resulting age for the Vredefort event is calculated to $1997 \pm 5 \mathrm{Ma}$; a larger error of $19 \mathrm{Ma}$ would be realistic if the additional error induced by our NL-25 homblende standard is considered.

A circumstance in favor of an origin by internal processes is the apparent coincidence of the Vredefort dome formation and other regional magmatotectonic processes. These are the emplacements of several alkaline granites and ayenites, namely the Schurwedraal complex (Rb-Sr errorchron of 2016 $\pm 61 \mathrm{Ma}$ [4]), the Lindequesdrift intrusion (2163 $\pm 31 \mathrm{Ma}{ }^{40} \mathrm{Ar}-39 \mathrm{Ar}$ plateau age of homblende [5]), the Rietfontein complex (2004 $\pm 16 \mathrm{Ma}{ }^{40 \mathrm{Ar}-39} \mathrm{Ar}$ plateau ages of biotite and homblende [6]), and-in an even wider regional context - the Bushveld complex, especially because Bushveld synchronous intrusives, such as the Losberg complex, occur close to the Vredefort structure. The age of the Losberg complex (Rb-Sr isochron of $2041 \pm 41 \mathrm{Ma}$ [7]), is in agreement with ages thought to represent the main Bushveld activity (2050-2060 Ma [1]), but, in general, ages have been determined ranging from 1900 to $2100 \mathrm{Ma}$, e.g., an ${ }^{10} \mathrm{Ar}-{ }^{39} \mathrm{Ar}$ age of Bushveld magnetite gabbro of $2096 \pm$ $12 \mathrm{Ma}[8]$ and an ${ }^{40} \mathrm{Ar}-{ }^{30} \mathrm{Ar}$ laser probe age of Merensky reef biotite of $2010 \mathrm{Ma}$ [9].

In agreement with an extended rather than short period of Bushveld activity are our own ${ }^{40} \mathrm{Ar}-{ }^{39} \mathrm{Ar}$ step heating results obtained for a Bushveld gabbro (whole rock, anorthite, and pyroxene), where two partial plateau can be identified in the age spectra: one corresponding to a mean age of $2.00 \mathrm{Ga}$ and the other to a mean age of $2.10 \mathrm{Ga}$. This could indicate a complex cooling or reheating history of the sample. Investigations are currently in progress to determine whether excess Ar could be the cause of this age dichotomy or whether the spectra are the result of a true two-stage geological history. No matter what the result will be, an event close to $2.00 \mathrm{Ga}$ will remain indicated.

If high-resolution geochronology could prove that the ages of the rocks related to the dynamic Vredefort event (granophyre, pseudotachylite) and the ages of the rocks formed in magmatotectonic processes are different, this would be an argument favoring Vredefort as an impact site, but considering the ages of the geologic activity around the Vredefort structure, we do not think that this is possible because of the extended duration of the tectonic processes.

Previous $10 \mathrm{Ar}-3 \% \mathrm{Ar}$ investigations of pscudotachylites from other localities in and around the dome resulted in a number of ages significantly lower than $2 \mathrm{Ga}$ for four out of six dated specimens [3].
Such recent formation ages would even question the single-stage formation of the Vredefort dome and its associated pseudotachylites [3]. Ages lower than $2 \mathrm{Ga}$ are not restricted to pseudotachylite either: a plagioclase separate of the lamprophyre from the Lindequesdrift intrusion dated at $2163 \mathrm{Ma}$ yielded a $1248 \pm 22 \mathrm{Ma}$ age [5]. Several mineral separates from Rietfontein complex rocks gave partial plateaus at about $2004 \mathrm{Ma}$, but also showed low ages in the low-temperature release steps comprising 20 to $50 \%$ of the ${ }^{39} \mathrm{Ar}$ release, suggestive of disturbances at $1170 \pm 14$ and $725 \mathrm{Ma}$ [6]. A pseudotachylite from the Riefontein complex (USA35) showed an irregular age pattem suggesting disturbances at $1400 \mathrm{Ma}$ and $800 \mathrm{Ma}$ [3]. In the outer (OGG) core of the Vredefort structure, pseudotachylite USA30A yielded an age of $1.39 \mathrm{Ga}$ [3], whereas a Rb-Sr mineral isochron for the host granite resulted in an age of $2002 \pm 8 \mathrm{Ma}$ and Ar-dated mineral separates yielded ages ranging from 1.39 to $1.76 \mathrm{Ga}$, all significantly lower than $2 \mathrm{Ga}$ [10]. Biotite separates from a granophyre sample (VVG) from a site less than $3 \mathrm{~km}$ from the USA 30 locality yielded a possible formation age of $2006 \pm 9 \mathrm{Ma}$, but with evidence in the age spectrum for significant overprinting at 700 and/or $1200 \mathrm{Ma}$ [6]. Biotite from OGG sample KK55 from the northwestem sector of the core yielded a $1935 \pm$ 8 Ma plateau age, still lower than $2 \mathrm{Ga}$ [6]. Finally, pseudotachylite USA31 provided an age pattern suggestive of partial degassing at 1.4 Ga [3], whereas its host rock, NW28, gave ages of $2070 \mathrm{Ma}$ (biotite) and $3030 \mathrm{Ma}$ (homblende). It should also be mentioned that four of our Witwatersrand pseudotachylite samples show lowtemperature fractions consistent with disturbances at $1400 \mathrm{Ma}$. Post-2-Ga events could thus have taken place at $1400,1200,1000$, and $700 \mathrm{Ma}$ ago. There are two possible scenarios that could explain this record of low ages for Vredefort samples. Firstly, the low pseudotachylite ages are seen as formation ages that date the result of post-2-Ga tectonic events. This would explain the different resetting degrees observed for samples from different localities, as well as observations of multiple geological hints for the existence of several pseudotachylite generations in the Vredefort structure

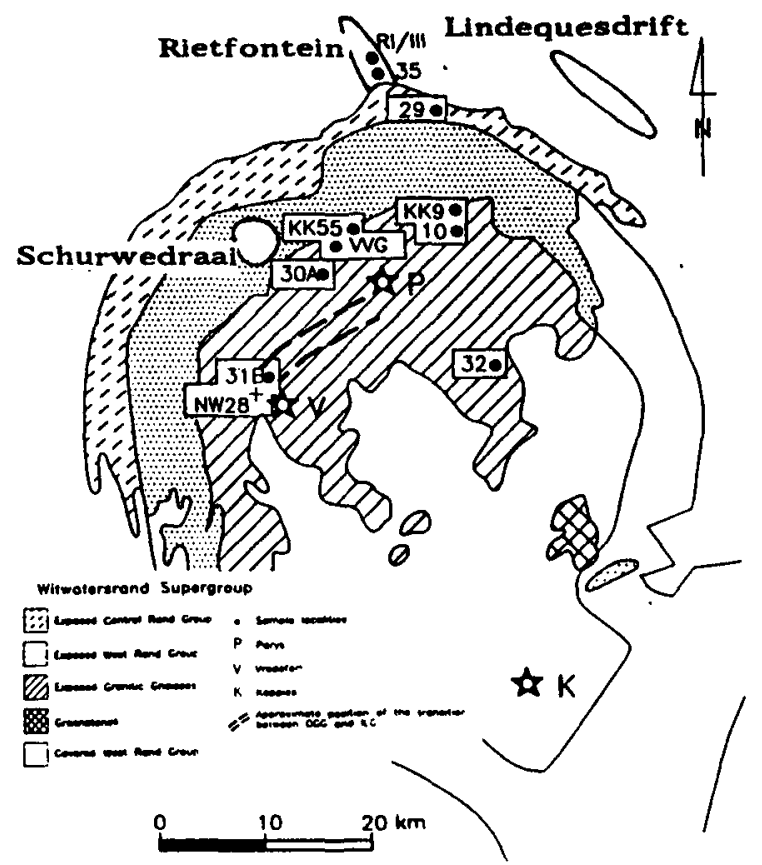

Fig. 2. Sample locality overview at the Vredefort structure (after [10]). 
[10]. Then it should be clear why there are not pseudotachylites older than $2 \mathrm{Ga}$. Secondly, the low ages could be due to post-2-Ga thermal overprint. Host rocks were then more or less intensely affected in accordance with the different Ar retentivities of different minerals, or different closure temperatures in the case of $\mathrm{Rb}-\mathrm{Sr}$ isotope systematics. A major problem is seen in the different intensities of the resetting events at different localities within the dome. This may be explained partly by additional hydrothermal activity.

Future investigations are still needed to completely clarify the nature and the duration of post-2-Ga processes that took place in the Vredefort structure.

Acknowledgments: We gratefully acknowledge the generous support from Anglo American Prospecting Services that permitted the analysis of Witwatersrand pseudotachylites, and the permission to report the results.

References: [1] Walraven F. et al. (1990) Tectonophysics, 171,23-48. [2] Compston W. and Nicolaysen L. O. in [1]. [3] Reimold W. U. et al. (1990) Tectonophysics, 171, 139-152. [4] Nicolaysen L. O. et al. (1963) Gen. Assem. Int. Union. Geol. Geophys. 13th, Berkeley, Calif., abstract. [5] Hargraves R. B. (1987) S. Afr. J. Geol., 90, 308-313. [6] Allsopp H. L. et al. (1991) Suid afrikaanse Tydskrif vir wetenskap, 87, 431-442. [7] Coetzow H. and Kruger F. J. (1989) S. Afr. J. Geol., 92, 37-41. [8] Burger A. J. and Walraven F. (1977) Annu. Geol. Survey S. Africa, 11, 323-329. [9] Onstott and Kruger in [1]. [10] Reimold W. U. et al. (1990) Geol. Soc. Austr., 27, 82.

AL UMCHAIMIN DEPRESSION, WESTERN IRAQ: AN IMPACT STRUCTURE? James R. Underwood Jr., Department of Geology, Kansas State University, Manhattan KS 66506-3201, USA.

Al Umchaimin, in Arabic "hiding place" or "place of ambush" [1], is located at latitude $32^{\circ} 35.5^{\prime} \mathrm{N}$ and longitude $39^{\circ} 25^{\prime} \mathrm{E}$. It lies

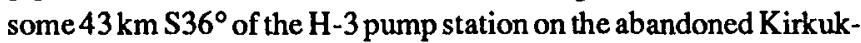
Haifa oil pipeline [2] and $60 \mathrm{~km} \mathrm{S49}{ }^{\circ} \mathrm{W}$ of the western desert town of Rutba. The nearly circular depression averages $2.75 \mathrm{~km}$ in diameter and is $33-42 \mathrm{~m}$ deep. It is floored with fine-grained, clayrich deposits, estimated to be $36 \mathrm{~m}$ thick [3], the surface of which shows well-developed desiccation fissures or mudcracks when dry. Because of its nearly circular planimetric shape and its apparent isolation from other surface and subsurface features, it has been considered by some to be a possible meteorite impact structure [4] and by others [5] to be a surface collapse feature that originated following removal of magma from the subsurface as the magma extruded elsewhere. Al Umchaimin was listed in the U.S. Geological Survey tabulation of 110 structures worldwide for which a meteorite impact origin had been suggested [6]. It was placed in Category VI Structures for which more data are required for classification.

K. M. Al Naqib, Iraq Petroleum Company, reported [7] that the petroleum geology community considered that Al Umchaimin had originated by fracture-controlled dissolution in the subsurface and eventual collapse into the resulting solution cavity. Al-Din and others [3] made geological and geophysical surveys of the depression in 1969 and 1970 and found no evidence for an impact origin. They concluded, as did Al Naqib, that a solution-collapse origin was likely.
Abbas and others [8] conducted additional geophysical studies and arrived at similar conclusions: (1) Al Umchaimin was not formed by meteorite impact and (2) probably it represents a solution-collapse feature. Greeley and others [9], in preparation for the Magellan mission to Venus, studied shuttle radar images of nine maar volcanos, one volcanic caldera dome, one impact structure, and one possible impact structure (Al Umchaimin). Concerning $\mathrm{Al}$ Umchaimin, they wrote: "Although no definitive impact features have been reported, the circularity and slightly uplifted rims suggest an impact origin."

In 1965, the author and the late Randolph Chapman, both visiting professors at the College of Science, University of Baghdad, spent half a day at $\mathrm{Al}$ Umchaimin during which a section was measured up the east wall, samples were collected for later thin sectioning, and a search made for meteoritic debris, shatter cones, impact glass, melt breccia, and so on. No evidence was found for an impact origin of the depression, nor did study of the thin sections from the east wall of the depression reveal any microscopic evidence of impact.

It is concluded that, on the basis of the studies that have been made of Al Umchaimin and on the basis of the brief site visit made, Al Umchaimin probably is not an impact structure but most likely resulted from the enlargement and coalescence of sink holes and eventual collapse of the roof material into the resulting cavity.

References: [1] Suleiman M. W., personal communication. [2] Army Map Service (1952) Wadi Hauran, Iraq, Sheet NI 37-15, scale 1:250,000. [3] Al-Din T. S. et al. (1970) J. Geol. Soc. Iraq, 3, 73-88. [4] Merriam R. and Holwerda J. G. (1957) Geograph. J., CXXIII, 231-233. [5] Mitchell R. C. (1958) Geograph. J., CXXIV, 578-580. [6] Freeberg J. H. (1966) U.S. Geol. Surv. Bull. 1220, 21. [7] Al Naqib K.M. (1967) U.S. Geol.Survey Prof. Pap. 560-G, G7. [8] Abbas M. J. et al. (1971) J.Geol.Soc.Iraq, 4, 25-40. [9] Greeley R. et al. (1987) Earth Moon Planets, 37, 89-111.

A LATE DEVONIAN IMPACT EVENT AND ITS ASSOCIATION WITH A POSSIBLE EXTINCTION EVENT ON EASTERN GONDWANA. K. Wang ${ }^{1}$ and H. H. J. Geldsetzer ${ }^{2}$, 'Department of Geology, University of Alberta, Edmonton, Alberta T6G 2E3, Canada, ${ }^{2}$ Geological Survey of Canada, 3303-33rd Street, N.W., Calgary, Alberta T2L 2A7, Canada.

Evidence from South China and Western Australia for a 365-Ma impact event in the Lower crepida conodont zone of the Famennian stage of the Late Devonian (about 1.5 Ma after the Frasnian/ Famennian extinction event) includes microtektitelike glassy microspherules [1], geochemical anomalies (including a weak Ir), a probable impact crater $(>70 \mathrm{~km})$ at Taihu in South China [2], and an Ir anomaly in Western Australia [3]. A brachiopod faunal turnover in South China, and the "strangelove ocean"-like ${ }^{13} \mathrm{C}$ excursions in both Chinese and Australian sections indicate that at least a regional-scale extinction might have occurred at the time of the impact. A paleoreconstruction shows that South China was very close to and facing Western Australia in the Late Devonian [4].

South China: An Upper Devonian carbonate section exposed at Qidong, Hunan, was studied for biostratigraphy, geochemistry, and sedimentology. A brachiopod faunal changeover from the traditional Yunnanellina to Yunnanella faunas [5] was recognized in the section. Abundant microspherules were found in a single stratigraphic horizon immediately below a $3-\mathrm{cm}$ clay with a geochemical anomaly. The microspherule horizon occurs in the Lower 
crepida conodont zone, based upon the presence of conodont species $P$ a.quadrantinodosalobata,Po. nodocostatus, I. iowaensis, I. cornutus, I. alternatus, and $\mathrm{Pel}$. inclinatus [6], and $\mathrm{Pa}$. crepida, $P a$. minuta minuta, $P a$. quadrantinodosalobata, $I$. iowaensis, $I$. alternatus helmsi, and I. alternatus alternatus [7]. Petrographic, SEM, XRD, and electron microprobe analyses indicate that the microspherules were like microtektites produced by a bolide impact, on the basis of their "splash form" shapes, inner bubble vesicles, glassy nature, silica glass inclusions (lechatelierite), and chemical compositions that are similar to those of microtektites. The geochemical anomaly in the 3-cm clay is characterized by siderophiles ( $\mathrm{Ir}, \mathrm{Fe}, \mathrm{Co}, \mathrm{Cr}$ ) and chalcophiles ( $\mathrm{Se}, \mathrm{Sb}, \mathrm{As}$ ) enriched by factors of 1 to several orders of magnitude over their background values, although Ir abundance in the clay is low (38 ppt). The $\delta^{13} \mathrm{C}$ maintains constantly positive values in the carbonate samples below the clay, but shifts suddenly to a minimum of $-1.97 \%$ in the clay and above. Although the carbonate rocks we analyzed were altered to some degree by diagenesis (as seen in the thin sections), we believe that the trend of the carbon isotopic change is still preserved. A "strangelove ocean"-like $\delta^{13} \mathrm{C}$ excursion of $2.7 \%$ (PDB) in the Qidong Section is consistent with the paleontological data suggesting that an extinction might have terminated the Yunnanellina fauna, which in turn gave rise to the Yunnanella fauna. Taihu Lake, a large circular structure, has long been speculated to be a probable impact crater. Recent work, on the basis of shock metamorphism found in the target sediments, has suggested that it is a probable impact crater [2].

Western Australia: A strong iridium anomaly (20 times the background value) was initially reported in the Famennian Upper triangularis conodont zone in the Canning Basin, Western Australia [3]. An evaluation of the conodont fauna proved that the Ir anomaly is actually in the Lower crepida zone, based upon the occurrence of $P a$. crepida [8]. This strongly indicates that the Canning Basin Ir anomaly occurs at the same stratigraphic level as the Qidong microspherule and geochemical anomaly horizon. Because the Australian Ir anomaly is associated with a Frutexites stromatolite, the interpretation was that the Ir was concentrated biologically by the cyanobacteria. We acknowledge this scenario but further propose that there must have been abundant Ir available in the environment for the biological concentration to take place. The most probable source for Ir is an impact near the region, such as the impact in South China. The presence of Frutexites stromatolites is probably the reason why there is a stronger Ir anomaly in the Canning Basin than in the Qidong area, where no Frutexites stromatolites are present. A negative $\delta^{13} \mathrm{C}$ excursion of about $1.5 \%$ is coincident with the Ir anomaly in the Canning Basin, and has been suggested to indicate a decrease in biomass [3].

The carbon isotopic excursions, which occur at the same stratigraphic level in both South China and Western Australia cannot be explained as being coincidental. The $\delta^{13} \mathrm{C}$ excursions and the brachiopod faunal turnover in South China indicate that there might have been at least a regional (possibly global) extinction in the Lower crepida zone. The impact-derived microspherules and geochemical anomalies (especially the Ir) indicate a Lower crepida zone impact event on eastern Gondwana. The location, type of target rocks, and possibly age of the Taihu Lake crater qualify as the probable site of this Late Devonian impact.

References: [1] Wang K. (1991)Geol.Soc.Am.Abstr.Progr., 23, A277. [2] Sharpton V. L. et al., in preparation. [3] Playford P. E. et al. (1984) Science, 226,437-439. [4] Scotese C. R. and McKerrow W. S. (1990) Geol. Soc. London Mem., 12, 1-21. [5] Tien C. C. (1938) Palaeont. Sinica, New series B, 4, 1-192. [6] Wang K. and
Bai S. (1988) Can. Soc. Petrol. Geol. Mem. 14, 3, 71-78. [7] Ji Q. (1988) Ph.D. thesis, Chin. Acad. Geol. Sci., Beijing, 140 pp. [8] Nicoll R.S. and Playford P. E. (1988) Geol.Soc.Austral. Abstr., $21,296$.

\section{ELECTRON PETROGRAPHY OF SILICA POLYMORPHS ASSOCIATED WITH PSEUDOTACHYLITE, VREDEFORT} STRUCTURE, SOUTH AFRICA. J. C. White, Center for Deformation Studies in the Earth Sciences, Department of Geology, University of New Brunswick, Fredericton, New Brunswick, Canada E3B 5A3.

High-pressure silica polymorphs (coesite and stishovite) have been described from the Vredefort structure $[1,2]$ in association with pseudotachylite veinlets. In addition to the fundamental significance of the polymorphs to genetic interpretations of the structure, it has been additionally argued that the type of pseudotachylite with which they occur forms during the compressional phase of the shock process, while the larger, classic pseudotachylite occurrences are barren of polymorphs and formed during passage of the rarefaction wave. This identification of temporal relationships among transient shock features at a regional scale is similar to observations from the Manicouagan structure, Quebec [3], where texturally distinct diaplectic plagioclase glasses formed during both compressional and decompressional phases of the shock process. The clarification of such relationships impinges directly on interpretations of natural shock processes and the identification of high probability targets for polymorph searches.

Detailed analytical scanning (SEM) and transmission electron microscopy (TEM) has been utilized to further establish the nature of both the pseudotachylite and the silica polymorph occurrences in
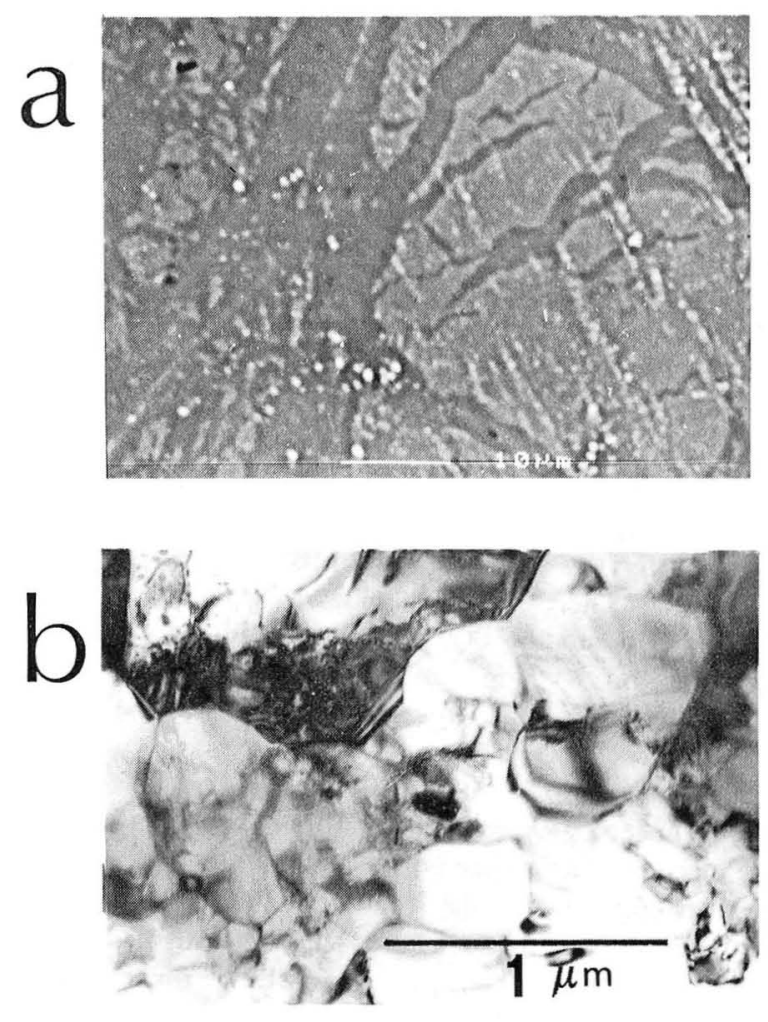

Fig. 1. 
the Vredefort rocks. This methodology enables the maintenance of strict control over the spatial, compositional, and crystallographic relationships of the deformed material. The brown, optically isotropic nature of the pseudotachylite belies an essentially pure silica composition. As has been previously noted [2], minor $\mathbf{K}$-feldspar, aluminosilicate (ky anite?) and primary mica are the significant nonsilica mineral phases. Backscattered electron imaging demonstrates complex relationships among the silica phases. Stishovite replacement by quartz (Fig. 1) often takes the form of tensile veinlets suggesting reconversion during shock wave relaxation. Coesite most commonly occurs as acicular grains and is widely dispersed at a fine scale throughout quartz. Reconverted quartz (Fig. 2) from both presumed melt and polymorphs can be remarkably finegrained, e.g., $\leq 200 \mathrm{~nm}$ grain diameters. Preservation of crystalline material of such small grain size would appear to preclude significant postformation thermal anneals, or otherwise requires extremely sluggish transformation kinetics.

References: [1] Martini J. E. J. (1978) Nature, 272, 715-717. [2] Martini J. E. J. (1991) EPSL, 103, 285-300. [3] White J.C.(1991) Geol. Assoc. Can. Prog. Abstr., 16, A131.

FLOOR-FRACTURED CRATER MODELS OF THE SUDBURY STRUCTURE, CANADA. R. W. Wichman and P. H. Schultz, Department of Geological Sciences, Brown University, Providence RI 02912, USA.

Introduction: The Sudbury structure in Ontario, Canada, is one of the oldest and largest impact structures recognized in the geological record [1]. It is also one of the most extensively deformed and volcanically modified impact structures on Earth [2-4]. Although few other terrestrial craters are recognized as volcanically modified, numerous impact craters on the Moon have been volcanically and tectonically modified [5] and provide possible analogs for the observed pattern of modification at Sudbury. In this study, we correlate the pattem of early deformation at Sudbury to fracture patterns in two alternative lunar analogs and then use these analogs both to estimate the initial size of the Sudbury structure and to model the nature of early crater modification at Sudbury.

Structure Descriptions: Two patterns of deformation can be distinguished at Sudbury: (1) an early sequence centered on the Sudbury Igneous Complex [6] and (2) several later episodes of regional deformation that cut basin-controlled features, i.e., are insensitive to the impact structure. The Main Igneous Complex presently defines an elliptical ring about $60 \mathrm{~km}$ long and $27 \mathrm{~km}$ across. This norite/micropegmatite layered intrusion has a crystallization age of $\sim 1850 \mathrm{Ma}$, which is commonly assigned to the time of impact [7]. It also feeds an extensive sequence of offset dikes in the surrounding basement rocks radial and concentric to the undeformed structure [6]. The radial dikes are the most evenly distributed and, although disrupted by later deformation, they can extend up to $30 \mathrm{~km}$ from the edge of the Main Igneous Complex. The less extensive concentric dikes mostly occur south of the structure where they are typically about 3-10 km from the Main Complex [6]. Lastly, basin-centered concentric lineaments can be identified in satellite images $20-30 \mathrm{~km}$ north and west of the structure [8]. Unfortunately, deformation along the Grenville front to the south and at the Wanapitae Impact to the east masks any similar trends elsewhere around the basin.

Similar patterns of crater-centered radial and concentric fractures are observed in lunar floor-fractured craters. Since these patterns appear to be partly controlled by the original impact structures, however, two altemative lunar analogs (i.e., complex craters and two-ring basins) can be identified for the Sudbury dike pattern. The first compares Sudbury to the central peak crater Haldane in Mare Smythii. Haldane is a multiringed structure with an outer rim diameter of $\mathbf{4 0} \mathrm{km}$ and an uplifted central "floor plate" separated from this rim by a wide $(-5 \mathrm{~km})$ moat structure $[5,9]$. Concentric fractures occur near the edge of the floor plate, in the moat and in a well-defined annulus 9-16 km beyond the crater rim. Radial fractures are typically restricted to the central plate and moat regions, but one set east of the crater extends over $10 \mathrm{~km}$ beyond the crater rim in association with additional concentric fracturing. Crater counts indicate that both the crater and the superposed fracture systems formed at nearly the same time, whereas volcanism in Haldane appears to be coeval with other basalt units in Mare Smythii. These volcanic units are primarily located along the outer fracture ring and in the crater moat structure [9].

The alternative analogy compares Sudbury with the lunar tworing basin Schrodinger. Schrodinger is $-300 \mathrm{~km}$ in diameter with a broad interior ring surrounding a central floor region $\sim 100 \mathrm{~km}$ in diameter. Roughly concentric fractures occur along the interior ring structure, whereas radial fractures typically extend from the inner ring toward the outer crater wall. Volcanic activity within the basin is limited, but a dark-haloed pit on one of the innermost concentric fractures indicates minor pyroclastic activity.

Comparison: The dike patterns at Sudbury thus can be interpreted in three ways. First, if the Sudbury Igneous Complex marks the location of the crater rim, the radial offset dikes might correspond to the fractures extending beyond the eastern rim of Haldane. The even distribution of these dikes around Sudbury, however, then requires a uniformly tensile regional stress field, which is inconsistent with the onset of the Penokean Orogeny shortly after the impact [10]. Further, since the Igneous Complex probably represents an impact melt unit [11], the edge of this unit is more likely to reflect the edge of the basin floor than the crater rim.

In the second interpretation, the radial offset dikes correspond to radial fractures observed in the Haldane moat. In this case, the concentric dikes and the Sudbury Igneous Complex would mark the edge of an uplifted floor plate, while floor uplift could produce a uniformly tensile stress field within the crater rim [12]. In addition, the absence of an uplifted central peak complex at Sudbury requires detachment of the impact melt from the central peaks during uplift. Although rare, such detachments are observed on the Moon, where a few craters (e.g., Billy, Camoens) show evidence for a "foundered central peak complex" $[5,12]$.

Third, the Sudbury dike pattern also matches the pattern of fracturing in the two-ring basin Schrodinger. The radial offset dikes are identified with the pattem of radial fractures occurring in the outer floor region at Schrodinger, whereas the concentric offset dikes correlate with the inner sequence of concentric fractures along the interior peak ring. Due to the close proximity of the Igneous Complex to the concentric offset dikes, this interpretation suggests that the Sudbury basin may preserve much of the original central impact melt sheet consistent with [11].

Discussion: The comparison of Sudbury to lunar floor-fractured craters thus provides two alternative models for the initial Sudbury structure. Further, the apparent correlation of crater floor fractures to specific elements of the original crater structure allows estimation of crater sizes for these two models. For the Haldane analogy, since radial fractures are confined to the crater interior, the extent of the radial offset dikes from the original basin center indicates a minimum Sudbury diameter of $\sim 100-120 \mathrm{~km}$. If the Sudbury basin contains a down-dropped central peak complex, the 
size of the Sudbury Igneous Complex then provides a maximum estimate for the crater size. Since strain analyses of deformation in the Sudbury basin indicate original basin dimensions of $60 \mathrm{~km}$ by 40 km [3], the basal diameter of the Sudbury central peak structures was probably no more than $35-40 \mathrm{~km}$. Using morphometric relations for unmodified lunar craters [13], these values indicate a maximum crater diameter of $\sim 120-140 \mathrm{~km}$.

Alternatively, the Schrodinger analogy indicates a larger multiring structure. Since radial fractures are confined to the outer crater floor in this model, the extent of the radial offset dikes provides a minimum basin diameter of $\sim 130-140 \mathrm{~km}$ (corresponding to a basin floor diameter of $\sim 100-120 \mathrm{~km}$ ). The maximum size of the original Sudbury Igneous Complex $(\sim 55-60 \mathrm{~km})$, however, also can be related to the basin rim diameter. If this value represents the initial size of the central basin floor, the rim crest diameter becomes approximately $170-180 \mathrm{~km}$, which is comparable to the recent estimate of $180-200 \mathrm{~km}$ derived from the distribution of preserved shock features around Sudbury $[11,14]$. Although erosional loss of the Igneous.Complex might accommodate an even larger basin structure, the inferred location of the inner basin ring relative to the concentric offset dikes probably precludes any drastic increase in this estimate.

The interpretation of Sudbury as a floor-fractured crater or tworing basin also provides two alternative models for early crater modification at Sudbury. First, most lunar floor-fractured craters apparently reflect deformation over a crater-centered laccolithic intrusion [5,12]. Since geophysical studies suggest the presence of a tabular ultramafic body beneath Sudbury [15], such an intrusion also may be the cause of deformation at Sudbury. The timing of dike formation at Sudbury, however, limits the potential melt sources of such an intrusion and requires direct interaction of the Sudbury impact with either a contemporaneous orogenic melt or with an orogenic thermal anomaly. Second, isostatic uplift of the basin floor could induce floor fracturing through flexure [16]. In this case, the dike magmas could be derived primarily from the impact melt sheet rather than from a mantle melt, but isotope analyses of the Sudbury ores still suggest a small (10-20\%) component of mantle-derived melts [17].

In either case, interaction of the Sudbury impact with the Penokean Orogeny can be inferred. Since both crater-centered intrusions and isostatic relaxation should be favored by enhanced temperature gradients, this is consistent with the higher heat flows and greater volcanism characteristic of orogenic settings. It also may explain why the majority of terrestrial impacts in more cratonic settings show little evidence of floor fracturing. Since high heat flows were apparently common during the early Archean, however, volcanic crater modification may have been more common at this time. Such early impact structures, therefore, may not resemble the more recent impact structures preserved in the terrestrial impact record. Instead, like Sudbury, they may be preserved primarily as complexes of (possibly anomolous) igneous intrusions.

References: [1] Grieve R. A. F. and Robertson P. B. (1979) Icarus, 38, 212-229. [2] French B. M. (1970) Bull. Volcanol., 34, 466-517. [3] Rousell D. H. (1984) In The Geology and Ore Deposits of the Sudbury Structure (Pye et al., eds.), 83-95. [4] The Geology and Ore Deposits of the Sudbury Structure (Pye et al., eds.), Ontario Geol. Survey, Spec. Vol. 1. [5] Schultz. P. H. (1976) Moon, 15, 241-273. [6] Grant R. W. and Bite A. (1984) In [4], 276-300. [7] Krough T. E. et al. (1984) In [4], 432-446. [8] Dressler B. O. (1984) In [4], 99-136. [9] Wolfe R. W. and El-Baz F. (1976) Proc. LPSC 7th, 2906-2912. [10] Peredery W. V. and Morison G. G. (1984) In [4], 491-511. [11] Grieve R. A. F. et al. (1991) JGR, 96,
22753-22764. [12] Wichman R. W. and Schultz P. H. (1992), in preparation. [13] Hale W. and Head J. W. (1979) Proc. LPSC 10th, 2623-2633. [14] Lakomy R. (1990) LPSCXXI, 678-679. [15] Gupta V. K. et al. (1984) In [4], 281-410. [16] Baldwin R. B. (1968) JGR, 73, 3227-3229. [17] Walker R. J. et al. (1991) EPSL, 105, 416-429.

VARIATION IN MULTIRING BASIN STRUCTURES AS A FUNCTION OF IMPACT ANGLE. R. W. Wichman and P. H. Schultz. Department of Geological Sciences, Brown University, Providence RI 02912, USA.

Introduction: Previous studies have demonstrated that the impact process in the laboratory varies as a function of impact angle [1-3]. This variation is attributed to changes in energy partitioning and projectile failure during the impact $[2,3]$ and, in simple craters, produces a sequence of progressively smaller and more asymmetric crater forms as impact angle decreases from $-20^{\circ}$ [1]. Crater shapes appear to be constant for higher impact angles. Further studies have compared the unique signatures of oblique impacts observed in the laboratory to much larger impacts on the Moon and Mercury [3-5] as well as Venus [6]. At the largest basin scales, the asymmetry of the transient cavity profile for highly oblique impacts results in an asymmetric lithospheric response [7]. Since transient cavity asymmetry should decrease with increasing impact angle, therefore, comparison of large impact basins produced by slightly different impact angles allows calibration of the effects such asymmetries may have on basin formation.

Basin Comparison: Although only Crisium shows a distinctly elongated basin outline, both the Crisium and Orientale basins on the Moon apparently resulted from oblique impacts. Both basins possess an asymmetric basin ejecta pattern (see [8] for a review), and both basins also exhibit features predicted [7] for collapse of an oblique impact cavity: a gravity high offset from the basin center [9-11] and a set of similarly offset basin ring centers [7]. Based on the crater outlines and ejecta distributions in laboratory impact experiments, Crisium probably represents an impact event at $\sim 10-15^{\circ}$ off the horizontal [3], whereas the ejecta pattern and more circular basin outline at Orientale more closely resemble laboratory impacts at $\sim 15-25^{\circ}$.

Three primary differences can be identified between the Crisium and Orientale basin structures. First, the Cordillera scarp in Orientale has a relief of $-4-6 \mathrm{~km}$ [12], whereas the outer basin scarp at Crisium is poorly defined and has a maximum relief of only 1$2 \mathrm{~km}$. Second, Orientale shows two distinct massif rings (the inner and outer Rook Montes) separated by a nearly continuous trough structure, whereas the massif ring at Crisium is only disrupted by a medial system of discontinuous troughs [13-15]. The distribution of massif topography is also different. The highest massifs in Orientale are in the Outer Rooks, but the highest massif elevations in Crisium occur in the innermost massifs bounding the central mare. Third, although mare volcanism in both basins has developed along the massif troughs and along the base of the outer basin scarps, such peripheral volcanism appears to be less extensive in Orientale (Lacus Veris, Autumnae) than in Crisium (Lacus Bonitatis, Mare Spumans, Undarum, Anguis).

Despite these differences, both Crisium and Orientale possess a common pattern of basin modification: an innermost steplike rise bounds the central mare; the massif ring(s) are split by a sequence of concentric troughs, and, in both cases, the outer basin scarp is most prominent uprange. Further, the occurrence of peripheral mare 
volcanism is similar. Although peripheral ponded mare units do occur downrange in Crisium (Mare Spumans, Undarum, Anguis), these units can be correlated with impacts by hypervelocity decapitated projectile fragments from the Crisium impactor [3]. We interpret these fundamental similarities between Crisium and Orientale to be common signatures of basin formation at oblique impact angles, whereas the observed differences are attributed to variations in cavity collapse as a function of impact angle.

Discusston: As discussed by [3,5,6], smaller complex craters $(20-100 \mathrm{~km})$ with asymmetric ejecta patterns typically exhibit offset central peaks and more extensive wall slumps uprange, reflecting the distinctive asymmetry of crater profiles for oblique impacts. Similarly, the differences in basin appearance between Crisium and Orientale provide insight into the effects of impact angle on cavity collapse during basin formation. First, the progression from discontinuous concentric troughs in the Crisium massif ring to a split massif ring at Orientale is consistent with increasing failure of the transient cavity rim at higher impact angles. In addition, the outer Crisium scarp is lower than the Cordillera scarp, whereas the inner Crisium massifs are much higher than the inner Rook massifs. These topographic differences also support greater slumping during cavity collapse with increased impact angles. Even the changing expression of the innermost ring structures (from a mare bench $\sim 200 \mathrm{~m}$ high in Crisium [16] to a combination of scarps and massifs in Orientale [8]) may reflect such variations in basin collapse, if the relation of rim failure to interior uplift resembles that observed in smaller terrestrial craters [17].

Second, the greater restriction of uprange peripheral volcanism in Orientale also can be related to greater cavity collapse. If reduced cavity collapse indicates reduced cavity equilibration, isostatic uplift after the impact should increase with decreasing impact angle. Since flexural stresses during such uplift are tensile at depth outside the basin region [7], conditions for structurally controlled dike formation will then depend on impact angle. For a given basin size, therefore, basins formed by highly oblique impacts should induce greater flexural stresses than higher-angle impacts; hence, magma columns should be more likely to reach the surface along peripheral basin faults resulting from lower-angle impacts.

Third, the greater prominance of the basin scarps uprange of both Crisium and Orientale may reflect the asymmetry of oblique impact cavities. In the ring tectonic model of basin scarp formation [18,19], the outer scarp reflects lithospheric failure over mantle flow into the collapsing cavity. For an axisymmetric flow field, therefore, the basin scarp should be equally well developed around the basin periphery. The uprange offset in deepest projectile penetration at low impact angles [1], however, should modify the pressure gradients driving mantle flow during cavity collapse. Since both wall slopes and cavity depths are reduced downrange [1], the volume of mantle flow into an oblique transient cavity may be predominantly derived from beneath the basin rim uprange. In addition, since projectile failure should reduce the energy of later (downrange) cavity excavation in an oblique impact, peak shock pressures also should be centered closer to the point of initial contact (uprange); thus shock disnuption and acoustic fluidization could be enhanced uprange of the transient cavity.

The observed settings of the peripheral mare units in Crisium and Orientale provide further support for the inferred asymmetry of cavity collapse. Although tectonically controlled mare units consistently develop along uprange scarps in Crisium and Orientale, peripheral volcanism downrange of Crisium apparently requires intersection of the ring fault with an impact structure. This observation suggests that magma column heights are greatest uprange of
Crisium and Orientale, which is consistent with greater scarp failure in these regions. In addition, however, the uprange offset in oblique impacts of the mantle uplift and deepest impactor penetration could produce such an asymmetry by shifting the mantle melt reservoirs uprange and by shifting the center of basin uplift and the associated flexural stress fields.

Conclusions: Variations in impact angle can produce differences in the appearance of multiring impact basins. Comparison of Orientale to the more oblique impact structure at Crisium also suggests that these differences primarily reflect the degree of cavity collapse. The relative changes in massif ring topography, basin scarp relief, and the distribution of peripheral mare units are consistent with a reduction in degree of cavity collapse with decreasing impact angle. The prominent uprange basin scarps and the restriction of tectonically derived peripheral mare units along uprange ring structures also may indicate an uprange enhancement of failure during cavity collapse. Finally, although basin ring faults appear to be preferred pathways for mare volcanism [16,20-22], fault-controlled peripheral mare volcanism occurs most readily uprange of an oblique impact; elsewhere such volcanism apparently requires superposition of an impact structure on the ring fault.

References: [1] Gault D. E. and Wedekind J. A. (1978) Proc. LPSC 9th, 3843-3875. [2] Schultz P. H. and Gault D. E. (1990) GSA Spec. Pap. 247, 239-261. [3] Schultz P. H. and Gault D. E. (1991) LPSC XXII, 1195-1196. [4] Schultz P. H. and Gault D. E. (1991) Meteoritics, 26, 392-393. [5] Schultz P. H., this volume. [6] Schultz P. H. (1992) LPSC XXIII, 1231-1232. [7] Wichman R. W. and Schultz P. H. (1992) LPSC XXIII, 1521-1522. [8] Wilhelms D. E. (1987) U.S. Geol. Surv. Prof. Pap. 1348. [9] Müller P. M. and Sjogren W. L. (1969) Appl. Mech. Rev., 22, 955-959. [10] Muller P.M. et al. (1974) Moon, 10, 195-205. [11] Sjogren W.L. and Smith J. C. (1976) Proc. LSC 7th, 2639-2648. [12] Howand K. A. et al. (1974) Rev. Geophys. Space Phys., 12, 309-327. [13] Casella C. J. and Binder A. B. (1972) U.S. Geol. Surv. Map I-707. [14] Olson A. B. and Wilhelms D. E. (1974) U.S. Geol. Surv. Map 1-837. [15] Schultz P. H. (1979) Proc. Conf. Lunar Highlands Crust, 141142. [16] Head J. W. et al. (1978) Mare Crisium: The View from Luna 24, 43-74. [17] Croft S. K. (1981) Multi-Ring Basins, Proc. LPSC 12A (P. Schultz and R. Merrill, eds.), 227-258, Pergamon, New York. [18] Melosh H. J. and McKinnon W. B. (1978) GRL, S, 985-988. [19] Melosh H. J. (1982) JGR, 87, 1880-1890. [20] Head J. W. (1976) Rev. Geophys. Space Phys., 14, 265-300. [21] Greeley R. (1976) Proc.LSC 7th, 2747-2759. [22] SchultzP.H. and Glicken H. (1979) JGR, 84, 8033-8047.

\section{SELF-ORGANIZED ROCK TEXTURES AND MULTIRING} STRUCTURE IN THE DUOLUN CRATER. Wu Siben and Zhang Jiayun, Institute of Mineral Deposits, Chinese Academy of Geological Science, Beijing 100037, China.

The Duolun impact crater is a multiring basin located $200 \mathrm{~km}$ north of Beijing $[1,2]$. From the center to the edge of the crater there are innermost rim, inner ring, outer rim, and outermost ring. The 5$\mathrm{km}$-diameter raised innermost rim, 80 to $150 \mathrm{~m}$ above the surrounding plain, is located in the cratering center and consists of volcanic rock (andesite, etc.). The prominent 70 - km-diameter ring, which is encircled by the Luan river, the Shandian river, and their tributaries, is a peripheral trough now occupied by the Lower Cretaceous coalbearing formation, etc. The $82-\mathrm{km}$-diameter outer rim, 200 to $250 \mathrm{~m}$ above the plain, consists of Archean metamorphic rocks 
(quartzite, schist), lower Permian limestone and impact melt, which may indicate the boundary of excavation. The $170-\mathrm{km}$-diameter outermost ring is marked by monomict megablock breccia.

Outside the innermost rim and near the cratering center there are some lobes of imbricate ground surge consisting of volcanic rocks or impact melt. The ground surges appear to be a lot of festoons consisting of a series of arclike ridges with steep outer slopes and gentle inner slopes. The incline of the ridge has a centripetal gradual decrease up to apparent disappearance. The outer edge of the ground surges forms an incomplete ring peak of $18-22 \mathrm{~km}$ diameter. The phenomenon indicates that the ground surges are products of oscillatory uplift near the cratering center.

Recently we have found some self-organized textures [3] or chaos phenomena in shock-metamorphic rocks from the Duolun impact crater, such as turbulence in matrices of impact glass, oscillatory zoning, or chemical chaos of spherulites in spherulitic splashed breccia, fractal wavy textures or self-similar wavy textures with varied scaling in impact glass, and crystallite beams shaped like Lorentz strange attractor. The rare phenomena indicate that the shock-metamorphic rocks from Duolun crater are formed far from equilibirum. If it is considerable that impact cratering generates momentarily under high-pressure and superhigh-temperature, occurrence of those chaos phenomena in shock-metamorphic rocks is not surprising.

This research is supported by NSF of China, and by the Chinese Foundation for Development of Geological Sciences and Techniques.

References: [1] Siben W.(1987)LPSXVIII,920-921. [2] Siben W. (1989) Meteoritics, 24, 342-343. [3] Ortolova P. J. (1990) Earth Sci. Rev., 29, 3-8.

GEOCHEMICAL ASPECT OF IMPACT CRATERING: STUDIES IN VERNADSKY INSTITUTE. O. I. Yakovlev and A. T. Basilevsky, Vernadsky Institute of Geochemistry and Analytical Chemistry, Russian Academy of Science, Moscow.

Studies of the geochemical effects of impact cratering at the Vernadsky Institute in collaboration with the Institute of Dynamics of Geospheres, Moscow State University, Leningrad State University, and some other institutions were fulfilled by several approaches.

At the initial stage, three approaches were used: (1) experimental studies of high-temperature vaporization of geological materials (basalts, granites, and so on) in vacuum that was considered as a model of behavior of impact melt and vapor; (2) search of impactinduced geochemical effects in the rock from terrestrial impact craters; and (3) studies of samples of lunar regolith.

The first approach resulted in the conclusion that even at not very high temperatures a selective vaporization of geologic materials occurs and may lead to noticeable changes in elements' contents and ratios. This effect is controlled by the volatilities of individual elements and compounds (sequences of volatilities were determined) as well as their interactions, e.g., realized through the socalled basicity-acidity effect known in igneous petrology.

The second approach resulted in the conclusion that geochemical effects that might be predicted from the experiments and theoretical work are seen in some impact melts, but these observations are not reliable enough and one of the major problems is the uncertainty in estimation of the preimpact target composition.

The third approach was successful in finding such predictable impact-induced effects as partial loss of alkalis, $\mathrm{Si}$, and Fe from regolith and some components of highland breccia.

The next stage of the studies included experiments on quasiequilibrium vaporization of geological material in Knudsen cells. This study gave reliable data on forms of occurrence of rockforming elements in the vapor phase, their fugacities, and time-andtemperature sequences of the elements' vaporization, which confirmed, in general, the earlier results from vacuum vaporization experiments. These results provided significant progress in understanding the geochemical effects of impact cratering, but it is evident that impact-induced vaporization is very fast and not equilibrium.

This is why recently a series of experiments using the light gas gun were made. The results show that even at a rather low velocity of impact (5 to $6 \mathrm{~km} / \mathrm{s}$ ) the silicate material involved in the shock displays effects of melting and partial vaporization. It is interesting that with this fast and unequilibrium process the associations of vaporized elements may differ drastically from those that resulted from the slow quasiequilibrium process. For example, refractory $U$ and Th vaporize quite easily. Effects of redox reaction between the materials of target and projectile were found.

The mentioned experimental data show that at small (laboratory experiments) scale geochemical effects do occur in high-velocity impacts. But their role in large-scale natural processes such as heavy bombardment at the early stages of planetary evolution should be clarified in future studies. 

$+$

r

-

-

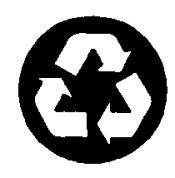

